\title{
SELECTED HYDROLOGIC DATA FOR FARMLAND \\ TREATED WITH SEWAGE SLUDGE NEAR \\ PLATTEVILLE, COLORADO, 1985-91
}

by David A. Johncox and Neville G. Gaggiani

U.S. GEOLOGICAL SURVEY

Open-File Report 91-529

Prepared in cooperation with the

METRO WASTEWATER RECLAMATION DISTRICT 


\title{
U.S. DEPARTMENT OF THE INTERIOR
}

MANUEL LUJAN, JR., Secretary

\section{U.S. GEOLOGICAL SURVEY}

\author{
Dallas L. Peck, Director
}

For additional information write to:

District Chief

U.S. Geological Survey

Box 25046, Mail Stop 415

Denver Federal Center

Denver, CO 80225-0046
Copies of this report can be purchased from:

U.S. Geological Survey

Books and Open-File Reports Section

Box 25425, Mail Stop 517

Denver Federal Center

Denver, CO 80225-0425 
CONTENTS

Page

Abstract--

Introduction--

Location and description of sampling sites--

Types of data and methods of collection and analysis-

References----

Hydrologic data--

System of numbering wells-_e

\section{FIGURES}

Figures 1-3. Maps showing:

Page

1. Location of study area-1.- 2

2. Location of hydrologic-data-collection sites-------- 5

3. Location of soil-sampling sites in the unsaturated zone--

4. Diagram of a typical observation well-_- 7

5. Diagram of a multilevel ground-water sampling device----- 8

6. System of numbering wells to obtain local well number---- 15

7. Water-level méasurements at selected observation wells, 1985-91-16

8. Volumetric soil-water content at the soil-moisture-tube sites--

9. Quarterly accumulative precipitation recorded at precipitation station in the study area, 1985-91------- 120

\section{TABLES}

Table 1. Observation wells used for sampling in the study area-------

Page

2. Multilevel ground-water sampling devices used in the study area---

3. Sampling sites in the unsaturated zone in the study area----- 9

4. Water levels in wells where water samples were obtained, 1985-91 - 24

5. Chemical and bacteriological analyses of water from the observation wells

6. Chemical analyses of water from the multilevel ground-water sampling devices--.-.- 106

7. Chemical analyses of soil at selected depths in the unsaturated zone-- 
Multiply

foot

inch

mile

square mile
By

0.3048

25.4

1.609

2.590
To obtain

meter

millimeter

kilometer

square kilometer

The following terms and abbreviations also are used in this report:

colonies per 100 milliliters $(\operatorname{col} . / 100 \mathrm{~mL})$

microgram per gram $(\mu g / g)$

microgram per liter $(\mu \mathrm{g} / \mathrm{L})$

microsiemens per centimeter $(\mu \mathrm{S} / \mathrm{cm})$

milligram per kilogram $(\mathrm{mg} / \mathrm{kg})$

milligram per liter $(\mathrm{mg} / \mathrm{L})$

Temperature in degree Celsius $\left({ }^{\circ} \mathrm{C}\right)$ may be converted to degree Fahrenheit $\left({ }^{\circ} \mathrm{F}\right)$ by using the following equation:

$$
{ }^{\circ} \mathrm{F}=9 / 5\left({ }^{\circ} \mathrm{C}\right)+32 \text {. }
$$

National Geodetic Vertical Datum of 1929 (NGVD of 1929): A Geodetic datum derived from a general adjustment of the first-order level nets of both the United States and Canada, formerly called "Sea Level Datum of 1929." 
SELECTED HYDROLOGIC DATA FOR FARMLAND TREATED WITH SEWAGE SLUDGE
NEAR PLATTEVILLE, COLORADO, 1985-91

By David A. Johncox and Neville G. Gaggiani

\begin{abstract}
The U.S. Geological Survey, in cooperation with the Metro Wastewater Reclamation District, studied the ground-water-quality effects of the application of anaerobic digested municipal sewage sludge at agronomic rates to farmland near Platteville. Beginning in the fall of 1985 , the sludge was injected annually into the sandy farmland in a 1-square-mile area. Generally, water-quality samples were collected from observation wells two or three times during each irrigation season from 1985 through 1990 and once each winter or late spring from 1987 through early 1991.

Water levels were measured, and water-quality, soil and soil-moisture samples, and precipitation data were collected at selected sites throughout the study area. This report presents the data collected during 1985-91 from observation wells, irrigation wells, domestic wells, and other selected sites in the study area.
\end{abstract}

\title{
INTRODUCTION
}

In 1985, the Metro Wastewater Reclamation District (MWRD) began a program of low-rate, near-surface application of anaerobic digested activated sludge to farmland. Although the sludge was to be applied at agronomic rates, the potential existed for leaching of organic and inorganic compounds into the shallow ground water. Leaching may be enhanced on irrigated farmland.

The U.S. Geological Survey (USGS), in cooperation with the MWRD, began a study in 1985 to evaluate the ground-water quality effects of applying treated municipal sewage sludge to 1 square mile of partially irrigated sandy farmland. The study area in the South Platte River Valley is about 35 miles northeast of Denver and about 2 miles east of Platteville (fig. 1). Beginning in the fall of 1985 and ending in the spring of 1990, sewage sludge was applied as fertilizer on section 16 (fig. 1) during the fall and spring of each year. To assess the effects of soil application of sewage sludge on the ground-water quality, data needed to be collected to determine the quality and the approximate flow rate of the water in the saturated and unsaturated zones. 

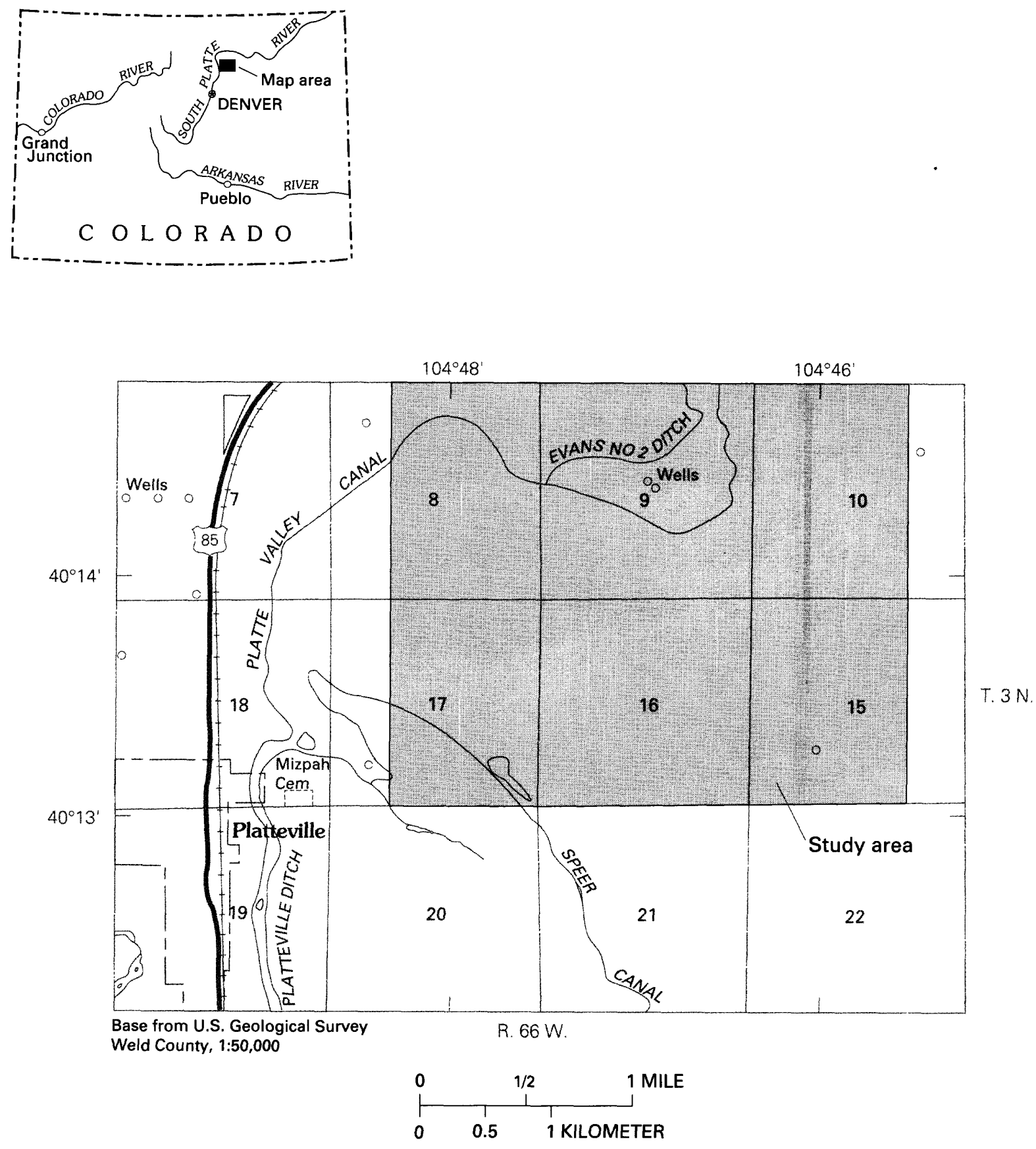

Figure 1.--Location of study area. 
This report describes sampling-site locations, types of data, and methods of collection and analysis in the 1-square-mile study area. Presented are water-level data and chemical and bacteriological analyses from 19 observation wells, chemical analyses from 5 multilevel ground-water sampling devices (MLGWSD), chemical analyses of soil samples collected from 5 sites in the unsaturated zone, volumetric soil-water content at 3 soil-moisture-tube sites, and quarterly precipitation data from a precipitation station in the study area.

\section{LOCATION AND DESCRIPTION OF SAMPLING SITES}

Nineteen observation wells (table 1; fig. 2) and five multilevel groundwater sampling devices (table 2; fig. 2) were established at sites used to determine the ground-water quality from the saturated zone (fig. 2). Three soil-moisture tubes were installed to monitor the movement of ground water in the unsaturated zone (table 3; fig. 2). Soil samples from the unsaturated zone were obtained from several depths at five sites for chemical analysis (table 3 ; fig. 3). A schematic diagram (fig. 6) and an explanation of the system of designating local well number is presented in the "System of

- Numbering Wells" subsection in the "Hydrologic Data" section at the back of this report.

In the ground-water sampling network, 15 observation wells are USGS wells completed in eolian deposits, 3 are privately owned domestic-use wells completed in bedrock, and 1 is an irrigation well completed in the alluvium. The 15 USGS eolian wells were drilled in April 1985 and range in depth from 6 to 45 feet below land surface. The eolian wells are constructed of 2-inch diameter polyvinyl chloride (PVC) casing that extends to the bottom of the we11. The lower 3 to 10 feet of the well is constructed of perforated or slotted PVC casing that is capped on the bottom. A gravel pack was placed around the well casing from the bottom of the well to about 4 feet below the land surface. Sand and soil were filled in from about 4 feet to as much as 2 feet below land surface. The upper 2 feet of the well then was sealed with concrete and an 8-in.-diameter steel surface casing was installed to protect the PVC well casing (fig. 4).

Multilevel ground-water sampling devices (MLGWSD) were installed in August 1987 with sampling depths ranging from 5 to 36 feet in the saturated zone (table 2). The MLGWSD is comprised of a 1.25-inch diameter PVC casing with four lengths of slotted 2-inch diameter PVC sections attached to the 1.25-inch PVC casing at different depths (fig. 5). A 0.25-inch diameter hole was drilled diagonally into the 1.25-inch PVC casing at the midpoint of each 2-inch diameter slotted section, and a 0.25 -inch (0.D.) polyethylene tube was attached so the end of the tubing fit snugly through the 1.25-inch PVC. This allowed sampling at different depths of the aquifer. Four depths thus can be sampled by each MLGWSD. Each sampling depth has an identified polyethylene tube that leads to the land surface for sampling access. The drill holes surrounding the MLGWSD's were filled with sand and soil to approximately 3 feet below land surface. Bentonite pellets and water were used to fill the void from approximately 3 to 2 feet below land surface, and an 8-inch diameter PVC surface casing was installed in concrete to protect each of the devices. 
Table 1.--Observation wells used for sampling in the study area

[NGVD, National Geodetic Vertical Datum; --, surface elevation unknown; all wells are U.S. Geological Survey wells unless noted]

\begin{tabular}{rlccc}
\hline $\begin{array}{c}\text { Site } \\
\text { designation } \\
\text { (see fig. 2) }\end{array}$ & $\begin{array}{c}\text { Local well } \\
\text { number } \\
\text { (see fig. 6) }\end{array}$ & $\begin{array}{c}\text { Well } \\
\text { depth } \\
\text { (feet) }\end{array}$ & $\begin{array}{c}\text { Surface elevation } \\
\text { (in feet above } \\
\text { NGVD of 1929) }\end{array}$ & $\begin{array}{c}\text { Aquifer } \\
\text { sampled }\end{array}$ \\
\hline 1 & SB0306616CDD & 6 & 4,941 & Eolian \\
2 & SB0306616DCC & 9 & 4,902 & Eolian \\
13 & SB0306616DAC & 20 & 4,878 & Eolian \\
4 & SB0306616CAC & 18 & 4,909 & Eolian \\
5 & SB0306616DAA2 & 24 & 4,890 & Eolian \\
6 & SB0306616DAB & 45 & 4,875 & Eolian \\
7 & SB0306616CAA & 25 & 4,889 & Eolian \\
8 & SB0306616BDC & 19 & 4,878 & Eolian \\
9 & SB0306616BCC & 14 & 4,900 & Eolian \\
10 & SB0306616AAC & 30 & 4,864 & Eolian \\
11 & SB0306616BBD & 27 & 4,889 & Eolian \\
12 & SB0306616AAA & 30 & 4,849 & Eolian \\
13 & SB0306616AAB & 39 & 4,860 & Eolian \\
14 & SB0306616BAA & 20 & 4,859 & Alluvial \\
15 & SB0306616BBA & 14 & 4,871 & Bedrock \\
216 & SB030669DDD & 52 & 4,845 & Bedrock \\
317 & SB030669AAA & 346 & -- & Bedrock \\
318 & SB030668ABA & 330 & -- & - \\
319 & SB0306617CDD & 331 & & \\
\hline
\end{tabular}

${ }^{1}$ No water-quality samples collected because well was destroyed.

${ }^{2}$ Irrigation well.

${ }^{3}$ Domestic well.

Table 2.--Multilevel ground-water sampling devices used in the study area

[MLGWSD, multilevel ground-water sampling device]

\begin{tabular}{llcl}
\hline $\begin{array}{c}\text { Site } \\
\text { designation } \\
\text { (see fig. 2) }\end{array}$ & $\begin{array}{c}\text { Local well } \\
\text { number } \\
\text { (see fig. 6) }\end{array}$ & $\begin{array}{c}\text { Sampling depths } \\
\text { (feet below } \\
\text { land surface) }\end{array}$ & $\begin{array}{c}\text { Aquifer } \\
\text { sampled }\end{array}$ \\
\hline MLGWSD-1 & SB0306616DAB2 & $20,25,30,34$ & Eolian \\
MLGWSD-2 & SB0306616BBD2 & $11,16,21,25$ & Eolian \\
MLGWSD-3 & SB0306616AAC2 & $11,16,21,25$ & Eolian \\
MLGWSD-4 & SB0306616AAB2 & $22,27,32,36$ & Eolian \\
MLGWSD-5 & WB0306616BAA2 & $5,10,15,19$ & Eolian \\
\hline
\end{tabular}




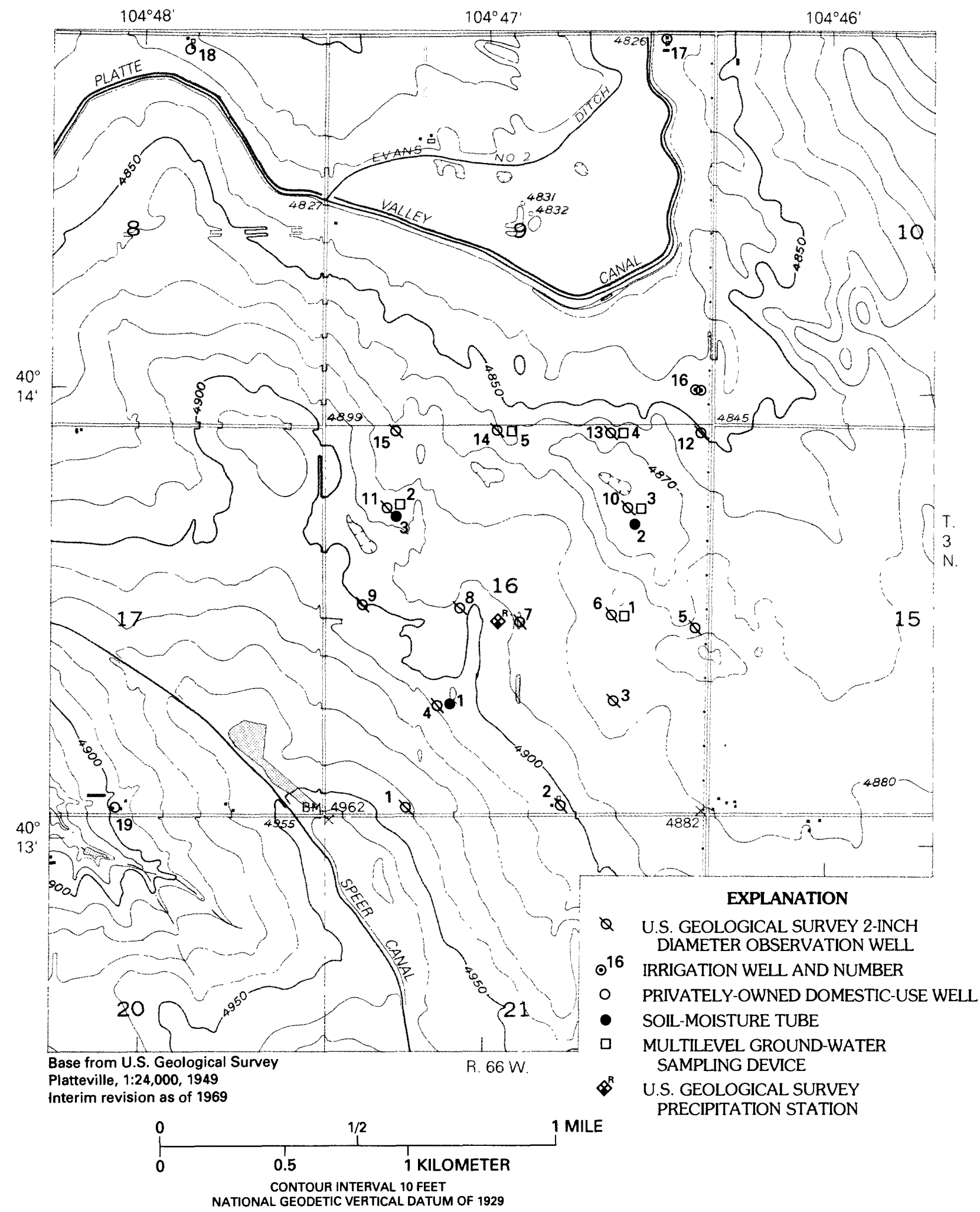

Figure 2.--Location of hydrologic-data-collection sites. 


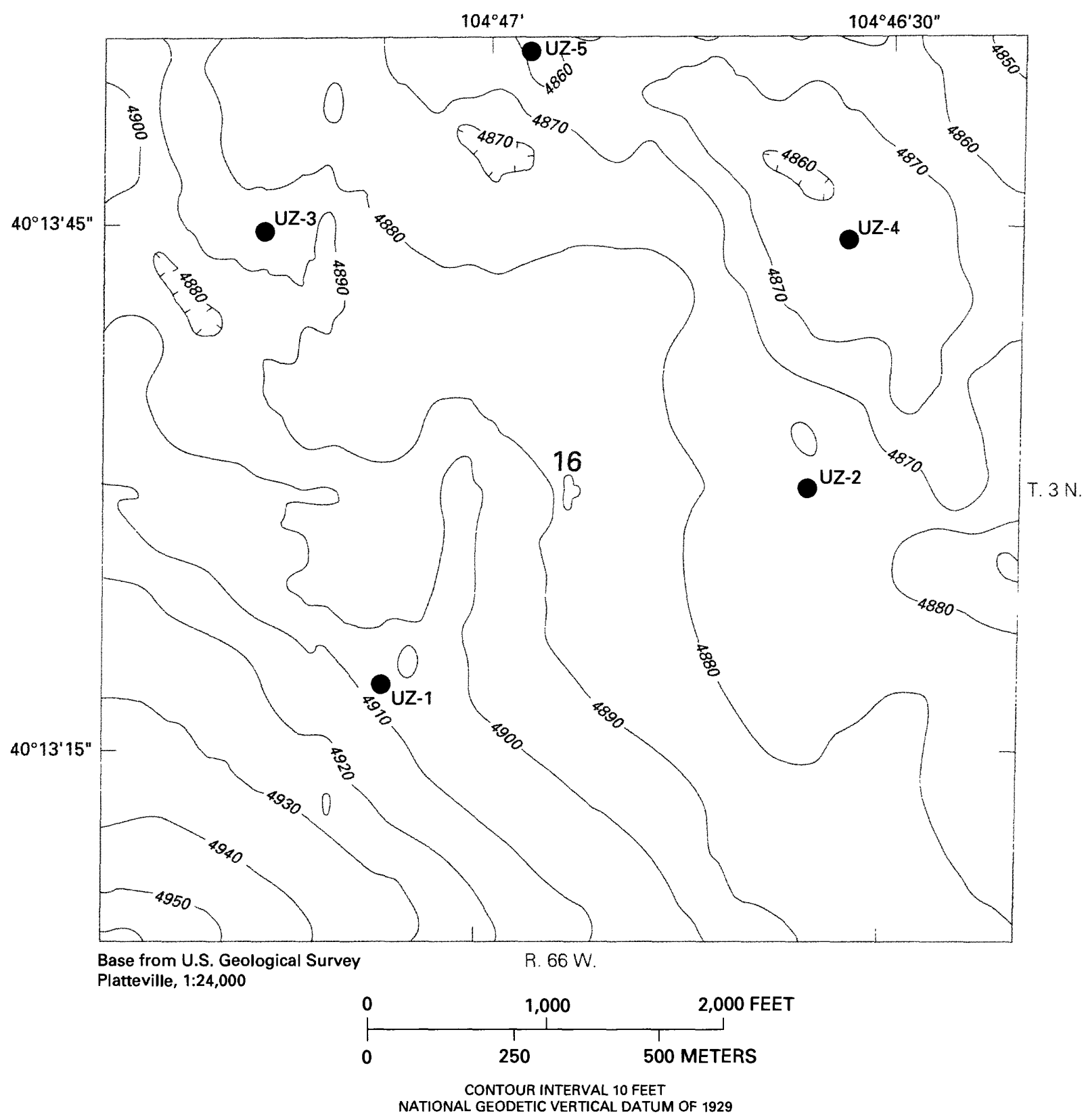

Figure 3.--Location of soil-sampling sites in the unsaturated zone. 




Note: Not to scale

Figure 4.--Diagram of a typical observation well. 


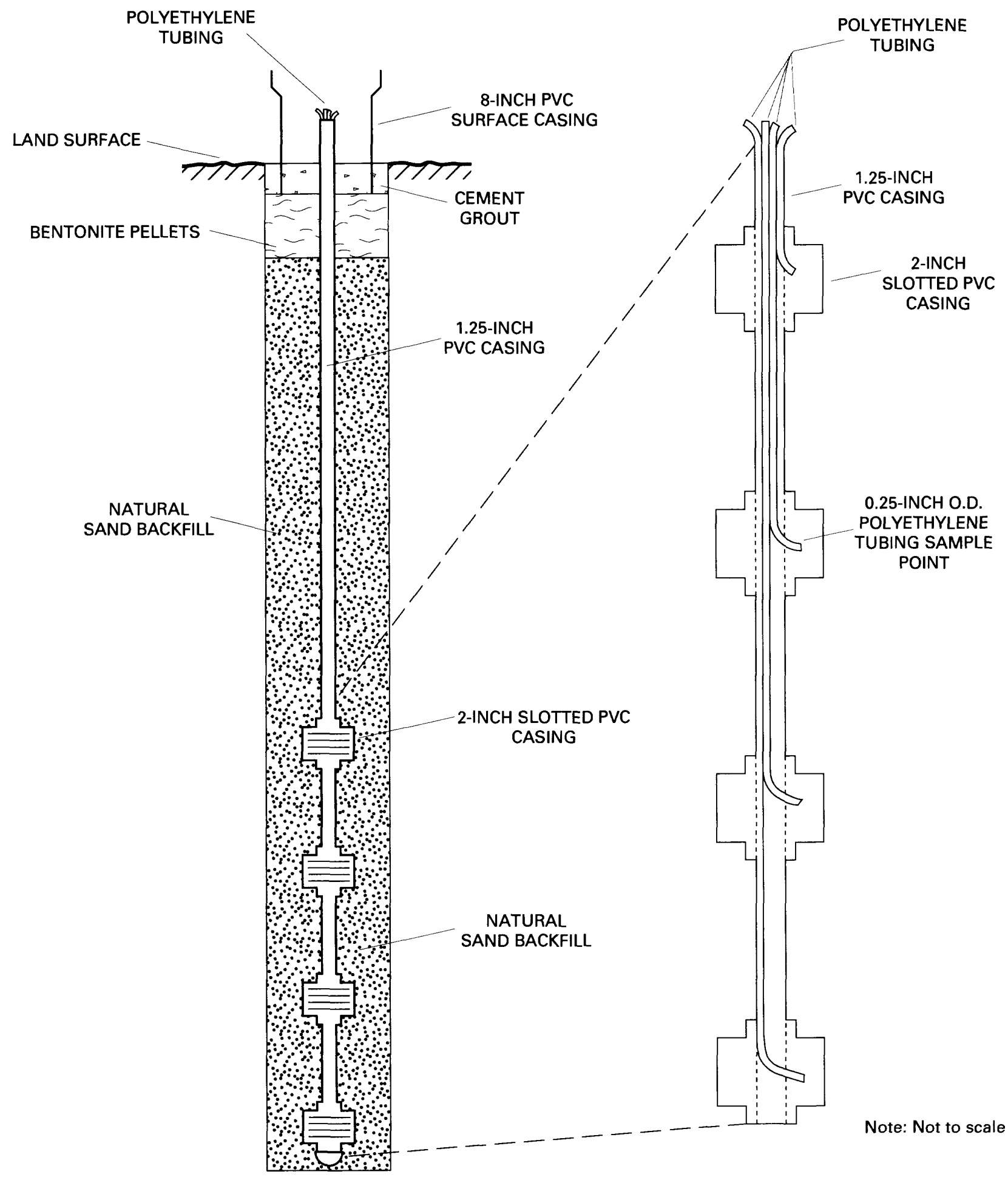

Figure 5.--Diagram of a multilevel ground-water sampling device. 
Table 3.--Sampling sites in the unsaturated zone in the study area [UZ, unsaturated zone; --, no sample collected]

\begin{tabular}{cc}
\hline $\begin{array}{c}\text { Site } \\
\text { designation } \\
\text { (see fig. 3) }\end{array}$ & $\begin{array}{c}\text { Depth of samples } \\
\text { collected from UZ } \\
\text { (feet below land surface) }\end{array}$ \\
\hline UZ-1 & $0,1.5,3.5,5.5$ \\
UZ-2 & $0,1.5,3.5,5.5$ \\
UZ-3 & $0,1.5,3.5,5.5$ \\
UZ-4 & $0,1.5,3.5,--$ \\
\hline
\end{tabular}

Soil-moisture tubes were installed at three selected locations in the study area to measure the volumetric soil-water content in the unsaturated zone. Ten-foot sections of 2-inch-diameter aluminum tubing were sealed at the bottom with a rubber stopper and were inserted into the ground through 2-inch drill holes.

Five soil-sampling sites were located in the study area to collect soil samples for chemical analysis from the unsaturated zone at depths ranging from the surface to 5.5 feet below land surface ( $t a b l e ~ 3)$. A small backhoe was used to dig a 6-foot deep trench so that samples could be collected at each site.

A precipitation station is located near the center of the study area (fig. 2). Precipitation was collected and recorded beginning in the third quarter of 1985 .

\section{TYPES OF DATA AND METHODS OF COLLECTION AND ANALYSIS}

Data in this report include water-level measurements (fig. 7; table 4) and chemical and bacteriological analyses from 19 observation wells (table 5), chemical conditions of the ground water at several depths from the MLGWSD's (table 6), chemical conditions of the unsaturated zone from soil samples (table 7), volumetric soil-water content (fig. 8), and quarterly accumulative precipitation quantities in the study area from 1985 through the spring of 1991 (fig. 9). Figures 7-9 and tables 4-7 are in the "Hydrologic Data" section at the back of this report.

Water levels for the USGS observation wells were measured approximately monthly and prior to water-quality sampling (fig. 7; table 4). Water levels were measured at well 3 on three separate occasions before the well was destroyed by farming equipment. There are no water-quality samples for well 3 as a result of its being destroyed. Two water-level measurements were made at well 16, an irrigation well. No water-level measurements were made at the three domestic wells (wells 17-19), but historical water-level measurements are presented. 
Specific conductance and $\mathrm{pH}$ were measured at each well site. Generally, water-quality samples were collected from the observation wells two or three times during each irrigation season from 1985 through 1990 and once each winter or late spring from 1987 through early 1991. Water samples were collected for analyses of dissolved inorganic constituents and bacteria at all wells, and samples for analyses of volatile organic constituents were collected at selected wells. The analyses for the dissolved inorganic constituents included nitrogen compounds, phosphorus, major cations and anions, and the following trace elements: cadmium, chromium, copper, iron, lead, manganese, nickel, and zinc. On September 2, 1988, water-quality samples were collected for a variety of total volatile organic analyses at wells $2,4,5$, 7-9, 13, and 15 (fig. 2 and table 5). Fecal-coliform and fecal-streptococcus bacteria also were analyzed (table 5).

Temperature, specific conductance, and $\mathrm{pH}$ were measured for each depth of four MLGWSDs. At the deeper MLGWSD site 4, there was not enough water to measure water-quality properties or to collect samples for inorganic analyses. Except for site 4, the MLGWSDs were sampled periodically from September 1987 through September 1988. The analyses for the dissolved inorganic constituents included nitrogen compounds, major cations and anions, and the following trace elements: cadmium, iron, lead, and manganese. On September 1, 1988, samples for total volatile organic analyses were collected at all five MLGWSDs (table 6).

Soil samples were collected from five soil-sampling sites within the study area for total inorganic analyses of the soil in the unsaturated zone at selected depths (table 7). The analyses for the total inorganic constituents included nitrogen compounds, phosphorus, and the following trace elements: arsenic, cadmium, chromium, cobalt, copper, iron, lead, manganese, mercury, and zinc.

Volumetric soil-water content was recorded periodically from October 1987 through November 1988 at three sites with the use of a neutron soil-moisture probe (fig. 8). Precipitation data were recorded at the USGS precipitation station during the study period. The incremental precipitation data were compiled and reported as quarterly accumulative precipitation (fig. 9).

Water levels were measured using a steel tape that measures depth below land surface. Bailers made from 1.5-inch-diameter PVC pipe were used to evacuate the wells. The wells were bailed dry and allowed to recover 24 to 48 hours before the water-quality samples were collected.

The samples for inorganic chemical analyses at the USGS observation wells were collected using the 1.5-inch-diameter PVC bailer. Water samples from the privately owned domestic and irrigation wells were collected from surface taps. A stainless steel bailer was used for sampling volatile organic constituents. The stainless steel bailer was flushed with deionized water after each sample was collected. The samples for inorganic and volatile organic analyses at the MLGWSDs were collected by connecting a Teflon tube from the intake end of a peristaltic pump to the polyethylene tube located at the surface of the MLGWSD for each of the four depths at every MLGWSD. The Teflon tubing from the peristaltic pump was flushed with deionized water after each 
sample was collected. A brass sampler on a steel cable was used to collect samples for bacteriological analyses. The enclosed chamber of the sampler was sterilized by igniting methanol added to the chamber after each sample.

All inorganic samples were filtered onsite through a 0.45 -micron membrane filter and were preserved and chilled according to Ward and Harr (1990). The organic samples were unfiltered and put into glass bottles prior to delivery to the laboratory for analyses. The bacteriological samples were put into individual autoclaved sample bottles and chilled while awaiting delivery to the laboratory. All samples were delivered to the laboratory within 24 hours after collection.

Inorganic and bacteriological analyses of water samples from the observation wells in the study area were done by the MWRD laboratory. The MWRD laboratory uses standard U.S. Environmental Protection Agency laboratory methods for the analyses of water-quality constituents (American Public Health Association and others, 1985). Split samples occasionally were collected and taken to the USGS National Water Quality Laboratory in Arvada, Colorado; the results were used for verification purposes only and are not included in this report. The organic samples were analyzed by the USGS laboratory.

Soil samples for inorganic chemical analyses were taken at the surface and at depths of $1.5,3.5$, and 5.5 feet below land surface along the soil profile. A 6-foot trench was dug at each sampling site with a small backhoe, and similar volumes of soil were removed from the trench wall at the designated depth and placed into plastic sample jars. All inorganic soil analyses were done by the USGS laboratory.

The volumetric soil-water content was determined by using a neutron soilmoisture probe. The neutron probe was inserted into 2 -inch-diameter aluminum soil-moisture tubes, and measurements were taken at 1-foot intervals to a depth of 10 feet below land surface. The precipitation quantities were recorded by using a tipping-bucket raingage and weighing-bucket snowgage near wel1 7.

\section{REFERENCES}

American Public Health Association, American Water Works Association, Water Pollution Control Federation, 1985, Standard methods for the examination of water and wastewater (16th ed.): Washington, D.C., American Public Health Association, 1,268 p.

Ward, J.R., and Harr, C.A., editors, 1990, Methods for collection and processing of surface-water and bed-material samples for physical and chemical analyses: U.S. Geological Survey Open-File Report 90-140, 71 p. 
HYDROLOGIC DATA 


\section{System of Numbering Wells}

The well locations (local well number) in tables 1,5 , and 7 are based on the U.S. Bureau of Land Management system of land subdivision and show the location of the well by quadrant, township, range, section, and position within the section. A graphic illustration of this method of well location is shown in figure 6 . The first letter "S" preceding the location number means that the well is located on the area governed by the sixth principal meridian. The second letter indicates the quadrant in which the well is located. Four quadrants are formed by the intersection of the base line and the principal meridian--A indicates the northeast quadrant, $B$ the northwest, $C$ the southwest, and $D$ the southeast. The first numeral indicates the township, the second the range, and the third the section in which the well is located. The letters following the section number locate the well within the section. The first letter denotes the quarter section, the second the quarter-quarter section. The letters are assigned within the section in a counter-clockwise direction, beginning with (A) in the northeast quarter. Letters are assigned within each quarter section and within each quarterquarter section in the same manner. Where two or more locations are within the smallest subdivision, consecutive numbers beginning with 1 are added in the order in which the wells were inventoried. For example, SC00304921CCB indicates a well in the northwest quarter of the southwest quarter of the southwest quarter of sec. 21, T. $3 \mathrm{~S}$., R. $49 \mathrm{~W}$. The "S" refers to the sixth principal meridian. The " $C$ " indicates the township is south of the base line and that the range is west of the principal meridian. 


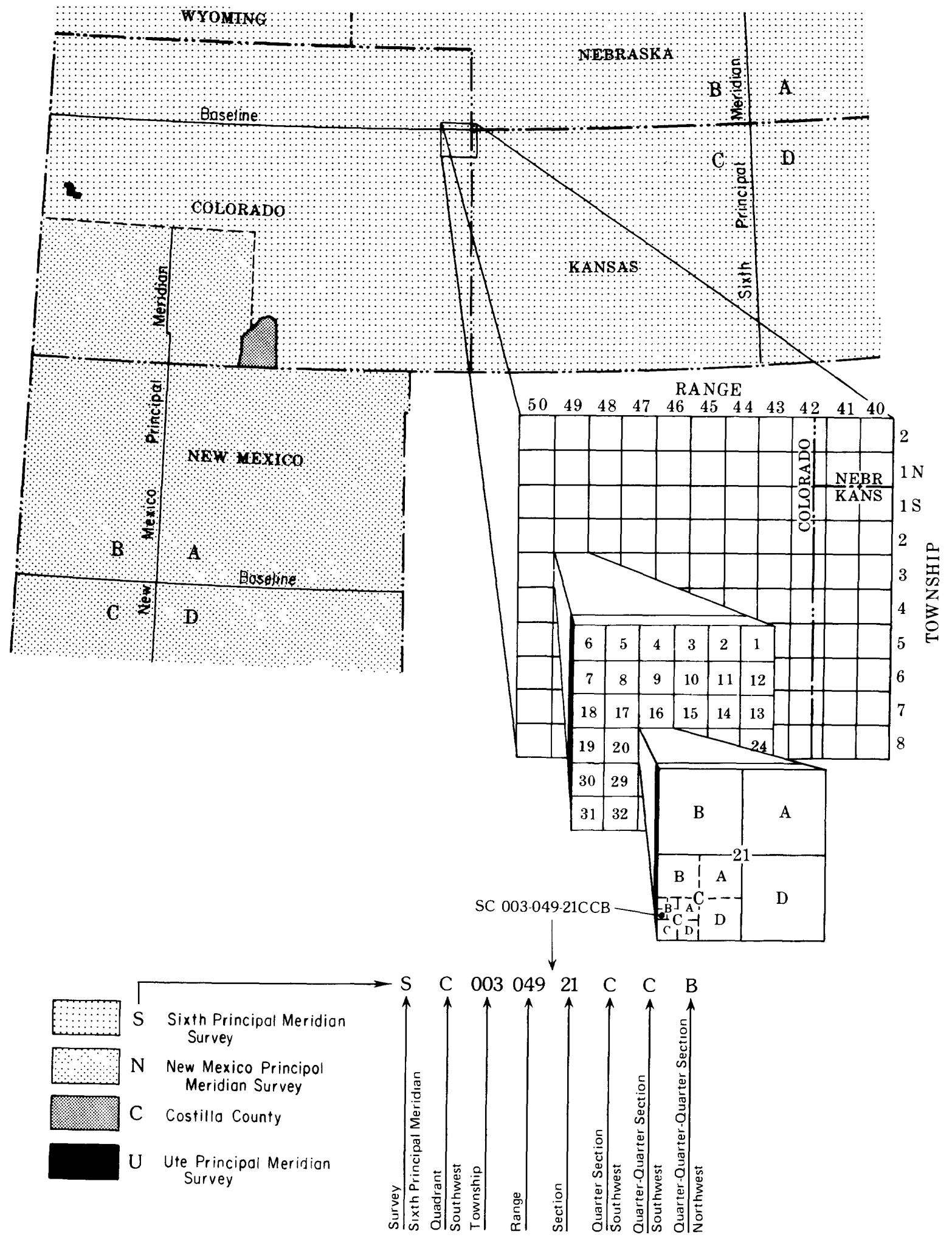

Figure 6.--System of numbering wells to obtain local well number. 


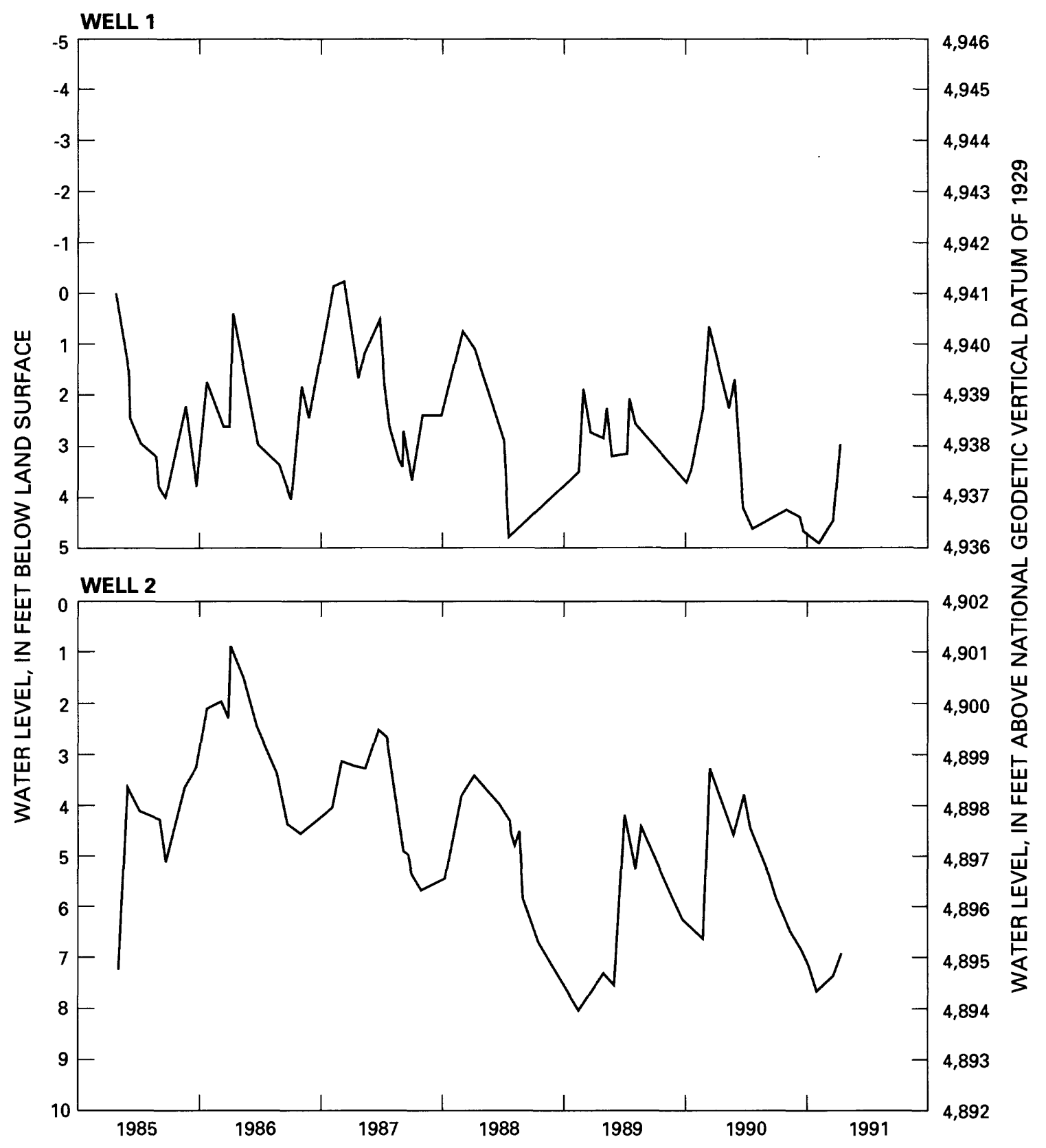

Figure 7.--Water-level measurements at selected observation wells, 1985-91. 


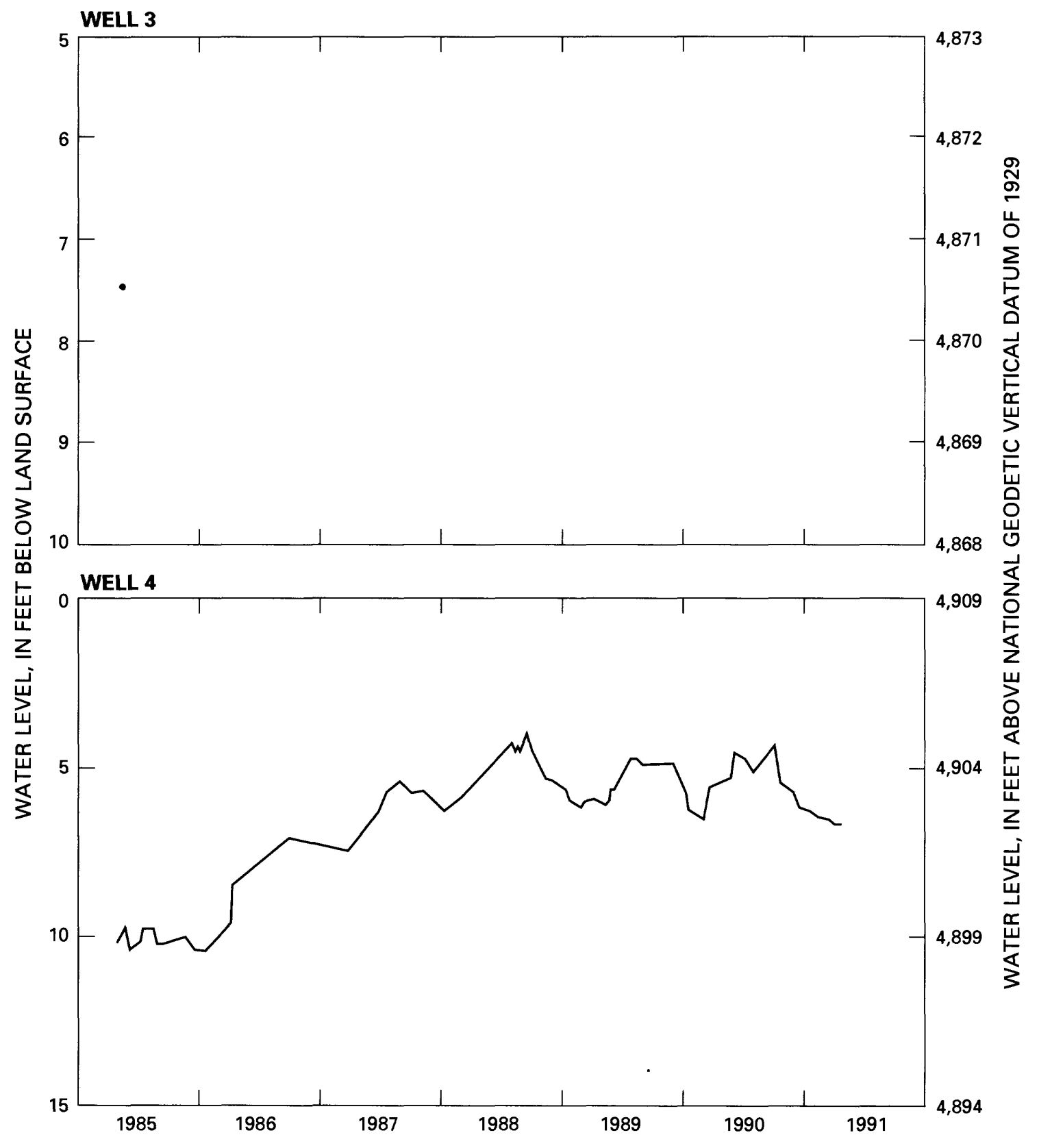

Figure 7.--Water-level measurements at selected observation wells, 1985-91--Continued. 




Figure 7.--Water-level measurements at selected observation wells, 1985-91--Continued. 


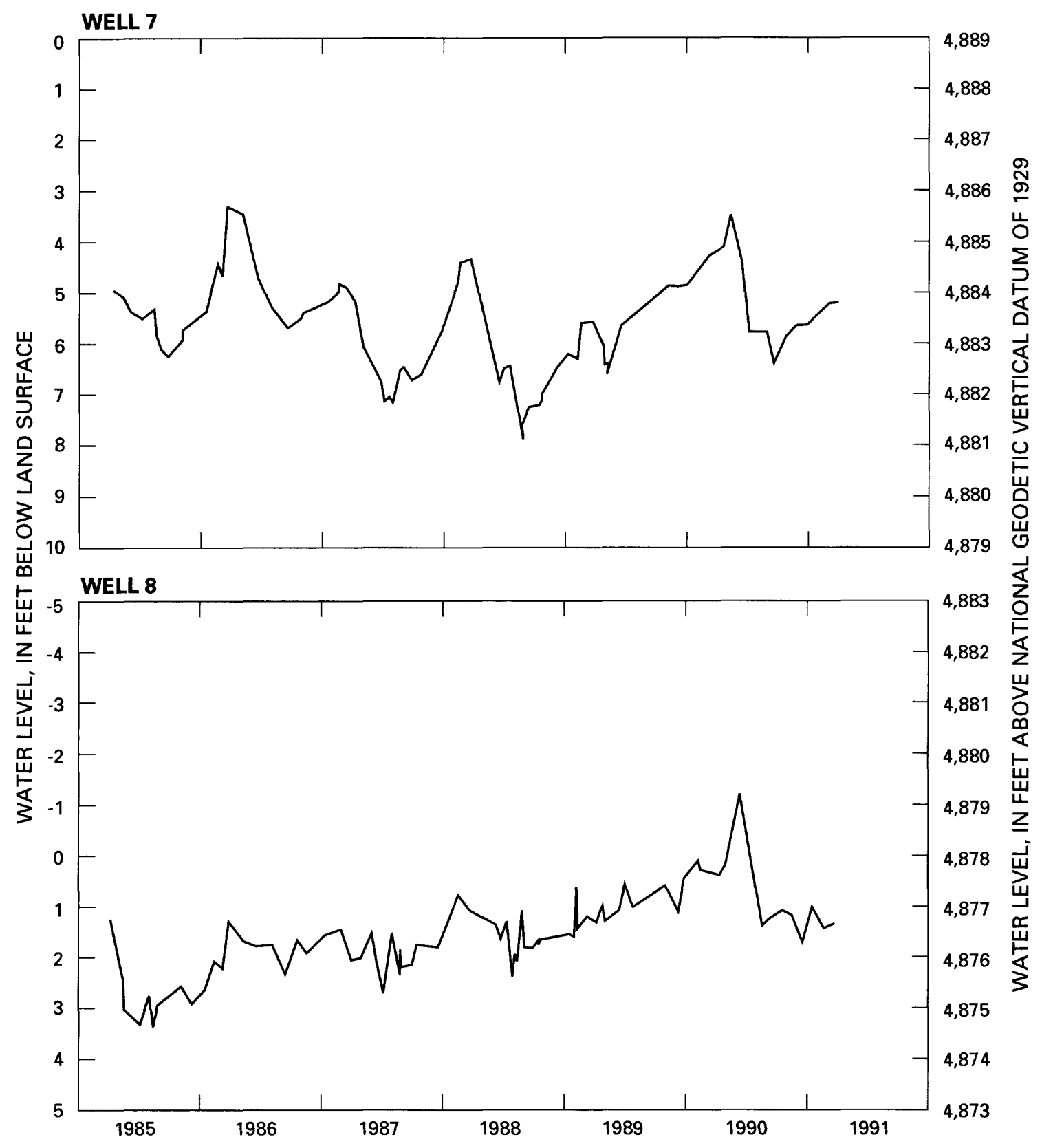

Figure 7.--Water-level measurements at selected observation we11s, 1985-91--Continued. 


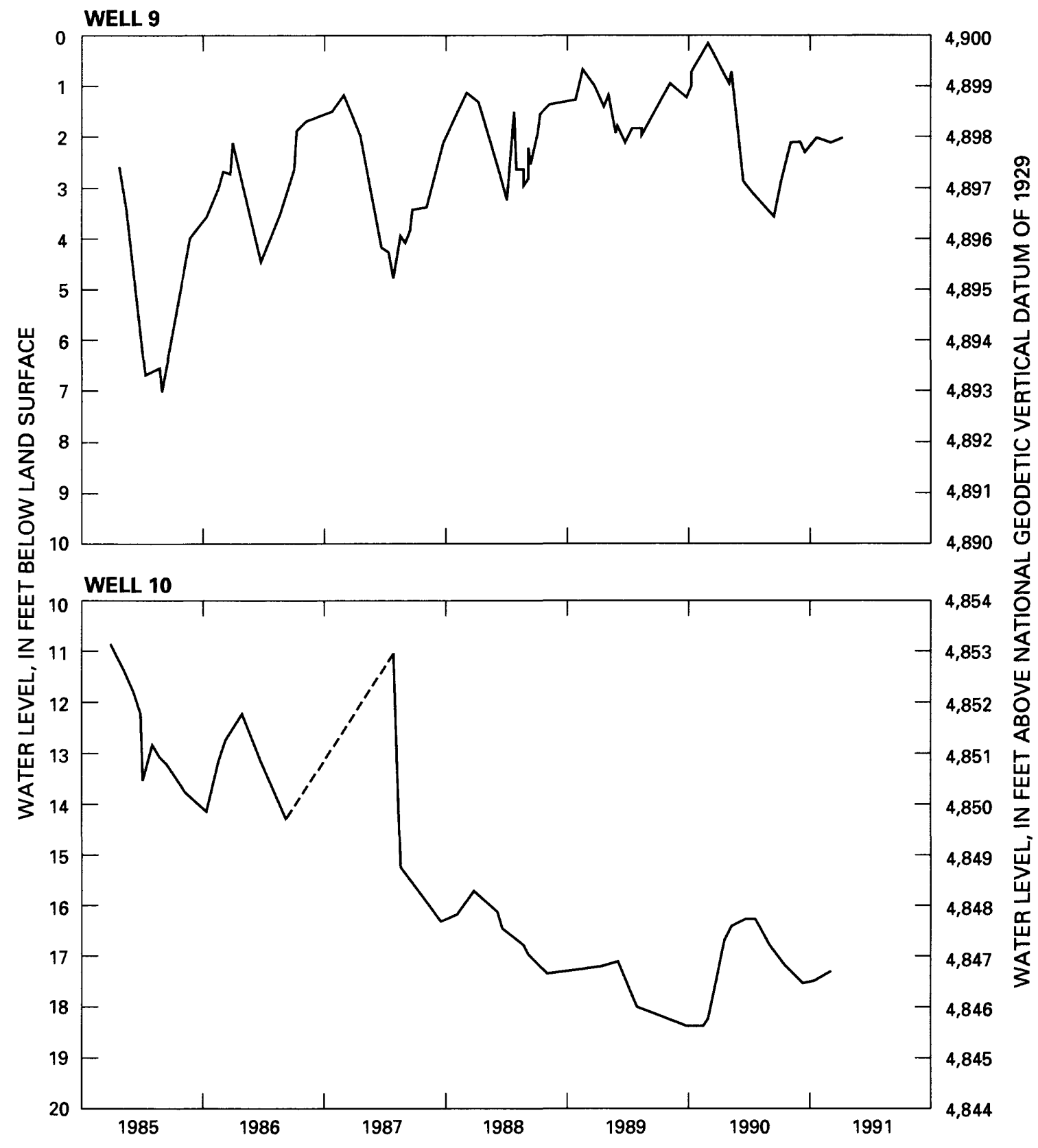

Figure 7.--Water-level measurements at selected observation wells, 1985-91--Continued. 


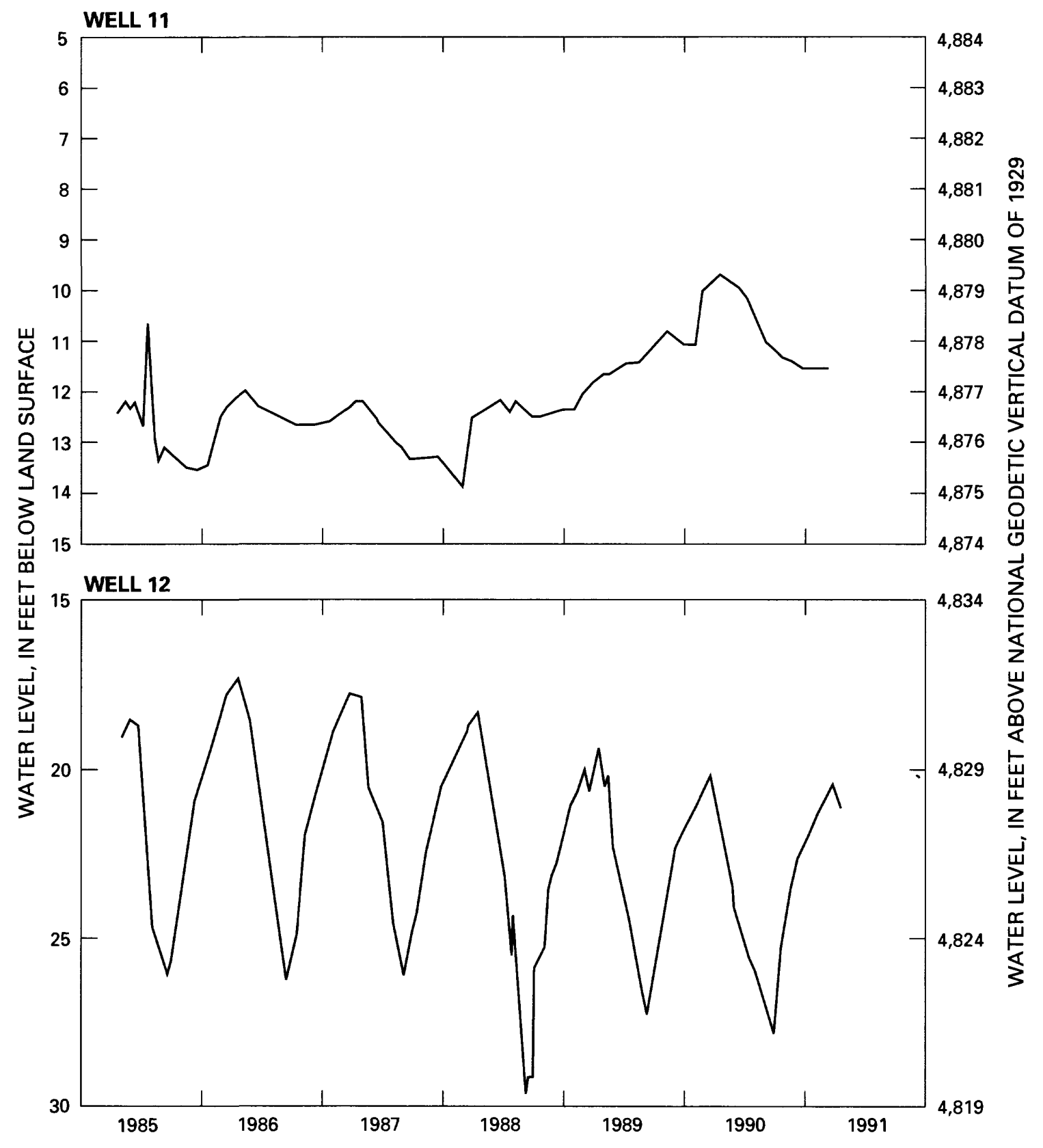

Figure 7.--Water-level measurements at selected observation wells, 1985-91--Continued. 




Figure 7.--Water-level measurements at selected observation wells, 1985-91--Continued. 


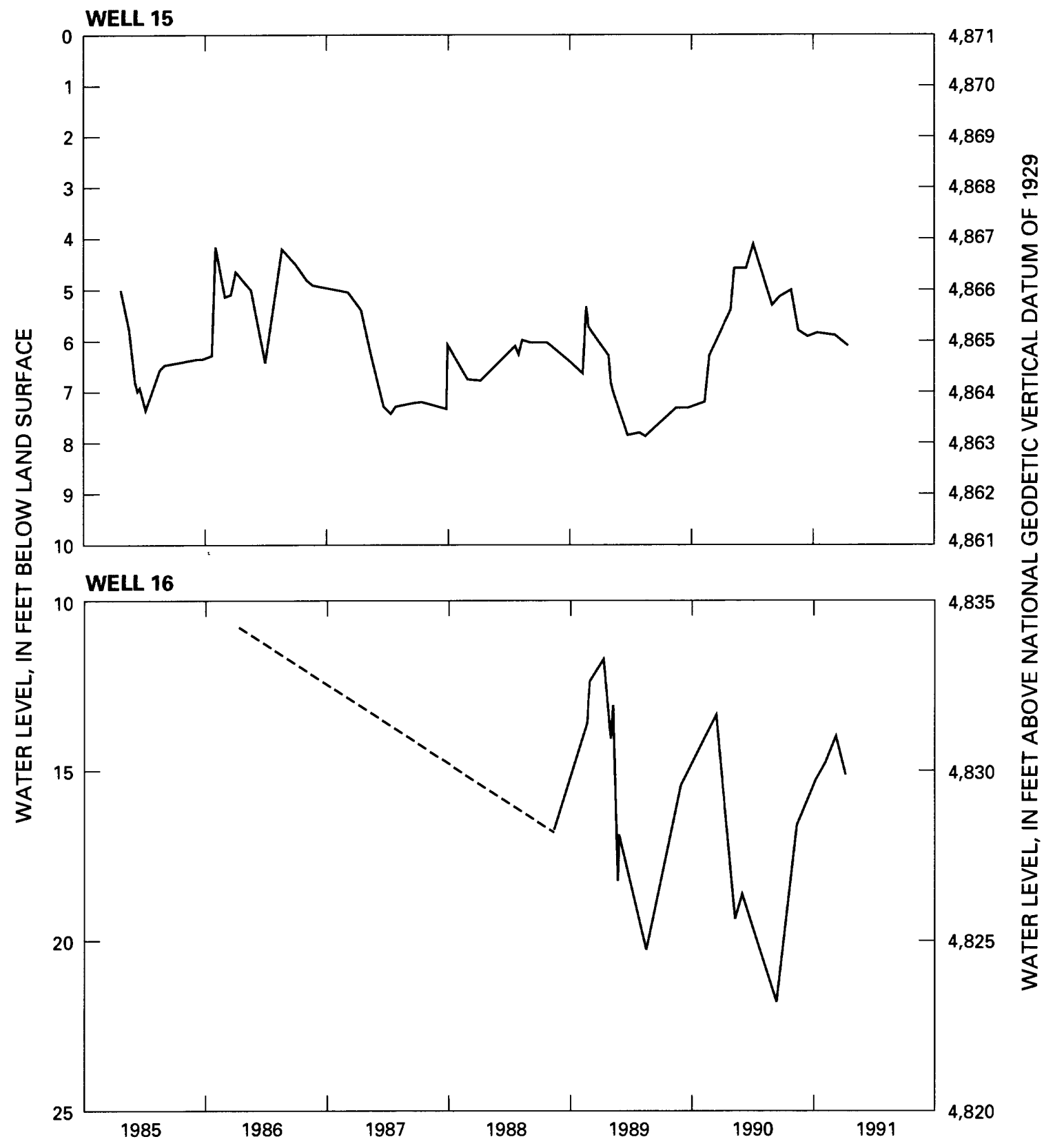

Figure 7.--Water-level measurements at selected observation wells, 1985-91--Continued. 
Table 4.--Water levels in wells where water samples were obtained, 1985-91

[Water levels, in feet above or below land surface; S, status of site (blank in this column means that there was no condition adversely affecting the accurate measurement of the water level); d, dry-water level was below bottom of well; o, obstruction in well; $\mathrm{v}$, foreign matter on water; $r$, well was recently pumped or bailed; $x$, affected by surface water site; +0.16 , the water level was 0.16 foot above land surface; --, no data available; wells shown in figure 2]

\begin{tabular}{|c|c|c|c|c|c|c|c|c|c|c|c|}
\hline Date & $\begin{array}{l}\text { Water } \\
\text { level }\end{array}$ & $\mathrm{S}$ & Date & $\begin{array}{l}\text { Water } \\
\text { level }\end{array}$ & $\mathrm{S}$ & Date & $\begin{array}{l}\text { Water } \\
\text { level }\end{array}$ & $\mathrm{S}$ & Date & $\begin{array}{l}\text { Water } \\
\text { leve1 }\end{array}$ & $\mathrm{S}$ \\
\hline
\end{tabular}

$\frac{1985}{\text { APR } 26}$ MAY 24

JUNE 07

JULY 09

AUG 15 28

SEPT 13

NOV 21

DEC 20

1986

JAN 23

MAR 07

27

APR 14

MAY 22

JULY 03

AUG 26

OCT 01

NOV 06

28

\begin{tabular}{|c|c|c|}
\hline & & 1987 \\
\hline 0.02 & $x$ & FEB \\
\hline 1.24 & & MAR \\
\hline 2.47 & & APR \\
\hline 2.93 & & MAY \\
\hline 3.17 & $x$ & JUNE \\
\hline 3.8 & & JULY \\
\hline 3.97 & & \\
\hline 2.19 & & AUG \\
\hline 3.75 & & SEPT \\
\hline 1.69 & & \\
\hline 2.58 & & OCT \\
\hline 2.59 & & NOV \\
\hline 0.36 & $x$ & 1988 \\
\hline 1.81 & & $\overline{\text { JAN }}$ \\
\hline 2.98 & $x$ & MAR \\
\hline 3.35 & & APR \\
\hline 4.03 & & JULY \\
\hline 1.81 & & \\
\hline 2.44 & & AUG \\
\hline
\end{tabular}

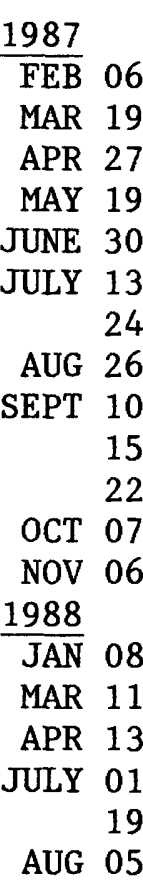

+.16
+.28
1.71
1.20
.50
1.82
2.47
3.32
3.44
2.74
3.13
3.66
2.44

2.45
.71
1.13
2.86
4.85
--

WELL 1

\begin{tabular}{|c|c|c|c|c|c|c|}
\hline 1988 & & & & 1989 & & \\
\hline$\overline{\mathrm{AUG}}$ & 16 & -- & d & $\overline{\text { JULY }}$ & 31 & 2.12 \\
\hline & 26 & -- & d & AUG & 17 & 2.61 \\
\hline SEPT & 01 & -- & d & & 28 & 2.68 \\
\hline & 12 & -- & d & DEC & 06 & 3.48 \\
\hline & 15 & -- & d & 1990 & & \\
\hline & 20 & -- & d & $\overline{\mathrm{JAN}}$ & 05 & 3.73 \\
\hline & 23 & -- & d & & 24 & 3.56 \\
\hline OCT & 19 & -- & d & FEB & 27 & 2.59 \\
\hline NOV & 02 & -- & d & MAR & 22 & .65 \\
\hline & 10 & -- & $\mathrm{d}$ & MAY & 21 & 2.34 \\
\hline 1989 & & & & JUNE & 04 & 1.68 \\
\hline $\mathrm{FEB}$ & 22 & 3.60 & & JULY & 10 & 4.16 \\
\hline MAR & 08 & 1.89 & & & 30 & 4.67 \\
\hline & 13 & 1.96 & & SEPT & 24 & \\
\hline APR & 10 & 2.80 & & OCT & 16 & \\
\hline MAY & 11 & 2.90 & & NOV & 20 & 4.27 \\
\hline & 17 & 2.29 & & $\mathrm{DEC}$ & 14 & 4.43 \\
\hline & 26 & 3.05 & & 1991 & & \\
\hline JUNE & 01 & 3.27 & & JAN & 14 & 4.74 \\
\hline JULY & 11 & 3.20 & & FEB & 15 & 4.92 \\
\hline & & & & MAR & 28 & 4.51 \\
\hline & & & & APR & 22 & 2.95 \\
\hline
\end{tabular}

WELL 2

\begin{tabular}{|c|c|c|c|c|c|c|c|c|c|c|c|c|c|}
\hline \multicolumn{2}{|l|}{1985} & \multicolumn{4}{|c|}{1986} & \multicolumn{4}{|c|}{1987} & \multicolumn{4}{|c|}{1988} \\
\hline APR & 26 & 7.11 & & $\overline{\text { MAR }}$ & 27 & 2.16 & & MAY & 19 & 3.20 & MAR & 10 & 3.85 \\
\hline MAY & 24 & 3.54 & & APR & 14 & 0.78 & & JUNE & 30 & 2.40 & APR & 13 & 3.33 \\
\hline JUNE & 07 & 3.60 & & MAY & 22 & 1.54 & & JULY & 13 & 2.51 & JULY & 01 & 4.00 \\
\hline JULY & 09 & 4.05 & & JULY & 03 & 2.34 & $x$ & & 24 & 2.60 & & 19 & 4.20 \\
\hline AUG & 15 & 4.20 & $\mathrm{x}$ & AUG & 26 & 3.27 & & AUG & 26 & 3.81 & AUG & 05 & 4.53 \\
\hline & 28 & 4.21 & & OCT & 01 & 4.33 & & SEPT & 10 & 4.47 & & 16 & 4.79 \\
\hline SEPT & 13 & 5.10 & & NOV & 06 & 4.49 & & & 15 & 4.90 & & 26 & 4.50 \\
\hline NOV & 21 & 3.55 & & & 28 & 4.38 & & & 22 & 4.93 & SEPT & 01 & 5.25 \\
\hline DEC & 20 & 3.20 & & 1987 & & & & OCT & 07 & 5.33 & & 12 & 5.85 \\
\hline 1986 & & & & FEB & 06 & 4.03 & & NOV & 06 & 5.67 & & 15 & 5.92 \\
\hline JAN & 23 & 2.03 & & MAR & 19 & 3.11 & & 1988 & & & & 20 & 6.05 \\
\hline MAR & 07 & 1.87 & & APR & 27 & 3.18 & & JAN & 08 & 5.47 & OCT & 19 & 6.75 \\
\hline
\end{tabular}


Table 4.--Water levels in wells where water samples were obtained, 1985-91--Continued

\begin{tabular}{|c|c|c|c|c|c|c|c|c|c|c|c|c|c|}
\hline \multicolumn{2}{|c|}{ Date } & $\begin{array}{l}\text { Water } \\
\text { level }\end{array}$ & $\mathrm{S}$ & \multicolumn{2}{|c|}{ Date } & $\begin{array}{l}\text { Water } \\
\text { level }\end{array}$ & \multicolumn{2}{|c|}{ Date } & $\begin{array}{l}\text { Water } \\
\text { level }\end{array}$ & $\mathrm{S}$ & \multicolumn{2}{|c|}{ Date } & $\begin{array}{l}\text { Water } \\
\text { level }\end{array}$ \\
\hline & & \multicolumn{12}{|c|}{ WELL 2--Continued } \\
\hline \multicolumn{2}{|l|}{1988} & & & \multicolumn{2}{|l|}{1989} & & \multicolumn{2}{|l|}{1990} & \multirow[b]{2}{*}{6.28} & & \multicolumn{2}{|l|}{1990} & \multirow[b]{2}{*}{5.93} \\
\hline \multirow[t]{3}{*}{ NOV } & 02 & 6.90 & & \multicolumn{2}{|c|}{ MAY 17} & & JAN & 5 & & & \multicolumn{2}{|c|}{$\frac{1990}{\text { OCT }} 16$} & \\
\hline & 10 & 7.02 & & & 26 & 7.47 & & 24 & 6.44 & & NOV & 20 & 6.44 \\
\hline & 14 & 7.03 & & \multirow{2}{*}{$\begin{array}{l}\text { JUNE } \\
\text { JULY }\end{array}$} & 01 & 7.56 & FEB & 27 & 6.65 & & $\mathrm{DEC}$ & 14 & 6.72 \\
\hline \multicolumn{2}{|c|}{$1989^{14}$} & & & & 11 & 4.19 & MAR & 22 & 3.20 & & \multicolumn{2}{|c|}{1991} & \\
\hline FEB & 22 & 8.05 & & \multirow{3}{*}{ AUG } & 31 & 4.56 & MAY & 21 & 4.31 & & JAN & 14 & 7.08 \\
\hline \multirow[t]{2}{*}{ MAR } & 08 & 7.97 & & & 17 & 5.31 & JUNE & 04 & 4.55 & & FEB & 15 & 7.67 \\
\hline & 13 & 7.88 & & & 28 & 4.40 & JULY & 10 & 3.78 & & MAR & 28 & 7.41 \\
\hline APR & 10 & 7.70 & & $\mathrm{DEC}$ & 06 & 5.95 & & 30 & 4.42 & & APR & 22 & 6.94 \\
\hline MAY & 11 & 7.35 & & & & & SEPT & 24 & 5.39 & & & & \\
\hline & & & & & & & WELL 3 & & & & & & \\
\hline 1985 & & & & 1985 & & & 1985 & & & & & & \\
\hline APR & 26 & 7.13 & & MAY & 24 & 7.49 & $\overline{J U N E}$ & 07 & 7.81 & & & & \\
\hline & & & & & & & WELL 4 & & & & & & \\
\hline 1985 & & & & 1987 & & & 1988 & & & & 1989 & & \\
\hline $\mathrm{APR}$ & 26 & 10.08 & & APR & 06 & 7.27 & SEPT & 20 & 3.95 & & AUG & 17 & 4.65 \\
\hline MAY & 24 & 9.63 & & & 07 & 7.23 & & 22 & 3.99 & & & 28 & 4.87 \\
\hline JUNE & 07 & 10.20 & & MAY & 19 & 6.70 & & 30 & 4.41 & & $\mathrm{DEC}$ & 06 & 4.78 \\
\hline JULY & 09 & 10.06 & & JUNE & 30 & 6.12 & OCT & 19 & 4.77 & & 1990 & & \\
\hline & 25 & 9.65 & & JULY & 14 & 5.87 & NOV & 02 & 5.09 & & JAN & 05 & 5.66 \\
\hline AUG & 15 & 9.63 & & & 24 & 5.67 & & 08 & 5.18 & & & 24 & 6.20 \\
\hline & 29 & 10.06 & & AUG & 26 & 5.38 & & 10 & 5.21 & & FEB & 27 & 6.39 \\
\hline SEPT & 13 & 10.08 & & SEPT & 10 & 5.45 & & 14 & 5.25 & & MAR & 22 & 5.52 \\
\hline NOV & 21 & 9.89 & & & 16 & 5.51 & 1989 & & & & MAY & 21 & 5.23 \\
\hline $\mathrm{DEC}$ & 20 & 10.20 & & & 22 & 5.60 & JAN & 10 & 5.67 & & JUNE & 04 & 4.49 \\
\hline 1986 & & & & OCT & 07 & 5.74 & & 31 & 5.94 & & JULY & 10 & 4.70 \\
\hline JAN & 23 & 10.26 & & NOV & 06 & 5.57 & FEB & 22 & 6.12 & & & 30 & 4.95 \\
\hline APR & 02 & 9.45 & & 1988 & & & MAR & 08 & 6.00 & & SEPT & 24 & 4.27 \\
\hline & 14 & 8.28 & & JAN & 08 & 6.15 & & 15 & 5.98 & & OCT & 16 & 5.41 \\
\hline MAY & 22 & 7.92 & & MAR & 10 & 5.82 & APR & 10 & 5.92 & & NOV & 20 & 5.61 \\
\hline $\mathrm{OCT}$ & 08 & 6.90 & & JULY & 01 & 4.50 & MAY & 11 & 6.03 & & $\mathrm{DEC}$ & 14 & 6.08 \\
\hline NOV & 06 & 6.99 & & AUG & 05 & 4.21 & & 17 & 5.93 & & 1991 & & \\
\hline & 28 & 7.08 & & & 16 & 4.48 & & 26 & 5.60 & & JAN & 14 & 6.20 \\
\hline 1987 & & & & & 26 & 4.40 & JUNE & 01 & 5.64 & & FEB & 15 & 6.38 \\
\hline FEB & 06 & 7.23 & & SEPT & 01 & 4.50 & JULY & 11 & 4.95 & & MAR & 28 & 6.53 \\
\hline MAR & 19 & 7.32 & & & 12 & 4.32 & & 31 & 4.67 & & APR & 22 & 6.58 \\
\hline & & & & & 15 & 4.22 & & & & & & & \\
\hline
\end{tabular}


Table 4.--Water levels in wells where water samples were obtained, 1985-91--Continued

\begin{tabular}{|c|c|c|c|c|c|c|c|c|c|c|c|}
\hline Date & $\begin{array}{l}\text { Water } \\
\text { level }\end{array}$ & $\mathrm{S}$ & Date & $\begin{array}{l}\text { Water } \\
\text { level }\end{array}$ & $\mathrm{S}$ & Date & $\begin{array}{l}\text { Water } \\
\text { level }\end{array}$ & $\mathrm{S}$ & Date & $\begin{array}{l}\text { Water } \\
\text { level }\end{array}$ & $S$ \\
\hline
\end{tabular}

WELL 5



\begin{tabular}{ccc}
$\frac{1989}{\text { FEB }}$ & 22 & 20.95 \\
MAR & 08 & 20.74 \\
& 13 & 20.58 \\
APR & 10 & 20.80 \\
MAY & 11 & 20.82 \\
& 17 & 20.95 \\
& 26 & 21.11 \\
JUNE & 01 & 21.18 \\
JULY & 11 & 21.27 \\
& 31 & 21.32 \\
AUG & 17 & 21.29 \\
& 28 & 21.31 \\
DEC & 06 & 20.10 \\
1990 & & \\
\hline JAN & 05 & 20.14 \\
& 24 & 20.16
\end{tabular}

WELI 6

\begin{tabular}{rrr}
$\begin{aligned} 1985 \\
\text { APR }\end{aligned}$ & & \\
MAY & 26 & 16.53 \\
JUNE & 07 & 16.76 \\
JULY & 09 & 17.98 \\
AUG & 15 & 18.50 \\
& 28 & 18.65 \\
SEPT & 13 & 18.95 \\
OCT & 02 & 19.32 \\
NOV & 21 & 19.74 \\
1986 & & \\
\hline JAN & 23 & 19.77 \\
MAR & 07 & 19.58 \\
& 27 & 19.50 \\
APR & 14 & 18.27 \\
MAY & 22 & 17.74 \\
JULY & 03 & 18.30 \\
AUG & 26 & 18.40 \\
OCT & 01 & 18.80 \\
NOV & 06 & 18.89 \\
& 28 & 18.93 \\
1987 & & \\
\hline FEB & 06 & 19.07 \\
MAR & 19 & 18.93
\end{tabular}

\begin{tabular}{|c|c|c|}
\hline \multicolumn{3}{|l|}{987} \\
\hline$\overline{\mathrm{APR}}$ & 27 & 19.2 \\
\hline MAY & 19 & \\
\hline JUNE & 30 & \\
\hline ULY & 08 & 2 \\
\hline & 13 & 20 \\
\hline & 24 & 20 \\
\hline AUG & 20 & 19 \\
\hline & 25 & \\
\hline SEPT & 09 & 19 \\
\hline & 15 & 19 \\
\hline & 21 & 19.36 \\
\hline OCT & 02 & 19.90 \\
\hline & 08 & 20.07 \\
\hline NoV & 06 & 19.99 \\
\hline 1988 & & \\
\hline$\overline{\mathrm{JAN}}$ & 08 & 19.67 \\
\hline MAR & 01 & 19.43 \\
\hline & 10 & 19.16 \\
\hline APR & 13 & 19.09 \\
\hline JULY & 01 & 19.14 \\
\hline & 19 & 20.10 \\
\hline AUG & 05 & 20.16 \\
\hline & 16 & 20 . \\
\hline
\end{tabular}

\begin{tabular}{rrr}
$\frac{1990}{\text { FEB }}$ & 27 & 20.25 \\
MAR & 22 & 20.08 \\
MAY & 21 & 19.40 \\
JUNE & 04 & 19.31 \\
JULY & 10 & 19.35 \\
& 30 & 19.34 \\
SEPT & 24 & 19.48 \\
OCT & 16 & 19.55 \\
NOV & 20 & 19.69 \\
DEC & 14 & 19.81 \\
1991 & & \\
\hline JAN & 14 & 20.08 \\
FEB & 15 & 20.23 \\
MAR & 28 & 20.48 \\
APR & 22 & 20.53
\end{tabular}

1989

AUG $17 \quad 21.86$ $28 \quad 21.24$

DEC $06 \quad 20.20$ 1990

\begin{tabular}{lll}
\hline JAN & 05 & 20.20
\end{tabular}

$24 \quad 21.21$

FEB $27 \quad 20.20$

MAR $22 \quad 18.60$

MAY $21 \quad 18.01$

JUNE $04 \quad 17.91$

JULY $10 \quad 17.14$

$\begin{array}{ll}30 & 17.71\end{array}$

SEPT $24 \quad 18.53$

OCT $16 \quad 18.67$

NOV $20 \quad 18.85$

DEC $14 \quad 19.01$

1991

$\begin{array}{lll}\text { JAN } & 14 & 19.28\end{array}$

FEB $15 \quad 19.39$

MAR $28 \quad 19.57$

APR $22 \quad 19.57$ 
Table 4.--Water levels in wells where water samples were obtained, 1985-91--Continued




Table 4.--Water levels in wells where water samples were obtained, 1985-91--Continued

\begin{tabular}{|c|c|c|c|c|c|c|c|c|c|}
\hline Date & $\begin{array}{l}\text { Water } \\
\text { level }\end{array}$ & $\mathbf{S}$ & Date & $\begin{array}{l}\text { Water } \\
\text { level }\end{array}$ & Date & $\begin{array}{l}\text { Water } \\
\text { level }\end{array}$ & $\mathbf{S}$ & Date & $\begin{array}{l}\text { Water } \\
\text { level }\end{array}$ \\
\hline & \multicolumn{9}{|c|}{ WELL 8--Continued } \\
\hline 1990 & & & 1990 & & 1990 & & & 1991 & \\
\hline$\overline{\text { MAR }} 22$ & .55 & & $\overline{J U L Y} 10$ & +.90 & NOV 20 & 1.37 & & JAN 14 & 1.97 \\
\hline MAY 21 & .61 & & SEPT 24 & 1.71 & DEC 14 & 1.46 & & FEB 15 & 1. \\
\hline JUNE 04 & .39 & & OCT 16 & 1.51 & & & & MAR 28 & 1.70 \\
\hline & & & & & & & & APR 22 & 1. \\
\hline
\end{tabular}

WELL 9

\begin{tabular}{|c|c|c|c|c|c|c|c|c|c|c|c|c|}
\hline 1985 & & & 1987 & & & & 1988 & & & 1989 & & \\
\hline$\overline{\mathrm{APR}}$ & 26 & 2.63 & $\overline{\text { FEB }}$ & 06 & 1.48 & & $\overline{\mathrm{AUG}}$ & 26 & 2.74 & $\overline{\text { JULY }}$ & 31 & 1.93 \\
\hline MAY & 24 & 3.52 & MAR & 19 & 1.24 & & SEPT & 01 & 3.02 & AUG & 17 & 1.97 \\
\hline JUNE & 07 & 4.57 & APR & 27 & 2.03 & & & 12 & 2.86 & & 28 & 2.07 \\
\hline JULY & 09 & 6.72 & MAY & 19 & 2.83 & & & 15 & 2.13 & $\mathrm{DEC}$ & 06 & .97 \\
\hline AUG & 15 & 6.54 & JUNE & 30 & 4.16 & & & 20 & 2.63 & 1990 & & \\
\hline & 29 & 7.00 & JULY & 13 & 4.32 & & & 22 & 2.58 & $\overline{\mathrm{JAN}}$ & 05 & 1.27 \\
\hline SEPT & 13 & 6.44 & & 24 & 4.79 & & OCT & 19 & 1.98 & & 24 & .99 \\
\hline NOV & 21 & 4.08 & AUG & 26 & 4.00 & & NOV & 02 & 1.58 & & 27 & .77 \\
\hline $\mathrm{DEC}$ & 20 & 3.74 & SEPT & 10 & 4.10 & & & 10 & 1.50 & MAR & 22 & .16 \\
\hline 1986 & & & & 15 & 3.98 & & & 14 & 1.41 & MAY & 21 & 1.19 \\
\hline JAN & 23 & 3.24 & & 22 & 3.91 & & 1989 & & & JUNE & 04 & .79 \\
\hline MAR & 07 & 2.64 & OCT & 08 & 3.55 & & $\overline{\mathrm{JAN}}$ & 31 & 1.38 & JULY & 10 & 2.98 \\
\hline & 27 & 2.68 & NOV & 06 & 3.44 & & FEB & 22 & 1.41 & & 30 & 3.17 \\
\hline APR & 14 & 2.06 & 1988 & & & & MAR & 08 & .84 & SEPT & 24 & 3.61 \\
\hline MAY & 22 & 3.23 & JAN & 08 & 1.95 & & & 13 & .69 & OCT & 16 & 2.99 \\
\hline JULY & 03 & 4.43 & MAR & 10 & 1.21 & & APR & 10 & 1.08 & NOV & 20 & 2.18 \\
\hline AUG & 26 & 3.32 & APR & 13 & 1.32 & & MAY & 11 & 1.46 & $\mathrm{DEC}$ & 14 & 2.16 \\
\hline OCT & 01 & 2.62 & JULY & 01 & 2.90 & & & 17 & 1.30 & 1991 & & \\
\hline NOV & 06 & 1.77 & & 19 & 3.30 & $r$ & & 26 & 2.04 & JAN & 14 & 2.27 \\
\hline & 28 & 1.67 & AUG & 05 & 1.42 & & JUNE & 01 & 1.97 & FEB & 15 & 2.08 \\
\hline & & & & 16 & 2.76 & & JULY & 11 & 2.18 & MAR & 28 & 2.18 \\
\hline & & & & & & & & & & APR & 22 & 2.05 \\
\hline
\end{tabular}

WELL 10

\begin{tabular}{|c|c|c|c|c|c|}
\hline 1985 & & & 1986 & & \\
\hline$\overline{\mathrm{APR}}$ & 26 & 10.89 & $\overline{\text { MAR }}$ & 07 & 12.96 \\
\hline MAY & 24 & 11.29 & & 27 & 12.62 \\
\hline JUNE & 07 & 11.48 & APR & 14 & 12.45 \\
\hline & 14 & 11.60 & MAY & 22 & 12.02 \\
\hline JULY & 09 & 12.05 & JULY & 03 & 12.82 \\
\hline & 25 & 13.32 & OCT & 01 & 14.19 \\
\hline AUG & 15 & 12.59 & 1987 & & \\
\hline & 29 & 12.77 & $\overline{\mathrm{AUG}}$ & 25 & 10.92 \\
\hline SEPT & 23 & 12.95 & SEPT & 09 & 15.02 \\
\hline NOV & 21 & 13.60 & & 15 & 15.27 \\
\hline & & & & 22 & 15.34 \\
\hline 198 & & & OCT & 02 & 15.41 \\
\hline & & 13.92 & & 08 & 15.47 \\
\hline
\end{tabular}

\begin{tabular}{|c|c|c|c|c|c|}
\hline 1987 & & & 1988 & & \\
\hline$\overline{\text { NOV }}$ & 06 & 15.76 & $\overline{\text { SEPT }}$ & 20 & 16.88 \\
\hline 1988 & & & OCT & 19 & 17.15 \\
\hline$\overline{\mathrm{JAN}}$ & 08 & 16.26 & NOV & 02 & 17.26 \\
\hline MAR & 10 & 16.12 & & 11 & 17.36 \\
\hline APR & 13 & 15.77 & & 14 & 17.39 \\
\hline JUNE & 28 & 16.12 & 1989 & & \\
\hline JULY & 19 & 16.48 & $\overline{M A Y}$ & 11 & 17.17 \\
\hline AUG & 05 & 16.55 & & 17 & 17.17 \\
\hline & 16 & 16.60 & & 26 & 17.19 \\
\hline & 26 & 16.65 & JUNE & 01 & 17.20 \\
\hline SEPT & 01 & 16.72 & JULY & 11 & 17.47 \\
\hline & 12 & 16.77 & & 31 & 17.73 \\
\hline & 15 & 16.82 & AUG & 17 & 17.96 \\
\hline
\end{tabular}


Table 4.--Water levels in wells where water samples were obtained, 1985-91--Continued

\begin{tabular}{|c|c|c|c|c|c|c|c|c|c|c|c|c|c|}
\hline \multicolumn{2}{|c|}{ Date } & $\begin{array}{l}\text { Water } \\
\text { level }\end{array}$ & $\mathbf{S}$ & \multicolumn{2}{|c|}{ Date } & $\begin{array}{l}\text { Water } \\
\text { level }\end{array}$ & \multicolumn{2}{|c|}{ Date } & $\begin{array}{l}\text { Water } \\
\text { level }\end{array}$ & $\mathrm{S}$ & \multicolumn{2}{|c|}{ Date } & $\begin{array}{l}\text { Water } \\
\text { level }\end{array}$ \\
\hline & & \multicolumn{12}{|c|}{ WELL 10--Continued } \\
\hline 1989 & & & & 1990 & & & 1990 & & & & 1991 & & \\
\hline$\overline{\mathrm{AUG}}$ & 28 & 18.03 & & $\overline{F E B}$ & 27 & 18.41 & $\overline{J U L Y}$ & 30 & 16.32 & & $\overline{\mathrm{JAN}}$ & 14 & 17.49 \\
\hline $\mathrm{DEC}$ & 06 & 18.32 & & MAR & 22 & 18.28 & SEPT & 24 & 16.74 & & FEB & 15 & 17.52 \\
\hline 1990 & & & & MAY & 21 & 16.68 & OCT & 16 & 16.95 & & MAR & 28 & 17.45 \\
\hline \multirow[t]{3}{*}{$\overline{J A N}$} & 05 & 18.38 & & JUNE & 04 & 16.50 & NOV & 20 & 17.17 & & APR & 22 & 17.33 \\
\hline & 24 & 18.37 & & JULY & 10 & 16.32 & $\mathrm{DEC}$ & 14 & 17.30 & & & & \\
\hline & & \multicolumn{12}{|c|}{ WELL 11} \\
\hline 1985 & & & & 1987 & & & 1988 & & & & 1989 & & \\
\hline$\overline{\mathrm{APR}}$ & 26 & 12.50 & & FEB & 06 & 12.70 & $\overline{\mathrm{AUG}}$ & 26 & 12.42 & & $\overline{\mathrm{AUG}}$ & 17 & 11.63 \\
\hline MAY & 24 & 12.31 & & MAR & 19 & 12.53 & SEPT & 01 & 12.47 & & & 28 & 11.63 \\
\hline \multirow[t]{2}{*}{ JUNE } & 07 & 12.40 & & APR & 27 & 12.39 & & 12 & 12.53 & & $\mathrm{DEC}$ & 06 & 10.98 \\
\hline & 14 & 12.28 & & MAY & 19 & 12.37 & & 15 & 12.53 & & 1990 & & \\
\hline \multirow[t]{2}{*}{ JULY } & 09 & 12.73 & & JUNE & 30 & 12.74 & & 20 & 12.58 & & $\overline{\text { JAN }}$ & 05 & 11.12 \\
\hline & 25 & 10.71 & & JULY & 13 & 12.88 & & 22 & 12.60 & & & 24 & 11.20 \\
\hline \multirow[t]{2}{*}{ AUG } & 15 & 12.98 & & & 24 & 12.95 & OCT & 19 & 12.71 & & FEB & 27 & 11.22 \\
\hline & 28 & 13.41 & & AUG & 20 & 13.14 & NOV & 02 & 12.70 & & MAR & 22 & 10.27 \\
\hline SEPT & 13 & 13.22 & & & 26 & 13.18 & & 11 & 12.72 & & MAY & 21 & 9.85 \\
\hline NOV & 21 & 13.62 & & SEPT & 10 & 13.31 & & 14 & 12.68 & & JUNE & 04 & 9.93 \\
\hline $\mathrm{DEC}$ & 20 & 13.67 & & & 15 & 13.29 & 1989 & & & & JULY & 10 & 10.12 \\
\hline 1986 & & & & & 22 & 13.39 & JAN & 10 & 12.58 & & & 30 & 10.31 \\
\hline JAN & 23 & 13.56 & & OCT & 02 & 13.44 & & 31 & 12.54 & & SEPT & 24 & 11.03 \\
\hline \multirow[t]{2}{*}{ MAR } & 07 & 12.61 & & & 07 & 13.44 & FEB & 22 & 12.56 & & OCT & 16 & 11.28 \\
\hline & 27 & 12.44 & & NOV & 06 & 13.55 & MAR & 08 & 12.39 & & NOV & 20 & 11.51 \\
\hline APR & 14 & 12.29 & & 1988 & & & & 13 & 12.29 & & $\mathrm{DEC}$ & 14 & 11.61 \\
\hline MAY & 22 & 12.10 & & JAN & 08 & 13.45 & APR & 10 & 12.07 & & 1991 & & \\
\hline JULY & 03 & 12.44 & & MAR & 10 & 14.04 & MAY & 11 & 11.89 & & $\overline{\text { JAN }}$ & 14 & 11.73 \\
\hline SEPT & 05 & 12.45 & & APR & 13 & 12.72 & & 17 & 11.91 & & FEB & 15 & 11.75 \\
\hline \multirow[t]{2}{*}{ OCT } & 01 & 12.73 & & JULY & 01 & 12.37 & & 26 & 11.87 & & MAR & 28 & 11.74 \\
\hline & 08 & 12.76 & & & 19 & 12.46 & JUNE & 01 & 11.87 & & APR & 22 & 11.76 \\
\hline \multirow[t]{2}{*}{ NOV } & 06 & 12.81 & & AUG & 05 & 12.57 & JULY & 11 & 11.75 & & & & \\
\hline & 28 & 12.82 & & & 16 & 12.50 & & 31 & 11.65 & & & & \\
\hline
\end{tabular}

WELL 12

\begin{tabular}{|c|c|c|c|c|c|}
\hline \multicolumn{2}{|l|}{1985} & \multicolumn{4}{|c|}{1986} \\
\hline$\overline{\mathrm{APR}}$ & 26 & 19.16 & $\overline{\text { JAN }}$ & 23 & 19.12 \\
\hline MAY & 24 & 18.72 & MAR & 07 & 18.01 \\
\hline JUNE & 07 & 18.83 & & 27 & 17.76 \\
\hline JULY & 09 & 24.49 & APR & 14 & 17.44 \\
\hline AUG & 15 & 25.98 & MAY & 22 & 18.92 \\
\hline & 28 & 26.25 & JULY & 03 & 22.00 \\
\hline SEPT & 13 & 25.99 & AUG & 26 & 26.53 \\
\hline NOV & 06 & 22.15 & OCT & 01 & 24.77 \\
\hline & 21 & 21.31 & NOV & 06 & 22.07 \\
\hline $\mathrm{DEC}$ & 20 & 20.20 & & 28 & 21.01 \\
\hline
\end{tabular}

$\begin{array}{rrr}\frac{1987}{\text { FEB }} & 06 & 18.91 \\ \text { MAR } & 19 & 17.92 \\ \text { APR } & 27 & 18.09 \\ \text { MAY } & 19 & 20.83 \\ \text { JUNE } & 30 & 22.01 \\ \text { JULY } & 13 & 23.27 \\ & 24 & 24.57 \\ \text { AUG } & 25 & 26.43 \\ \text { SEPT } & 09 & 25.40 \\ & 16 & 25.19\end{array}$

1987

$\begin{array}{ll}\text { SEPT } & 22 \\ 24.99\end{array}$

$\begin{array}{lll}\text { OCT } & 08 & 24.27\end{array}$

NOV $06 \quad 22.57$

1988

JAN $08 \quad 20.46$

MAR $01 \quad 19.29$

$10 \quad 19.04$

$\begin{array}{lll}\text { APR } & 13 \quad 18.56\end{array}$

JUNE $28 \quad 23.42$

JULY $19 \quad 25.76$ 
Table 4.--Water levels in wells where water samples were obtained, 1985-91--Continued

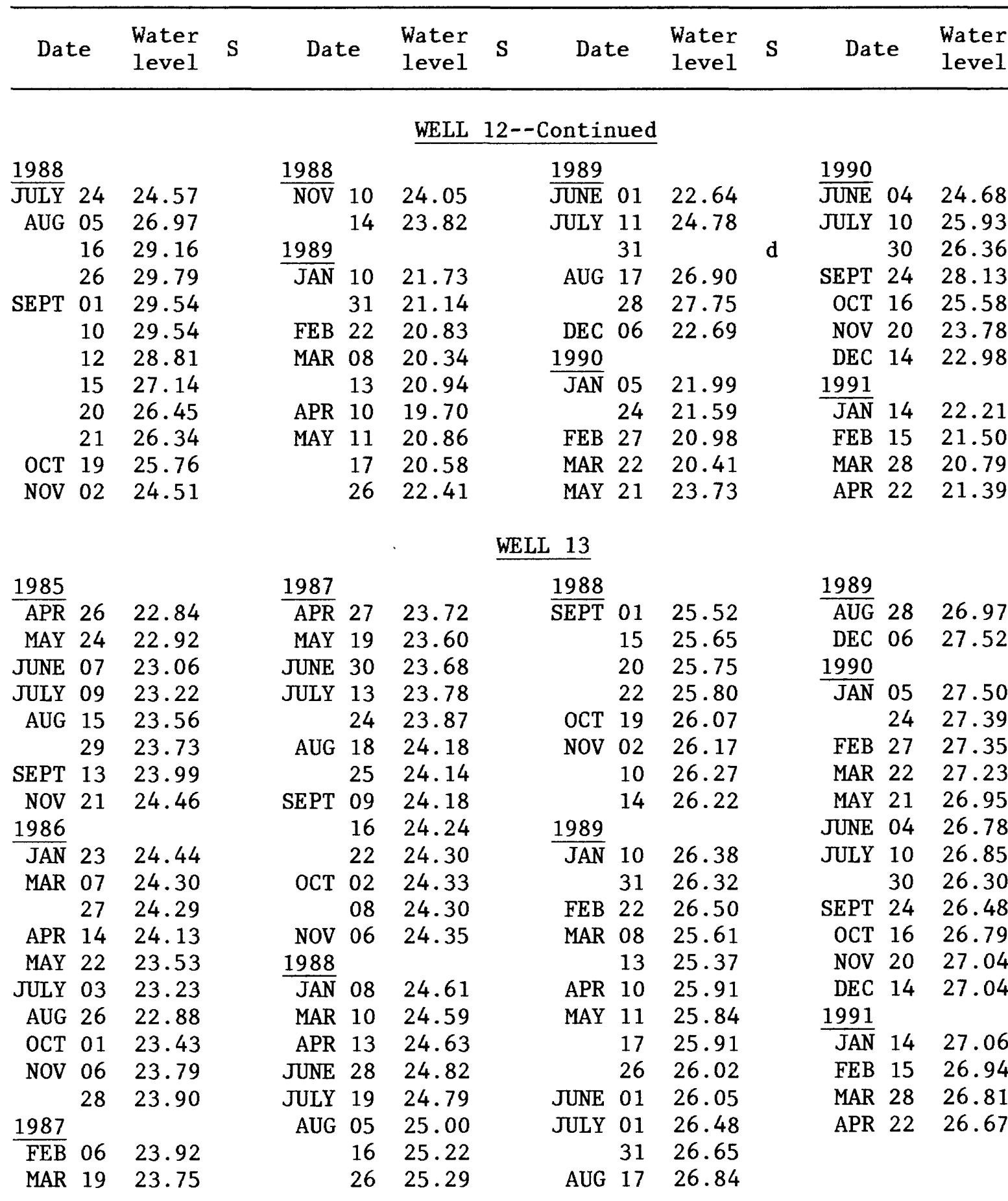


Table 4.--Water levels in wells where water samples were obtained, 1985-91--Continued

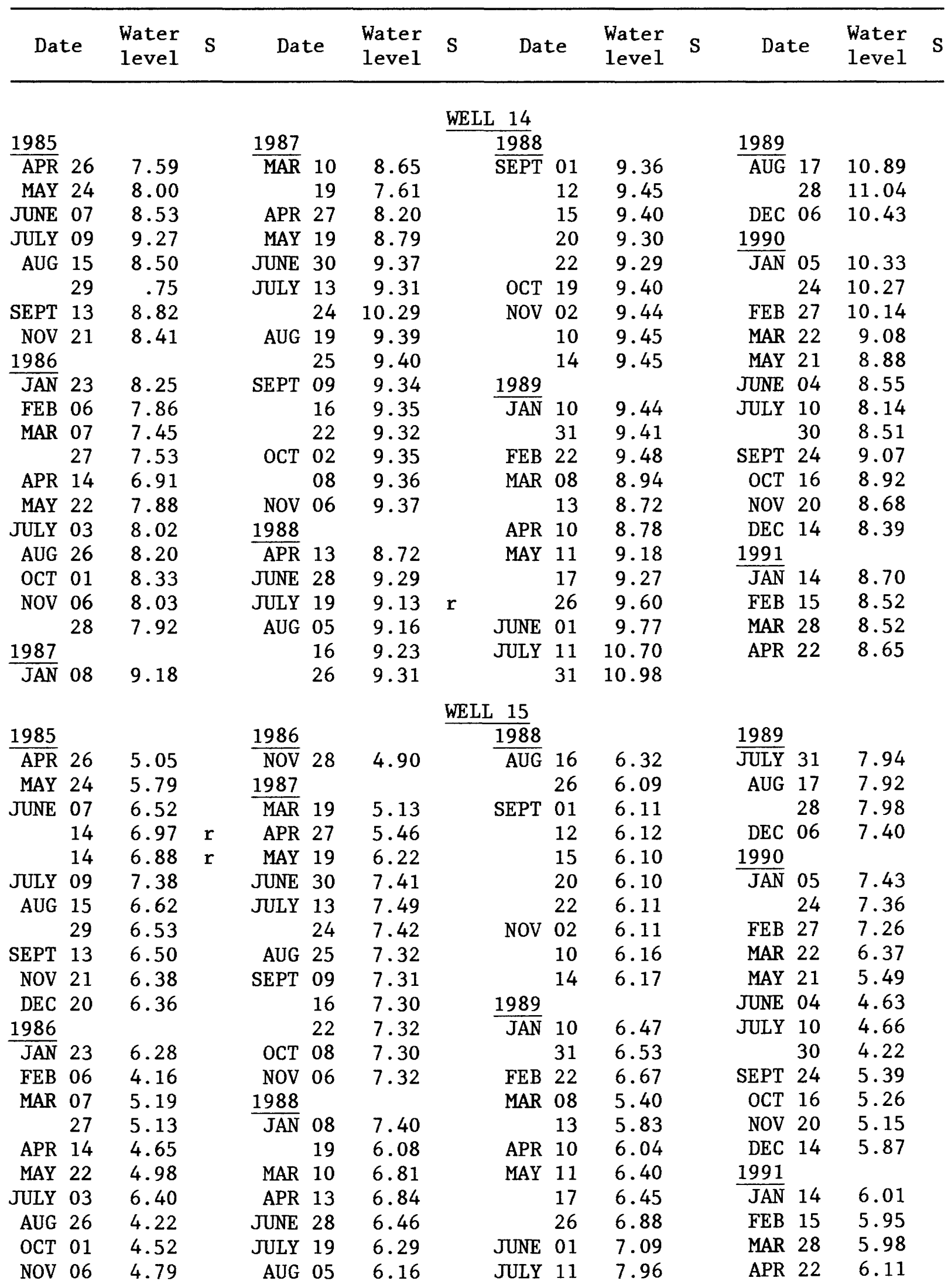


Table 4.--Water levels in wells where water samples were obtained, 1985-91--Continued

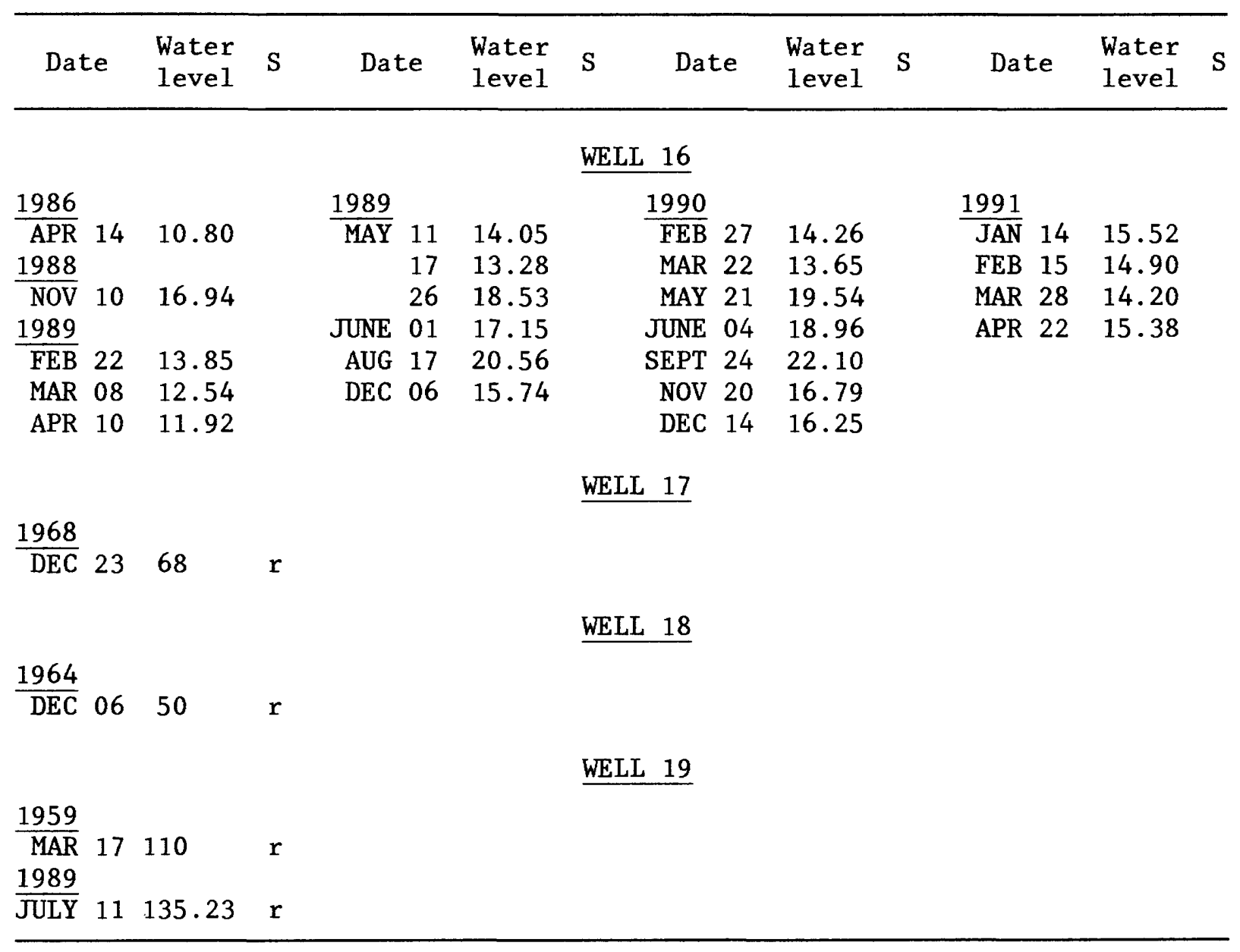


Table 5.--Chemical and bacteriological analyses of water from the observation wells

$\left[\mu \mathrm{S} / \mathrm{cm}\right.$, microsiemens per centimeter; mg/L, milligrams per liter; ${ }^{\circ} \mathrm{C}$, degrees Celsius; $\mathrm{NO}_{2}+\mathrm{NO}_{3}$, nitrite plus nitrate; --, no data available; $\mu_{g} / \mathrm{L}$, micrograms per liter; cols./100mL, colonies per 100 milliliters; tot rec, total recoverable; <, less than the detection limit for analytical method and sample dilution used; >, greater than]

\begin{tabular}{|c|c|c|c|c|c|c|c|c|c|}
\hline $\begin{array}{c}\text { Sample } \\
\text { date }\end{array}$ & $\begin{array}{c}\text { Specific } \\
\text { conduct- } \\
\text { ance } \\
(\mu \mathrm{S} / \mathrm{cm})\end{array}$ & $\begin{array}{c}\mathrm{pH} \\
\text { (units) }\end{array}$ & $\begin{array}{l}\text { Residue } \\
\text { at } \\
105^{\circ} \mathrm{C} \text {, } \\
\text { dis- } \\
\text { solved } \\
\text { (mg/L) }\end{array}$ & $\begin{array}{l}\text { Nitrogen, } \\
\text { ammonia, } \\
\text { dis- } \\
\text { solved } \\
\text { (mg/L } \\
\text { as } N \text { ) }\end{array}$ & $\begin{array}{l}\text { Nitrogen, } \\
\text { nitrite, } \\
\text { dis- } \\
\text { solved } \\
(\mathrm{mg} / \mathrm{L} \\
\text { as } \mathrm{N})\end{array}$ & $\begin{array}{l}\text { Nitrogen, } \\
\text { ammonia, } \\
\text { torganic, } \\
\text { dissolved } \\
\text { (mg/L } \\
\text { as N) }\end{array}$ & $\begin{array}{c}\mathrm{Nitrogen}, \\
\mathrm{NO}_{2}+\mathrm{NO}_{3} \\
\text { dis- } \\
\text { solved } \\
(\mathrm{mg} / \mathrm{L} \\
\text { as } \mathrm{N})\end{array}$ & $\begin{array}{l}\text { Phos- } \\
\text { phorus, } \\
\text { ortho, } \\
\text { dissolved } \\
\text { (mg/L } \\
\text { as } P \text { ) }\end{array}$ & $\begin{array}{l}\text { Hard- } \\
\text { ness, } \\
\text { total } \\
(\mathrm{mg} / \mathrm{L} \\
\text { as } \\
\left.\mathrm{CaCO}_{3}\right)\end{array}$ \\
\hline
\end{tabular}

WELL 1

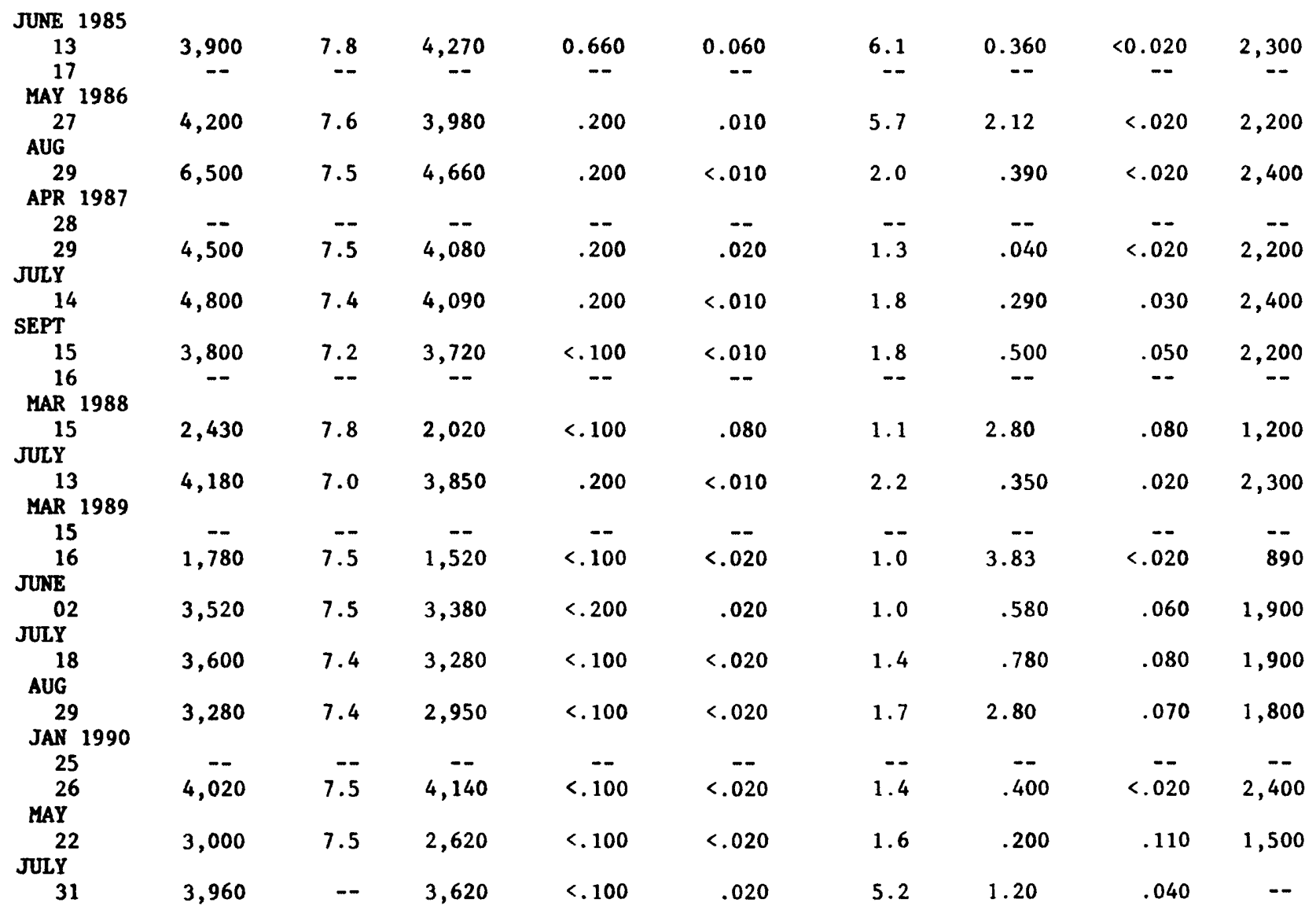


Table 5.--Chemical and bacteriological analyses of water from the observation wells--Continued

\begin{tabular}{|c|c|c|c|c|c|c|c|c|}
\hline $\begin{array}{c}\text { Sample } \\
\text { date }\end{array}$ & $\begin{array}{l}\text { Calcium } \\
\text { dis- } \\
\text { solved } \\
\text { (mg/L } \\
\text { as Ca) }\end{array}$ & $\begin{array}{l}\text { Magne- } \\
\text { sium, } \\
\text { dis- } \\
\text { solved } \\
\text { (mg/L } \\
\text { as } M g)\end{array}$ & $\begin{array}{l}\text { Sodium, } \\
\text { dis- } \\
\text { solved } \\
\text { (mg/L } \\
\text { as } \mathrm{Na} \text { ) }\end{array}$ & $\begin{array}{l}\text { Potas- } \\
\text { sium, } \\
\text { dis- } \\
\text { solved } \\
\text { (mg/L } \\
\text { as K) }\end{array}$ & $\begin{array}{c}\text { Chloride, } \\
\text { dis- } \\
\text { solved } \\
\text { (mg/L } \\
\text { as Cl) }\end{array}$ & $\begin{array}{l}\text { Sulfate, } \\
\text { dis- } \\
\text { solved } \\
(\mathrm{mg} / \mathrm{L} \\
\left.\text { as } \mathrm{SO}_{4}\right)\end{array}$ & $\begin{array}{l}\text { Cadmium, } \\
\text { dis- } \\
\text { solved } \\
\left(\mu_{g} / L\right. \\
\text { as Cd) }\end{array}$ & $\begin{array}{c}\text { Chromium, } \\
\text { dis- } \\
\text { solved } \\
\left(\mu_{g} / L\right. \\
\text { as } C r)\end{array}$ \\
\hline
\end{tabular}

WELL 1--Continued

JUNE 1985

13
17
MAY 1986

27
AUG

29

28

29

JULY

14

SEPT

15

16
AR 1988

MAR 19

JULY

13

MAR 1989

15

16

JUNE

02

JULY

18
AUG

29

JAN 1990

380

330

-.

430

420

280

320

400

--

290

420

400

--

250

420

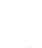

200

400

390

360

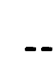

280

22

JULY

130

\section{0}

360



91

11

8.0

60

73

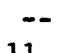

$--$

300

11

10

87

80

9.9

82

$280 \quad 280$

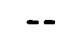

150

25

10

67

$310 \quad 320$

72

$-$

$97 \quad 100$

13

21

$8.0 \quad 67$

12

11

60

85

-- 97

8.4

57

63

$-$

$190 \quad 210$

--
2,400

2,300

0.3

2,300

.9

2,300

$-2$

2,300

1.5

2,200

$<.2$

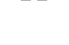

920

.8

2,100

.7

$\overline{800}$

1.0

1,700

$<.2$

1,800

.9

1,500

.9

2,400



.1

5,200

$<20$

-- $\quad--\quad$--

$+2$ 
Table 5.--Chemical and bacteriological analyses of water

from the observation wells--Continued

\begin{tabular}{|c|c|c|c|c|c|c|c|c|}
\hline $\begin{array}{c}\text { Sample } \\
\text { date }\end{array}$ & $\begin{array}{l}\text { Copper, } \\
\text { dis- } \\
\text { solved } \\
\left(\mu_{8} / L\right. \\
\text { as } \mathrm{Cu})\end{array}$ & $\begin{array}{l}\text { Iron, } \\
\text { dis- } \\
\text { solved } \\
\left(\mu_{8} / \mathrm{L}\right. \\
\text { as Fe) }\end{array}$ & $\begin{array}{l}\text { Lead, } \\
\text { dis- } \\
\text { solved } \\
\left(\mu_{8} / \mathrm{L}\right. \\
\text { as } \mathrm{Pb})\end{array}$ & $\begin{array}{c}\text { Manga- } \\
\text { nese, } \\
\text { dissolved } \\
(\mu g / L \\
\text { as } M n)\end{array}$ & $\begin{array}{l}\text { Nickel, } \\
\text { dis- } \\
\text { solved } \\
\left(\mu_{8} / \mathrm{L}\right. \\
\text { as } \mathrm{Ni})\end{array}$ & $\begin{array}{l}\text { Zinc, } \\
\text { dis- } \\
\text { solved } \\
\left(\mu_{g} / L\right. \\
\text { as } Z n)\end{array}$ & $\begin{array}{l}\text { Coli- } \\
\text { form, } \\
\text { fecal } \\
(\operatorname{col} . / \\
100 \mathrm{~mL})\end{array}$ & $\begin{array}{l}\text { Strepto- } \\
\text { cocci, } \\
\text { fecal } \\
\text { (col./ } \\
100 \mathrm{~mL})\end{array}$ \\
\hline
\end{tabular}

WELL 1--Continued

JUNE 1985

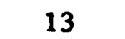

17

MAY 1986

AUG

29

APR 1987

28

JULY

14

SEPT

15
16

MAR 1988

15

JULY

13

MAR 1989

15

JUNE

02

JULY

AUG

29

JAN 1990

25
26
MAY
22

JULY

--

$<20$

$<100$

$--$

$<60$

$<20$

$--$

$<20$

$<20$

$-\overline{20}$

$<20$

$<20$

80

$<20$

$--$

$<20$

--

$\begin{array}{cc}30 & -- \\ -- & -- \\ <50 & <10 \\ 1,800 & <250\end{array}$

$\begin{array}{ll}-- & -- \\ 290 & <50\end{array}$

$<200<10$

$350<10$

$--$

$<50$

$--$

$<50$

$<10$

$<10$

$--\quad<10$

$<100$

$<10$

450

$<10$

$<50$

$<10$

$--\quad \quad-$

$<50<10$

100

$--$

--

30

$<530<60$

$800 \quad 250$

$\begin{array}{ll}-- & -\end{array}$

420

430

60

380

380

90

150

$<20$

$<20$

$<20$

-- -

$<20$

$<20$

$<40$

$<20$

$<20$

$90 \quad 100$

980

100

60

-.

$--$

$--$

$<20$

$<20$

20

90

$<20$

$<10$

$--$

31 
Table 5.--Chemical and bacteriological analyses of water from the observation wells--Continued

\begin{tabular}{|c|c|c|c|c|c|c|c|c|c|c|}
\hline $\begin{array}{c}\text { Sample } \\
\text { date }\end{array}$ & $\begin{array}{l}\text { Spe- } \\
\text { cific } \\
\text { con- } \\
\text { duct- } \\
\text { ance } \\
(\mu \mathrm{S} / \mathrm{cm})\end{array}$ & $\underset{\text { (units) }}{\mathbf{p H}}$ & $\begin{array}{l}\text { Residue } \\
\text { at } \\
105^{\circ} \mathrm{C}, \\
\text { dis- } \\
\text { solved } \\
\text { (mg/L) }\end{array}$ & $\begin{array}{l}\text { Nitrogen, } \\
\text { ammonia, } \\
\text { dis- } \\
\text { solved } \\
\text { (mg/L } \\
\text { as } N \text { ) }\end{array}$ & $\begin{array}{c}\text { Nitrogen, } \\
\text { nitrite, } \\
\text { dis- } \\
\text { solved } \\
(\mathrm{mg} / \mathrm{L} \\
\text { as } N)\end{array}$ & $\begin{array}{l}\text { Nitrogen, } \\
\text { ammonia, } \\
\text { torganic, } \\
\text { dissolved } \\
(\mathrm{mg} / \mathrm{L} \\
\text { as } N)\end{array}$ & $\begin{array}{c}\text { Nitrogen, } \\
\mathrm{NO}_{2}+\mathrm{NO}_{3} \\
\text { dis- } \\
\text { solved } \\
(\mathrm{mg} / \mathrm{L} \\
\text { as } \mathrm{N} \text { ) }\end{array}$ & $\begin{array}{l}\text { Phos- } \\
\text { phorus, } \\
\text { ortho, } \\
\text { dissolved } \\
\text { (mg/L } \\
\text { as P) }\end{array}$ & $\begin{array}{l}\text { Hard- } \\
\text { ness, } \\
\text { total } \\
(\mathrm{mg} / \mathrm{L} \\
\text { as } \\
\mathrm{CaCO}_{3} \text { ) }\end{array}$ & $\begin{array}{l}\text { Cal- } \\
\text { cium, } \\
\text { dis- } \\
\text { solved } \\
\text { (mg/L } \\
\text { as Ca) }\end{array}$ \\
\hline \multicolumn{11}{|c|}{ WELL 2} \\
\hline \multicolumn{11}{|l|}{ JUNE 1985} \\
\hline 13 & 5,500 & 7.8 & 6,200 & 0.720 & 1.72 & 8.3 & 4.45 & 0.040 & 2,200 & 380 \\
\hline 17 & - & -- & -- & -- & - & - & - & - & $=$ & - \\
\hline \multicolumn{11}{|l|}{ AUG } \\
\hline 29 & - & - & - & -- & - & -- & -- & - & - & -- \\
\hline 30 & 7,100 & 6.9 & 7,300 & 1.40 & .020 & 6.0 & .350 & .200 & 3,200 & 490 \\
\hline MAY 1986 & & & & & & & & & & \\
\hline 27 & 3,900 & 7.6 & 3,420 & 3.80 & 2.48 & 6.0 & 10.5 & $<.020$ & 1,900 & 330 \\
\hline \multicolumn{11}{|l|}{ AUG } \\
\hline 28 & -- & -- & -- & -- & - & -- & -- & -- & -- & -- \\
\hline 29 & 6,500 & 7.3 & 5,640 & 1.20 & .330 & 3.8 & 13.8 & $<.020$ & 2,500 & 370 \\
\hline $\begin{array}{c}\text { APR } 1987 \\
28\end{array}$ & & & & & & & & & & \\
\hline $\begin{array}{l}28 \\
29\end{array}$ & -- & $-\overline{7}$ & $\overline{-5}$ & $-\overline{0}$ & $-\infty$ & -- & -- & -- & -- & $\overline{-}$ \\
\hline $\begin{array}{l}29 \\
\text { JULY }\end{array}$ & 3,400 & 7.7 & 3,130 & .200 & .020 & 1.1 & 14.0 & $<.020$ & 1,900 & 320 \\
\hline \multicolumn{11}{|l|}{ JULY } \\
\hline \multirow{2}{*}{\multicolumn{11}{|c|}{ SEPT }} \\
\hline $\begin{array}{r}\text { SEPT } \\
15\end{array}$ & & & & & & & & & & \\
\hline $\begin{array}{l}15 \\
16\end{array}$ & $\begin{array}{c}3,900 \\
--\end{array}$ & 7.3 & 4,310 & .300 & $<.010$ & 1.3 & 11.7 & .030 & 2,200 & 380 \\
\hline \multirow{2}{*}{\multicolumn{11}{|c|}{ MAR 1988}} \\
\hline 15 & & & & & & & & & & \\
\hline 17 & 3,050 & 7.4 & 2,950 & $<.100$ & $<.020$ & .90 & 6.10 & .020 & 1,600 & 260 \\
\hline \multirow{2}{*}{\multicolumn{11}{|c|}{ JULY }} \\
\hline 13 & & & & & & & & & & \\
\hline $\begin{array}{l}13 \\
\text { SEPT }\end{array}$ & 3,780 & 7.3 & 3,380 & .100 & .010 & 1.5 & 21.5 & $<.020$ & 1,800 & 270 \\
\hline 02 & -- & -- & -- & -- & -- & -- & -- & -. & - & -- \\
\hline$\stackrel{23}{\text { MAR } 1989}$ & 4,480 & 7.3 & 4,330 & $<.100$ & .060 & .60 & 4.80 & $<.020$ & 2,000 & 340 \\
\hline 15 & -- & -- & -- & -- & -- & -- & -- & -- & -- & -- \\
\hline \multicolumn{11}{|l|}{ JUNE } \\
\hline 02 & 6,440 & 7.6 & -- & $<.200$ & .060 & 1.5 & .610 & $<.020$ & 2,800 & 400 \\
\hline \multicolumn{11}{|l|}{ JULY } \\
\hline \multirow{2}{*}{\multicolumn{5}{|c|}{ AUG }} & $<.020$ & .50 & 7.30 & .030 & 1,500 & 280 \\
\hline 29 & 3,450 & 7.5 & 3,580 & $<.100$ & $<.020$ & 1.6 & 6.20 & .020 & & \\
\hline JAN 1990 & & & & & & & & & & \\
\hline 25 & -- & -- & -- & -- & -- & -- & -- & -- & -- & -- \\
\hline 26 & 4,110 & 7.5 & 3,730 & $<.100$ & $<.020$ & .70 & 5.20 & $<.020$ & 1,900 & -- \\
\hline \multicolumn{11}{|l|}{ JULY } \\
\hline 31 & 3,470 & 7.5 & 2,890 & $<.100$ & $<.020$ & 5.8 & 12.2 & $<.020$ & 1,400 & 230 \\
\hline \multicolumn{11}{|l|}{ SEPT } \\
\hline 25 & 4,610 & 7.5 & 3,410 & $<.100$ & .050 & .50 & 23.3 & $<.020$ & 1,300 & 210 \\
\hline \multicolumn{11}{|l|}{ JAN 1991} \\
\hline 24 & - & - & - & -- & -- & -- & -- & -- & -- & $\overline{--}$ \\
\hline 25 & 4,430 & 7.5 & 4,100 & $<.100$ & .030 & 1.2 & 1.10 & .190 & 1,600 & 270 \\
\hline
\end{tabular}


Table 5.--Chemical and bacteriological analyses of water from the observation wells--Continued

\begin{tabular}{|c|c|c|c|c|c|c|c|c|c|c|c|}
\hline $\begin{array}{c}\text { Sample } \\
\text { date }\end{array}$ & $\begin{array}{c}\text { Magne- } \\
\text { sium, } \\
\text { dis- } \\
\text { solved } \\
\text { (mg/L } \\
\text { as } \mathrm{Mg}_{\mathrm{g}} \text { ) }\end{array}$ & $\begin{array}{l}\text { Sodium, } \\
\text { dis- } \\
\text { solved } \\
(\mathrm{mg} / \mathrm{L} \\
\text { as } \mathrm{Na})\end{array}$ & $\begin{array}{l}\text { Potas- } \\
\text { sium, } \\
\text { dis- } \\
\text { solved } \\
\text { (mg/L } \\
\text { as K) }\end{array}$ & $\begin{array}{l}\text { Chlo- } \\
\text { ride, } \\
\text { dis- } \\
\text { solved } \\
\text { (mg/L } \\
\text { as }(1)\end{array}$ & $\begin{array}{c}\text { Sulfate, } \\
\text { dis- } \\
\text { solved } \\
\left(\mathrm{mg}^{\prime} \mathrm{L}\right. \\
\left.\text { as } \mathrm{SO}_{4}\right)\end{array}$ & $\begin{array}{c}\text { Cadmium, } \\
\text { dis- } \\
\text { solved } \\
\left(\mu_{g} / L\right. \\
\text { as Cd) }\end{array}$ & $\begin{array}{l}\text { Chro- } \\
\text { mium, } \\
\text { dis- } \\
\text { solved } \\
\left(\mu_{g} / L\right. \\
\text { as } \mathrm{Cr})\end{array}$ & $\begin{array}{l}\text { Copper, } \\
\text { dis- } \\
\text { solved } \\
\left(\mu_{8} / \mathrm{L}\right. \\
\text { as } \mathrm{Cu})\end{array}$ & $\begin{array}{l}\text { Iron, } \\
\text { dis- } \\
\text { solved } \\
(\mu g / L \\
\text { as Fe) }\end{array}$ & $\begin{array}{l}\text { Lead, } \\
\text { dis- } \\
\text { solved } \\
(\mu \mathrm{g} / \mathrm{L} \\
\text { as } \mathrm{Pb})\end{array}$ & $\begin{array}{l}\text { Manga- } \\
\text { nese, } \\
\text { dis- } \\
\text { solved } \\
(\mu g / L \\
\text { as Mn) }\end{array}$ \\
\hline
\end{tabular}

WELL 2--Continued

JUNE 1985

\begin{tabular}{|c|c|c|c|c|c|c|c|c|c|c|c|}
\hline 13 & 310 & 740 & 29 & 190 & 3,000 & $\cdots$ & -- & $\cdots$ & 2,100 & -- & -- \\
\hline 17 & -- & -- & -- & - & -- & -- & -- & -- & - & -- & -- \\
\hline \multicolumn{12}{|l|}{ AUG } \\
\hline 29 & -- & - & -- & -- & -- & - & -- & -- & -- & -- & - \\
\hline 30 & 480 & 1,200 & 18 & 300 & 3,800 & $<0.1$ & $<20$ & $<20$ & 5,700 & $<10$ & 3,900 \\
\hline \multicolumn{12}{|l|}{ MAY 1986} \\
\hline 27 & 260 & 320 & 10 & 110 & 1,800 & .3 & $<20$ & $<20$ & $<50$ & $<10$ & $<560$ \\
\hline \multicolumn{12}{|l|}{ AUG } \\
\hline 28 & -- & -- & -- & -- & -- & -- & -- & -- & -- & -- & -- \\
\hline 29 & 380 & 660 & 10 & 150 & 3,000 & .9 & 100 & $<100$ & 1,900 & $<250$ & 830 \\
\hline \multicolumn{12}{|l|}{ APR 1987} \\
\hline 28 & -- & -- & -- & -- & -- & -- & -- & -- & -- & -- & -- \\
\hline 29 & 260 & 270 & 5.0 & 83 & 1,700 & .7 & $<20$ & $<20$ & $<50$ & 50 & 60 \\
\hline \multicolumn{12}{|l|}{ JULY } \\
\hline 14 & 240 & 270 & 6.3 & 76 & 1,500 & .5 & -- & $<40$ & $<100$ & $<10$ & 90 \\
\hline SEPT & & & & & & & & & & & \\
\hline $\begin{array}{l}15 \\
16\end{array}$ & 300 & 500 & 8.8 & 100 & 2,500 & .4 & -- & $<20$ & 430 & $<10$ & 400 \\
\hline \multicolumn{12}{|l|}{ MAR 1988} \\
\hline 15 & 220 & 310 & 5.3 & 68 & 1,600 & .2 & -- & $<20$ & $<50$ & $<10$ & 90 \\
\hline 17 & -- & -- & -- & -- & - & -- & -- & -- & -- & -- & -- \\
\hline \multicolumn{12}{|l|}{ JULY } \\
\hline $\operatorname{SEPT}^{13}$ & 270 & 390 & 6.9 & 75 & 1,900 & -- & $<20$ & $<20$ & 100 & $<10$ & 160 \\
\hline 02 & -- & -- & -- & -- & -- & -- & -- & $\ldots$ & -- & -- & -- \\
\hline 23 & 270 & 490 & 9.0 & 95 & 2,500 & .6 & $<20$ & $<20$ & $<50$ & $<10$ & -- \\
\hline \multicolumn{12}{|l|}{ MAR 1989} \\
\hline $\mathrm{JUNE}^{15}$ & -- & -- & - & -- & -- & -- & -- & -- & - & -- & -- \\
\hline 02 & 430 & 850 & 9.0 & 150 & 2,800 & $<.2$ & $<20$ & $<20$ & 50 & $<10$ & 350 \\
\hline \multicolumn{12}{|l|}{ JULY } \\
\hline 18 & 200 & 340 & 6.0 & 76 & 1,600 & .6 & 60 & $<20$ & 180 & $<10$ & 70 \\
\hline \multicolumn{12}{|l|}{ AUG } \\
\hline$\stackrel{29}{\text { JAN }_{1990}}$ & 240 & 250 & .7 .0 & 64 & 1,700 & .7 & $<20$ & $<20$ & $<50$ & $<10$ & 110 \\
\hline 25 & -- & -- & -- & -- & -- & -- & -- & -- & - & -- & -- \\
\hline JULY & -- & -- & -- & 98 & 2,300 & -- & -- & -- & -- & -- & -- \\
\hline 31 & 200 & 360 & 6.8 & 120 & 1,500 & .2 & $<40$ & $<40$ & $<100$ & $<10$ & 50 \\
\hline SEPT & & & & & & & & & & & \\
\hline $\begin{array}{c}25 \\
\text { JAN } 1991\end{array}$ & 190 & 350 & 6.6 & 110 & 1,700 & .5 & $<40$ & $<40$ & 340 & $<10$ & 60 \\
\hline 24 & -- & -- & -- & -- & -- & -- & -- & -- & - & -- & - \\
\hline 25 & 220 & 490 & 5.8 & 110 & 2,200 & .3 & $<20$ & $<20$ & 430 & $<10$ & 160 \\
\hline
\end{tabular}


Table 5.--Chemical and bacteriological analyses of water from the observation wells--Continued

\begin{tabular}{|c|c|c|c|c|c|c|c|c|c|c|}
\hline $\begin{array}{c}\text { Sample } \\
\text { date }\end{array}$ & $\begin{array}{l}\text { Nickel, } \\
\text { dis- } \\
\text { solved } \\
\left(\mu_{\mathrm{g}} / \mathrm{L}\right. \\
\text { as } \mathrm{Ni})\end{array}$ & $\begin{array}{l}\text { Zinc, } \\
\text { dis- } \\
\text { solved } \\
\left(\mu_{g} / L\right. \\
\text { as } Z n)\end{array}$ & $\begin{array}{l}\text { Coli- } \\
\text { form, } \\
\text { fecal } \\
\text { (col./ } \\
100 \mathrm{~mL})\end{array}$ & $\begin{array}{c}\text { Strepto- } \\
\text { cocci, } \\
\text { fecal } \\
(\text { col.l } \\
100 \mathrm{~mL})\end{array}$ & $\begin{array}{c}\text { Dichloro- } \\
\text { bromo- } \\
\text { methane, } \\
\text { total } \\
\left(\mu_{g} / L\right)\end{array}$ & $\begin{array}{c}\text { Carbon } \\
\text { tetra- } \\
\text { chloride, } \\
\text { total } \\
\left(\mu_{\mathrm{g}} / \mathrm{L}\right)\end{array}$ & $\begin{array}{l}1,2 \text {-di- } \\
\text { chloro- } \\
\text { ethane, } \\
\text { total } \\
\left(\mu_{g} / L\right)\end{array}$ & $\begin{array}{c}\text { Bromo- } \\
\text { form, } \\
\text { tota } 1 \\
\left(\mu_{g} / L\right)\end{array}$ & $\begin{array}{l}\text { Chloro- } \\
\text { dibromo- } \\
\text { methane, } \\
\text { total } \\
(\mu \mathrm{g} / \mathrm{L})\end{array}$ & $\begin{array}{c}\text { Chloro- } \\
\text { form, } \\
\text { total } \\
\left(\mu_{\mathbf{g}} / \mathrm{L}\right)\end{array}$ \\
\hline
\end{tabular}

WELL 2--Continued

JUNE 1985

\begin{tabular}{|c|c|c|c|c|c|c|c|c|c|c|}
\hline 13 & -- & 10 & -- & -- & -- & -- & -- & -- & -- & -- \\
\hline 17 & -- & -- & $<1$ & $<1$ & -- & -- & -- & -- & -- & -- \\
\hline \multicolumn{11}{|l|}{ AUG } \\
\hline 29 & -- & -- & $<20$ & 230 & -- & -- & -- & -- & -- & -- \\
\hline 30 & 260 & 20 & -- & -- & -- & -- & -- & -- & -- & -- \\
\hline \multicolumn{11}{|l|}{ MAY 1986} \\
\hline 27 & $<70$ & 80 & $<1$ & $<1$ & -- & -- & - & -- & -- & -- \\
\hline \multicolumn{11}{|l|}{ AUG } \\
\hline 28 & -- & -- & 3 & 760 & -- & -- & -- & -- & -- & -- \\
\hline 29 & 150 & 150 & -- & -- & -- & -- & -- & -- & -- & -- \\
\hline \multicolumn{11}{|l|}{ APR 1987} \\
\hline 28 & -- & -- & $<1$ & 9 & -- & -- & -- & - & - & -- \\
\hline 29 & 50 & 50 & -- & -- & -- & -- & -- & -- & -- & -- \\
\hline \multicolumn{11}{|l|}{ JULY } \\
\hline 14 & 40 & 40 & $<2$ & $<2$ & -- & -- & -- & -- & -- & -- \\
\hline \multicolumn{11}{|l|}{ SEPT } \\
\hline 15 & 90 & $<20$ & -- & -- & -- & -- & -- & -- & -- & -- \\
\hline 16 & -- & -- & $<2$ & 2,800 & -- & -- & -- & -- & -- & -- \\
\hline \multicolumn{11}{|l|}{ MAR 1988} \\
\hline 15 & 40 & $<20$ & -- & -- & -- & -- & -- & -- & -- & -- \\
\hline 17 & -- & -- & $<2$ & 23 & -- & -- & -- & -- & -- & -- \\
\hline \multicolumn{11}{|l|}{ JULY } \\
\hline${ }_{\text {SEPT }}^{13}$ & 50 & 40 & $<2$ & $<2$ & -- & \multicolumn{4}{|c|}{ SEPT } & -- \\
\hline 02 & -- & -- & -- & -- & $<3.0$ & $<3.0$ & $<3.0$ & $<3.0$ & $<3.0$ & $<3.0$ \\
\hline 23 & 40 & 30 & $<2$ & $<12$ & -- & -- & -- & -- & -- & -- \\
\hline \multicolumn{11}{|l|}{ MAR 1989} \\
\hline 15 & -- & -- & -- & -- & -- & - & -- & -- & -- & -- \\
\hline \multicolumn{11}{|l|}{ JUNE } \\
\hline 02 & 30 & 50 & -- & -- & -- & -- & -- & -- & -- & -- \\
\hline \multicolumn{11}{|l|}{ JULY } \\
\hline 18 & 60 & 150 & $<30$ & 40 & -- & -- & -- & -- & -- & -- \\
\hline \multicolumn{11}{|l|}{ AUG } \\
\hline 29 & 40 & 40 & $<2$ & $<2$ & -- & -- & -- & -- & -- & -- \\
\hline \multicolumn{11}{|l|}{ JAN 1990} \\
\hline 25 & -- & -- & $<20^{\circ}$ & 18 & - & -- & -- & -- & -- & -- \\
\hline 26 & -- & -- & -- & -- & -- & -- & -- & -- & -- & -- \\
\hline \multicolumn{11}{|l|}{ JULY } \\
\hline \multicolumn{11}{|l|}{ SEPT } \\
\hline 25 & $<40$ & $<40$ & $<20$ & 4 & -- & -- & -- & -- & -- & -- \\
\hline \multicolumn{11}{|l|}{ JAN 1991} \\
\hline 24 & -- & -- & $<20$ & 10 & -- & -- & -- & -- & -- & -- \\
\hline 25 & 50 & $<20$ & -- & -- & -- & -- & -- & - & -- & -- \\
\hline
\end{tabular}


Table 5.--Chemical and bacteriological analyses of water from the observation wells--Continued

\begin{tabular}{|c|c|c|c|c|c|c|c|c|c|c|}
\hline $\begin{array}{c}\text { Sample } \\
\text { date }\end{array}$ & $\begin{array}{c}\text { Toluene, } \\
\text { total } \\
\left(\mu_{g} / L\right)\end{array}$ & $\begin{array}{l}\text { Benzene, } \\
\text { total } \\
\left(\mu_{g} / L\right)\end{array}$ & $\begin{array}{l}\text { Chloro- } \\
\text { benzene, } \\
\text { total } \\
\left(\mu_{8} / L\right)\end{array}$ & $\begin{array}{c}\text { Chloro- } \\
\text { ethane, } \\
\text { total } \\
\left(\mu_{8} / L\right)\end{array}$ & $\begin{array}{c}\text { Ethyl- } \\
\text { benzene, } \\
\text { total } \\
\left(\mu_{g} / L\right)\end{array}$ & $\begin{array}{l}\text { Methyl- } \\
\text { bromide, } \\
\text { total } \\
\left(\mu_{\mathrm{g}} / \mathrm{L}\right)\end{array}$ & $\begin{array}{c}\text { Methyl- } \\
\text { chloride, } \\
\text { total } \\
\left(\mu_{g} / L\right)\end{array}$ & $\begin{array}{c}\text { Methyl- } \\
\text { ene } \\
\text { chlo- } \\
\text { ride, } \\
\text { total } \\
\left(\mu_{8} / L\right)\end{array}$ & $\begin{array}{l}\text { Tetra- } \\
\text { chloro- } \\
\text { ethyl- } \\
\text { ene, } \\
\text { total } \\
(\mu \mathrm{g} / \mathrm{L})\end{array}$ & $\begin{array}{l}\text { Tri- } \\
\text { chloro- } \\
\text { fluoro- } \\
\text { methane, } \\
\text { total } \\
\left(\mu_{g} / L\right)\end{array}$ \\
\hline
\end{tabular}

WELL 2--Continued

\begin{tabular}{|c|c|c|c|c|c|c|c|c|c|c|}
\hline \multicolumn{11}{|l|}{ JUNE 1985} \\
\hline 13 & -- & -- & -- & -- & -- & -- & -- & -- & -- & -- \\
\hline 17 & -- & -- & -- & -- & -- & -- & -- & -- & -- & -- \\
\hline \multicolumn{11}{|l|}{ AUG } \\
\hline 29 & -- & -- & -- & -- & -- & -- & -- & -- & -- & -- \\
\hline 30 & -- & -- & -- & -- & -- & -- & -- & -- & -- & -- \\
\hline \multicolumn{11}{|l|}{ MAY 1986} \\
\hline 27 & -- & -- & -- & -- & -- & -- & -- & -- & -- & -- \\
\hline \multicolumn{11}{|l|}{ AUG } \\
\hline 28 & -- & -- & -- & -- & -- & -- & -- & -- & -- & -- \\
\hline 29 & -- & -- & -- & -- & -- & -- & -- & -- & -- & -- \\
\hline \multicolumn{11}{|l|}{ APR 1987} \\
\hline 28 & -- & -- & -- & -- & -- & -- & -- & -- & -- & -- \\
\hline 29 & -- & -- & -- & -- & -- & -- & -- & -- & -- & -- \\
\hline \multicolumn{11}{|l|}{ JULY } \\
\hline 14 & -- & -- & -- & -- & -- & -- & -- & -- & -- & -- \\
\hline \multicolumn{11}{|l|}{ SEPT } \\
\hline 15 & -- & -- & -- & -- & -- & -- & -- & -- & -- & -- \\
\hline 16 & -- & -- & -- & -- & -- & -- & -- & -- & -- & -- \\
\hline \multicolumn{11}{|l|}{ MAR 1988} \\
\hline 15 & -- & -- & -- & -- & -- & -- & -- & -- & -- & -- \\
\hline 17 & -- & -- & -- & -- & -- & -- & -- & $-\dot{-}$ & -- & -- \\
\hline \multicolumn{11}{|l|}{ JUYY } \\
\hline 13 & -- & -- & -- & -- & -- & -- & -- & -- & -- & -- \\
\hline \multicolumn{11}{|l|}{ SEPT } \\
\hline 02 & $<3.0$ & $<3.0$ & $<3.0$ & $<3.0$ & $<3.0$ & $<3.0$ & $<3.0$ & $<3.0$ & $<3.0$ & $<3.0$ \\
\hline 23 & -- & -- & -- & -- & -- & -- & -- & -- & -- & - \\
\hline
\end{tabular}


Table 5.--Chemical and bacteriological analyses of water from the observation wells--Continued

\begin{tabular}{|c|c|c|c|c|c|c|c|c|c|c|}
\hline $\begin{array}{c}\text { Sample } \\
\text { date }\end{array}$ & $\begin{array}{c}1,1-d i- \\
\text { chloro- } \\
\text { ethane, } \\
\text { total } \\
\left(\mu_{g} / L\right)\end{array}$ & $\begin{array}{l}\text { 1,1-di- } \\
\text { chloro- } \\
\text { ethyl- } \\
\text { ene, } \\
\text { total } \\
\left(\mu_{g} / L\right)\end{array}$ & $\begin{array}{c}1,1,1- \\
\text { tri- } \\
\text { chloro- } \\
\text { ethane, } \\
\text { total } \\
\left(\mu_{g} / L\right)\end{array}$ & $\begin{array}{c}1,1,2- \\
\text { tri- } \\
\text { chloro- } \\
\text { ethane, } \\
\text { total } \\
\left(\mu_{g} / L\right)\end{array}$ & $\begin{array}{l}1,1,2,2 \\
\text { tetra- } \\
\text { chloro- } \\
\text { ethane, } \\
\text { total } \\
\left(\mu_{g} / L\right)\end{array}$ & $\begin{array}{c}1,2-\mathrm{di}- \\
\text { chloro- } \\
\text { benzene, } \\
\text { total } \\
\left(\mu_{\mathrm{g}} / \mathrm{L}\right)\end{array}$ & $\begin{array}{l}1,2-\text { di- } \\
\text { chloro- } \\
\text { propane, } \\
\text { total } \\
\left(\mu_{\mathrm{g}} / \mathrm{L}\right)\end{array}$ & $\begin{array}{l}\text { Trans- } \\
1,2-d i- \\
\text { chloro- } \\
\text { ethane, } \\
\text { total } \\
\left(\mu_{8} / L\right)\end{array}$ & $\begin{array}{l}1,3-d i- \\
\text { chloro- } \\
\text { propene, } \\
\text { total } \\
(\mu g / L)\end{array}$ & $\begin{array}{c}1,3-\mathrm{di}- \\
\text { chloro- } \\
\text { benzene, } \\
\text { total } \\
\left(\mu_{\mathrm{g}} / \mathrm{L}\right)\end{array}$ \\
\hline
\end{tabular}

WELL 2--Continued

\begin{tabular}{|c|c|c|c|c|c|c|c|c|c|c|}
\hline \multirow{2}{*}{\multicolumn{11}{|c|}{ JUNE 1985}} \\
\hline & & & & & & & & & & \\
\hline 13 & -- & $\cdots$ & -- & -- & -- & -- & -- & -- & -- & -- \\
\hline 17 & -- & -- & -- & -- & -- & -- & -- & -- & -- & -- \\
\hline \multicolumn{11}{|l|}{ AUG } \\
\hline 29 & -- & -- & -- & -- & -- & -- & -- & -- & -- & -- \\
\hline 30 & -- & -- & -- & -- & $\cdots$ & - & -- & -- & -- & -- \\
\hline \multicolumn{11}{|c|}{ MAY 1986} \\
\hline 27 & -- & -- & -- & -- & -- & -- & -- & -- & -- & -- \\
\hline \multicolumn{11}{|l|}{ AUG } \\
\hline 28 & -- & -- & -- & -- & -- & -- & -- & -- & -- & -- \\
\hline 29 & -- & - & -- & -- & -- & -- & -- & -- & -- & -- \\
\hline \multicolumn{11}{|c|}{ APR 1987} \\
\hline 28 & -- & -- & -- & -- & - & -- & -- & -- & -- & -- \\
\hline 29 & -- & - & -- & -- & -- & -- & -- & -- & -- & -- \\
\hline \multicolumn{11}{|l|}{ JULY } \\
\hline 14 & -- & - & -- & -- & -- & -- & -- & -- & -- & -- \\
\hline \multicolumn{11}{|l|}{ SEPT } \\
\hline 15 & -- & -- & -- & -- & -- & -- & -- & -- & -- & -- \\
\hline 16 & -- & -- & -- & -- & -- & -- & -- & -- & -- & -- \\
\hline \multicolumn{11}{|c|}{ MAR 1988} \\
\hline 15 & -- & -- & -- & -- & -- & -- & -- & -- & -- & -- \\
\hline 17 & -- & -- & -- & -- & -- & -- & -- & -- & -- & -- \\
\hline \multicolumn{11}{|l|}{ JULY } \\
\hline 13 & -- & -- & -- & -- & -- & -- & -- & -- & -- & -- \\
\hline \multicolumn{11}{|l|}{ SEPT } \\
\hline 02 & $<3.0$ & $<3.0$ & $<3.0$ & $<3.0$ & $<3.0$ & $<3.0$ & $<3.0$ & $<3.0$ & $<3.0$ & $<3.0$ \\
\hline 23 & - & - & -- & - & - & -- & -- & -- & -- & -- \\
\hline
\end{tabular}


Table 5.--Chemical and bacteriological analyses of water from the observation wells--Continued

\begin{tabular}{|c|c|c|c|c|c|c|c|c|c|c|}
\hline $\begin{array}{c}\text { Sample } \\
\text { date }\end{array}$ & $\begin{array}{c}1,4,- \text { di- } \\
\text { chloro- } \\
\text { benzene, } \\
\text { total } \\
(\mu \mathrm{g} / \mathrm{L})\end{array}$ & $\begin{array}{l}\text { 2-chloro- } \\
\text { ethyl- } \\
\text { vinyl- } \\
\text { ether, } \\
\text { total } \\
(\mu \mathrm{g} / \mathrm{L})\end{array}$ & $\begin{array}{c}\text { Dichloro- } \\
\text { difluoro- } \\
\text { methane, } \\
\text { total } \\
(\mu \mathrm{g} / \mathrm{L})\end{array}$ & $\begin{array}{c}\text { Trans- } \\
1,3-d i- \\
\text { chloro- } \\
\text { propene, } \\
\text { total } \\
\left(\mu_{g} / L\right)\end{array}$ & $\begin{array}{l}\text { Cis- } \\
1,3-d i- \\
\text { chloro- } \\
\text { propene, } \\
\text { total } \\
\left(\mu_{8} / L\right)\end{array}$ & $\begin{array}{l}\text { Vinyl } \\
\text { chlo- } \\
\text { ride, } \\
\text { total } \\
\left(\mu_{8} / L\right)\end{array}$ & $\begin{array}{c}\text { Tri- } \\
\text { ch1oro- } \\
\text { ethyl- } \\
\text { ene, } \\
\text { total } \\
\left(\mu_{\mathrm{g}} / \mathrm{L}\right)\end{array}$ & $\begin{array}{c}\text { Sty- } \\
\text { rene, } \\
\text { total } \\
(\mu \mathrm{g} / \mathrm{L})\end{array}$ & $\begin{array}{c}1,2- \\
\text { dibromo- } \\
\text { ethane, } \\
\text { total } \\
(\mu \mathrm{g} / \mathrm{L})\end{array}$ & $\begin{array}{c}\text { Xylene, } \\
\text { total } \\
\text { tot rec } \\
(\mu \mathrm{g} / \mathrm{L})\end{array}$ \\
\hline \multicolumn{11}{|c|}{ WELL 2--Continued } \\
\hline \multicolumn{11}{|l|}{ JUNE 1985} \\
\hline 13 & -- & -- & -- & -- & -- & -- & -- & -- & -- & -- \\
\hline 17 & -- & -- & -- & -- & -- & -- & -- & -- & -- & -- \\
\hline \multicolumn{11}{|l|}{ AUG } \\
\hline 29 & -- & -- & -- & -- & -- & -- & -- & -- & -- & -- \\
\hline & -- & -- & -- & -- & -- & -- & -- & -- & -- & -- \\
\hline \multicolumn{11}{|l|}{ MAY 1986} \\
\hline 27 & -- & -- & -- & -- & -- & -- & -- & -- & -- & -- \\
\hline \multicolumn{11}{|l|}{ AUG } \\
\hline 28 & -- & -- & -- & -- & -- & -- & -- & -- & -- & -- \\
\hline \multirow{2}{*}{\multicolumn{3}{|c|}{ APR 1987}} & -- & -- & -- & -- & & - & - & -- \\
\hline 28 & -- & -- & -- & -- & -- & -. & -- & -- & -. & \\
\hline 29 & -- & -- & -- & -- & - & -- & -- & -- & -- & -. \\
\hline \multicolumn{11}{|l|}{ JULY } \\
\hline \multirow{2}{*}{\multicolumn{11}{|c|}{ SEPT }} \\
\hline & & & & & & & & & & \\
\hline 15 & -- & -- & -- & -- & -- & -- & -- & -- & -- & -- \\
\hline 16 & -- & -- & -- & -- & -- & -- & -- & -- & -- & -- \\
\hline \multicolumn{11}{|l|}{ MAR 1988} \\
\hline 15 & -- & -- & - & -- & -- & -- & -- & -- & -- & -- \\
\hline 17 & -- & -- & -- & -- & -- & -- & -- & -- & -- & -- \\
\hline \multicolumn{11}{|l|}{ JULY } \\
\hline 13 & -- & -- & -- & -- & -- & -- & -- & -- & -- & -- \\
\hline \multicolumn{11}{|l|}{ SEPT } \\
\hline 02 & $<3.0$ & $<3.0$ & $<3.0$ & $<3.0$ & $<3.0$ & $<3.0$ & $<3.0$ & $<3.0$ & $<3.0$ & $<3.0$ \\
\hline 23 & -- & -- & -- & -- & -- & -- & $\cdots$ & -- & -- & -- \\
\hline 23 & -- & -- & -- & -- & -- & -- & -- & -- & -- & -- \\
\hline
\end{tabular}

WELL 3 destroyed before sampling could be initiated 
Table 5.--Chemical and bacteriological analyses of water

from the observation wells--Continued

\begin{tabular}{|c|c|c|c|c|c|c|c|c|c|c|}
\hline $\begin{array}{c}\text { Sample } \\
\text { date }\end{array}$ & $\begin{array}{l}\text { Spe- } \\
\text { cific } \\
\text { con- } \\
\text { duct- } \\
\text { ance } \\
(\mu \mathrm{S} / \mathrm{cm})\end{array}$ & $\underset{\text { (units) }}{\mathrm{pH}}$ & $\begin{array}{c}\text { Residue } \\
\text { at } \\
105^{\circ} \mathrm{C}, \\
\text { dis- } \\
\text { solved } \\
\text { (mg/L) }\end{array}$ & $\begin{array}{l}\text { Nitrogen, } \\
\text { ammonia, } \\
\text { dis- } \\
\text { solved } \\
\text { (mg/L } \\
\text { as } \mathrm{N} \text { ) }\end{array}$ & $\begin{array}{l}\text { Nitrogen, } \\
\text { nitrite, } \\
\text { dis- } \\
\text { solved } \\
\text { (mg/L } \\
\text { as } \mathrm{N} \text { ) }\end{array}$ & $\begin{array}{l}\text { Nitrogen, } \\
\text { ammonia, } \\
\text { torganic, } \\
\text { dissolved } \\
\text { (mg/L } \\
\text { as } \mathrm{N} \text { ) }\end{array}$ & $\begin{array}{c}\text { Nitrogen, } \\
\mathrm{NO}_{2}+\mathrm{NO}_{3} \\
\text { dis- } \\
\text { solved } \\
\text { (mg/L } \\
\text { as } \mathrm{N})\end{array}$ & $\begin{array}{l}\text { Phos- } \\
\text { phorus, } \\
\text { ortho, } \\
\text { dissolved } \\
\text { (mg/L } \\
\text { as P) }\end{array}$ & $\begin{array}{l}\text { Hard- } \\
\text { ness, } \\
\text { total } \\
\text { (mg/L } \\
\text { as } \\
\mathrm{CaCO}_{3} \text { ) }\end{array}$ & $\begin{array}{l}\text { Cal- } \\
\text { cium, } \\
\text { dis- } \\
\text { solved } \\
\text { (mg/L } \\
\text { as Ca) }\end{array}$ \\
\hline & & & & & WELL 4 & & & & & \\
\hline \multicolumn{11}{|l|}{ JNE 1985} \\
\hline 14 & -- & -- & 986 & 0.330 & 0.040 & 7.8 & 18.3 & 0.020 & 560 & 110 \\
\hline \multirow{2}{*}{\multicolumn{11}{|c|}{ AUG }} \\
\hline & & & & & & & & & & \\
\hline $\begin{array}{l}30 \\
\operatorname{MAY} 1986\end{array}$ & 1,650 & 7.4 & 1,110 & .100 & $<.010$ & .90 & 22.2 & .020 & 600 & 130 \\
\hline $\begin{array}{c}27 \\
\text { APR } 1987\end{array}$ & 1,200 & 7.7 & 796 & $<.100$ & $<.010$ & .60 & 7.15 & $<.020$ & 410 & 86 \\
\hline 28 & -- & -- & -- & -- & -- & -. & -- & - & - & -- \\
\hline JULY & 1,400 & 7.6 & 980 & $<.100$ & $<.010$ & .70 & 4.50 & $<.20$ & 450 & 96 \\
\hline $\begin{array}{l}15 \\
\text { SEPT }\end{array}$ & 2,100 & 7.3 & 1,500 & $<.100$ & $<.020$ & .90 & 30.0 & .060 & 720 & 150 \\
\hline${ }_{\text {MAR }}^{16} 1988$ & 2,850 & $7: 2$ & 1,790 & $<.100$ & $<.010$ & .80 & 29.0 & .080 & 950 & 200 \\
\hline 15 & 2,850 & 7.3 & 1,960 & $<.100$ & $<.020$ & 1.4 & 54.0 & .040 & 1,100 & 230 \\
\hline \multirow{2}{*}{\multicolumn{11}{|c|}{ JULY }} \\
\hline & & & & & & & & & & \\
\hline 15 & 2,940 & 6.8 & 2,240 & $<.100$ & $<.010$ & 2.3 & 4.00 & .030 & 1,200 & 250 \\
\hline \multicolumn{11}{|l|}{ SEPT } \\
\hline 02 & - & -- & - & -- & -- & -- & -- & -- & -- & -- \\
\hline 22 & 3,170 & 7.2 & 2,210 & .100 & .020 & 1.4 & 92.0 & .060 & 1,100 & 250 \\
\hline${ }^{23} 1989$ & -. & -- & -- & -- & $\cdots$ & -- & -- & -- & -- & $\cdots$ \\
\hline 16 & 3,470 & 7.1 & 2,390 & $<.100$ & $<.020$ & 1.0 & 56.0 & $<.020$ & 1,300 & 270 \\
\hline $\begin{array}{c}\text { JNE } \\
01\end{array}$ & -- & -- & $\ldots$ & -- & -. & - & $\ldots$ & -- & -- & .- \\
\hline 02 & 3,470 & 7.3 & 2,610 & $<.200$ & $<.020$ & .60 & 53.2 & .060 & 1,300 & 270 \\
\hline \multicolumn{11}{|l|}{ JULY } \\
\hline \multirow{2}{*}{\multicolumn{11}{|c|}{ AUG }} \\
\hline & & & & & & & & & & \\
\hline $\begin{array}{l}\text { JAN } 1990 \\
26\end{array}$ & & & & & & & & & & \\
\hline MAY & 3,540 & -- & 2,560 & $<.100$ & $<.020$ & 1.3 & 28.8 & $<.020$ & 1,200 & 260 \\
\hline $\begin{array}{r}22 \\
\text { JULY }\end{array}$ & 3,700 & 7.2 & 2,720 & $<.100$ & $<.020$ & 1.3 & 85.3 & .060 & 1,300 & 290 \\
\hline 31 & 3,860 & 7.2 & 2,640 & $<.100$ & $<.020$ & 6.0 & 144 & .020 & 1,400 & 300 \\
\hline AUG & & & & & & & & & & \\
\hline $\begin{array}{l}03 \\
\text { SEPT }\end{array}$ & -- & -- & -- & -- & -- & -- & -- & -- & $\cdots$ & - \\
\hline 25 & 3,780 & 7.3 & 3,170 & $<.100$ & .030 & 1.5 & 178 & $<.020$ & 1,400 & 300 \\
\hline $\begin{array}{l}\text { NOV } \\
16\end{array}$ & & $-\pi$ & & & & & & & & \\
\hline $\begin{array}{l}16 \\
\text { JAN } 1991\end{array}$ & -- & $\cdots$ & $\cdots$ & -- & -- & -- & 150 & -- & - & -- \\
\hline 24 & -- & -- & -- & -- & -- & - & -- & - & -- & -- \\
\hline 25 & 3,800 & 7.3 & 2,700 & $<.100$ & $<.020$ & 1.7 & 119 & $<.020$ & 1,200 & 270 \\
\hline
\end{tabular}


Table 5.--Chemical and bacteriological analyses of water

from the observation wells--Continued

\begin{tabular}{|c|c|c|c|c|c|c|c|c|c|c|c|}
\hline $\begin{array}{c}\text { Sample } \\
\text { date }\end{array}$ & $\begin{array}{c}\text { Magne- } \\
\text { sium, } \\
\text { dis- } \\
\text { solved } \\
(\mathrm{mg} / \mathrm{L} \\
\text { as } \mathrm{Mg})\end{array}$ & $\begin{array}{l}\text { Sodium, } \\
\text { dis- } \\
\text { solved } \\
\text { ( } \mathrm{mg} / \mathrm{L} \\
\text { as } \mathrm{Na} \text { ) }\end{array}$ & $\begin{array}{l}\text { Potas- } \\
\text { sium, } \\
\text { dis- } \\
\text { solved } \\
\text { (mg/L } \\
\text { as K) }\end{array}$ & $\begin{array}{l}\text { Chlo- } \\
\text { ride, } \\
\text { dis- } \\
\text { solved } \\
\text { (mg/L } \\
\text { as } C l \text { ) }\end{array}$ & $\begin{array}{l}\text { Sulfate, } \\
\text { dis- } \\
\text { solved } \\
(\mathrm{mg} / \mathrm{L} \\
\left.\text { as } \mathrm{SO}_{4}\right)\end{array}$ & $\begin{array}{c}\text { Cadmium, } \\
\text { dis- } \\
\text { solved } \\
\left(\mu_{g} / L\right. \\
\text { as Cd) }\end{array}$ & $\begin{array}{l}\text { Chro- } \\
\text { mium, } \\
\text { dis- } \\
\text { solved } \\
(\mu g / L \\
\text { as } C r)\end{array}$ & $\begin{array}{l}\text { Copper, } \\
\text { dis- } \\
\text { solved } \\
\left(\mu_{g} / L\right. \\
\text { as } C u)\end{array}$ & $\begin{array}{l}\text { Iron, } \\
\text { dis- } \\
\text { solved } \\
(\mu \mathrm{g} / \mathrm{L} \\
\text { as } \mathrm{Fe})\end{array}$ & $\begin{array}{l}\text { Lead, } \\
\text { dis- } \\
\text { solved } \\
\left(\mu_{g} / L\right. \\
\text { as } \mathrm{Pb})\end{array}$ & $\begin{array}{l}\text { Manga- } \\
\text { nese, } \\
\text { dis- } \\
\text { solved } \\
(\mu g / L \\
\text { as Mn) }\end{array}$ \\
\hline
\end{tabular}

WELL 4--Continued

JUNE 1985

\begin{tabular}{|c|c|c|c|c|c|c|c|c|c|c|c|}
\hline 14 & 68 & 130 & 4.6 & 180 & 180 & -- & -- & -- & $<50$ & -- & -- \\
\hline 20 & -- & -- & -- & -- & -- & -- & - & -- & -- & -- & - \\
\hline \multicolumn{12}{|l|}{ AUG } \\
\hline${ }_{\text {MAY }}^{30} 1986$ & 67 & 140 & 2.8 & 200 & 220 & 0.4 & $<20$ & 10 & 50 & $<10$ & 10 \\
\hline 27 & 47 & 110 & 2.0 & 99 & 200 & .3 & $<20$ & $<20$ & $<50$ & $<10$ & $<20$ \\
\hline APR 1987 & & & & & & & & & & & \\
\hline 28 & -- & -- & -- & -- & -- & -- & -- & -- & -- & -- & -- \\
\hline 29 & 51 & 120 & 1.8 & 100 & 250 & .4 & $<20$ & $<20$ & $<50$ & $<50$ & $<20$ \\
\hline \multicolumn{12}{|l|}{ JULY } \\
\hline 15 & 82 & 170 & 2.6 & 290 & 320 & .5 & $<20$ & $<20$ & $<50$ & $<10$ & $<20$ \\
\hline \multicolumn{12}{|l|}{ SEPT } \\
\hline$\stackrel{16}{\text { MAR }^{16} 198}$ & 110 & 180 & 3.0 & 350 & 400 & .7 & -- & $<20$ & $<50$ & $<10$ & $<20$ \\
\hline 15 & 120 & 200 & 3.3 & 360 & 550 & .3 & $<20$ & $<20$ & $<50$ & $<10$ & $<20$ \\
\hline 17 & - & -- & - & - & - & - & -- & -- & -- & -- & -- \\
\hline \multicolumn{12}{|l|}{ JULY } \\
\hline 13 & -- & -- & -- & -- & -- & -- & -- & -- & -- & -- & -- \\
\hline 15 & 130 & 240 & 3.6 & 450 & 620 & .3 & 20 & $<20$ & 50 & $<10$ & $<20$ \\
\hline \multicolumn{12}{|l|}{ SEPT } \\
\hline 02 & -- & -- & -- & -- & -- & -- & -- & -- & -- & -- & -- \\
\hline 22 & 120 & 250 & 2.8 & 400 & 520 & 3.9 & $<20$ & $<20$ & $<50$ & $<10$ & - \\
\hline 23 & -- & -- & -- & -- & -- & -- & -- & -- & -- & -- & -- \\
\hline \multicolumn{12}{|l|}{ MAR 1989} \\
\hline 16 & 140 & 270 & 3.2 & 470 & 680 & .5 & $<20$ & $<20$ & $<50$ & $<10$ & $<20$ \\
\hline \multicolumn{12}{|l|}{ JUNE } \\
\hline 01 & -- & -- & -- & -- & -- & -- & -- & -- & -- & -- & -- \\
\hline 02 & 150 & 300 & 3.6 & 550 & 670 & $<.2$ & $<40$ & $<40$ & $<100$ & $<10$ & $<40$ \\
\hline \multicolumn{12}{|l|}{ JULY } \\
\hline 18 & 150 & 280 & 2.6 & 490 & 660 & .9 & 60 & $<20$ & 160 & $<10$ & $<20$ \\
\hline \multicolumn{12}{|l|}{ AUG } \\
\hline 29 & 150 & 350 & 3.6 & 480 & 690 & .8 & $<20$ & $<20$ & $<50$ & $<10$ & $<20$ \\
\hline JAN 1990 & & & & & & & & & & & \\
\hline $\begin{array}{l}26 \\
\text { MAY }\end{array}$ & 140 & 290 & 3.3 & 410 & 660 & .4 & $<200$ & $<200$ & $<500$ & $<10$ & $<200$ \\
\hline 22 & 150 & 260 & 3.3 & 260 & -- & .3 & $<20$ & $<20$ & $<50$ & $<10$ & $<20$ \\
\hline JULY & & & & & & & & & & & \\
\hline 31 & 160 & 310 & 4.0 & 430 & 730 & .4 & $<40$ & $<40$ & $<100$ & $<10$ & $<40$ \\
\hline AUG & & & & & & & & & & & \\
\hline 03 & -- & -- & -- & - & -- & - & -- & -- & -- & -- & - \\
\hline SEPT & & & & & & & & & & & \\
\hline 25 & 160 & 340 & 1.4 & 310 & 570 & .6 & $<40$ & $<40$ & $<100$ & $<10$ & $<40$ \\
\hline NOV & & & & & & & & & & & \\
\hline $\begin{array}{c}16 \\
\text { JAN } 1991\end{array}$ & -- & -- & - & -- & -- & -- & -- & -- & -- & -- & - \\
\hline 24 & -- & -- & -- & -- & -- & -- & -- & -- & -- & -- & -- \\
\hline 25 & 140 & 300 & 2.6 & 360 & 490 & .3 & $<20$ & $<20$ & $<50$ & $<10$ & $<20$ \\
\hline
\end{tabular}


Table 5.--Chemical and bacteriological analyses of water from the observation wells--Continued

\begin{tabular}{|c|c|c|c|c|c|c|c|c|c|c|}
\hline $\begin{array}{c}\text { Sample } \\
\text { date }\end{array}$ & $\begin{array}{l}\text { Nickel, } \\
\text { dis- } \\
\text { solved } \\
(\mu g / L \\
\text { as } N i)\end{array}$ & $\begin{array}{l}\text { Zinc, } \\
\text { dis-- } \\
\text { solved } \\
\left(\mu_{g} / L\right. \\
\text { as } \mathrm{Zn})\end{array}$ & $\begin{array}{l}\text { Coli- } \\
\text { form, } \\
\text { fecal } \\
\text { (col./ } \\
100 \mathrm{~mL})\end{array}$ & $\begin{array}{l}\text { Strepto- } \\
\text { cocci, } \\
\text { fecal } \\
\text { (col./ } \\
100 \mathrm{~mL})\end{array}$ & $\begin{array}{c}\text { Dichloro- } \\
\text { bromo- } \\
\text { methane, } \\
\text { total } \\
(\mu \mathrm{g} / \mathrm{L})\end{array}$ & $\begin{array}{c}\text { Carbon } \\
\text { tetra- } \\
\text { chloride, } \\
\text { total } \\
(\mu \mathrm{g} / \mathrm{L})\end{array}$ & $\begin{array}{l}\text { 1,2-di- } \\
\text { chloro- } \\
\text { ethane, } \\
\text { total } \\
(\mu \mathrm{g} / \mathrm{L})\end{array}$ & $\begin{array}{l}\text { Bromo- } \\
\text { form, } \\
\text { total } \\
\left(\mu_{g} / L\right)\end{array}$ & $\begin{array}{l}\text { Chloro- } \\
\text { dibromo- } \\
\text { methane, } \\
\text { total } \\
\left(\mu_{\mathrm{g}} / \mathrm{L}\right)\end{array}$ & $\begin{array}{l}\text { Chloro- } \\
\text { form, } \\
\text { total } \\
(\mu \mathrm{g} / \mathrm{L})\end{array}$ \\
\hline \multicolumn{11}{|c|}{ WELL 4--Continued } \\
\hline JUNE 1985 & & & & & & & & & & \\
\hline 14 & -- & 20 & -- & -. & -- & -- & -- & -- & -- & -- \\
\hline 20 & -- & - & $<1$ & 27 & -- & -- & -. & -- & -- & -- \\
\hline AUG & & & & & & & & & & \\
\hline 30 & 30 & 90 & $<1$ & 5 & -- & -- & -- & -- & -- & -- \\
\hline $\begin{array}{l}\text { MAY } 1986 \\
27\end{array}$ & & & & & & & & & & \\
\hline APR 1987 & $<20$ & $<20$ & $<1$ & $<1$ & -- & -- & -- & -- & -- & -- \\
\hline 28 & -- & -- & 3 & $<6$ & -- & -- & -- & -- & - & -- \\
\hline 29 & $<20$ & 20 & -- & -- & -- & -- & -- & -- & -- & -- \\
\hline JULY & & & & & & & & & & \\
\hline 15 & 20 & $<20$ & $<2$ & 170 & -- & -- & -- & -- & -- & -- \\
\hline SEPT & & & & & & & & & & \\
\hline $\begin{array}{l}16 \\
\text { MAR } 1988\end{array}$ & 40 & $<20$ & -- & $<2$ & -- & -- & -- & -- & -- & -- \\
\hline 15 & $<20$ & $<20$ & -- & -- & -- & -- & - & -- & -. & -- \\
\hline 17 & - & -- & $<2$ & $<2$ & -- & -- & -- & -- & - & -- \\
\hline JULY & & & & & & & & & & \\
\hline 13 & -- & -- & $<2$ & $<2$ & -- & -- & -- & -- & -- & -- \\
\hline 15 & 20 & $<40$ & -- & -- & -- & -- & -- & -- & -- & -- \\
\hline SEPT & & & & & & & & & & \\
\hline 02 & -- & -- & -- & -- & $<3.0$ & $<3.0$ & $<3.0$ & $<3.0$ & $<3.0$ & $<3.0$ \\
\hline 22 & 20 & $<20$ & -- & -- & -- & -- & -- & -- & -- & - \\
\hline 23 & - & -- & $<2$ & $<2$ & -- & -- & - & -- & -- & -- \\
\hline MAR 1989 & & & & & & & & & & \\
\hline $\begin{array}{l}16 \\
\text { JUNE }\end{array}$ & 20 & 30 & -- & -- & -- & -- & -- & -- & - & -- \\
\hline $\begin{array}{l}\text { JUNE } \\
01\end{array}$ & -. & -- & $<2$ & 50 & -- & -- & -- & -- & .- & -- \\
\hline 02 & $<20$ & $<20$ & $\ldots$ & - & -- & -- & - & -- & -- & -- \\
\hline JULY & & & & & & & & & & \\
\hline 18 & 40 & 270 & $<2$ & $<2$ & -. & -- & - & -- & $\cdots$ & - \\
\hline AUG & & & & & & & & & & \\
\hline $\begin{array}{c}29 \\
\text { JAN } 1990\end{array}$ & 40 & 120 & $<2$ & 9 & - & -- & -- & -- & -- & -- \\
\hline 26 & $<200$ & 1,000 & $<20$ & $<20$ & -- & -- & -- & -- & -- & -- \\
\hline $\begin{array}{l}\text { MAY } \\
22\end{array}$ & $<20$ & $<20$ & $<20$ & 1 & -- & -- & -- & -- & -- & -- \\
\hline JULY & & & & & & & & & & \\
\hline 31 & 30 & $<40$ & $<20$ & $<20$ & -- & -- & -- & -- & -- & -- \\
\hline $\begin{array}{c}\text { AUG } \\
03\end{array}$ & & & & & & & & & & \\
\hline $\begin{array}{l}03 \\
\text { SEPT }\end{array}$ & -- & -- & -- & -- & -- & -- & -- & -- & -- & -- \\
\hline SEPT & & & & & & & & & & \\
\hline $\begin{array}{l}25 \\
\text { Nov }\end{array}$ & $<40$ & $<40$ & $<20$ & 5 & -- & -- & -- & -- & -- & -- \\
\hline & -- & -- & - & -- & -- & -- & -- & -- & -- & -- \\
\hline JAN 1991 & & & & & & & & & & \\
\hline 24 & -- & -- & $<20$ & 5 & -- & -- & -- & -- & -- & -- \\
\hline 25 & 30 & $<20$ & -- & -- & -- & -- & -- & -- & -- & -- \\
\hline
\end{tabular}


Table 5.--Chemical and bacteriological analyses of water from the observation wells--Continued

\begin{tabular}{|c|c|c|c|c|c|c|c|c|c|c|}
\hline $\begin{array}{c}\text { Sample } \\
\text { date }\end{array}$ & $\begin{array}{c}\text { Toluene, } \\
\text { total } \\
\left(\mu_{g} / L\right)\end{array}$ & $\begin{array}{c}\text { Benzene, } \\
\text { total } \\
\left(\mu_{\mathrm{g} / L}\right)\end{array}$ & $\begin{array}{l}\text { Chloro- } \\
\text { benzene, } \\
\text { total } \\
\left(\mu_{\mathrm{g}} / \mathrm{L}\right)\end{array}$ & $\begin{array}{l}\text { Chloro- } \\
\text { ethane, } \\
\text { total } \\
\left(\mu_{8} / L\right)\end{array}$ & $\begin{array}{l}\text { Ethyl- } \\
\text { benzene, } \\
\text { total } \\
(\mu \mathrm{g} / L)\end{array}$ & $\begin{array}{l}\text { Methyl- } \\
\text { bromide, } \\
\text { total } \\
\left(\mu_{g} / L\right)\end{array}$ & $\begin{array}{l}\text { Methyl- } \\
\text { chloride, } \\
\text { total } \\
\left(\mu_{g} / L\right)\end{array}$ & $\begin{array}{c}\text { Methyl- } \\
\text { ene } \\
\text { chlo- } \\
\text { ride } \\
\text { total } \\
(\mu \mathrm{g} / \mathrm{L})\end{array}$ & $\begin{array}{l}\text { Tetra- } \\
\text { chloro- } \\
\text { ethyl- } \\
\text { ene, } \\
\text { total } \\
(\mu \mathrm{g} / \mathrm{L})\end{array}$ & $\begin{array}{l}\text { Tri- } \\
\text { chloro- } \\
\text { fluoro- } \\
\text { methane, } \\
\text { total } \\
\left(\mu_{g} / L\right)\end{array}$ \\
\hline
\end{tabular}

WELL 4--Continued

\begin{tabular}{|c|c|c|c|c|c|c|c|c|c|c|}
\hline \multicolumn{11}{|l|}{ JUNE 1985} \\
\hline 14 & -- & -- & - & -- & -- & -- & -- & -- & -- & -- \\
\hline 20 & -- & -. & - & -- & -- & -- & -- & $\rightarrow$ & - & -- \\
\hline \multicolumn{11}{|l|}{ AUG } \\
\hline $\begin{array}{c}30 \\
\text { MAY } 1986\end{array}$ & -- & -- & -- & -- & -- & -- & -- & -- & -- & -- \\
\hline $\begin{array}{c}27 \\
\text { APR } 1987\end{array}$ & -- & -- & -- & -- & -- & -- & -- & -- & -- & -- \\
\hline 28 & - & - & - & $\ldots$ & -- & -- & -- & - & -- & -- \\
\hline 29 & -- & -- & -- & -- & -- & -- & -- & -- & -- & -- \\
\hline \multicolumn{11}{|l|}{ JULY } \\
\hline SEPT $^{15}$ & -- & -- & -- & -- & -- & -- & -- & -- & -- & -- \\
\hline $\begin{array}{c}16 \\
\text { MAR } 1988\end{array}$ & -- & - & -- & - & - & -- & -- & -- & -- & -- \\
\hline 15 & - & -- & - & - & -- & -- & -- & -- & -- & -- \\
\hline 17 & -- & -- & -- & -- & -- & -- & -- & -- & -- & -- \\
\hline \multicolumn{11}{|l|}{ JULY } \\
\hline 13 & -- & -- & -- & -- & -- & -- & -- & -- & -- & -- \\
\hline 15 & -- & -- & -- & -- & -- & -- & -- & -- & - & -- \\
\hline \multicolumn{11}{|l|}{ SEPT } \\
\hline 02 & $<3.0$ & $<3.0$ & $<3.0$ & $<3.0$ & $<3.0$ & $<3.0$ & $<3.0$ & $<3.0$ & $<3.0$ & $<3.0$ \\
\hline 22 & -- & -- & -- & - & -- & -- & -- & -- & -- & -- \\
\hline 23 & -- & -- & - & - & -- & -- & -- & -- & -- & -- \\
\hline $\begin{array}{c}\text { Sample } \\
\text { date }\end{array}$ & $\begin{array}{l}1,1 \text {-di- } \\
\text { chloro- } \\
\text { ethane, } \\
\text { total } \\
\left(\mu_{g} / L\right)\end{array}$ & $\begin{array}{l}\text { 1, 1-di- } \\
\text { chloro- } \\
\text { ethyl- } \\
\text { ene, } \\
\text { total } \\
\left(\mu_{\mathrm{g}} / \mathrm{L}\right)\end{array}$ & $\begin{array}{c}1,1,1- \\
\text { tri- } \\
\text { chloro- } \\
\text { ethane, } \\
\text { total } \\
\left(\mu_{g} / L\right)\end{array}$ & $\begin{array}{c}1,1,2- \\
\text { tri- } \\
\text { chloro- } \\
\text { ethane, } \\
\text { total } \\
\left(\mu_{8} / L\right)\end{array}$ & $\begin{array}{l}1,1,2,2 \\
\text { tetra- } \\
\text { chloro- } \\
\text { ethane, } \\
\text { total } \\
\left(\mu_{\mathrm{g}} / \mathrm{L}\right)\end{array}$ & $\begin{array}{l}1,2 \text {-di- } \\
\text { chloro- } \\
\text { benzene, } \\
\text { total } \\
\left(\mu_{\mathrm{g}} / \mathrm{L}\right)\end{array}$ & $\begin{array}{l}1,2-\text { di- } \\
\text { chloro- } \\
\text { propane, } \\
\text { total } \\
\left(\mu_{g} / L\right)\end{array}$ & $\begin{array}{l}\text { Trans- } \\
1,2-\text { di- } \\
\text { chloro- } \\
\text { ethane, } \\
\text { total } \\
(\mu g / L)\end{array}$ & $\begin{array}{l}1,3-\mathrm{di}- \\
\text { chloro- } \\
\text { propene, } \\
\text { total } \\
(\mu \mathrm{g} / \mathrm{L})\end{array}$ & $\begin{array}{l}1,3-\mathrm{di}- \\
\text { chloro- } \\
\text { benzene, } \\
\text { total } \\
(\mu \mathrm{g} / \mathrm{L})\end{array}$ \\
\hline
\end{tabular}

JNE 1985

\begin{tabular}{|c|c|c|c|c|c|c|c|c|c|c|}
\hline 14 & -- & -- & - & $\cdots$ & - & -- & -- & -- & -- & - \\
\hline 20 & -- & -- & - & -- & -- & - & -- & -- & -- & -- \\
\hline AUG & & & & & & & & & & \\
\hline $\begin{array}{c}30 \\
\text { MAY } 1986\end{array}$ & -- & -- & -- & -- & -- & -- & -- & -- & -- & -- \\
\hline$\stackrel{27}{\text { APR } 1987}$ & -- & -- & -- & -- & -- & -- & -- & -- & -- & -- \\
\hline 28 & -- & -- & -- & -- & -- & -- & -- & -- & -- & - \\
\hline $\begin{array}{r}29 \\
\text { SLY }\end{array}$ & - & -- & -- & -- & -- & -- & -- & -- & -- & -- \\
\hline 15 & -- & -- & - & -- & -- & -- & -- & -- & -- & -- \\
\hline$\stackrel{16}{\text { MAR } 1988}$ & -- & -- & -- & -- & -- & -- & -- & -- & -- & -- \\
\hline 15 & -- & -- & -- & -- & -- & -- & -- & -- & -- & - \\
\hline${ }_{\text {JULY }}^{17}$ & -- & -- & -- & -- & -- & -- & - & -- & -- & -- \\
\hline 13 & -- & -- & -- & -- & -- & -- & -- & -- & -- & -- \\
\hline SEPT & - & -- & -- & -- & -- & -- & -- & -- & - & -- \\
\hline 02 & $<3.0$ & $<3.0$ & $<3.0$ & $<3.0$ & $<3.0$ & $<3.0$ & $<3.0$ & $<3.0$ & $<3.0$ & $<3.0$ \\
\hline 22 & -- & - & -- & -- & -- & -- & -- & -- & -- & -- \\
\hline 23 & -- & -- & -- & -- & -- & -- & -- & -- & -- & -- \\
\hline
\end{tabular}


Table 5.- Chemical and bacteriological analyses of water from the observation wells--Continued

\begin{tabular}{|c|c|c|c|c|c|c|c|c|c|}
\hline $\begin{array}{c}\text { Sample } \\
\text { date }\end{array}$ & $\begin{array}{c}1,4,-\mathrm{di}- \\
\text { chloro- } \\
\text { benzene, } \\
\text { total } \\
(\mu \mathrm{g} / \mathrm{L})\end{array}$ & $\begin{array}{l}\text { 2-chloro- } \\
\text { ethyl- } \\
\text { vinyl- } \\
\text { ether, } \\
\text { total } \\
(\mu \mathrm{g} / \mathrm{L})\end{array}$ & $\begin{array}{c}\text { Dichloro- } \\
\text { difluoro- } \\
\text { methane, } \\
\text { total } \\
(\mu \mathrm{g} / \mathrm{L})\end{array}$ & $\begin{array}{c}\text { Trans- } \\
1,3-\text { di- } \\
\text { chloro- } \\
\text { propene, } \\
\text { total } \\
\left(\mu_{g} / L\right)\end{array}$ & $\begin{array}{c}\text { Cis- } \\
1,3-d i- \\
\text { chloro- } \\
\text { propene, } \\
\text { total } \\
\left(\mu_{\mathrm{g}} / \mathrm{L}\right)\end{array}$ & $\begin{array}{c}\text { Vinyl } \\
\text { chloride, } \\
\text { total } \\
(\mu \mathrm{g} / \mathrm{L})\end{array}$ & $\begin{array}{c}\text { Tri- } \\
\text { chloro- } \\
\text { ethylene, } \\
\text { total } \\
(\mu \mathrm{g} / \mathrm{L})\end{array}$ & $\begin{array}{c}\text { Styrene, } \\
\text { total } \\
(\mu \mathrm{g} / \mathrm{L})\end{array}$ & $\begin{array}{l}\text { Xylene, } \\
\text { total } \\
\text { tot rec } \\
(\mu \mathrm{g} / \mathrm{L})\end{array}$ \\
\hline \multicolumn{10}{|c|}{ WELL 4--Continued } \\
\hline JUNE 1985 & & & & & & & & & \\
\hline 14 & -- & -- & -- & -- & -- & -- & -- & - & -- \\
\hline 20 & -- & -- & -- & -- & -- & -- & -- & -- & -- \\
\hline AUG & & & & & & & & & \\
\hline $\begin{array}{c}30 \\
\text { MAY } 1986\end{array}$ & -- & -- & -- & -- & -- & -- & -- & -- & -- \\
\hline $\begin{array}{c}27 \\
\text { APR } 1987\end{array}$ & -- & -- & -- & -- & -- & -- & -- & -- & -- \\
\hline 28 & -- & -- & -- & -- & -- & -- & -- & -- & -- \\
\hline $\begin{array}{l}29 \\
\text { JULY }\end{array}$ & -- & -- & -- & -- & -- & -- & -- & -- & -- \\
\hline 15 & -- & -- & -- & -- & -- & -- & -- & -- & -- \\
\hline SEPT & & & & & & & & & \\
\hline $\begin{array}{l}16 \\
\text { MAR } 1988\end{array}$ & -- & -- & -- & -- & - & -- & - & -- & -- \\
\hline 15 & -- & -- & -- & -- & - & -- & -- & - & -- \\
\hline 17 & -- & -- & -- & -- & - & -- & -- & -- & -- \\
\hline JULY & & & & & & & & & \\
\hline 13 & -- & -- & -- & -- & - & -- & -- & -- & -- \\
\hline 15 & -- & -- & -- & -- & -- & -- & -- & -- & -- \\
\hline SEPT & & & & & & & & & \\
\hline 02 & $<3.0$ & $<3.0$ & $<3.0$ & $<3.0$ & $<3.0$ & $<3.0$ & $<3.0$ & $<3.0$ & $<3.0$ \\
\hline 22 & -- & -- & -- & -- & -- & -- & -- & -- & -- \\
\hline 23 & -- & -- & -- & -- & -- & -- & -- & -- & -- \\
\hline
\end{tabular}


Table 5.--Chemical and bacteriological analyses of water from the observation wells--Continued

\begin{tabular}{|c|c|c|c|c|c|c|c|c|c|c|}
\hline $\begin{array}{c}\text { Sample } \\
\text { date }\end{array}$ & $\begin{array}{l}\text { Spe- } \\
\text { cific } \\
\text { con- } \\
\text { duct- } \\
\text { ance } \\
(\mu \mathrm{S} / \mathrm{cm})\end{array}$ & $\begin{array}{c}\mathrm{pH} \\
\text { (units) }\end{array}$ & $\begin{array}{l}\text { Residue } \\
\text { at } \\
105^{\circ} \mathrm{C}, \\
\text { dis- } \\
\text { solved } \\
\text { (mg/L) }\end{array}$ & $\begin{array}{l}\text { Nitrogen, } \\
\text { ammonia, } \\
\text { dis- } \\
\text { solved } \\
\text { (mg/L } \\
\text { as } N \text { ) }\end{array}$ & $\begin{array}{l}\text { Nitrogen, } \\
\text { nitrite, } \\
\text { dis- } \\
\text { solved } \\
\text { (mg/L } \\
\text { as } N \text { ) }\end{array}$ & $\begin{array}{l}\text { Nitrogen, } \\
\text { ammonia, } \\
\text { torganic, } \\
\text { dissolved } \\
\text { (mg/L } \\
\text { as } \mathrm{N} \text { ) }\end{array}$ & $\begin{array}{c}\mathrm{Nitrogen}, \\
\mathrm{NO}_{2}+\mathrm{NO}_{3} \\
\text { dis- } \\
\text { solved } \\
\text { (mg/L } \\
\text { as } \mathrm{N} \text { ) }\end{array}$ & $\begin{array}{l}\text { Phos- } \\
\text { phorus, } \\
\text { ortho, } \\
\text { dissolved } \\
\text { (mg/L } \\
\text { as P) }\end{array}$ & $\begin{array}{l}\text { Hard- } \\
\text { ness, } \\
\text { total } \\
\text { (mg/L } \\
\text { as } \\
\left.\mathrm{CaCO}_{3}\right)\end{array}$ & $\begin{array}{l}\text { Cal- } \\
\text { cium, } \\
\text { dis- } \\
\text { solved } \\
\text { (mg/L } \\
\text { as } \mathrm{Ca} \text { ) }\end{array}$ \\
\hline
\end{tabular}

WELL 5

\begin{tabular}{|c|c|c|c|c|c|c|c|c|c|c|}
\hline \multicolumn{11}{|l|}{ SEPT 1987} \\
\hline 15 & 2,500 & 7.5 & 2,040 & 0.200 & 3.20 & 1.0 & 4.20 & $<0.020$ & 1,000 & 250 \\
\hline 16 & - & -- & -. & -- & -- & -- & -- & -- & -- & -- \\
\hline \multicolumn{11}{|l|}{ MAR 1988} \\
\hline 15 & 2,450 & 7.3 & 2,120 & $<.100$ & .110 & .70 & 7.50 & .100 & 960 & 220 \\
\hline 17 & -- & -- & -- & -- & -- & -- & -- & -- & -- & -- \\
\hline \multicolumn{11}{|l|}{ JULY } \\
\hline 22 & 2,600 & 7.5 & 2,170 & .200 & .250 & 1.2 & 6.80 & .080 & 1,000 & 230 \\
\hline \multicolumn{11}{|l|}{ SEPT } \\
\hline 02 & -- & -- & -- & -- & -- & -- & -- & -- & -- & -- \\
\hline${ }_{\text {MAR }}^{23} 1989$ & 2,550 & 7.6 & 1,910 & $<.100$ & .190 & $<.30$ & 12.4 & $<.020$ & 1,000 & 230 \\
\hline 15 & -- & - & - & - & -- & -- & -- & -- & -- & -- \\
\hline 16 & 2,870 & 7.4 & -- & -- & -- & -- & -- & -- & 950 & 220 \\
\hline \multicolumn{11}{|l|}{ JUNE } \\
\hline JULY & 2,430 & 7.6 & 2,190 & $<.200$ & .030 & $<.30$ & 12.0 & .070 & 1,000 & 240 \\
\hline 18 & 2,820 & 7.6 & 2,260 & $<.100$ & .060 & $<.30$ & 11.7 & $<.020$ & 1,100 & 260 \\
\hline \multicolumn{11}{|l|}{ AUG } \\
\hline $\begin{array}{c}29 \\
\text { JAN } 1990\end{array}$ & 2,900 & 7.6 & -- & $<.100$ & .020 & 1.2 & 13.3 & .020 & 1,000 & 240 \\
\hline 25 & 2,860 & 7.2 & 2,220 & $<.100$ & .030 & 1.0 & 12.6 & .050 & 1,100 & 220 \\
\hline 26 & -- & -- & -- & -- & $\cdots$ & -- & -- & -- & -- & -- \\
\hline \multicolumn{11}{|l|}{ MAY } \\
\hline JULY & 3,100 & 7.5 & 2,450 & $<.100$ & $<.020$ & .90 & 14.0 & .080 & 1,100 & 250 \\
\hline 31 & 3,160 & 7.5 & 2,490 & $<.100$ & $<.020$ & .80 & 17.3 & $<.020$ & 1,200 & 260 \\
\hline \multicolumn{11}{|l|}{ SEPT } \\
\hline $\begin{array}{l}25 \\
\text { JAN } 1991\end{array}$ & 3,130 & 7.4 & 2,600 & $<.100$ & $<.020$ & 1.1 & 16.0 & $<.020$ & 1,200 & 270 \\
\hline 24 & 3,300 & 7.6 & 2,700 & $<.100$ & $<.020$ & .80 & 19.0 & .170 & 1,200 & 260 \\
\hline
\end{tabular}


Table 5.--Chemical and bacteriological analyses of water

from the observation wells--Continued

\begin{tabular}{|c|c|c|c|c|c|c|c|c|c|c|c|}
\hline $\begin{array}{c}\text { Sample } \\
\text { date }\end{array}$ & $\begin{array}{c}\text { Magne- } \\
\text { sium, } \\
\text { dis- } \\
\text { solved } \\
\text { (mg/L } \\
\text { as } M g \text { ) }\end{array}$ & $\begin{array}{l}\text { Sodium, } \\
\text { dis- } \\
\text { solved } \\
\text { (mg/L } \\
\text { as } \mathrm{Na} \text { ) }\end{array}$ & $\begin{array}{l}\text { Potas- } \\
\text { sium, } \\
\text { dis- } \\
\text { solved } \\
(\mathrm{mg} / L \\
\text { as } K)\end{array}$ & $\begin{array}{l}\text { Chlo- } \\
\text { ride, } \\
\text { dis- } \\
\text { solved } \\
(\mathrm{mg} / \mathrm{L} \\
\text { as } \mathrm{Cl})\end{array}$ & $\begin{array}{c}\text { Sulfate, } \\
\text { dis- } \\
\text { solved } \\
\left(\mathrm{mg}^{\prime} \mathrm{L}\right. \\
\left.\text { as } \mathrm{SO}_{4}\right)\end{array}$ & $\begin{array}{c}\text { Cadmium, } \\
\text { dis- } \\
\text { solved } \\
\left(\mu_{g} / L\right. \\
\text { as Cd) }\end{array}$ & $\begin{array}{l}\text { Chro- } \\
\text { mium, } \\
\text { dis- } \\
\text { solved } \\
(\mu \mathrm{g} / \mathrm{L} \\
\text { as } \mathrm{Cr})\end{array}$ & $\begin{array}{c}\text { Copper, } \\
\text { dis- } \\
\text { solved } \\
\left(\mu_{g} / L\right. \\
\text { as } \mathrm{Cu})\end{array}$ & $\begin{array}{l}\text { Iron, } \\
\text { dis- } \\
\text { solved } \\
(\mu g / L \\
\text { as } \mathrm{Fe})\end{array}$ & $\begin{array}{l}\text { Lead, } \\
\text { dis- } \\
\text { solved } \\
\left(\mu_{g} / L\right. \\
\text { as } \mathrm{Pb})\end{array}$ & $\begin{array}{l}\text { Manga- } \\
\text { nese, } \\
\text { dis- } \\
\text { solved } \\
(\mu g / L \\
\text { as Mn) }\end{array}$ \\
\hline
\end{tabular}

WELL 5--Continued

SEPT 1987

\begin{tabular}{|c|c|c|c|c|c|c|c|c|c|c|c|}
\hline 15 & 97 & 240 & 11 & 170 & 890 & 0.4 & $<20$ & $<20$ & $<50$ & $<10$ & 1,500 \\
\hline $\operatorname{MAR}^{16} 1988$ & -- & -- & -- & -- & -- & -- & -- & -- & -- & -- & -- \\
\hline 15 & 100 & 230 & 7.4 & 180 & 1,000 & -- & $<20$ & $<20$ & $<50$ & 10 & 2,700 \\
\hline${ }_{\text {JULY }}^{17}$ & -- & -- & -- & -- & -- & -- & -- & -- & -- & -- & -- \\
\hline $\begin{array}{r}\text { JULY } \\
22 \\
\text { SEPT }\end{array}$ & 100 & 250 & 5.8 & 180 & 1,100 & .4 & $<20$ & $<20$ & $<50$ & $<10$ & 1,300 \\
\hline 02 & - & -- & - & -- & - & - & -- & -- & -- & -- & -- \\
\hline$\stackrel{23}{23}$ MAR 1989 & 100 & 240 & 5.1 & 160 & 930 & .3 & $<20$ & $<20$ & $<50$ & $<10$ & -- \\
\hline $\begin{array}{l}15 \\
16\end{array}$ & $\ddot{98}$ & $2 \overline{--}$ & -- & 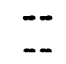 & -- & -- & $\begin{array}{l}-- \\
<20\end{array}$ & $<--$ & $\begin{array}{r}-- \\
<50\end{array}$ & $<\overline{10}$ & $\overline{910}$ \\
\hline JUNE & & & & & & & & & & & \\
\hline $\begin{array}{c}02 \\
\text { JULY }\end{array}$ & 100 & 260 & 4.5 & 180 & 1,100 & $<.2$ & $<20$ & $<20$ & $<50$ & $<10$ & 1,200 \\
\hline${ }_{\text {AUG }}^{18}$ & 110 & 260 & 4.6 & 180 & 1,000 & .4 & 50 & $<20$ & $<50$ & $<10$ & 710 \\
\hline $\begin{array}{c}29 \\
\text { JAN } 1990\end{array}$ & 110 & 230 & 4.0 & 180 & 1,100 & $<.2$ & $<20$ & $<20$ & $<50$ & $<10$ & 750 \\
\hline 25 & 120 & 270 & 3.8 & 200 & 1,100 & .3 & $<200$ & $<200$ & $<500$ & $<10$ & 40 \\
\hline$\stackrel{26}{M A Y}$ & -- & -- & -- & -- & - & -- & -- & -- & -- & -- & -- \\
\hline JULY & 120 & 270 & 3.5 & 200 & -- & .2 & $<20$ & $<20$ & $<50$ & $<10$ & 180 \\
\hline $\begin{array}{l}31 \\
\text { SEPT }\end{array}$ & 130 & 300 & 3.6 & 210 & 1,200 & .3 & $<40$ & $<40$ & $<100$ & $<10$ & 50 \\
\hline $\begin{array}{c}25 \\
\text { JAN } 1991\end{array}$ & 130 & 310 & 4.2 & 200 & 1,100 & .3 & $<40$ & $<40$ & $<100$ & $<10$ & $<40$ \\
\hline 24 & 130 & 300 & 3.6 & 210 & 1,100 & .4 & $<20$ & $<20$ & 60 & $<10$ & $<20$ \\
\hline
\end{tabular}


Table 5.--Chemical and bacteriological analyses of water from the observation wells--Continued

\begin{tabular}{|c|c|c|c|c|c|c|c|c|c|c|}
\hline $\begin{array}{c}\text { Sample } \\
\text { date }\end{array}$ & $\begin{array}{l}\text { Nickel, } \\
\text { dis- } \\
\text { solved } \\
\left(\mu_{g} / L\right. \\
\text { as } N i)\end{array}$ & $\begin{array}{l}\text { Zinc, } \\
\text { dis- } \\
\text { solved } \\
\left(\mu_{g} / L\right. \\
\text { as } Z n)\end{array}$ & $\begin{array}{l}\text { Coli- } \\
\text { form, } \\
\text { fecal } \\
\text { (coi./ } \\
100 \mathrm{~mL} \text { ) }\end{array}$ & $\begin{array}{c}\text { Strepto- } \\
\text { cocci, } \\
\text { fecal } \\
(\text { col./ } \\
100 \mathrm{~mL})\end{array}$ & $\begin{array}{c}\text { Dichloro- } \\
\text { bromo- } \\
\text { methane, } \\
\text { total } \\
(\mu g / L)\end{array}$ & $\begin{array}{c}\text { Carbon } \\
\text { tetra- } \\
\text { chloride, } \\
\text { total } \\
(\mu g / L)\end{array}$ & $\begin{array}{l}1,2-d i- \\
\text { chloro- } \\
\text { ethane, } \\
\text { total } \\
(\mu g / L)\end{array}$ & $\begin{array}{c}\text { Bromo- } \\
\text { form, } \\
\text { total } \\
\left(\mu_{\mathrm{g}} / \mathrm{L}\right)\end{array}$ & $\begin{array}{l}\text { Chloro- } \\
\text { dibromo- } \\
\text { methane, } \\
\text { total } \\
(\mu \mathrm{g} / \mathrm{L})\end{array}$ & $\begin{array}{c}\text { Chloro- } \\
\text { form, } \\
\text { total } \\
\left(\mu_{g} / L\right)\end{array}$ \\
\hline
\end{tabular}

WELL 5--Continued

SEPT 1987

\begin{tabular}{|c|c|c|c|c|c|c|c|c|c|c|}
\hline 15 & 40 & $<20$ & -- & -- & -- & -- & -- & -- & -- & -- \\
\hline 16 & -- & -- & -- & $<2$ & -- & -- & -- & -- & -- & -- \\
\hline \multicolumn{11}{|l|}{ MAR 1988} \\
\hline 15 & 30 & $<20$ & -- & -- & - & -- & -- & -- & -- & -- \\
\hline 17 & -- & -- & $<2$ & $<2$ & -- & -- & -- & -- & -- & -- \\
\hline \multicolumn{11}{|l|}{ JULY } \\
\hline 22 & 30 & $<20$ & -- & -- & -- & -- & -- & -- & -- & -- \\
\hline \multicolumn{11}{|l|}{ SEPT } \\
\hline 02 & -- & -- & -- & -- & $<3.0$ & $<3.0$ & $<3.0$ & $<3.0$ & $<3.0$ & $<3.0$ \\
\hline 23 & $<20$ & 40 & $<2$ & $<2$ & -- & - & -- & -- & -- & - \\
\hline \multicolumn{11}{|l|}{ MAR 1989} \\
\hline 15 & -- & -- & $<2$ & 9 & -- & -- & -- & -- & -- & -- \\
\hline 16 & $<20$ & 40 & - & - & -- & -- & -- & -- & -- & -. \\
\hline \multicolumn{11}{|l|}{ JUNE } \\
\hline 02 & $<20$ & $<20$ & $<2$ & 2 & -- & -- & -- & -- & -- & - \\
\hline \multicolumn{11}{|l|}{ JULY } \\
\hline $\begin{array}{c}18 \\
\text { AUG }\end{array}$ & 60 & \multicolumn{8}{|c|}{ AUG } & -- \\
\hline 29 & $<20$ & $<20$ & $<20$ & 230 & -- & -- & -- & -- & -- & -. \\
\hline \multicolumn{11}{|l|}{ JAN 1990} \\
\hline 25 & $<200$ & 500 & - & -- & -- & -- & -- & -- & -- & -- \\
\hline 26 & -- & -- & $<20$ & $<20$ & -- & -- & -- & -- & -- & -- \\
\hline \multicolumn{11}{|l|}{ MAY } \\
\hline 22 & $<20$ & $<20$ & $<20$ & $<20$ & -- & -- & -- & -- & -- & -- \\
\hline \multicolumn{11}{|l|}{ JULY } \\
\hline $\begin{array}{l}31 \\
\text { SEPT }\end{array}$ & 30 & 30 & $<20$ & $<20$ & -- & -- & -- & -- & -- & -- \\
\hline $\begin{array}{l}25 \\
\text { JAN } 1991\end{array}$ & $<40$ & $<40$ & $<20$ & $<20$ & -- & -- & -- & -- & -- & -- \\
\hline 24 & 20 & $<20$ & $<20$ & $<20$ & -- & -- & -- & -- & -- & -- \\
\hline
\end{tabular}


Table 5.--Chemical and bacteriological analyses of water from the observation wells--Continued

\begin{tabular}{|c|c|c|c|c|c|c|c|c|c|c|}
\hline $\begin{array}{l}\text { Sample } \\
\text { date }\end{array}$ & $\begin{array}{c}\text { Toluene, } \\
\text { total } \\
\left(\mu_{g} / L\right)\end{array}$ & $\begin{array}{c}\text { Benzene, } \\
\text { total } \\
(\mu \mathrm{g} / L)\end{array}$ & $\begin{array}{l}\text { Chloro- } \\
\text { benzene, } \\
\text { total } \\
\left(\mu_{\mathrm{g}} / \mathrm{L}\right)\end{array}$ & $\begin{array}{l}\text { Chloro- } \\
\text { ethane, } \\
\text { total } \\
\left(\mu_{g} / L\right)\end{array}$ & $\begin{array}{c}\text { Ethyl- } \\
\text { benzene, } \\
\text { total } \\
\left(\mu_{g} / L\right)\end{array}$ & $\begin{array}{l}\text { Methyl- } \\
\text { bromide, } \\
\text { total } \\
\left(\mu_{8} / L\right)\end{array}$ & $\begin{array}{c}\text { Methyl- } \\
\text { chloride, } \\
\text { total } \\
\left(\mu_{g} / L\right)\end{array}$ & $\begin{array}{c}\text { Methyl- } \\
\text { ene } \\
\text { chlo- } \\
\text { ride, } \\
\text { total } \\
\left(\mu_{8} / L\right)\end{array}$ & $\begin{array}{l}\text { Tetra- } \\
\text { chloro- } \\
\text { ethyl- } \\
\text { ene, } \\
\text { total } \\
\left(\mu_{g} / L\right)\end{array}$ & $\begin{array}{l}\text { Tri- } \\
\text { chloro- } \\
\text { fluoro- } \\
\text { methane, } \\
\text { total } \\
\left(\mu_{g} / L\right)\end{array}$ \\
\hline
\end{tabular}

\section{WELL 5--Continued}

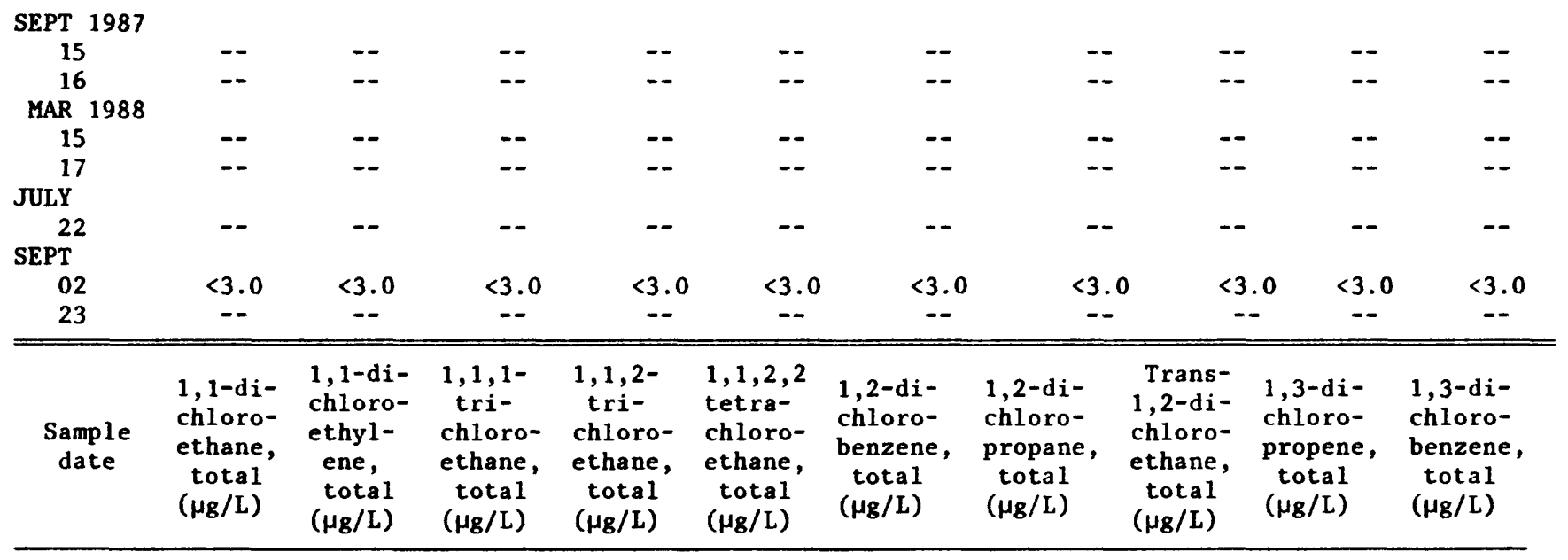

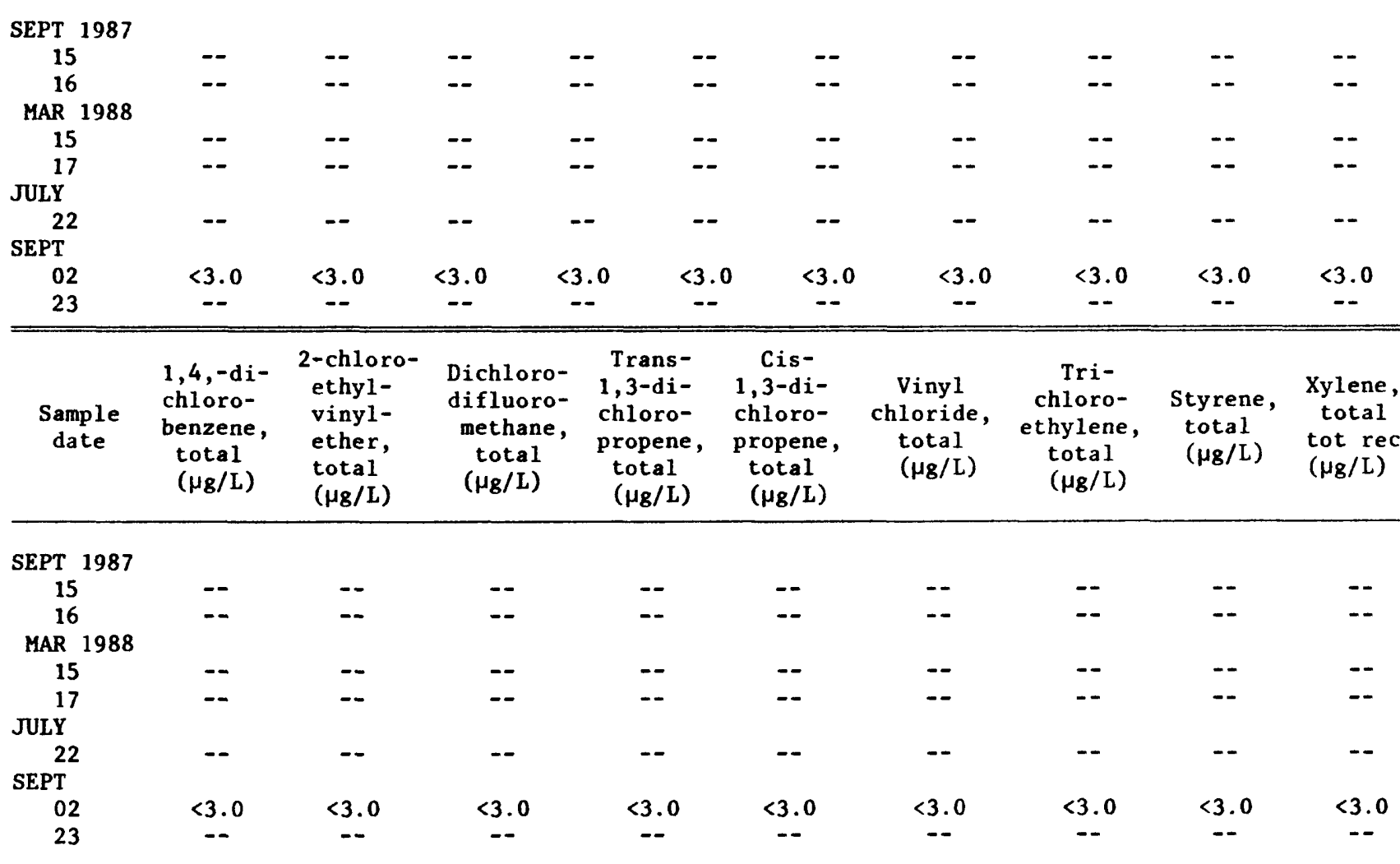


Table 5.--Chemical and bacteriological analyses of water from the observation wells--Continued

\begin{tabular}{|c|c|c|c|c|c|c|c|c|c|}
\hline $\begin{array}{c}\text { Sample } \\
\text { date }\end{array}$ & $\begin{array}{c}\text { Specific } \\
\text { conduct- } \\
\text { ance } \\
(\mu \mathrm{S} / \mathrm{cm})\end{array}$ & $\underset{\text { (units) }}{\mathrm{pH}}$ & $\begin{array}{l}\text { Residue } \\
\text { at } \\
105^{\circ} \mathrm{C}, \\
\text { dis- } \\
\text { solved } \\
\text { (mg/L) }\end{array}$ & $\begin{array}{l}\text { Nitrogen, } \\
\text { ammonia, } \\
\text { dis- } \\
\text { solved } \\
\text { (mg/L } \\
\text { as } \mathrm{N} \text { ) }\end{array}$ & $\begin{array}{c}\text { Nitrogen, } \\
\text { nitrite, } \\
\text { dis- } \\
\text { solved } \\
\text { (mg/L } \\
\text { as } N \text { ) }\end{array}$ & $\begin{array}{l}\text { Nitrogen, } \\
\text { ammonia, } \\
\text { torganic, } \\
\text { dissolved } \\
\text { (mg/L } \\
\text { as } \mathrm{N} \text { ) }\end{array}$ & $\begin{array}{c}\text { Nitrogen, } \\
\mathrm{NO}_{2}+\mathrm{NO}_{3} \\
\text { dis- } \\
\text { solved } \\
\text { (mg/L } \\
\text { as } \mathrm{N})\end{array}$ & $\begin{array}{l}\text { Phos- } \\
\text { phorus, } \\
\text { ortho, } \\
\text { dissolved } \\
\text { (mg/L } \\
\text { as } P \text { ) }\end{array}$ & $\begin{array}{l}\text { Hard- } \\
\text { ness, } \\
\text { total } \\
(\mathrm{mg} / \mathrm{L} \\
\text { as } \\
\left.\mathrm{CaCO}_{3}\right)\end{array}$ \\
\hline \multicolumn{10}{|c|}{ WELL 6} \\
\hline \multicolumn{10}{|l|}{ JUNE 1985} \\
\hline 13 & 2,400 & 8.7 & 1,860 & 0.110 & 3.25 & 1.8 & 26.6 & $<0.020$ & 510 \\
\hline 17 & -- & -- & -- & -- & -- & -- & -- & -- & -- \\
\hline \multicolumn{10}{|l|}{ AUG } \\
\hline 29 & -- & -- & -- & -- & -- & -- & -- & -- & -- \\
\hline 30 & 1,710 & 8.5 & 1,210 & .200 & .190 & .80 & 33.0 & $<.020$ & 260 \\
\hline MAY 1986 & & & & & & & & & \\
\hline 27 & 6,500 & 8.1 & 5,420 & $<.100$ & $<.010$ & .60 & 7.73 & $<.020$ & 1,800 \\
\hline \multicolumn{10}{|l|}{ AUG } \\
\hline 28 & -- & -- & -- & -- & -- & -- & -- & -. & -- \\
\hline 29 & 7,000 & 7.3 & 5,790 & $<.100$ & $<.010$ & .90 & 5.18 & $<.020$ & 1,500 \\
\hline \multicolumn{10}{|l|}{ APR 1987} \\
\hline 28 & -- & -- & -- & -- & -- & -- & -- & -- & -- \\
\hline 29 & 6,000 & 7.6 & 5,160 & $<.100$ & $<.010$ & .80 & 4.50 & $<.020$ & 1,800 \\
\hline \multicolumn{10}{|l|}{ JULY } \\
\hline $\begin{array}{l}14 \\
\text { SEPT }\end{array}$ & 4,990 & 7.4 & 5,150 & $<.100$ & $<.010$ & 1.3 & 4.59 & $<.020$ & 1,800 \\
\hline 15 & 5,200 & 7.5 & 4,530 & .200 & $<.010$ & 1.0 & 5.20 & $<.020$ & 1,500 \\
\hline 16 & - & - & -. & -- & -- & - & - & -- & - \\
\hline \multicolumn{10}{|l|}{ MAR 1988} \\
\hline 15 & 5,600 & 7.3 & 4,700 & $<.100$ & $<.020$ & .40 & 4.40 & .020 & 1,500 \\
\hline 17 & -- & -- & - & -- & -- & -- & - & -- & -. \\
\hline \multicolumn{10}{|l|}{ JULY } \\
\hline 13 & -- & -- & -- & -- & -- & -- & -- & - & -- \\
\hline 14 & 5,410 & 7.4 & 4,450 & $<.100$ & $<.010$ & .70 & 4.20 & $<.020$ & 1,600 \\
\hline \multicolumn{10}{|l|}{ SEPT } \\
\hline $\begin{array}{l}23 \\
\text { MAR } 1989\end{array}$ & 5,180 & 7.4 & 4,220 & $<.100$ & $<.020$ & .40 & .760 & $<.020$ & 1,500 \\
\hline 15 & - & -- & -- & -- & -- & -- & - & -- & -- \\
\hline 16 & 5,880 & 7.3 & 4,740 & $<.100$ & $<.020$ & .50 & 1.97 & $<.020$ & 1,700 \\
\hline \multicolumn{10}{|l|}{ AUG } \\
\hline $\begin{array}{c}29 \\
\text { JAN } 1990\end{array}$ & 5,200 & 7.5 & 4,360 & $<.100$ & $<.020$ & .80 & 4.40 & .030 & 1,500 \\
\hline 25 & 5,490 & -- & 4,360 & $<.100$ & .120 & 1.2 & .500 & .040 & 1,600 \\
\hline MAY & & & & & & & & & \\
\hline 22 & 5,600 & 7.4 & 4,730 & $<.100$ & $<.020$ & .70 & .900 & .070 & 1,500 \\
\hline JULY & & & & & & & & & \\
\hline 31 & 5,800 & 7.4 & 4,800 & $<.100$ & $<.020$ & 1.9 & 5.20 & $<.020$ & 1,600 \\
\hline SEPT & & & & & & & & & \\
\hline 25 & 5,760 & 7.4 & 4,910 & $<.100$ & $<.020$ & .80 & 4.40 & $<.020$ & 1,600 \\
\hline JAN 1991 & & & & & & & & & \\
\hline 24 & -- & -- & -- & -- & -- & -- & -- & -- & -- \\
\hline 24 & 5,760 & 7.5 & 4,690 & $<.100$ & $<.020$ & 1.1 & .900 & .160 & 1,500 \\
\hline
\end{tabular}


Table 5.--Chemical and bacteriological analyses of water from the observation wells--Continued

\begin{tabular}{|c|c|c|c|c|c|c|c|c|}
\hline $\begin{array}{c}\text { Sample } \\
\text { date }\end{array}$ & $\begin{array}{l}\text { Calcium } \\
\text { dis- } \\
\text { solved } \\
\text { (mg/L } \\
\text { as Ca) }\end{array}$ & $\begin{array}{l}\text { Magne- } \\
\text { sium, } \\
\text { dis- } \\
\text { solved } \\
\text { (mg/L } \\
\text { as Mg) }\end{array}$ & $\begin{array}{l}\text { Sodium, } \\
\text { dis- } \\
\text { solved } \\
\text { (mg/L } \\
\text { as } \mathrm{Na} \text { ) }\end{array}$ & $\begin{array}{l}\text { Potas- } \\
\text { sium, } \\
\text { dis- } \\
\text { solved } \\
(m g / L \\
\text { as K) }\end{array}$ & $\begin{array}{l}\text { Chloride, } \\
\text { dis- } \\
\text { solved } \\
\text { (mg/L } \\
\text { as Cl) }\end{array}$ & $\begin{array}{l}\text { Sulfate, } \\
\text { dis- } \\
\text { solved } \\
(\mathrm{mg} / \mathrm{L} \\
\text { as } \mathrm{SO}_{4} \text { ) }\end{array}$ & $\begin{array}{l}\text { Cadmi um, } \\
\text { dis- } \\
\text { solved } \\
\text { ( } \mu g / L \\
\text { as Cd) }\end{array}$ & $\begin{array}{c}\text { Chromium, } \\
\text { dis- } \\
\text { solved } \\
\left(\mu_{g} / L\right. \\
\text { as } C r)\end{array}$ \\
\hline
\end{tabular}

WELL 6--Continued

JUNE 1985

13
17
AUG
29
30
27

$\begin{array}{rrrrr}120 & 52 & 470 & 9.9 & 140 \\ -- & -- & -- & -- & - \\ -- & -- & -- & -- & -\end{array}$

AUG

28

29

57

$29 \quad 300$

4.4

$\overline{73}$

40

320

$230 \quad 1,000$

$9.0 \quad 460$

$8.0 \quad 510$

7.8

$310 \quad 240$

1,000

500

950

7.8

470

8.2

470

7.1

$--$

$-$

$-$

MAR 1988

15

17

JULY

13

SEPT

23

MAR 1989

15

16

AUG

29

JAN 1990

$$
25
$$

MAY

22

31

SEPT

JAN 1991

24

$250 \quad 210$

820

7.4

460

$--$

$--$

840

7.6

440

$7.2 \quad 450$

770

$--$

7.6

490

6.9

420

4.0

500

$7.5 \quad 340$

470

7.2

430

7.8

440

6.8

780

$\begin{array}{ccc}1,100 & -- & -- \\ -- & -- & - \\ -- & -- & -- \\ 450 & 0.2 & <10\end{array}$

$2,700<.1<20$

$2, \overline{800} \quad-\overline{0} \quad--$

$2, \overline{700} \quad--\overline{4} \quad--$

$2,700<.2<60$

$2,300 \quad .4 \quad<20$

$2,400 \quad .5 \quad<20$

$2,200 \quad-\overline{3} \quad<20$

$2,100 \quad .5 \quad<20$

$2,500 \quad--\bar{r} \quad--$

$2,000 \quad .5<20$

$2,300 \quad .3<200$

$\begin{array}{lll}-- & .5 & <20\end{array}$

$2,500 \quad .2<60$

$\begin{array}{lll}2,100 & .8 & <80\end{array}$

$2,400 \quad .7 \quad<20$


Table 5.--Chemical and bacteriological analyses of water

from the observation wells--Continued

\begin{tabular}{|c|c|c|c|c|c|c|c|c|}
\hline $\begin{array}{c}\text { Sample } \\
\text { date }\end{array}$ & $\begin{array}{l}\text { Copper, } \\
\text { dis- } \\
\text { solved } \\
(\mu \mathrm{g} / \mathrm{L} \\
\text { as } \mathrm{Cu})\end{array}$ & $\begin{array}{l}\text { Iron, } \\
\text { dis- } \\
\text { solved } \\
(\mu \mathrm{g} / \mathrm{L} \\
\text { as } \mathrm{Fe})\end{array}$ & $\begin{array}{l}\text { Lead, } \\
\text { dis- } \\
\text { solved } \\
(\mu \mathrm{g} / \mathrm{L} \\
\text { as } \mathrm{Pb})\end{array}$ & $\begin{array}{c}\text { Manga- } \\
\text { nese, } \\
\text { dissolved } \\
(\mu g / L \\
\text { as } M n)\end{array}$ & $\begin{array}{c}\text { Nickel, } \\
\text { dis- } \\
\text { solved } \\
\text { ( } \mu \mathrm{g} / \mathrm{L} \\
\text { as } \mathrm{Ni} \text { ) }\end{array}$ & $\begin{array}{l}\text { Zinc, } \\
\text { dis- } \\
\text { solved } \\
(\mu \mathrm{g} / \mathrm{L} \\
\text { as } \mathrm{Zn})\end{array}$ & $\begin{array}{c}\text { Coli- } \\
\text { form, } \\
\text { fecal } \\
(\text { col./ } \\
100 \mathrm{~mL})\end{array}$ & $\begin{array}{r}\text { Strept } \\
\text { cocci } \\
\text { fecal } \\
\text { (col. } \\
100 \mathrm{~mL}\end{array}$ \\
\hline \multicolumn{9}{|c|}{ WELL 6--Continued } \\
\hline \multicolumn{9}{|l|}{ JUNE 1985} \\
\hline 13 & -- & 50 & -- & -- & -- & 50 & -- & -- \\
\hline 17 & -- & -- & -- & -- & -- & -- & $<1$ & $<1$ \\
\hline \multicolumn{9}{|l|}{ AUG } \\
\hline 29 & -- & -- & -- & -- & -- & -- & $<1$ & $<1$ \\
\hline $3^{30}$ & $<10$ & $<50$ & $<10$ & $<10$ & 110 & $<10$ & -- & -- \\
\hline 27 & $<10$ & $<50$ & $<10$ & $<20$ & $<60$ & 30 & $<1$ & $<1$ \\
\hline \multicolumn{9}{|l|}{ AUG } \\
\hline 28 & -- & -- & -- & -- & -- & -- & $<1$ & $<1$ \\
\hline 29 & $<100$ & 900 & $<250$ & 100 & 100 & 200 & -- & -- \\
\hline \multicolumn{9}{|l|}{ APR 1987} \\
\hline 28 & -- & -- & -- & -- & -- & -- & $<1$ & 4 \\
\hline 29 & $<10$ & $<50$ & $<50$ & $<20$ & 60 & 30 & -- & -- \\
\hline \multicolumn{9}{|l|}{ JULY } \\
\hline 14 & $<60$ & $<200$ & $<10$ & $<60$ & $<60$ & $<60$ & $<2$ & $<2$ \\
\hline \multicolumn{9}{|l|}{ SEPT } \\
\hline 15 & $<20$ & $<50$ & $<10$ & $<20$ & 60 & $<20$ & -- & -- \\
\hline 16 & -- & -- & -- & -- & -- & -- & $<2$ & $<2$ \\
\hline \multicolumn{9}{|l|}{ MAR 1988} \\
\hline 15 & $<20$ & $<50$ & $<10$ & $<20$ & $<40$ & $<20$ & -- & -- \\
\hline 17 & -- & -- & -- & -- & -- & -- & $<2$ & 3 \\
\hline \multicolumn{9}{|l|}{ JULY } \\
\hline 13 & -- & -- & -- & -- & -- & -- & $<2$ & $<2$ \\
\hline \multirow{2}{*}{\multicolumn{9}{|c|}{ SEPT }} \\
\hline & & & & & & & & \\
\hline$\stackrel{23}{\operatorname{MAR} 1989}$ & $<20$ & $<50$ & $<10$ & -- & $<20$ & $<20$ & $<2$ & MAR 1989 \\
\hline 15 & -- & -- & -- & -- & -- & -- & $<2$ & 11 \\
\hline 16 & $<20$ & $<50$ & $<10$ & $<20$ & $<20$ & 40 & - & - \\
\hline \multicolumn{9}{|l|}{ AUG } \\
\hline & \multicolumn{8}{|c|}{ JAN 1990} \\
\hline $\begin{array}{l}\text { JAN } 1990 \\
25\end{array}$ & $<200$ & $<500$ & $<10$ & $<200$ & $<200$ & 500 & $<20$ & 2 \\
\hline \multicolumn{9}{|l|}{ MAY } \\
\hline JULY 22 & $<20$ & $<50$ & $<10$ & $<20$ & 100 & $<20$ & $<20$ & 1 \\
\hline & $<60$ & $<150$ & $<10$ & $<60$ & 50 & 20 & $<20$ & $<20$ \\
\hline \multicolumn{9}{|l|}{ SEPT } \\
\hline $\begin{array}{c}25 \\
\text { JAN } 1991\end{array}$ & $<80$ & $<200$ & $<10$ & $<80$ & $<80$ & $<80$ & $<20$ & 11 \\
\hline 24 & $<20$ & 90 & $<10$ & $<20$ & $<50$ & 20 & $<20$ & 10 \\
\hline
\end{tabular}


Table 5.--Chemical and bacteriological analyses of water from the observation wells--Continued

\begin{tabular}{|c|c|c|c|c|c|c|c|c|c|c|}
\hline $\begin{array}{c}\text { Sample } \\
\text { date }\end{array}$ & $\begin{array}{l}\text { Spe- } \\
\text { cific } \\
\text { con- } \\
\text { duct- } \\
\text { ance } \\
(\mu \mathrm{S} / \mathrm{cm})\end{array}$ & $\underset{\text { (units) }}{\mathrm{pH}}$ & $\begin{array}{l}\text { Residue } \\
\text { at } \\
105^{\circ} \mathrm{C}, \\
\text { dis- } \\
\text { solved } \\
(\mathrm{mg} / \mathrm{L})\end{array}$ & $\begin{array}{l}\text { Nitrogen, } \\
\text { ammonia, } \\
\text { dis- } \\
\text { solved } \\
\text { (mg/L } \\
\text { as } N \text { ) }\end{array}$ & $\begin{array}{l}\text { Nitrogen, } \\
\text { nitrite, } \\
\text { dis- } \\
\text { solved } \\
\text { (mg/L } \\
\text { as } N \text { ) }\end{array}$ & $\begin{array}{l}\text { Nitrogen, } \\
\text { ammonia, } \\
\text { torganic, } \\
\text { dissolved } \\
\text { (mg/L } \\
\text { as } N \text { ) }\end{array}$ & $\begin{array}{c}\mathrm{Nitrogen}, \\
\mathrm{NO}_{2}+\mathrm{NO}_{3} \\
\text { dis- } \\
\text { solved } \\
(\mathrm{mg} / \mathrm{L} \\
\text { as } \mathrm{N})\end{array}$ & $\begin{array}{l}\text { Phos- } \\
\text { phorus, } \\
\text { ortho, } \\
\text { dissolved } \\
\text { (mg/L } \\
\text { as } P \text { ) }\end{array}$ & $\begin{array}{l}\text { Hard- } \\
\text { ness, } \\
\text { total } \\
(\mathrm{mg} / \mathrm{L} \\
\text { as } \\
\left.\mathrm{CaCO}_{3}\right)\end{array}$ & $\begin{array}{l}\text { Cal- } \\
\text { cium, } \\
\text { dis- } \\
\text { solved } \\
\text { (mg/L } \\
\text { as Ca) }\end{array}$ \\
\hline
\end{tabular}

\section{WELL 7}

JUNE 1985

\begin{tabular}{|c|c|c|c|c|c|c|c|c|c|c|}
\hline 13 & 1,770 & 10.0 & 1,130 & 0.950 & 2.46 & 5.8 & 4.70 & $<0.020$ & 420 & 93 \\
\hline 17 & $=$ & -- & - & -- & -- & -- & -- & -- & - & -- \\
\hline \multicolumn{11}{|l|}{ AUG } \\
\hline 29 & -- & -- & - & -- & -- & -- & -- & -- & -- & -- \\
\hline $\mathrm{MAY}_{1986}^{30}$ & 1,670 & 8.4 & 1,060 & .400 & .280 & 2.2 & 7.00 & .200 & 350 & 62 \\
\hline $\begin{array}{c}27 \\
\text { AUG }\end{array}$ & 2,150 & 8.6 & 1,330 & $<.100$ & $<.010$ & .80 & 10.9 & $<.020$ & 570 & 78 \\
\hline 28 & - & -- & - & -- & -- & -- & -- & -- & -- & -- \\
\hline 29 & 1,950 & 7.8 & 1,150 & $<.100$ & $<.010$ & .40 & 10.2 & -- & 440 & 64 \\
\hline \multicolumn{11}{|l|}{ APR 1987} \\
\hline 28 & -- & -- & -- & -- & -- & -- & -- & -- & -- & -- \\
\hline 29 & 2,300 & 8.0 & 1,430 & $<.10$ & $<.010$ & 1.6 & 15.0 & $<.020$ & 650 & 90 \\
\hline \multicolumn{11}{|l|}{ JULY } \\
\hline 14 & 1,900 & 7.9 & 1,230 & $<.100$ & .030 & 1.5 & 13.0 & .040 & 510 & 70 \\
\hline \multicolumn{11}{|l|}{ SEPT } \\
\hline 15 & 1,710 & 7.8 & 1,130 & .600 & $<.010$ & 1.1 & 10.1 & .060 & 430 & 66 \\
\hline 16 & -- & -- & -- & -- & -- & -- & -- & -- & -- & -- \\
\hline \multicolumn{11}{|l|}{ MAR 1988} \\
\hline 15 & 2,220 & 7.8 & 1,420 & $<.100$ & $<.020$ & .60 & 12.3 & .050 & 640 & 88 \\
\hline 17 & -- & -- & -- & -- & -- & -- & -- & -- & -- & -- \\
\hline \multicolumn{11}{|l|}{ JULY } \\
\hline 13 & -- & -- & -- & -- & -- & -- & -- & -- & -- & -- \\
\hline 14 & 2,000 & 7.4 & 1,280 & .100 & $<.010$ & 1.2 & 11.0 & $<.020$ & 560 & 76 \\
\hline \multicolumn{11}{|l|}{ SEPT } \\
\hline 02 & -- & -- & -- & -- & -- & -- & -- & -- & -- & -- \\
\hline 23 & 1,840 & 7.9 & 1,100 & $<.100$ & .020 & $<.30$ & 11.4 & .020 & 420 & 64 \\
\hline \multicolumn{11}{|l|}{ MAR 1989} \\
\hline 15 & -- & -- & -- & -- & -- & -- & -- & -- & -- & -- \\
\hline 16 & 2,170 & 7.8 & 1,400 & $<.100$ & $<.020$ & .40 & 21.3 & $<.020$ & 590 & 86 \\
\hline \multicolumn{11}{|l|}{ JUNE } \\
\hline JULY & 2,190 & 7.7 & 1,490 & $<.200$ & .090 & .30 & 21.8 & .090 & 610 & 82 \\
\hline $\begin{array}{l}18 \\
\text { AUG }\end{array}$ & 1,900 & 7.9 & 1,160 & $<.100$ & $<.020$ & .30 & 9.10 & $<.020$ & 440 & 68 \\
\hline $\begin{array}{l}29 \\
\text { JAN } 1990\end{array}$ & 1,870 & 8.0 & 1,140 & $<.100$ & $<.020$ & .70 & 10.0 & .030 & 430 & 66 \\
\hline$\stackrel{25}{M A Y}$ & 2,140 & -- & 1,350 & $<.100$ & .050 & .70 & 30.0 & .050 & 650 & 87 \\
\hline 22 & 2,510 & 7.8 & 1,710 & $<.100$ & .030 & 1.2 & 50.4 & .120 & 820 & 99 \\
\hline $\begin{array}{r}\text { JULY } \\
31\end{array}$ & & & & & & & & & & \\
\hline $\begin{array}{l}31 \\
\text { SEPT }\end{array}$ & 2,090 & 7.8 & 1,320 & $<.100$ & .040 & 1.3 & 18.3 & .030 & 550 & 76 \\
\hline$\stackrel{25}{\text { JAN } 1991}$ & 1,940 & 7.8 & 1,200 & $<.100$ & .020 & .90 & 8.30 & $<.020$ & 450 & 60 \\
\hline 24 & 2,360 & 7.8 & 1,500 & $<.100$ & $<.020$ & 1.2 & 29.5 & $<.020$ & 640 & 89 \\
\hline
\end{tabular}


Table 5.--Chemical and bacteriological analyses of water from the observation wells--Continued

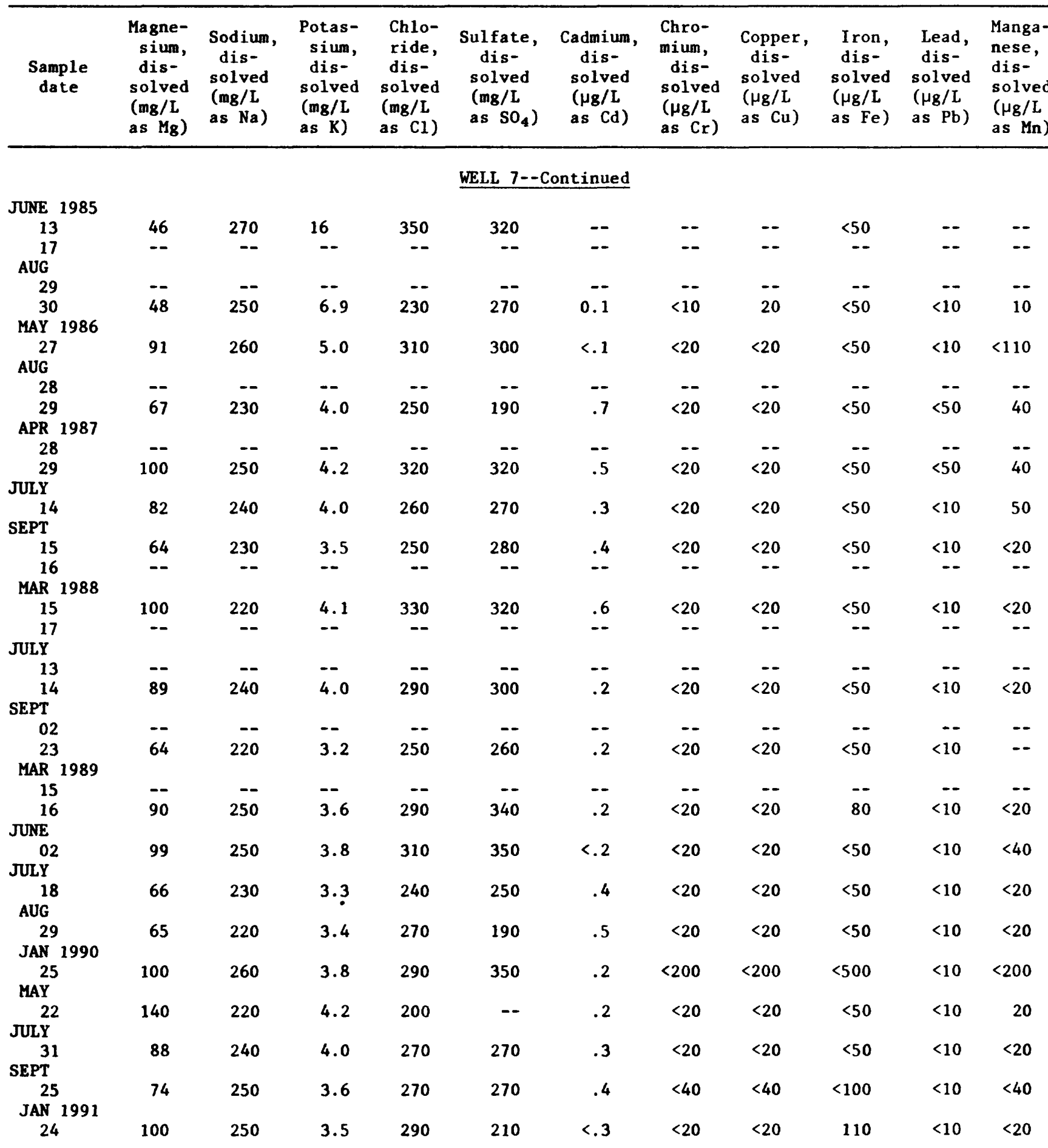


Table 5.--Chemical and bacteriological analyses of water from the observation wells--Continued

\begin{tabular}{|c|c|c|c|c|c|c|c|c|c|c|}
\hline $\begin{array}{r}\text { Sam } \\
\text { da }\end{array}$ & $\begin{array}{l}\text { Nickel, } \\
\text { dis- } \\
\text { solved } \\
(\mu g / L \\
\text { as } N i)\end{array}$ & $\begin{array}{l}\text { Zinc, } \\
\text { dis- } \\
\text { solved } \\
\left(\mu_{g} / L\right. \\
\text { as } \mathrm{Zn})\end{array}$ & $\begin{array}{l}\text { Coli- } \\
\text { form, } \\
\text { fecal } \\
(\text { col./ } \\
100 \mathrm{~mL})\end{array}$ & $\begin{array}{l}\text { Strepto- } \\
\text { cocci, } \\
\text { fecal } \\
(\text { col.l } \\
100 \mathrm{~mL})\end{array}$ & $\begin{array}{c}\text { Dichloro- } \\
\text { bromo- } \\
\text { methane, } \\
\text { total } \\
\left(\mu_{g} / L\right)\end{array}$ & $\begin{array}{c}\text { Carbon } \\
\text { tetra- } \\
\text { chloride, } \\
\text { tota } 1 \\
\left(\mu_{\mathrm{g}} / \mathrm{L}\right)\end{array}$ & $\begin{array}{l}1,2-\mathrm{di}- \\
\text { chloro- } \\
\text { ethane, } \\
\text { total } \\
\left(\mu_{\mathrm{g}} / \mathrm{L}\right)\end{array}$ & $\begin{array}{c}\text { Bromo- } \\
\text { form, } \\
\text { total } \\
\left(\mu_{\mathrm{g}} / \mathrm{L}\right)\end{array}$ & $\begin{array}{l}\text { Chloro- } \\
\text { dibromo- } \\
\text { methane, } \\
\text { total } \\
\left(\mu_{\mathrm{g} / L}\right)\end{array}$ & $\begin{array}{l}\text { Chloro- } \\
\text { form, } \\
\text { total } \\
\left(\mu_{\mathrm{g}} / \mathrm{L}\right)\end{array}$ \\
\hline
\end{tabular}

WELL 7--Continued

JUNE 1985

\begin{tabular}{|c|c|c|c|c|c|c|c|c|c|c|}
\hline JUNE 1985 & & & & & & & & & & \\
\hline 13 & -- & 10 & -- & $=$ & -- & -- & -- & -- & -- & -- \\
\hline 17 & -- & -- & $<1$ & 250 & -- & -- & -- & -- & -- & -- \\
\hline AUG & & & & & & & & & & \\
\hline 29 & - & -- & $<1$ & 30 & - & -- & -- & -- & -- & -- \\
\hline 30 & 190 & $<10$ & -- & -- & - & -- & -- & -- & -- & -- \\
\hline MAY 1986 & & & & & & & & & & \\
\hline 27 & $<30$ & $<20$ & $<1$ & $<1$ & - & -- & -- & -- & -- & -- \\
\hline AUG & & & & & & & & & & \\
\hline 28 & -- & - & $<1$ & 240 & -- & -- & -- & -- & -- & -- \\
\hline 29 & $<20$ & $<20$ & -- & -- & -- & -- & -- & -- & -- & -- \\
\hline APR 1987 & & & & & & & & & & \\
\hline 28 & $-\overline{-}$ & -- & $<1$ & $<1$ & -- & -- & -- & -- & -- & -- \\
\hline 29 & 30 & $<20$ & -- & -- & -- & -- & -- & -- & - & -- \\
\hline JUL1 & & & & & & & & & & \\
\hline SEPT & 30 & $<20$ & $<2$ & $<2$ & -- & $\cdots$ & -- & -- & - & - \\
\hline 15 & 20 & $<20$ & -- & -- & $-\infty$ & -- & -- & -- & -- & -- \\
\hline 16 & -- & -- & $<2$ & $<2$ & -- & -- & -- & -- & -- & -- \\
\hline MAR 1988 & & & & & & & & & & \\
\hline 15 & $<20$ & $<20$ & -- & $\overline{-}$ & -- & -- & -- & -- & -- & -- \\
\hline 17 & - & $-\infty$ & $<2$ & $<2$ & $\cdots$ & - & -- & -- & -- & -- \\
\hline JULY & & & & & & & & & & \\
\hline 13 & $-\overline{-}$ & $-\bar{x}$ & $<2$ & $<2$ & -- & -- & -- & -- & -- & -- \\
\hline 14 & $<20$ & $<20$ & $<2$ & $<2$ & - & -- & -- & -- & -- & -- \\
\hline SEPT & & & & & & & & & & \\
\hline 02 & -- & -- & -- & -- & $<3.0$ & $<3.0$ & $<3.0$ & $<3.0$ & $<3.0$ & $<3.0$ \\
\hline 23 & $<20$ & $<20$ & $<2$ & $<2$ & -- & $\cdots$ & -- & $\cdots$ & -- & $\cdots$ \\
\hline MAR 1989 & & & & & & & & & & \\
\hline 15 & -- & $-\overline{-}$ & $<2$ & 22 & -- & -- & -- & -- & -- & -- \\
\hline 16 & $<20$ & $<20$ & -- & -- & -- & -- & -- & -- & -- & -- \\
\hline JUNE & & & & & & & & & & \\
\hline 02 & $<20$ & $<20$ & $<2$ & 24 & - & $\cdots$ & - & -- & -- & -- \\
\hline JULY & & & & & & & & & & \\
\hline 18 & $<20$ & 20 & $<2$ & $<2$ & -- & - & - & -- & -- & -- \\
\hline AUG & & & & & & & & & & \\
\hline $\begin{array}{l}29 \\
\text { JAN } 1990\end{array}$ & $<20$ & $<20$ & $<2$ & $<2$ & - & -- & -- & -- & -- & -- \\
\hline 25 & $<200$ & 400 & $<20$ & $<20$ & -- & -- & - & -- & -- & -- \\
\hline MAY & & & & & & & & & & \\
\hline 22 & $<20$ & $<20$ & $<20$ & $<20$ & -- & -- & -- & -- & -- & -- \\
\hline JULY & & & & & & & & & & \\
\hline 31 & $<20$ & $<20$ & $<20$ & $<20$ & -- & -- & -- & -- & -- & -- \\
\hline SEPT & & & & & & & & & & \\
\hline 25 & $<40$ & $<40$ & $<20$ & $<20$ & -- & -- & -- & - & -- & -- \\
\hline JAN 1991 & & & & & & & & & & \\
\hline 24 & $<20$ & $<20$ & $<20$ & $<20$ & -- & -- & -- & -- & -- & -- \\
\hline
\end{tabular}


Table 5.--Chemical and bacteriological analyses of water from the observation wells--Continued

\begin{tabular}{|c|c|c|c|c|c|c|c|c|c|c|}
\hline $\begin{array}{c}\text { Sample } \\
\text { date }\end{array}$ & $\begin{array}{c}\text { Toluene, } \\
\text { total } \\
\left(\mu_{g} / L\right)\end{array}$ & $\begin{array}{l}\text { Benzene, } \\
\text { total } \\
\left(\mu_{\mathrm{g}} / \mathrm{L}\right)\end{array}$ & $\begin{array}{l}\text { Chloro- } \\
\text { benzene, } \\
\text { total } \\
\left(\mu_{g} / L\right)\end{array}$ & $\begin{array}{l}\text { Chloro- } \\
\text { ethane, } \\
\text { total } \\
\left(\mu_{g} / L\right)\end{array}$ & $\begin{array}{l}\text { Ethyl- } \\
\text { benzene, } \\
\text { total } \\
\left(\mu_{\mathrm{g}} / \mathrm{L}\right)\end{array}$ & $\begin{array}{l}\text { Methyl- } \\
\text { bromide, } \\
\text { total } \\
\left(\mu_{g} / L\right)\end{array}$ & $\begin{array}{c}\text { Methyl- } \\
\text { chloride, } \\
\text { total } \\
\left(\mu_{\mathrm{g}} / \mathrm{L}\right)\end{array}$ & $\begin{array}{c}\text { Methyl- } \\
\text { ene } \\
\text { chlo- } \\
\text { ride, } \\
\text { total } \\
(\mu \mathrm{g} / \mathrm{L})\end{array}$ & $\begin{array}{l}\text { Tetra- } \\
\text { chloro- } \\
\text { ethyl- } \\
\text { ene, } \\
\text { total } \\
(\mu \mathrm{g} / \mathrm{L})\end{array}$ & $\begin{array}{l}\text { Tri- } \\
\text { chloro- } \\
\text { fluoro- } \\
\text { methane, } \\
\text { total } \\
\left(\mu_{g} / L\right)\end{array}$ \\
\hline
\end{tabular}

\section{WELL 7--Continued}

\begin{tabular}{|c|c|c|c|c|c|c|c|c|c|c|}
\hline \multicolumn{11}{|l|}{ JUNE 1985} \\
\hline 13 & -- & -- & -- & -- & - & -- & -- & - & -- & -- \\
\hline 17 & -- & -- & -- & -- & -- & -- & -- & -- & -- & -- \\
\hline \multicolumn{11}{|l|}{ AUG } \\
\hline 29 & -- & -- & -- & -- & -- & - & -- & -- & -- & -- \\
\hline 30 & -- & -- & -- & -- & -- & -- & -- & -- & -- & -- \\
\hline \multicolumn{11}{|l|}{ MAY 1986} \\
\hline 27 & -- & -- & -- & -- & -- & -- & -- & -- & -- & -- \\
\hline \multicolumn{11}{|l|}{ AUG } \\
\hline 28 & -- & -- & -- & -- & -- & -- & -- & -- & -- & -- \\
\hline 29 & -- & -- & -- & -- & -- & -- & -- & -- & -- & -- \\
\hline \multicolumn{11}{|l|}{ APR 1987} \\
\hline 28 & -- & -- & -- & -- & -- & -- & -- & -- & -- & -- \\
\hline 29 & -- & -- & -- & -- & -- & -- & -- & -- & -- & -- \\
\hline \multicolumn{11}{|l|}{ JULY } \\
\hline 14 & -- & -- & -- & -- & -- & -- & -- & -- & -- & -- \\
\hline \multicolumn{11}{|l|}{ SEPT } \\
\hline 15 & -- & -- & -- & -- & -- & -- & -- & -- & -- & -- \\
\hline $\operatorname{MAR}^{16} 1988$ & -- & -- & -- & -- & -- & -- & -- & -- & -- & -- \\
\hline 15 & -- & -- & -- & -- & -- & -- & -- & -- & -- & -- \\
\hline 17 & -- & -- & -- & -- & -- & -- & -- & -- & -- & -- \\
\hline \multicolumn{11}{|l|}{ JULY } \\
\hline 13 & -- & -- & -- & -- & -- & -- & -- & -- & -- & -- \\
\hline 14 & -- & -- & -- & -- & -- & -- & -- & -- & -- & -- \\
\hline \multicolumn{11}{|l|}{ SEPT } \\
\hline 02 & $<3.0$ & $<3.0$ & $<3.0$ & $<3.0$ & $<3.0$ & $<3.0$ & $<3.0$ & $<3.0$ & $<3.0$ & $<3.0$ \\
\hline 23 & -- & -- & -- & -- & -- & -- & -- & -- & -- & -- \\
\hline
\end{tabular}


Table 5.--Chemical and bacteriological analyses of water from the observation wells--Continued

\begin{tabular}{|c|c|c|c|c|c|c|c|c|c|c|}
\hline $\begin{array}{c}\text { Sample } \\
\text { date }\end{array}$ & $\begin{array}{c}1,1-\text { di- } \\
\text { chloro- } \\
\text { ethane, } \\
\text { total } \\
(\mu g / L)\end{array}$ & $\begin{array}{l}\text { 1, 1-di- } \\
\text { chloro- } \\
\text { ethyl- } \\
\text { ene, } \\
\text { total } \\
\left(\mu_{g} / L\right)\end{array}$ & $\begin{array}{c}1,1,1- \\
\text { tri- } \\
\text { chloro- } \\
\text { ethane, } \\
\text { total } \\
(\mu g / L)\end{array}$ & $\begin{array}{c}1,1,2- \\
\text { tri- } \\
\text { chloro- } \\
\text { ethane, } \\
\text { total } \\
\left(\mu_{g} / L\right)\end{array}$ & $\begin{array}{l}1,1,2,2 \\
\text { tetra- } \\
\text { chloro- } \\
\text { ethane, } \\
\text { total } \\
(\mu \mathrm{g} / \mathrm{L})\end{array}$ & $\begin{array}{l}1,2-d i- \\
\text { chloro- } \\
\text { benzene, } \\
\text { total } \\
(\mu \mathrm{g} / \mathrm{L})\end{array}$ & $\begin{array}{l}1,2-\text { di- } \\
\text { chloro- } \\
\text { propane, } \\
\text { total } \\
\left(\mu_{\mathrm{g}} / \mathrm{L}\right)\end{array}$ & $\begin{array}{c}\text { Trans- } \\
1,2-\text { di- } \\
\text { chloro- } \\
\text { ethane, } \\
\text { total } \\
\left(\mu_{g} / L\right)\end{array}$ & $\begin{array}{l}1,3-d i- \\
\text { chloro- } \\
\text { propene, } \\
\text { total } \\
(\mu \mathrm{g} / L)\end{array}$ & $\begin{array}{c}1,3 \text {-di- } \\
\text { chloro- } \\
\text { benzene, } \\
\text { total } \\
\left(\mu_{g} / L\right)\end{array}$ \\
\hline
\end{tabular}

WELL 7--Continued

JUNE 1985

\begin{tabular}{|c|c|c|c|c|c|c|c|c|c|c|}
\hline 13 & -- & - & -- & -- & -- & -- & -- & -- & -- & -- \\
\hline 17 & -- & -- & -- & -- & -- & -- & -- & -- & -- & -- \\
\hline \multicolumn{11}{|l|}{ AUG } \\
\hline 29 & -- & -- & -- & -- & -- & -- & -- & -- & -- & -- \\
\hline 30 & -- & -- & -- & -- & -- & -- & -- & -- & -- & -- \\
\hline \multicolumn{11}{|l|}{ MAY 1986} \\
\hline 27 & -- & -- & -- & -- & -- & -- & -- & -- & -- & -- \\
\hline \multicolumn{11}{|l|}{ AUG } \\
\hline 28 & -- & -- & -- & -- & -- & -- & -- & -- & -- & -- \\
\hline 29 & -- & -- & -- & -- & -- & -- & -- & -- & -- & -- \\
\hline \multicolumn{11}{|l|}{ APR 1987} \\
\hline 28 & -- & -- & -- & -- & -- & -- & -- & -- & -- & -- \\
\hline 29 & -- & -- & $-\infty$ & -- & -- & -- & -- & -- & -- & -- \\
\hline \multicolumn{11}{|l|}{ JULY } \\
\hline 14 & -- & -- & -- & -- & -- & -- & -- & -- & -- & -- \\
\hline \multicolumn{11}{|l|}{ SEPT } \\
\hline 15 & -- & -- &.-- & -- & -- & -- & -- & -- & -- & -- \\
\hline 16 & -- & -- & -- & -- & - & -- & -- & -- & -- & -- \\
\hline \multicolumn{11}{|l|}{ MAR 1988} \\
\hline 15 & -- & -- & $-\infty$ & -- & -- & -- & -- & -- & -- & -- \\
\hline 17 & -- & -- & -- & -- & -- & -- & -- & -- & -- & -- \\
\hline \multicolumn{11}{|l|}{ JULY } \\
\hline 13 & -- & -- & -- & -- & -- & -- & -- & -- & -- & -- \\
\hline 14 & -- & -- & -- & -- & -- & -- & -- & -- & -- & -- \\
\hline \multicolumn{11}{|l|}{ SEPT } \\
\hline 02 & $<3.0$ & $<3.0$ & $<3.0$ & $<3.0$ & $<3.0$ & $<3.0$ & $<3.0$ & $<3.0$ & $<3.0$ & $<3.0$ \\
\hline 23 & -- & -- & -- & -- & -- & -- & -- & -- & -- & 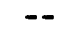 \\
\hline
\end{tabular}


Table 5.--Chemical and bacteriological analyses of water from the observation wells--Continued

\begin{tabular}{|c|c|c|c|c|c|c|c|c|c|}
\hline $\begin{array}{c}\text { Sample } \\
\text { date }\end{array}$ & $\begin{array}{l}1,4,-\mathrm{di}- \\
\text { chloro- } \\
\text { benzene, } \\
\text { total } \\
(\mu \mathrm{L} / \mathrm{L})\end{array}$ & $\begin{array}{l}\text { 2-chloro- } \\
\text { ethyl- } \\
\text { vinyl- } \\
\text { ether, } \\
\text { total } \\
(\mu \mathrm{g} / \mathrm{L})\end{array}$ & $\begin{array}{c}\text { Dichloro- } \\
\text { difluoro- } \\
\text { methane, } \\
\text { total } \\
(\mu g / L)\end{array}$ & $\begin{array}{l}\text { Trans- } \\
1,3-\text { di - } \\
\text { chloro- } \\
\text { propene, } \\
\text { total } \\
\left(\mu_{8} / \mathrm{L}\right)\end{array}$ & $\begin{array}{l}\text { Cis- } \\
1,3-d i- \\
\text { chloro- } \\
\text { propene, } \\
\text { total } \\
(\mu \mathrm{g} / \mathrm{L})\end{array}$ & $\begin{array}{c}\text { Vinyl } \\
\text { chloride, } \\
\text { total } \\
\left(\mu_{\mathrm{g}} / \mathrm{L}\right)\end{array}$ & $\begin{array}{c}\text { Tri- } \\
\text { chloro- } \\
\text { ethylene, } \\
\text { total } \\
(\mu \mathrm{g} / L)\end{array}$ & $\begin{array}{l}\text { Styrene, } \\
\text { total } \\
(\mu \mathrm{g} / \mathrm{L})\end{array}$ & $\begin{array}{c}\text { Xylene, } \\
\text { total } \\
\text { tot rec } \\
(\mu \mathrm{g} / \mathrm{L})\end{array}$ \\
\hline
\end{tabular}

\section{WELL 7--Continued}

\begin{tabular}{|c|c|c|c|c|c|c|c|c|c|}
\hline \multirow{2}{*}{\multicolumn{10}{|c|}{ JUNE 1985}} \\
\hline & & & & & & & & & \\
\hline 13 & -- & -- & -- & -- & -- & -- & -- & -- & -- \\
\hline \multirow{2}{*}{\multicolumn{10}{|c|}{ AUG }} \\
\hline & & & & & & & & & \\
\hline 29 & -- & -- & -- & -- & -- & -- & -- & -- & -- \\
\hline 30 & -- & -- & -- & -- & -- & -- & -- & -- & -- \\
\hline \multicolumn{10}{|c|}{ MAY 1986} \\
\hline 27 & -- & -- & -- & -- & -- & -- & -- & -- & -- \\
\hline \multicolumn{10}{|l|}{ AUG } \\
\hline 28 & -- & -- & -- & -- & -- & -- & -- & -- & -- \\
\hline 29 & -- & -- & -- & -- & -- & -- & -- & -- & -- \\
\hline \multicolumn{10}{|c|}{ APR 1987} \\
\hline 28 & -- & -- & -- & -- & -- & -- & -- & -- & -- \\
\hline 29 & -- & -- & -- & -- & -- & -- & -- &.- & -- \\
\hline \multicolumn{10}{|l|}{ JULY } \\
\hline 14 & -- & -- & -- & $\cdots$ & -- & -- & -- & -- & -- \\
\hline \multicolumn{10}{|l|}{ SEPT } \\
\hline 15 & - & -- & -- & -- & -- & -- & -- & -- & -- \\
\hline 16 & -- & -- & -- & -- & -- & -- & -- & -- & -- \\
\hline \multicolumn{10}{|c|}{ MAR 1988} \\
\hline 15 & -- & -- & -- & -- & -- & -- & -- & -- & -- \\
\hline 17 & -- & -- & -- & -- & -- & -- & -- & -- & -- \\
\hline \multicolumn{10}{|l|}{ JULY } \\
\hline 13 & -- & -- & -- & -- & -- & -- & -- & -- & -- \\
\hline 14 & $\cdots$ & -- & -- & -- & -- & -- & -- & -- & -- \\
\hline \multicolumn{10}{|l|}{ SEPT } \\
\hline 02 & $<3.0$ & $<3.0$ & $<3.0$ & $<3.0$ & $<3.0$ & $<3.0$ & $<3.0$ & $<3.0$ & $<3.0$ \\
\hline 23 & -- & - & -- & -- & -- & -- & -- & -- & -- \\
\hline
\end{tabular}


Table 5.--Chemical and bacteriological analyses of water

from the observation wells--Continued

\begin{tabular}{|c|c|c|c|c|c|c|c|c|c|c|}
\hline $\begin{array}{c}\text { Sample } \\
\text { date }\end{array}$ & $\begin{array}{l}\text { Spe- } \\
\text { cific } \\
\text { con- } \\
\text { duct- } \\
\text { ance } \\
(\mu S / c m)\end{array}$ & $\underset{\text { (units) }}{\mathrm{pH}}$ & $\begin{array}{l}\text { Residue } \\
\text { at } \\
105^{\circ} \mathrm{C}, \\
\text { dis- } \\
\text { solved } \\
\text { (mg/L) }\end{array}$ & $\begin{array}{l}\text { Nitrogen, } \\
\text { ammonia, } \\
\text { dis- } \\
\text { solved } \\
\text { (mg/L } \\
\text { as N) }\end{array}$ & $\begin{array}{l}\text { Nitrogen, } \\
\text { nitrite, } \\
\text { dis- } \\
\text { solved } \\
(\mathrm{mg} / \mathrm{L} \\
\text { as } N)\end{array}$ & $\begin{array}{l}\text { Nitrogen, } \\
\text { ammonia, } \\
\text { torganic, } \\
\text { dissolved } \\
\text { (mg/L } \\
\text { as } N \text { ) }\end{array}$ & $\begin{array}{c}\text { Nitrogen, } \\
\mathrm{NO}_{2}+\mathrm{NO}_{3} \\
\text { dis- } \\
\text { solved } \\
(\mathrm{mg} / \mathrm{L} \\
\text { as } \mathrm{N})\end{array}$ & $\begin{array}{l}\text { Phos- } \\
\text { phorus, } \\
\text { ortho, } \\
\text { dissolved } \\
\text { (mg/L } \\
\text { as P) }\end{array}$ & $\begin{array}{l}\text { Hard- } \\
\text { ness, } \\
\text { total } \\
(\mathrm{mg} / \mathrm{L} \\
\text { as } \\
\mathrm{CaCO}_{3} \text { ) }\end{array}$ & $\begin{array}{l}\text { Cal- } \\
\text { cium, } \\
\text { dis- } \\
\text { solved } \\
\text { (mg/L } \\
\text { as } \mathrm{Ca} \text { ) }\end{array}$ \\
\hline & & & & & WELL 8 & & & & & \\
\hline \multicolumn{11}{|l|}{ JUNE 1985} \\
\hline 13 & 3,000 & 9.2 & 2,300 & 0.310 & 0.210 & 2.5 & 30.4 & $<0.020$ & 1,200 & 150 \\
\hline 17 & -- & -- & -- & -- & -- & -- & -- & -- & - & -- \\
\hline \multicolumn{11}{|l|}{ AUG } \\
\hline 29 & -- & -- & -- & -- & -- & -- & -- & -- & -- & -- \\
\hline 30 & 3,000 & 7.6 & 2,320 & .200 & .090 & 2.1 & 28.0 & .100 & 1,200 & 130 \\
\hline MAY 1986 & & & & & & & & & & \\
\hline 27 & 3,400 & 8.1 & 2,390 & $<.100$ & $<.010$ & 1.2 & 30.7 & $<.020$ & 1,200 & 120 \\
\hline \multicolumn{11}{|l|}{ AUG } \\
\hline 28 & -- & -- & -- & -- & -- & -- & -- & -- & -- & -- \\
\hline 29 & 3,600 & 7.6 & 2,220 & $<.100$ & .030 & 2.1 & 45.5 & $<.020$ & 1,100 & 110 \\
\hline \multicolumn{11}{|l|}{ APR 1987} \\
\hline 28 & -- & -- & -- & -- & -- & -- & -- & -- & -- & -- \\
\hline 29 & 2,700 & 7.7 & 2,070 & $<.100$ & $<.010$ & 1.4 & 44.0 & $<.020$ & 1,100 & 110 \\
\hline \multicolumn{11}{|l|}{ JULY } \\
\hline 14 & 3,000 & 7.5 & 2,150 & $<.100$ & $<.010$ & 1.9 & 39.0 & .050 & 1,100 & 110 \\
\hline \multicolumn{11}{|l|}{ SEPT } \\
\hline 15 & 2,900 & 7.5 & 2,250 & $<.100$ & .030 & 1.5 & 28.0 & .020 & 1,100 & 130 \\
\hline $\operatorname{MAR}^{16} 1988$ & - & -- & -- & -- & -- & -- & -- & -- & - & $-\infty$ \\
\hline 15 & 3,750 & 6.0 & 2,590 & $<.100$ & $<.020$ & 3.0 & 25.0 & $<.020$ & 1,300 & 120 \\
\hline 17 & - & - & -- & -- & -- & -- & - & -- & - & - \\
\hline \multicolumn{11}{|l|}{ JULY } \\
\hline 13 & -- & -- & -- & -- & -- & -- & -- & -- & -- & -- \\
\hline 14 & 4,610 & 7.2 & 3,490 & $<.100$ & .020 & 5.8 & 20.0 & .090 & 1,900 & 200 \\
\hline \multicolumn{11}{|l|}{ SEPT } \\
\hline 02 & -- & -- & -- & -- & -- & - & -- & -- & -- & - \\
\hline 23 & 3,790 & 7.4 & 2,780 & $<.100$ & .020 & 1.2 & 26.2 & .050 & 1,400 & 150 \\
\hline \multicolumn{11}{|l|}{ MAR 1989} \\
\hline 15 & - & - & -- & -- & -- & -- & -- & -- & -- & - \\
\hline 16 & 4,160 & 7.5 & 3,050 & $<.100$ & .020 & 1.4 & 41.2 & $<.020$ & 1,600 & 170 \\
\hline \multicolumn{11}{|l|}{ JUNE } \\
\hline 02 & 4,210 & 7.5 & 3,100 & $<.200$ & $<.020$ & .90 & 47.5 & .080 & 1,500 & 160 \\
\hline \multicolumn{11}{|l|}{ JULY } \\
\hline 18 & 4,210 & 7.5 & 3,240 & $<.100$ & $<.020$ & 1.8 & 58.0 & .020 & 1,900 & 300 \\
\hline AUG & & & & & & & & & & \\
\hline $\begin{array}{l}29 \\
\text { JAN } 1990\end{array}$ & 4,100 & 7.5 & 3,190 & $<.100$ & $<.020$ & 2.1 & 70.0 & .060 & 1,600 & 170 \\
\hline MAY & 3,970 & -- & 2,860 & $<.100$ & $<.020$ & 1.6 & 67.9 & $<.020$ & 1,600 & 200 \\
\hline JULY & 3,950 & 7.5 & 2,940 & $<.100$ & $<.020$ & 1.5 & 58.5 & .100 & 1,400 & 160 \\
\hline $\begin{array}{l}31 \\
\text { SEPT }\end{array}$ & 3,890 & 7.5 & 2,940 & $<.100$ & $<.020$ & .90 & 66.1 & .030 & 1,500 & 170 \\
\hline $\begin{array}{c}25 \\
\text { JAN } 1991\end{array}$ & 3,780 & 7.4 & 3,110 & $<.100$ & .030 & 1.9 & 69.4 & $<.020$ & 1,400 & 180 \\
\hline 24 & -- & -- & -- & -- & - & -- & - & -- & -- & -- \\
\hline 25 & 3,940 & 7.6 & 2,930 & .500 & $<.020$ & 1.9 & 48.1 & .240 & 1,400 & 160 \\
\hline
\end{tabular}


Table 5.--Chemical and bacteriological analyses of water from the observation wells--Continued

\begin{tabular}{|c|c|c|c|c|c|c|c|c|c|c|c|}
\hline $\begin{array}{c}\text { Sample } \\
\text { date }\end{array}$ & $\begin{array}{l}\text { Magne- } \\
\text { sium, } \\
\text { dis- } \\
\text { solved } \\
\text { (mg/L } \\
\text { as } \mathrm{Mg})\end{array}$ & $\begin{array}{l}\text { Sodium, } \\
\text { dis- } \\
\text { solved } \\
\text { (mg/L } \\
\text { as } \mathrm{Na} \text { ) }\end{array}$ & $\begin{array}{l}\text { Potas- } \\
\text { sium, } \\
\text { dis- } \\
\text { solved } \\
\text { (mg/L } \\
\text { as } K \text { ) }\end{array}$ & $\begin{array}{l}\text { Chlo- } \\
\text { ride, } \\
\text { dis- } \\
\text { solved } \\
\text { (mg/L. } \\
\text { as Cl) }\end{array}$ & $\begin{array}{c}\text { Sulfate, } \\
\text { dis- } \\
\text { solved } \\
\left(\mathrm{mg}^{-} \mathrm{I}\right. \\
\left.\text { as } \mathrm{SO}_{4}\right)\end{array}$ & $\begin{array}{l}\text { Cadmium, } \\
\text { dis- } \\
\text { solved } \\
\text { ( } \mu_{g} / L \\
\text { as Cd) }\end{array}$ & $\begin{array}{l}\text { Chro- } \\
\text { mium, } \\
\text { dis- } \\
\text { solved } \\
\left(\mu_{g} / L\right. \\
\text { as } C r)\end{array}$ & $\begin{array}{l}\text { Copper, } \\
\text { dis- } \\
\text { solved } \\
\left(\mu_{g} / \mathrm{L}\right. \\
\text { as } \mathrm{Cu})\end{array}$ & $\begin{array}{l}\text { Iron, } \\
\text { dis- } \\
\text { solved } \\
\left(\mu_{g} / \mathrm{L}\right. \\
\text { as Fe) }\end{array}$ & $\begin{array}{l}\text { Lead, } \\
\text { dis- } \\
\text { solved } \\
\left(\mu_{g} / \mathrm{L}\right. \\
\text { as } \mathrm{Pb})\end{array}$ & $\begin{array}{l}\text { Manga- } \\
\text { nese, } \\
\text { dis- } \\
\text { solved } \\
\left(\mu_{g} / L\right. \\
\text { as Mn })\end{array}$ \\
\hline
\end{tabular}

WELL 8--Continued

JUNE 1985

\begin{tabular}{|c|c|c|c|c|c|c|c|c|c|c|c|}
\hline 13 & 190 & 330 & 12 & 390 & 730 & -- & -- & - & $<50$ & -- & $\cdots$ \\
\hline 17 & -- & -- & -- & -- & -- & -- & -- & -- & -- & -- & -- \\
\hline \multicolumn{12}{|l|}{ AUG } \\
\hline 29 & -- & -- & -- & -- & -- & -- & -- & - & -- & -- & -- \\
\hline 30 & 200 & 310 & 5.2 & 370 & 710 & 0.2 & $<10$ & $<10$ & $<50$ & $<10$ & $<10$ \\
\hline MAY 1986 & & & & & & & & & & & \\
\hline 27 & 210 & 330 & 5.0 & 380 & 790 & .2 & $<20$ & $<20$ & $<50$ & $<20$ & $<130$ \\
\hline \multicolumn{12}{|l|}{ AUG } \\
\hline 28 & -- & -- & -- & -- & $\ldots$ & -- & -- & $\ldots$ & -- & -- & -- \\
\hline 29 & 200 & 290 & 4.0 & 290 & 770 & .9 & 100 & $<40$ & 460 & $<100$ & 240 \\
\hline \multicolumn{12}{|l|}{ APR 1987} \\
\hline 28 & -- & -- & -. & $\ldots$ & -- & -- & -. & $\ldots$ & -- & -- & $\ldots$ \\
\hline 29 & 210 & 280 & 2.9 & 310 & 650 & .7 & $<20$ & $<20$ & $<50$ & $<50$ & $<20$ \\
\hline \multicolumn{12}{|l|}{ JULY } \\
\hline 14 & 210 & 290 & 3.7 & 360 & 610 & .3 & $<40$ & $<40$ & $<100$ & $<10$ & 70 \\
\hline SEPT & & & & & & & & & & & \\
\hline 15 & 200 & 290 & 4.5 & 360 & 650 & $<.2$ & $<20$ & $<20$ & $<50$ & $<10$ & 60 \\
\hline 16 & -- & -- & -- & -- & -- & -- & -- & - & -- & -- & -- \\
\hline \multicolumn{12}{|l|}{ MAR 1988} \\
\hline 15 & 250 & 330 & 3.3 & 490 & 830 & .3 & $<20$ & $<20$ & $<50$ & $<10$ & 60 \\
\hline 17 & -- & -- & -- & -- & -- & -- & -- & -- & -- & -- & -- \\
\hline \multicolumn{12}{|l|}{ JULY } \\
\hline 13 & -- & -- & -- & -- & -- & -- & -- & -- & -- & -- & $\cdots$ \\
\hline 14 & 340 & 460 & 10 & 660 & 1,100 & .4 & $<20$ & $<20$ & $<50$ & $<10$ & 90 \\
\hline \multicolumn{12}{|l|}{ SEPT } \\
\hline 02 & -- & $\cdots$ & -- & - & -- & -- & -- & -- & -- & $\cdots$ & - \\
\hline 23 & 260 & 340 & 4.1 & 510 & 950 & .5 & $<20$ & $<20$ & 460 & $<10$ & - \\
\hline \multicolumn{12}{|l|}{ MAR 1989} \\
\hline 15 & -- & -- & -- & -- & - & -- & - & -- & -- & -- & -- \\
\hline 16 & 290 & 350 & 3.5 & 530 & 1,100 & .3 & $<20$ & $<20$ & 120 & $<10$ & 200 \\
\hline \multicolumn{12}{|l|}{ JUNE } \\
\hline JULY & 280 & 350 & 4.4 & 590 & 970 & $<.2$ & $<40$ & $<40$ & $<100$ & $<10$ & 260 \\
\hline $\begin{array}{c}18 \\
\text { AUG }\end{array}$ & 270 & 230 & 2.4 & 470 & 1,000 & .7 & 70 & $<20$ & 180 & $<10$ & 100 \\
\hline $\begin{array}{c}29 \\
\text { JAN } 1990\end{array}$ & 290 & 350 & 4.8 & 490 & 930 & $<.2$ & $<20$ & $<20$ & $<50$ & $<10$ & 170 \\
\hline 25 & 270 & 350 & 2.6 & 500 & 1,000 & .1 & $<200$ & $<200$ & $<500$ & $<10$ & $<200$ \\
\hline \multicolumn{12}{|l|}{ MAY } \\
\hline 22 & 240 & 310 & 3.7 & 260 & - & .2 & $<20$ & $<20$ & $<50$ & $<10$ & 180 \\
\hline \multicolumn{12}{|l|}{ JULY } \\
\hline SEPT & 250 & 380 & 4.4 & 460 & 930 & .3 & $<40$ & $<40$ & $<100$ & $<10$ & 100 \\
\hline 25 & 240 & 370 & 4.6 & 390 & 820 & .5 & $<40$ & $<40$ & 520 & $<10$ & 180 \\
\hline $\begin{array}{l}\text { JAN } 1991 \\
24\end{array}$ & - & -- & -- & -- & $-\pi$ & $\pi$ & & & & 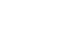 & \\
\hline 25 & 240 & 370 & 3.2 & 430 & 790 & .4 & $<20$ & $<20$ & 90 & $<10$ & 60 \\
\hline
\end{tabular}


Table 5.--Chemical and bacteriological analyses of water from the observation wells--Continued

\begin{tabular}{|c|c|c|c|c|c|c|c|c|c|c|}
\hline $\begin{array}{c}\text { Sample } \\
\text { date }\end{array}$ & $\begin{array}{l}\text { Nickel, } \\
\text { dis- } \\
\text { solved } \\
\left(\mu_{g} / L\right. \\
\text { as } N i)\end{array}$ & $\begin{array}{l}\text { Zinc, } \\
\text { dis- } \\
\text { solved } \\
\left(\mu_{g} / L\right. \\
\text { as } Z n)\end{array}$ & $\begin{array}{l}\text { Coli- } \\
\text { form, } \\
\text { fecal } \\
(\text { col./ } \\
100 \mathrm{~mL})\end{array}$ & $\begin{array}{l}\text { Strepto- } \\
\text { cocci, } \\
\text { fecal } \\
(\text { col./ } \\
100 \mathrm{~mL})\end{array}$ & $\begin{array}{c}\text { Dichloro- } \\
\text { bromo- } \\
\text { methane, } \\
\text { total } \\
(\mu \mathrm{g} / \mathrm{L})\end{array}$ & $\begin{array}{c}\text { Carbon } \\
\text { tetra- } \\
\text { chloride, } \\
\text { total } \\
\left(\mu_{g} / L\right)\end{array}$ & $\begin{array}{l}1,2-d i- \\
\text { chloro- } \\
\text { ethane, } \\
\text { total } \\
\left(\mu_{g} / L\right)\end{array}$ & $\begin{array}{l}\text { Bromo- } \\
\text { form, } \\
\text { total } \\
\left(\mu_{\mathrm{g}} / \mathrm{L}\right)\end{array}$ & $\begin{array}{l}\text { Chloro- } \\
\text { dibromo- } \\
\text { methane, } \\
\text { total } \\
\left(\mu_{\mathrm{g}} / \mathrm{L}\right)\end{array}$ & $\begin{array}{c}\text { Chloro- } \\
\text { form, } \\
\text { total } \\
(\mu \mathrm{g} / L)\end{array}$ \\
\hline
\end{tabular}

WELL 8--Continued

JUNE 1985

\begin{tabular}{|c|c|c|c|c|c|c|c|c|c|c|}
\hline 13 & -- & 10 & -- & -- & -- & -- & -- & -- & -- & -- \\
\hline 17 & -- & -- & $<1$ & 4 & -- & -- & -- & -- & -- & -- \\
\hline \multicolumn{11}{|l|}{ AUG } \\
\hline 29 & -- & -- & $<1$ & $<1$ & -- & -- & -- & -- & -- & -- \\
\hline 30 & $<10$ & 10 & -- & -- & - & - & -- & -- & -- & -- \\
\hline \multicolumn{11}{|l|}{ MAY 1986} \\
\hline 27 & $<50$ & 10 & $<1$ & 2 & -- & -- & -- & -- & -- & -- \\
\hline \multicolumn{11}{|l|}{ AUG } \\
\hline 28 & -- & -- & $<1$ & 32 & -- & -- & -- & -- & -- & -- \\
\hline 29 & 100 & 60 & -- & -- & -- & -- & -- & -- & -- & -- \\
\hline \multicolumn{11}{|l|}{ APR 1987} \\
\hline 28 & -- & -- & $<1$ & $<1$ & -- & -- & -- & - & -- & -- \\
\hline 29 & 40 & $<20$ & -- & -- & -- & - & -- & -- & -- & -- \\
\hline \multicolumn{11}{|l|}{ JULY } \\
\hline 14 & 50 & $<40$ & -- & -- & -- & -- & -- & -- & -- & -- \\
\hline \multicolumn{11}{|l|}{ SEPT } \\
\hline 15 & 60 & $<20$ & -- & -- & -- & -- & -- & -- & -- & -- \\
\hline 16 & -- & -- & $<2$ & $<2$ & - & -- & -- & -- & -- & -- \\
\hline \multicolumn{11}{|l|}{ MAR 1988} \\
\hline 15 & 40 & $<20$ & -- & -- & -- & -- & -- & -- & -- & -- \\
\hline 17 & -- & -- & $<2$ & 18 & $\cdots$ & -- & -- & -- & -- & -- \\
\hline \multicolumn{11}{|l|}{ JULY } \\
\hline 13 & -- & -- & 82 & 170 & -- & -- & -- & -- & $\cdots$ & -- \\
\hline 14 & 40 & $<20$ & -- & -- & -- & -- & -- & -- & -- & - \\
\hline \multicolumn{11}{|l|}{ SEPT } \\
\hline 02 & -- & -- & -- & -- & $<3.0$ & $<3.0$ & $<3.0$ & $<3.0$ & $<3.0$ & $<3.0$ \\
\hline 23 & $<20$ & $<20$ & 4 & 24 & -- & -- & -- & -- & -- & -- \\
\hline \multicolumn{11}{|l|}{ MAR 1989} \\
\hline 15 & -- & -- & $<2$ & 13 & - & -- & -- & -- & - & -- \\
\hline 16 & 20 & 40 & -- & -- & - & -- & -- & -- & -- & -- \\
\hline \multicolumn{11}{|l|}{ JUNE } \\
\hline 02 & $<20$ & $<20$ & $<2$ & 13 & -- & -- & -- & -- & -- & -- \\
\hline \multicolumn{11}{|l|}{ JULY } \\
\hline 18 & 40 & 120 & $<2$ & $<2$ & -- & -- & - & -- & -- & -- \\
\hline \multicolumn{11}{|l|}{ AUG } \\
\hline 29 & 50 & 70 & $<2$ & $<2$ & - & -- & -- & -- & -- & -- \\
\hline \multicolumn{11}{|l|}{ JAN 1990} \\
\hline 25 & $<200$ & 400 & $<20$ & $<20$ & -- & -- & -- & -- & -- & -- \\
\hline \multicolumn{11}{|l|}{ MAY } \\
\hline 22 & $<20$ & $<20$ & $<20$ & 13 & -- & -- & -- & -- & -- & -- \\
\hline \multicolumn{11}{|l|}{ JULY } \\
\hline 31 & 50 & $<40$ & $<20$ & $<20$ & - & -- & - & -- & -- & -- \\
\hline \multicolumn{11}{|l|}{ SEPT } \\
\hline 25 & $<40$ & $<40$ & $<20$ & $<20$ & $\cdots$ & -- & -- & -- & -- & -- \\
\hline \multicolumn{11}{|l|}{ JAN 1991} \\
\hline 24 & $\overline{-}$ & $-\overline{0}$ & $<20$ & 18 & -- & -- & $\cdots$ & -- & -- & -- \\
\hline 25 & 30 & $<20$ & - & -- & $\cdots$ & -- & $\cdots$ & -- & -- & -- \\
\hline
\end{tabular}


Table 5.--Chemical and bacteriological analyses of water from the observation wells--Continued

\begin{tabular}{|c|c|c|c|c|c|c|c|c|c|c|}
\hline $\begin{array}{c}\text { Sample } \\
\text { date }\end{array}$ & $\begin{array}{c}\text { Toluene, } \\
\text { total } \\
\left(\mu_{g} / L\right)\end{array}$ & $\begin{array}{l}\text { Benzene, } \\
\text { total } \\
(\mu \mathrm{g} / \mathrm{L})\end{array}$ & $\begin{array}{l}\text { Chloro- } \\
\text { benzene, } \\
\text { total } \\
(\mu \mathrm{g} / \mathrm{L})\end{array}$ & $\begin{array}{c}\text { Chloro- } \\
\text { ethane, } \\
\text { total } \\
\left(\mu_{g} / L\right)\end{array}$ & $\begin{array}{c}\text { Ethyl- } \\
\text { benzene, } \\
\text { total } \\
(\mu \mathrm{g} / \mathrm{L})\end{array}$ & $\begin{array}{l}\text { Methyl- } \\
\text { bromide, } \\
\text { total } \\
\left(\mu_{g} / L\right)\end{array}$ & $\begin{array}{c}\text { Methyl- } \\
\text { chloride, } \\
\text { total } \\
\left(\mu_{\mathrm{g}} / \mathrm{L}\right)\end{array}$ & $\begin{array}{c}\text { Methyl- } \\
\text { ene } \\
\text { chlo- } \\
\text { ride, } \\
\text { total } \\
(\mu \mathrm{g} / \mathrm{L})\end{array}$ & $\begin{array}{l}\text { Tetra- } \\
\text { chloro- } \\
\text { ethyl- } \\
\text { ene, } \\
\text { total } \\
(\mu \mathrm{g} / \mathrm{L})\end{array}$ & $\begin{array}{l}\text { Tri- } \\
\text { chloro- } \\
\text { fluoro- } \\
\text { methane, } \\
\text { total } \\
(\mu \mathrm{g} / \mathrm{L})\end{array}$ \\
\hline
\end{tabular}

WELL 8--Continued

JUNE 1985

\begin{tabular}{|c|c|c|c|c|c|c|c|c|c|c|}
\hline 13 & -- & -- & -- & -- & -- & -- & - & -- & -- & -- \\
\hline 17 & -- & -- & -- & -- & -- & -- & -- & -- & -- & -- \\
\hline \multicolumn{11}{|l|}{ AUG } \\
\hline 29 & -- & -- & -- & -- & -- & -- & -- & -- & -- & -- \\
\hline 30 & -- & -- & -- & -- & -- & -- & - & -- & -- & -- \\
\hline \multicolumn{11}{|l|}{ MAY 1986} \\
\hline 27 & -- & -- & -- & -- & -- & -- & -- & -- & -- & -- \\
\hline \multicolumn{11}{|l|}{ AUG } \\
\hline 28 & -- & -- & -- & -- & -- & -- & -- & - & -- & -- \\
\hline 29 & -- & -- & -- & -- & - & -- & -- & -- & -- & -- \\
\hline \multicolumn{11}{|l|}{ APR 1987} \\
\hline 28 & -- & -- & -- & -- & -- & -- & -- & - & -- & -- \\
\hline 29 & -- & -- & -- & -- & -- & -- & -- & -- & -- & -- \\
\hline \multicolumn{11}{|l|}{ JULY } \\
\hline 14 & -- & -- & -- & -- & -- & -- & -- & - & -- & -- \\
\hline \multicolumn{11}{|l|}{ SEPT } \\
\hline 15 & -- & -- & -- & -- & -- & -- & -- & -- & - & -- \\
\hline 16 & -- & -- & -- & -- & -- & -- & -- & -- & -- & -- \\
\hline \multicolumn{11}{|l|}{ MAR 1988} \\
\hline 15 & -- & -- & -- & -- & -- & -- & -- & -- & -- & -- \\
\hline 17 & -- & -- & -- & -- & -- & -- & -- & -- & -- & -- \\
\hline \multicolumn{11}{|l|}{ JULY } \\
\hline 13 & -- & -- & -- & -- & -- & - & -- & -- & -- & -- \\
\hline 14 & -- & -- & -- & - & -- & - & -- & - & -- & -- \\
\hline \multicolumn{11}{|l|}{ SEPT } \\
\hline 02 & $<3.0$ & $<3.0$ & $<3.0$ & $<3.0$ & $<3.0$ & $<3.0$ & $<3.0$ & $<3.0$ & $<3.0$ & $<3$. \\
\hline 23 & -- & -- & -- & -- & -- & -- & -- & -- & -- & - \\
\hline
\end{tabular}


Table 5.--Chemical and bacteriological analyses of water from the observation wells--Continued

\begin{tabular}{|c|c|c|c|c|c|c|c|c|c|c|}
\hline $\begin{array}{c}\text { Sample } \\
\text { date }\end{array}$ & $\begin{array}{l}1,1-\text { di- } \\
\text { chloro- } \\
\text { ethane, } \\
\text { tota } 1 \\
(\mu g / L)\end{array}$ & $\begin{array}{c}1,1-d i- \\
\text { chloro- } \\
\text { ethyl- } \\
\text { ene, } \\
\text { total } \\
(\mu g / L)\end{array}$ & $\begin{array}{c}1,1,1- \\
\text { tri- } \\
\text { chloro- } \\
\text { ethane, } \\
\text { total } \\
\left(\mu_{8} / L\right)\end{array}$ & $\begin{array}{c}1,1,2- \\
\text { tri- } \\
\text { chloro- } \\
\text { ethane, } \\
\text { total } \\
(\mu g / L)\end{array}$ & $\begin{array}{l}1,1,2,2 \\
\text { tetra- } \\
\text { chloro- } \\
\text { ethane, } \\
\text { total } \\
\left(\mu_{g} / L\right)\end{array}$ & $\begin{array}{c}1,2-d i- \\
\text { chloro- } \\
\text { benzene, } \\
\text { total } \\
(\mu \mathrm{g} / \mathrm{L})\end{array}$ & $\begin{array}{l}1,2-\text { di- } \\
\text { chloro- } \\
\text { propane, } \\
\text { total } \\
\left(\mu_{\mathrm{g}} / \mathrm{L}\right)\end{array}$ & $\begin{array}{l}\text { Trans- } \\
1,2-d i- \\
\text { chloro- } \\
\text { ethane, } \\
\text { total } \\
(\mu \mathrm{g} / \mathrm{L})\end{array}$ & $\begin{array}{l}1,3-d i- \\
\text { chloro- } \\
\text { propene, } \\
\text { total } \\
(\mu \mathrm{g} / \mathrm{L})\end{array}$ & $\begin{array}{c}1,3 \text {-di- } \\
\text { chloro- } \\
\text { benzene, } \\
\text { total } \\
\left(\mu_{g} / \mathrm{L}\right)\end{array}$ \\
\hline
\end{tabular}

WELL 8--Continued

JUNE 1985
13
17
AUG


Table 5.--Chemical and bacteriological analyses of water from the observation wells--Continued

\begin{tabular}{|c|c|c|c|c|c|c|c|c|c|c|}
\hline $\begin{array}{c}\text { Sample } \\
\text { date }\end{array}$ & $\begin{array}{c}1,4,- \text { di- } \\
\text { chloro- } \\
\text { benzene, } \\
\text { total } \\
\left(\mu_{g} / L\right)\end{array}$ & $\begin{array}{l}\text { 2-chloro- } \\
\text { ethyl- } \\
\text { vinyl- } \\
\text { ether, } \\
\text { total } \\
(\mu \mathrm{g} / \mathrm{L})\end{array}$ & $\begin{array}{c}\text { Dichloro- } \\
\text { difluoro- } \\
\text { methane, } \\
\text { total } \\
(\mu \mathrm{g} / \mathrm{L})\end{array}$ & $\begin{array}{c}\text { Trans- } \\
1,3-\text { di- } \\
\text { chloro- } \\
\text { propene, } \\
\text { total } \\
\left(\mu_{\mathrm{g} / L}\right)\end{array}$ & $\begin{array}{l}\text { Cis- } \\
1,3-\text { di- } \\
\text { chloro- } \\
\text { propene, } \\
\text { total } \\
\left(\mu_{g} / L\right)\end{array}$ & $\begin{array}{l}\text { Vinyl } \\
\text { chlo- } \\
\text { ride, } \\
\text { total } \\
(\mu g / L)\end{array}$ & $\begin{array}{c}\text { Tri- } \\
\text { chloro- } \\
\text { ethyl- } \\
\text { ene, } \\
\text { total } \\
(\mu g / L)\end{array}$ & $\begin{array}{l}\text { Sty- } \\
\text { rene, } \\
\text { total } \\
(\mu \mathrm{g} / \mathrm{L})\end{array}$ & $\begin{array}{c}1,2- \\
\text { dibromo- } \\
\text { ethane, } \\
\text { total } \\
(\mu \mathrm{g} / \mathrm{L})\end{array}$ & $\begin{array}{l}\text { Xylene, } \\
\text { total } \\
\text { tot rec } \\
(\mu \mathrm{g} / \mathrm{L})\end{array}$ \\
\hline \multicolumn{11}{|c|}{ WELL 8--Continued } \\
\hline JUNE 1985 & & & & & & & & & & \\
\hline 13 & -- & -- & -- & -- & - & - & -- & -- & -- & -- \\
\hline 17 & - & -- & -- & -- & -- & -- & -- & -- & -- & -- \\
\hline \multicolumn{11}{|l|}{ AUG } \\
\hline 29 & -- & -- & -- & -- & -- & -- & -- & -- & -- & -- \\
\hline 30 & - & -- & -- & -- & -- & - & -- & - & -- & -- \\
\hline MAY 1986 & & & & & & & & & & \\
\hline 27 & -- & -- & -- & -- & -- & -- & -- & -- & -- & -- \\
\hline \multicolumn{11}{|l|}{ AUG } \\
\hline 28 & -- & -- & -- & -- & -- & -- & -- & $\cdots$ & -- & -- \\
\hline 29 & -- & -- & -- & -- & - & -- & -- & -- & -- & -- \\
\hline \multicolumn{11}{|l|}{ APR 1987} \\
\hline 28 & -- & -- & -- & -- & -- & - & -- & -- & -- & -- \\
\hline 29 & -- & -- & -- & -- & -- & -. & -- & -- & -- & -- \\
\hline \multicolumn{11}{|l|}{ JULY } \\
\hline 14 & -- & -- & -- & -- & -- & -- & -- & -- & -- & -- \\
\hline \multicolumn{11}{|l|}{ SEPT } \\
\hline 15 & -- & -- & -- & -- & -- & -- & -- & -- & -- & -- \\
\hline 16 & -- & - & -- & -- & - & -- & -- & -- & -- & -- \\
\hline \multicolumn{11}{|l|}{ MAR 1988} \\
\hline 15 & -- & -- & -- & -- & -- & -- & -- & -- & -- & -- \\
\hline 17 & -- & -- & -- & -- & -- & -- & -- & -- & -- & -- \\
\hline \multicolumn{11}{|l|}{ JULY } \\
\hline 13 & -- & -- & -- & -- & -- & -- & -- & -- & -- & - \\
\hline 14 & -- & -- & -- & -- & -- & -- & -- & -- & -- & -- \\
\hline \multicolumn{11}{|l|}{ SEPT } \\
\hline 02 & $<3.0$ & $<3.0$ & $<3.0$ & $<3.0$ & $<3.0$ & $<3.0$ & $<3.0$ & $<3.0$ & $<3.0$ & $<3.0$ \\
\hline 23 & -- & -- & -- & -- & -- & -- & -- & -- & -- & -- \\
\hline
\end{tabular}


Table 5.--Chemical and bacteriological analyses of water from the observation wells--Continued

\begin{tabular}{|c|c|c|c|c|c|c|c|c|c|c|}
\hline $\begin{array}{c}\text { Sample } \\
\text { date }\end{array}$ & $\begin{array}{l}\text { Spe- } \\
\text { cific } \\
\text { con- } \\
\text { duct- } \\
\text { ance } \\
(\mu \mathrm{s} / \mathrm{cm})\end{array}$ & $\underset{\text { (units) }}{\mathrm{pH}}$ & $\begin{array}{l}\text { Residue } \\
\text { at } \\
105^{\circ} \mathrm{C}, \\
\text { dis- } \\
\text { solved } \\
(\mathrm{mg} / \mathrm{L})\end{array}$ & $\begin{array}{l}\text { Nitrogen, } \\
\text { ammonia, } \\
\text { dis- } \\
\text { solved } \\
\text { (mg/L } \\
\text { as N) }\end{array}$ & $\begin{array}{l}\text { Nitrogen, } \\
\text { nitrite, } \\
\text { dis- } \\
\text { solved } \\
\text { (mg/L } \\
\text { as } N \text { ) }\end{array}$ & $\begin{array}{l}\text { Nitrogen, } \\
\text { ammonia, } \\
\text { torganic, } \\
\text { dissolved } \\
\text { (mg/L } \\
\text { as } N \text { ) }\end{array}$ & $\begin{array}{c}\text { Nitrogen, } \\
\mathrm{NO}_{2}+\mathrm{NO}_{3} \\
\text { dis- } \\
\text { solved } \\
\text { (mg/L } \\
\text { as } \mathrm{N} \text { ) }\end{array}$ & $\begin{array}{l}\text { Phos- } \\
\text { phorus, } \\
\text { ortho, } \\
\text { dissolved } \\
\text { (mg/L } \\
\text { as P) }\end{array}$ & $\begin{array}{l}\text { Hard- } \\
\text { ness, } \\
\text { total } \\
(\mathrm{mg} / \mathrm{L} \\
\text { as } \\
\left.\mathrm{CaCO}_{3}\right)\end{array}$ & $\begin{array}{l}\text { Cal- } \\
\text { cium, } \\
\text { dis- } \\
\text { solved } \\
\text { (mg/L } \\
\text { as Ca) }\end{array}$ \\
\hline \multicolumn{11}{|c|}{ WELL 9} \\
\hline JUNE 1985 & & & & & & & & & & \\
\hline 13 & 1,500 & -- & 1,070 & 0.100 & 0.240 & 2.6 & 15.2 & $<0.020$ & 540 & 120 \\
\hline 17 & -- & -- & - & -- & -- & -- & -- & -- & -- & -- \\
\hline \multicolumn{11}{|l|}{ AUG } \\
\hline $\mathrm{MAY}_{1986}^{30}$ & 1,590 & 7.4 & 1,060 & .100 & .100 & 1.2 & 25.0 & $<.020$ & 470 & 110 \\
\hline 27 & -- & -- & -- & -- & -- & -- & -- & -- & -- & -- \\
\hline 28 & 2,550 & 7.3 & 1,600 & $<.100$ & .360 & 1.2 & 56.7 & $<.020$ & 740 & 180 \\
\hline \multicolumn{11}{|l|}{ AUG } \\
\hline 28 & -- & $\rightarrow-$ & -- & -- & - & -- & -- & -- & -- & -- \\
\hline 29 & 3,800 & 7.3 & 1,950 & $<.100$ & .020 & 1.4 & 65.7 & $<.020$ & 900 & 210 \\
\hline \multicolumn{11}{|l|}{ APR 1987} \\
\hline 28 & -- & -- & -- & -- & - & -- & - & -- & -- & -- \\
\hline 29 & 1,950 & 7.5 & 1,350 & $<.100$ & $<.010$ & .60 & 47.0 & $<.020$ & 640 & 150 \\
\hline \multicolumn{11}{|l|}{ JULY } \\
\hline $\begin{array}{l}14 \\
\text { SEPT }\end{array}$ & \multicolumn{9}{|c|}{ SEPT } & 150 \\
\hline 15 & 1,850 & 7.4 & 1,270 & $<.100$ & .020 & 1.5 & 36.0 & $<.020$ & 640 & 150 \\
\hline \multicolumn{11}{|l|}{ MAR 1988} \\
\hline 15 & 2,000 & 7.5 & 1,320 & $<.100$ & $<.020$ & .40 & 26.0 & .030 & 660 & 150 \\
\hline 17 & - & - & - & -- & - & -- & - & -- & -- & - \\
\hline \multicolumn{11}{|l|}{ JULY } \\
\hline 13 & -- & -- & -- & -- & - & -- & -- & -- & -- & -- \\
\hline 14 & 1,850 & 7.4 & 1,270 & .100 & .080 & 4.4 & 27.0 & $<.020$ & 600 & 140 \\
\hline \multicolumn{11}{|l|}{ SEPT } \\
\hline 02 & -- & -- & -- & -- & -- & -- & -- & -- & -- & -- \\
\hline 23 & 2,050 & 7.4 & 1,350 & $<.100$ & .110 & .60 & 41.0 & $<.020$ & 700 & 160 \\
\hline \multicolumn{11}{|l|}{ MAR 1989} \\
\hline 15 & -- & -- & -- & - & -- & -- & -- & -- & -- & -- \\
\hline 16 & 2,050 & 7.3 & 1,400 & $<.100$ & .020 & .60 & 38.2 & $<.020$ & 760 & 180 \\
\hline \multicolumn{11}{|l|}{ JUNE } \\
\hline 02 & 1,980 & 7.4 & 1,370 & $<.200$ & .040 & $<.30$ & 41.6 & .050 & 680 & 150 \\
\hline \multicolumn{11}{|l|}{ JULY } \\
\hline AUG $^{18}$ & \multicolumn{7}{|c|}{ AUG } & $<.020$ & 710 & 160 \\
\hline $\begin{array}{c}29 \\
\text { JAN } 1990\end{array}$ & 1,980 & 7.4 & 1,350 & $<.100$ & .110 & 1.0 & 41.5 & $<.020$ & 700 & 150 \\
\hline $\begin{array}{l}25 \\
\text { MAY }\end{array}$ & 2,060 & -- & 1,270 & $<.100$ & .080 & .80 & 62.2 & $<.020$ & 820 & 190 \\
\hline JULY & 2,360 & 7.4 & 1,390 & $<.100$ & .030 & .80 & 56.4 & .030 & 710 & 160 \\
\hline 31 & 2,110 & 7.4 & 1,110 & $<.100$ & .020 & $<.30$ & 68.8 & $<.020$ & 710 & 160 \\
\hline SEPT & & & & & & & & & & \\
\hline $\begin{array}{c}25 \\
\text { JAN } 1991\end{array}$ & 2,110 & 7.3 & 1,500 & $<.100$ & .050 & .80 & 70.6 & $<.020$ & 790 & 170 \\
\hline 24 & -- & -- & - & -- & -- & -- & -- & -- & -- & -- \\
\hline 25 & 2,140 & 7.4 & 1,430 & .300 & $<.020$ & 1.1 & 47.1 & .240 & 760 & 180 \\
\hline
\end{tabular}


Table 5.--Chemical and bacteriological analyses of water

from the observation wells--Continued

\begin{tabular}{|c|c|c|c|c|c|c|c|c|c|c|c|}
\hline $\begin{array}{c}\text { Sample } \\
\text { date }\end{array}$ & $\begin{array}{l}\text { Magne- } \\
\text { sium, } \\
\text { dis- } \\
\text { solved } \\
\text { (mg/L } \\
\text { as Mg) }\end{array}$ & $\begin{array}{l}\text { Sodium, } \\
\text { dis- } \\
\text { solved } \\
\text { (mg/L } \\
\text { as } \mathrm{Na} \text { ) }\end{array}$ & $\begin{array}{l}\text { Potas- } \\
\text { sium, } \\
\text { dis- } \\
\text { solved } \\
\text { (mg/L } \\
\text { as K) }\end{array}$ & $\begin{array}{l}\text { Chlo- } \\
\text { ride, } \\
\text { dis- } \\
\text { solved } \\
\text { (mg/L } \\
\text { as Cl) }\end{array}$ & $\begin{array}{l}\text { Sulfate, } \\
\text { dis- } \\
\text { solved } \\
\text { (mg/L } \\
\text { as } \mathrm{SO}_{4} \text { ) }\end{array}$ & $\begin{array}{c}\text { Cadmium, } \\
\text { dis- } \\
\text { solved } \\
\left(\mu_{g} / L\right. \\
\text { as Cd) }\end{array}$ & $\begin{array}{l}\text { Chro- } \\
\text { mium, } \\
\text { dis- } \\
\text { solved } \\
(\mu g / L \\
\text { as Cr) }\end{array}$ & $\begin{array}{l}\text { Copper, } \\
\text { dis- } \\
\text { solved } \\
(\mu g / L \\
\text { as } C u)\end{array}$ & $\begin{array}{l}\text { Iron, } \\
\text { dis- } \\
\text { solved } \\
(\mu g / L \\
\text { as Fe) }\end{array}$ & $\begin{array}{l}\text { Lead, } \\
\text { dis- } \\
\text { solved } \\
(\mu \mathrm{g} / \mathrm{L} \\
\text { as } \mathrm{Pb})\end{array}$ & $\begin{array}{l}\text { Manga- } \\
\text { nese, } \\
\text { dis- } \\
\text { solved } \\
(\mu g / L \\
\text { as Mn) }\end{array}$ \\
\hline
\end{tabular}

WELL 9--Continued

JUNE 1985

\begin{tabular}{|c|c|c|c|c|c|c|c|c|c|c|c|}
\hline 13 & 56 & 210 & 5.1 & 130 & 500 & -- & $=-$ & -- & 30 & -- & - \\
\hline 17 & -- & -- & -- & -- & -- & -- & - & -- & -- & -- & - \\
\hline \multicolumn{12}{|l|}{ AUG } \\
\hline \multicolumn{11}{|l|}{ MAY 1986} & 630 \\
\hline 27 & -- & - & -- & -- & - & - & - & -- & -- & -- & - \\
\hline 28 & 71 & 240 & 2.0 & 230 & 310 & .3 & $<20$ & $<20$ & $<50$ & $<30$ & $<40$ \\
\hline \multicolumn{12}{|l|}{ AUG } \\
\hline 28 & -- & -- & -- & -- & -- & -- & - & -- & -- & -- & -- \\
\hline \multirow{2}{*}{\multicolumn{12}{|c|}{ APR 1987}} \\
\hline & & & & & & & & & & & \\
\hline 28 & -- & -- & -- & -- & -- & -- & -- & -- & -- & -- & -- \\
\hline 29 & 63 & 180 & 2.2 & 220 & 280 & $<.2$ & $<20$ & $<20$ & $<50$ & $<50$ & $<20$ \\
\hline \multicolumn{12}{|l|}{ JULY } \\
\hline 14 & 69 & 170 & 2.8 & 200 & 260 & .5 & $<20$ & $<20$ & 90 & $<10$ & 270 \\
\hline \multicolumn{12}{|l|}{ SEPT } \\
\hline 15 & 66 & 160 & 2.7 & 190 & 300 & 2.3 & $<20$ & $<20$ & $<50$ & $<10$ & 650 \\
\hline \multirow{2}{*}{\multicolumn{12}{|c|}{ MAR 1988}} \\
\hline & & & & & & & & & & & \\
\hline 15 & 67 & 180 & 2.1 & 220 & 280 & .8 & $<20$ & $<20$ & $<50$ & $<10$ & -- \\
\hline 17 & -- & -- & -- & -- & - & -- & -- & -- & -- & -- & -- \\
\hline \multicolumn{12}{|l|}{ JULY } \\
\hline 13 & -- & -- & -- & -- & -- & -- & -- & -- & -- & -- & -- \\
\hline 14 & 63 & 170 & 3.0 & 200 & 270 & .3 & $<20$ & $<20$ & $<50$ & $<10$ & 180 \\
\hline \multicolumn{12}{|l|}{ SEPT } \\
\hline 02 & -- & -- & -- & -- & -- & -- & -- & -- & -- & -- & - \\
\hline \multicolumn{12}{|l|}{ MAR 1989} \\
\hline 15 & -- & -- & -- & -- & -- & -- & -- & -- & -- & -- & -- \\
\hline 16 & 75 & 160 & 2.7 & 200 & 320 & .1 & $<20$ & $<20$ & $<50$ & $<10$ & 290 \\
\hline \multicolumn{12}{|l|}{ JUNE } \\
\hline 02 & 73 & 160 & 2.8 & 210 & 290 & $<.2$ & $<20$ & $<20$ & $<50$ & $<10$ & 620 \\
\hline \multicolumn{12}{|l|}{ JULY } \\
\hline 18 & 75 & 160 & 2.8 & 190 & 270 & .9 & $<20$ & $<20$ & $<50$ & $<10$ & 790 \\
\hline \multicolumn{12}{|l|}{ AUG } \\
\hline 29 & 76 & 160 & 3.1 & 200 & 210 & $<.2$ & $<20$ & $<20$ & $<50$ & $<10$ & 710 \\
\hline \multicolumn{12}{|l|}{ JAN 1990} \\
\hline 25 & 82 & 160 & 3.3 & 180 & 280 & .3 & $<200$ & 200 & $<500$ & $<10$ & 800 \\
\hline \multicolumn{12}{|l|}{ MAY } \\
\hline 22 & 73 & 150 & 2.7 & 180 & -- & .1 & $<20$ & $<20$ & $<50$ & $<10$ & 650 \\
\hline \multicolumn{12}{|l|}{ JULY } \\
\hline 31 & 77 & 160 & 3.3 & 180 & 250 & .2 & $<20$ & $<20$ & $<50$ & $<10$ & 790 \\
\hline \multicolumn{12}{|l|}{ SEPT } \\
\hline 25 & 86 & 170 & 3.2 & 180 & 200 & .6 & $<40$ & $<40$ & 220 & $<10$ & 860 \\
\hline \multicolumn{12}{|l|}{ JAN 1991} \\
\hline $\begin{array}{l}24 \\
25\end{array}$ & $\overline{74}$ & $\overline{170}$ & $2 .-\overline{2}$ & $\overline{170}$ & 280 & $-\overline{3}$ & $<\overline{20}$ & $<20$ & $\begin{array}{r}-- \\
<50\end{array}$ & $<10$ & 440 \\
\hline
\end{tabular}


Table 5.--Chemical and bacteriological analyses of water from the observation wells--Continued

\begin{tabular}{|c|c|c|c|c|c|c|c|c|c|c|}
\hline $\begin{array}{c}\text { Sample } \\
\text { date }\end{array}$ & $\begin{array}{l}\text { Nickel, } \\
\text { dis- } \\
\text { solved } \\
\left(\mu_{g} / L\right. \\
\text { as } N i)\end{array}$ & $\begin{array}{l}\text { Zinc, } \\
\text { dis- } \\
\text { solved } \\
\left(\mu_{g} / L\right. \\
\text { as } \mathrm{Zn})\end{array}$ & $\begin{array}{l}\text { Coli- } \\
\text { form, } \\
\text { fecal } \\
\text { (col./ } \\
100 \mathrm{~mL})\end{array}$ & $\begin{array}{c}\text { Strepto- } \\
\text { cocci, } \\
\text { fecal } \\
\text { (col./ } \\
100 \mathrm{~mL} \text { ) }\end{array}$ & $\begin{array}{c}\text { Dichloro- } \\
\text { bromo- } \\
\text { methane, } \\
\text { total } \\
\left(\mu_{\mathrm{g}} / \mathrm{L}\right)\end{array}$ & $\begin{array}{c}\text { Carbon } \\
\text { tetra- } \\
\text { chloride, } \\
\text { total } \\
\left(\mu_{g} / L\right)\end{array}$ & $\begin{array}{l}1,2-\mathrm{di}- \\
\text { chloro- } \\
\text { ethane, } \\
\text { total } \\
\left(\mu_{\mathrm{g}} / \mathrm{L}\right)\end{array}$ & $\begin{array}{c}\text { Bromo- } \\
\text { form, } \\
\text { total } \\
\left(\mu_{g} / L\right)\end{array}$ & $\begin{array}{l}\text { Chloro- } \\
\text { dibromo- } \\
\text { methane, } \\
\text { total } \\
(\mu \mathrm{g} / \mathrm{L})\end{array}$ & $\begin{array}{c}\text { Chloro- } \\
\text { form, } \\
\text { total } \\
\left(\mu_{\mathrm{g} / L}\right)\end{array}$ \\
\hline
\end{tabular}

WELL 9--Continued

JUNE 1985

\begin{tabular}{|c|c|c|c|c|c|c|c|c|c|c|}
\hline 13 & -- & $<20$ & -- & - & - & - & -- & -- & -- & - \\
\hline 17 & $\cdots$ & -- & $<1$ & 4 & - & $\cdots$ & -- & -- & -- & $\cdots$ \\
\hline \multicolumn{11}{|l|}{ AUG } \\
\hline 30 & 210 & 20 & $<1$ & 2 & - & -- & -- & - & - & -- \\
\hline \multicolumn{11}{|l|}{ MAY 1986} \\
\hline 27 & $\cdots$ & -- & $<1$ & $<1$ & - & - & -- & $\ldots$ & -- & - \\
\hline 28 & $<20$ & 20 & -- & -- & - & - & -- & -- & - & -- \\
\hline \multicolumn{11}{|l|}{ AUG } \\
\hline 28 & $\cdots$ & -- & $<1$ & 21 & - & - & - & -- & -- & $\cdots$ \\
\hline 29 & 60 & 60 & - & -- & -- & -- & -- & -- & -- & -- \\
\hline \multicolumn{11}{|l|}{ APR 1987} \\
\hline 28 & - & -- & $<1$ & $<1$ & - & -- & $\cdots$ & - & - & - \\
\hline 29 & 20 & $<20$ & $\cdots$ & - & $\cdots$ & $\cdots$ & $\cdots$ & - & - & - \\
\hline \multicolumn{11}{|l|}{ JULY } \\
\hline 14 & 20 & 40 & $<2$ & $<2$ & -- & $\cdots$ & -- & -- & - & -- \\
\hline \multicolumn{11}{|l|}{ SEPT } \\
\hline 15 & 20 & $<20$ & - & - & - & - & -- & -- & - & -- \\
\hline 16 & -- & - & $<2$ & $<2$ & - & - & -- & - & -- & -- \\
\hline \multicolumn{11}{|l|}{ MAR 1988} \\
\hline 15 & $<20$ & $<20$ & - & $\cdots$ & - & $\cdots$ & - & - & $\cdots$ & -- \\
\hline 17 & - & - & $<2$ & $<2$ & - & - & $\ldots$ & -- & $\cdots$ & - \\
\hline \multicolumn{11}{|l|}{ JULY } \\
\hline 13 & - & -- & $<2$ & $<2$ & $\cdots$ & - & -- & -- & $\cdots$ & $\cdots$ \\
\hline 14 & $<20$ & $<20$ & $\cdots$ & $\ldots$ & - & $\cdots$ & -- & - & -- & -- \\
\hline \multicolumn{11}{|l|}{ SEPT } \\
\hline 02 & -- & $\cdots$ & -- & $\cdots$ & $<3.0$ & $<3.0$ & $<3.0$ & $<3.0$ & $<3.0$ & $<3.0$ \\
\hline 23 & $<20$ & $<20$ & $<2$ & $<2$ & -- & - & -- & -- & -- &.- \\
\hline \multicolumn{11}{|l|}{ MAR 1989} \\
\hline 15 & -- & - & $<2$ & $<2$ & - & $\cdots$ & - & - & -- & - \\
\hline 16 & $<20$ & $<20$ & -- & $\cdots$ & $\cdots$ & $\cdots$ & - & $\cdots$ & -- & - \\
\hline \multicolumn{11}{|l|}{ JUNE } \\
\hline 02 & $<20$ & $<20$ & $<2$ & 7 & -- & -- & -- & -- & -- & -- \\
\hline \multicolumn{11}{|l|}{ JULY } \\
\hline 18 & $<20$ & 20 & $<2$ & $<2$ & $\cdots$ & $\cdots$ & $\cdots$ & $\cdots$ & -- & -- \\
\hline \multicolumn{11}{|l|}{ AUG } \\
\hline 29 & $<20$ & 20 & $<2$ & $<2$ & $\cdots$ & $\cdots$ & -- & -- & $\cdots$ & -- \\
\hline \multicolumn{11}{|l|}{ JAN 1990} \\
\hline 25 & $<200$ & 20 & $<20$ & $<20$ & -- & $\cdots$ & -- & -- & - & -- \\
\hline \multicolumn{11}{|l|}{ MAY } \\
\hline 22 & $<20$ & $<20$ & $<20$ & $<20$ & $\cdots$ & $\cdots$ & -- & - & $\cdots$ & -- \\
\hline \multicolumn{11}{|l|}{ JULY } \\
\hline 31 & $<20$ & $<20$ & $<20$ & $<20$ & $\cdots$ & -- & - & -- & $\cdots$ & - \\
\hline \multicolumn{11}{|l|}{ SEPT } \\
\hline \multicolumn{10}{|l|}{ JAN 1991} & - \\
\hline 24 & $\cdots$ & $\cdots$ & $<20$ & 15 & $\cdots$ & $\cdots$ & -- & -- & -- & -- \\
\hline 25 & $<20$ & $<20$ & -- & - & - & -- & -- & -- & -- & -- \\
\hline
\end{tabular}


Table 5.--Chemical and bacteriological analyses of water from the observation wells--Continued

\begin{tabular}{|c|c|c|c|c|c|c|c|c|c|c|}
\hline $\begin{array}{c}\text { Sample } \\
\text { date }\end{array}$ & $\begin{array}{c}\text { Toluene, } \\
\text { total } \\
(\mu \mathrm{g} / \mathrm{L})\end{array}$ & $\begin{array}{c}\text { Benzene, } \\
\text { total } \\
\left(\mu_{8} / L\right)\end{array}$ & $\begin{array}{l}\text { Chloro- } \\
\text { benzene, } \\
\text { total } \\
\left(\mu_{g} / L\right)\end{array}$ & $\begin{array}{l}\text { Chloro- } \\
\text { ethane, } \\
\text { total } \\
\left(\mu_{g} / L\right)\end{array}$ & $\begin{array}{l}\text { Ethyl- } \\
\text { benzene, } \\
\text { total } \\
(\mu \mathrm{g} / \mathrm{L})\end{array}$ & $\begin{array}{l}\text { Methyl- } \\
\text { bromide, } \\
\text { tota1 } \\
\left(\mu_{\mathrm{g}} / \mathrm{L}\right)\end{array}$ & $\begin{array}{l}\text { Methyl- } \\
\text { chloride, } \\
\text { total } \\
\left(\mu_{\mathrm{g}} / \mathrm{L}\right)\end{array}$ & $\begin{array}{l}\text { Methyl- } \\
\text { ene } \\
\text { chlo- } \\
\text { ride, } \\
\text { total } \\
(\mu g / L)\end{array}$ & $\begin{array}{l}\text { Tetra- } \\
\text { chloro- } \\
\text { ethyl- } \\
\text { ene, } \\
\text { total } \\
\left(\mu_{g} / L\right)\end{array}$ & $\begin{array}{l}\text { Tri- } \\
\text { chloro- } \\
\text { fluoro- } \\
\text { methane, } \\
\text { total } \\
(\mu g / L)\end{array}$ \\
\hline
\end{tabular}

WELL 9--Continued

\begin{tabular}{|c|c|c|c|c|c|c|c|c|c|c|}
\hline JNE 1985 & & & & & & & & & & \\
\hline 13 & -- & -- & -- & -- & -- & -- & -- & -- & -- & -- \\
\hline 17 & -- & -- & -- & -- & -- & -- & -- & -- & -- & -- \\
\hline AUG & & & & & & & & & & \\
\hline 30 & -- & - & -- & - & -- & -- & -- & -- & -- & -- \\
\hline MAY 1986 & & & & & & & & & & \\
\hline 27 & -- & -- & -- & -- & -- & -- & -- & -- & -- & -- \\
\hline 28 & -- & -- & - & -- & -- & -- & -- & -- & -- & -- \\
\hline AUG & & & & & & & & & & \\
\hline 28 & -- & - & - & -- & -- & -- & -- & -- & - & -- \\
\hline 29 & -- & - & - & -- & -- & -- & -- & -- & -- & -- \\
\hline APR 1987 & & & & & & & & & & \\
\hline 28 & -- & -. & - & - & -- & -- & -- & -- & -- & - \\
\hline 29 & -- & -- & -- & -- & -- & -- & -- & -- & -- & -- \\
\hline JULY & & & & & & & & & & \\
\hline 14 & -- & -- & -- & - & -- & -- & -- & -- & -- & -- \\
\hline SEPT & & & & & & & & & & \\
\hline 15 & -- & -- & -- & -- & - & -- & -- & -- & -- & -- \\
\hline $\begin{array}{l}16 \\
\text { MAR } 1988\end{array}$ & -- & -- & -- & -- & -- & -- & -- & -- & - & -- \\
\hline $\begin{array}{l}\text { MAR } 1988 \\
15\end{array}$ & -- & -- & -- & -- & -- & -- & -- & -- & -- & -- \\
\hline 17 & -- & -- & -- & -- & -- & -- & -- & -. & -- & -- \\
\hline JULY & & & & & & & & & & \\
\hline 13 & -- & -- & -- & -- & -- & -- & -- & -- & -- & -- \\
\hline 14 & -- & -- & -- & -- & -- & -- & -- & -- & -- & -- \\
\hline SEPT & & & & & & & & & & \\
\hline 02 & $<3.0$ & $<3.0$ & $<3.0$ & $<3.0$ & $<3.0$ & $<3.0$ & $<3.0$ & $<3.0$ & $<3.0$ & $<3.0$ \\
\hline 23 & -- & -- & -- & -- & -- & -- & -- & -- & -- & -- \\
\hline
\end{tabular}


Table 5.--Chemical and bacteriological analyses of water from the observation wells--Continued

\begin{tabular}{|c|c|c|c|c|c|c|c|c|c|c|}
\hline $\begin{array}{c}\text { Sample } \\
\text { date }\end{array}$ & $\begin{array}{l}1,4,-\mathrm{di}- \\
\text { chloro- } \\
\text { benzene, } \\
\text { total } \\
\left(\mu_{\mathrm{g}} / \mathrm{L}\right)\end{array}$ & $\begin{array}{l}\text { 2-chloro- } \\
\text { ethyl- } \\
\text { vinyl- } \\
\text { ether, } \\
\text { total } \\
\left(\mu_{8} / L\right)\end{array}$ & $\begin{array}{c}\text { Dichloro- } \\
\text { difluoro- } \\
\text { methane, } \\
\text { total } \\
\left(\mu_{8} / L\right)\end{array}$ & $\begin{array}{l}\text { Trans- } \\
1,3-\text { di- } \\
\text { chloro- } \\
\text { propene, } \\
\text { total } \\
\left(\mu_{g} / L\right)\end{array}$ & $\begin{array}{l}\text { Cis- } \\
1,3-d i- \\
\text { chloro- } \\
\text { propene, } \\
\text { total } \\
\left(\mu_{8} / L\right)\end{array}$ & $\begin{array}{l}\text { Vinyl } \\
\text { chlo- } \\
\text { ride, } \\
\text { total } \\
(\mu g / L)\end{array}$ & $\begin{array}{c}\text { Tri- } \\
\text { chloro- } \\
\text { ethyl- } \\
\text { ene, } \\
\text { total } \\
\left(\mu_{g} / L\right)\end{array}$ & $\begin{array}{l}\text { Sty- } \\
\text { rene, } \\
\text { total } \\
\left(\mu_{8} / L\right)\end{array}$ & $\begin{array}{l}1,2- \\
\text { dibromo- } \\
\text { ethane, } \\
\text { total } \\
\left(\mu_{8} / L\right)\end{array}$ & $\begin{array}{c}\text { Xylene, } \\
\text { total } \\
\text { tot rec } \\
\left(\mu_{\mathrm{g}} / \mathrm{L}\right)\end{array}$ \\
\hline
\end{tabular}

WELL 9--Continued

JUNE 1985

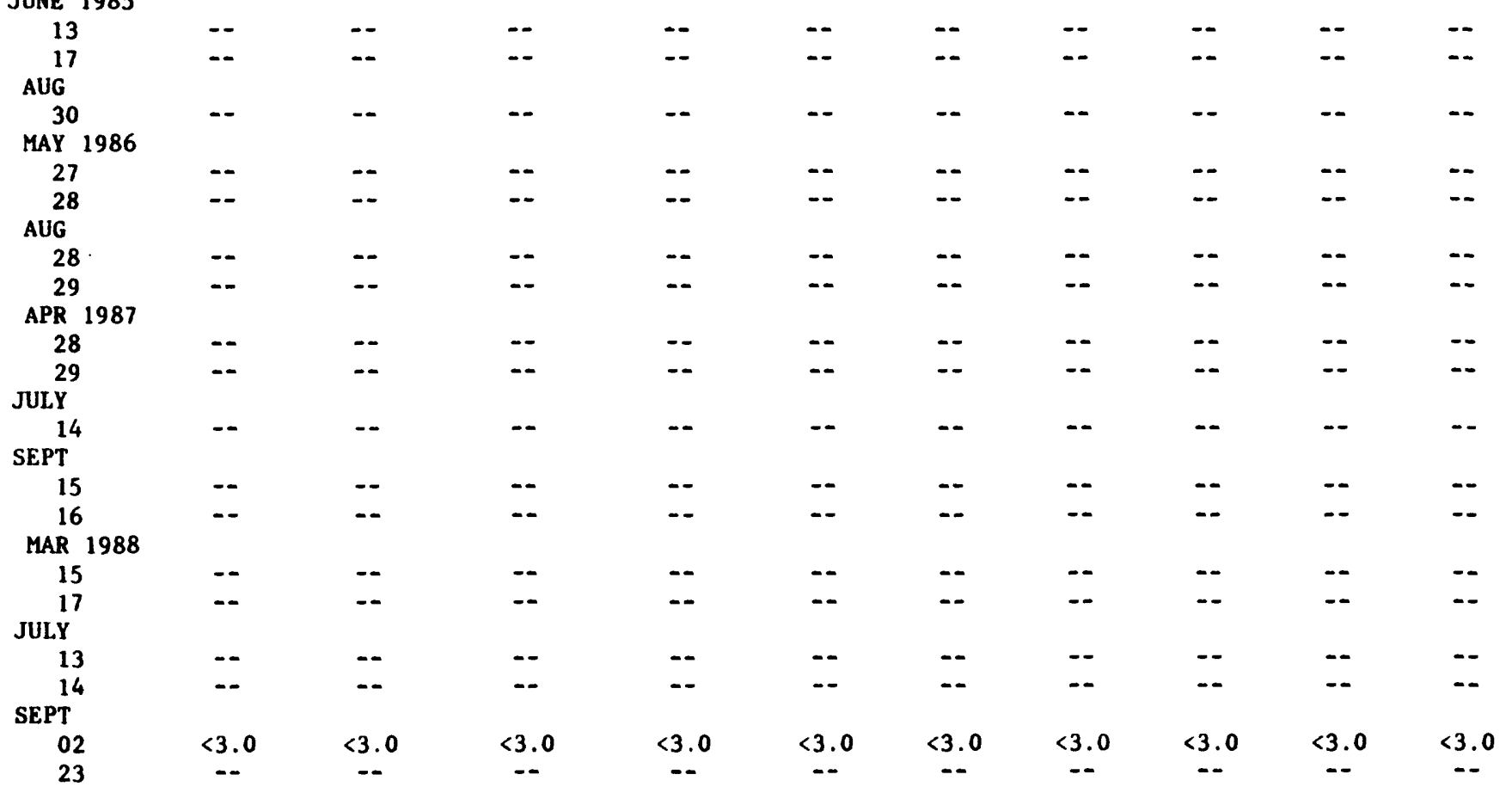


Table 5.--Chemical and bacteriological analyses of water from the observation wells--Continued

\begin{tabular}{|c|c|c|c|c|c|c|c|c|c|c|}
\hline $\begin{array}{c}\text { Sample } \\
\text { date }\end{array}$ & $\begin{array}{c}1,1 \text {-di- } \\
\text { chloro- } \\
\text { ethane, } \\
\text { total } \\
\left(\mu_{g} / L\right)\end{array}$ & $\begin{array}{l}\text { 1,1-di- } \\
\text { chloro- } \\
\text { ethyl- } \\
\text { ene, } \\
\text { total } \\
\left(\mu_{8} / L\right)\end{array}$ & $\begin{array}{c}1,1,1- \\
\text { tri- } \\
\text { chloro- } \\
\text { ethane, } \\
\text { total } \\
\left(\mu_{g} / L\right)\end{array}$ & $\begin{array}{c}1,1,2- \\
\text { tri- } \\
\text { chloro- } \\
\text { ethane, } \\
\text { total } \\
\left(\mu_{8} / L\right)\end{array}$ & $\begin{array}{l}1,1,2,2 \\
\text { tetra- } \\
\text { chloro- } \\
\text { ethane, } \\
\text { total } \\
\left(\mu_{g} / L\right)\end{array}$ & $\begin{array}{c}1,2 \text {-di- } \\
\text { chloro- } \\
\text { benzene, } \\
\text { total } \\
\left(\mu_{\mathrm{g}} / \mathrm{L}\right)\end{array}$ & $\begin{array}{l}1,2-\text { di- } \\
\text { chloro- } \\
\text { propane, } \\
\text { total } \\
\left(\mu_{g} / L\right)\end{array}$ & $\begin{array}{c}\text { Trans- } \\
1,2-d i- \\
\text { chloro- } \\
\text { ethane, } \\
\text { total } \\
(\mu g / L)\end{array}$ & $\begin{array}{l}\text { 1,3-di- } \\
\text { chloro- } \\
\text { propene, } \\
\text { total } \\
\left(\mu_{\mathrm{g}} / \mathrm{L}\right)\end{array}$ & $\begin{array}{c}1,3 \text {-di- } \\
\text { chloro- } \\
\text { benzene, } \\
\text { total } \\
\left(\mu_{\mathrm{g}} / \mathrm{L}\right)\end{array}$ \\
\hline
\end{tabular}

WELL 9--Continued

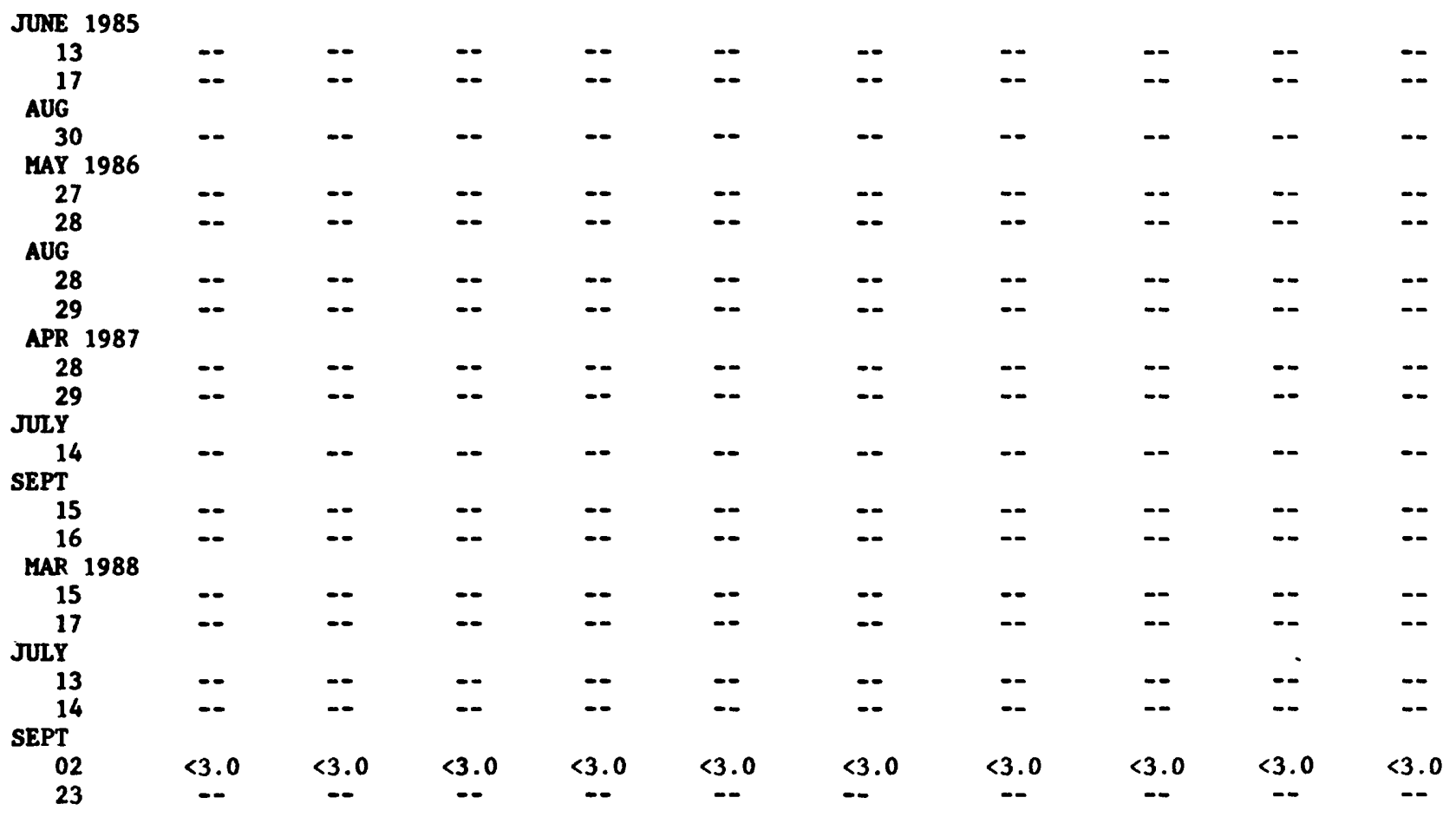


Table 5.--Chemical and bacteriological analyses of water from the observation wells--Continued

\begin{tabular}{|c|c|c|c|c|c|c|c|c|c|}
\hline $\begin{array}{c}\text { Sample } \\
\text { date }\end{array}$ & $\begin{array}{l}\text { Specific } \\
\text { conduct- } \\
\text { ance } \\
(\mu \mathrm{S} / \mathrm{cm})\end{array}$ & $\underset{\text { (units) }}{\mathrm{pH}}$ & $\begin{array}{l}\text { Residue } \\
\text { at } \\
105^{\circ} \mathrm{C}, \\
\text { dis- } \\
\text { solved } \\
\left(\mathrm{mg}_{\mathrm{g}} / \mathrm{L}\right)\end{array}$ & $\begin{array}{l}\text { Nitrogen, } \\
\text { ammonia, } \\
\text { dis- } \\
\text { solved } \\
(\mathrm{mg} / \mathrm{L} \\
\text { as } \mathrm{N})\end{array}$ & $\begin{array}{c}\text { Nitrogen, } \\
\text { nitrite, } \\
\text { dis- } \\
\text { solved } \\
\text { (mg/L } \\
\text { as } N \text { ) }\end{array}$ & $\begin{array}{l}\text { Nitrogen, } \\
\text { ammonia, } \\
\text { torganic, } \\
\text { dissolved } \\
(\mathrm{mg} / \mathrm{L} \\
\text { as } \mathrm{N})\end{array}$ & $\begin{array}{c}\text { Nitrogen, } \\
\mathrm{NO}_{2}+\mathrm{NO}_{3} \\
\text { dis- } \\
\text { solved } \\
(\mathrm{mg} / \mathrm{L} \\
\text { as } \mathrm{N})\end{array}$ & $\begin{array}{l}\text { Phos- } \\
\text { phorus, } \\
\text { ortho, } \\
\text { dissolved } \\
\text { (mg/L } \\
\text { as } \mathrm{P} \text { ) }\end{array}$ & $\begin{array}{l}\text { Hard- } \\
\text { ness, } \\
\text { total } \\
\text { (mg/L } \\
\text { as } \\
\left.\mathrm{CaCO}_{3}\right)\end{array}$ \\
\hline \multicolumn{10}{|c|}{ WELL 10} \\
\hline \multicolumn{10}{|l|}{ JUNE 1985} \\
\hline 14 & $>8,000$ & 8.8 & 12,100 & 0.090 & 1.60 & 12 & 11.5 & $<0.020$ & 3,900 \\
\hline 17 & -- & - & - & - & - & $\ldots$ & - & - & - \\
\hline \multicolumn{10}{|l|}{ AUG } \\
\hline 30 & -- & -- & -- & -- & -- & -- & -- & -- & -- \\
\hline 31 & 14,000 & 7.6 & 11,400 & .100 & .030 & 2.0 & 13.8 & $<.020$ & 3,800 \\
\hline \multicolumn{10}{|l|}{ MAY 1986} \\
\hline 27 & -- & -- & -- & $\therefore$ & -- & -- & - & -- & -- \\
\hline 28 & $>8,000$ & 8.1 & 11,300 & $<.100$ & $<.010$ & 1.8 & 13.7 & $<.020$ & 2,600 \\
\hline \multicolumn{10}{|l|}{ SEPT 1987} \\
\hline 15 & 15,000 & 7.6 & 11,600 & .100 & $<.010$ & 2.0 & 12.2 & $<.020$ & 4,100 \\
\hline 16 & -. & $\ldots$ & - & $\ldots$ & $\ldots$ & $\ldots$ & $=$ & - & $\ldots$ \\
\hline \multicolumn{10}{|l|}{ MAR 1988} \\
\hline 15 & 15,000 & 7.5 & 12,300 & $<.100$ & .040 & 1.8 & 12.6 & $<.020$ & 4,300 \\
\hline 17 & - & - & - & - & - & - & $\ldots$ & - & $\ldots$ \\
\hline \multicolumn{10}{|l|}{ JULY } \\
\hline 13 & $\ldots$ & -- & -- & -- & -- & -- & -- & -- & -- \\
\hline 14 & 12,160 & 7.5 & 12,000 & $<.100$ & $<.010$ & 2.0 & 15.0 & $<.020$ & 4,200 \\
\hline \multicolumn{10}{|l|}{ SEPT } \\
\hline$\stackrel{23}{\text { MAR } 1989}$ & 12,200 & -- & -- & .100 & $<20.0$ & 1.5 & 9.00 & .040 & 4,100 \\
\hline 15 & - & - & - & $\ldots$ & - & -- & -- & -- & -- \\
\hline 16 & 12,500 & 7.4 & 10,700 & $<.100$ & $<.020$ & 1.0 & 12.8 & $<.020$ & 3,700 \\
\hline \multicolumn{10}{|l|}{ JUNE } \\
\hline $\begin{array}{c}02 \\
\text { JULY }\end{array}$ & 11,700 & 7.7 & 12,100 & $<.200$ & $<.020$ & .70 & .700 & .040 & 3,900 \\
\hline 18 & 10,100 & 7.7 & 12,200 & $<.100$ & $<.020$ & 1.5 & 8.50 & $<.020$ & 4,200 \\
\hline \multicolumn{10}{|l|}{ AUG } \\
\hline $\begin{array}{c}29 \\
\text { JAN } 1990\end{array}$ & 12,300 & 7.7 & 12,100 & $<.100$ & $<.020$ & 1.7 & 15.0 & .050 & 4,100 \\
\hline 25 & -- & - & -- & - & -. & -- & -- & -- & -- \\
\hline 26 & 12,500 & 7.3 & 11,500 & $<.100$ & $<.020$ & 1.0 & 13.0 & $<.020$ & 3,900 \\
\hline MAY & & & & & & & & & \\
\hline JULY & 10,000 & 7.6 & 11,900 & .600 & $<.020$ & 1.9 & 9.50 & .090 & 3,900 \\
\hline 31 & 12,400 & 7.6 & 11,800 & $<.100$ & $<.020$ & 1.8 & 13.6 & $<.020$ & 3,500 \\
\hline SEPT & & & & & & & & & \\
\hline $\begin{array}{c}25 \\
\text { JAN } 1991\end{array}$ & 12,400 & 7.5 & 12,300 & $<.100$ & $<.020$ & 1.3 & 17.2 & $<.020$ & 3,700 \\
\hline 24 & 12,900 & 7.6 & 12,200 & $<.100$ & $<.020$ & 1.8 & .600 & .230 & 4,200 \\
\hline
\end{tabular}


Table 5.--Chemical and bacteriological analyses of water

from the observation wells--Continued

\begin{tabular}{|c|c|c|c|c|c|c|c|c|}
\hline $\begin{array}{c}\text { Sample } \\
\text { date }\end{array}$ & $\begin{array}{l}\text { Calcium } \\
\text { dis- } \\
\text { solved } \\
\text { (mg/L } \\
\text { as Ca) }\end{array}$ & $\begin{array}{l}\text { Magne- } \\
\text { sium, } \\
\text { dis- } \\
\text { solved } \\
\text { (mg/L } \\
\text { as } \mathrm{Mg} \text { ) }\end{array}$ & $\begin{array}{l}\text { Sodium, } \\
\text { dis- } \\
\text { solved } \\
\text { (mg/L } \\
\text { as Na) }\end{array}$ & $\begin{array}{l}\text { Potas- } \\
\text { sium, } \\
\text { dis- } \\
\text { solved } \\
\text { (mg/L } \\
\text { as } K \text { ) }\end{array}$ & $\begin{array}{l}\text { Chloride, } \\
\text { dis- } \\
\text { solved } \\
\text { (mg/L } \\
\text { as Cl) }\end{array}$ & $\begin{array}{l}\text { Sulfate, } \\
\text { dis- } \\
\text { solved } \\
\text { (mg/L } \\
\left.\text { as } \mathrm{SO}_{4}\right)\end{array}$ & $\begin{array}{c}\text { Cadmium, } \\
\text { dis- } \\
\text { solved } \\
\left(\mu_{g} / L\right. \\
\text { as Cd) }\end{array}$ & $\begin{array}{c}\text { Chromium, } \\
\text { dis- } \\
\text { solved } \\
(\mu g / L \\
\text { as } C r)\end{array}$ \\
\hline
\end{tabular}

WELL 10--Continued

JUNE 1985

\begin{tabular}{|c|c|c|c|c|c|c|c|c|}
\hline 14 & 350 & 740 & 2,500 & 42 & 1,100 & 7,000 & -- & -- \\
\hline 17 & -- & - & - & -- & - & -- & -- & -- \\
\hline \multicolumn{9}{|l|}{ AUG } \\
\hline 30 & -- & - & - & -- & -- & -- & -- & - \\
\hline 31 & 330 & 720 & 2,300 & 22 & 910 & 6,800 & 0.2 & $<10$ \\
\hline \multicolumn{9}{|l|}{ MAY 1986} \\
\hline 27 & -- & -- & -- & $\cdots$ & $\cdots$ & -- & -- & -- \\
\hline 28 & 300 & 450 & 2,000 & 20 & 800 & 5,900 & $<.1$ & $<20$ \\
\hline \multicolumn{9}{|l|}{ SEPT 1987} \\
\hline 15 & 380 & 760 & 2,000 & 17 & 870 & 6,300 & .4 & $<20$ \\
\hline 16 & - & -- & -- & -- & -- & $\cdots$ & $\cdots$ & -- \\
\hline \multicolumn{9}{|l|}{ MAR 1988} \\
\hline 15 & 410 & 800 & 2,200 & 19 & 890 & 7,000 & 2.6 & $<20$ \\
\hline 17 & - & -- & -- & -- & - & -- & -- & -- \\
\hline \multicolumn{9}{|l|}{ JULY } \\
\hline 13 & -- & -- & $\cdots$ & $\cdots$ & $\cdots$ & -- & -- & -- \\
\hline 14 & 420 & 760 & 2,000 & 17 & 460 & 7,200 & .6 & $<20$ \\
\hline \multicolumn{9}{|l|}{ SEPT } \\
\hline 23 & 410 & 750 & 2,200 & 19 & 990 & 6,900 & .2 & $<20$ \\
\hline \multicolumn{9}{|l|}{ MAR 1989} \\
\hline 13 & & - & - & -- & -- & -- & -- & -- \\
\hline \multirow{2}{*}{\multicolumn{9}{|c|}{ JUNE }} \\
\hline & & & & & & & & \\
\hline 02 & 410 & 710 & 2,200 & 14 & 980 & 6,400 & $<.2$ & $<40$ \\
\hline \multicolumn{9}{|l|}{ JULY } \\
\hline AUG & 850 & 500 & 1,600 & 10 & 1,100 & 6,300 & 1.2 & $<20$ \\
\hline \multicolumn{9}{|l|}{ AUG } \\
\hline \multicolumn{8}{|l|}{ JAN 1990} & $<20$ \\
\hline 25 & - & -- & - & - & -- & -- & -- & - \\
\hline 26 & 420 & 690 & 1,900 & 10 & 1,000 & 6,200 & .4 & $<2,000$ \\
\hline \multicolumn{9}{|l|}{ MAY } \\
\hline 22 & 430 & 680 & 1,900 & 16 & 940 & -- & .3 & 200 \\
\hline \multicolumn{9}{|l|}{ JULY } \\
\hline 31 & 410 & 600 & 1,700 & 15 & 1,100 & 5,500 & .4 & $<60$ \\
\hline \multicolumn{9}{|l|}{ SEPT } \\
\hline $\begin{array}{c}25 \\
\text { JAN } 1991\end{array}$ & 410 & 650 & 1,900 & 14 & 890 & 6,400 & 1.2 & $<200$ \\
\hline 24 & 430 & 760 & 2,200 & 13 & 970 & 6,100 & .7 & $<20$ \\
\hline
\end{tabular}


Table 5.--Chemical and bacteriological analyses of water from the observation wells--Continued

\begin{tabular}{|c|c|c|c|c|c|c|c|c|}
\hline $\begin{array}{c}\text { Sample } \\
\text { date }\end{array}$ & $\begin{array}{l}\text { Copper, } \\
\text { dis- } \\
\text { solved } \\
\left(\mu_{\mathrm{g}} / \mathrm{L}\right. \\
\text { as } \mathrm{Cu})\end{array}$ & $\begin{array}{l}\text { Iron, } \\
\text { dis- } \\
\text { solved } \\
(\mu \mathrm{g} / \mathrm{L} \\
\text { as Fe) }\end{array}$ & $\begin{array}{l}\text { Lead, } \\
\text { dis- } \\
\text { solved } \\
\left(\mu_{g} / L\right. \\
\text { as } \mathrm{Pb})\end{array}$ & $\begin{array}{c}\text { Manga- } \\
\text { nese, } \\
\text { dissolved } \\
\left(\mu_{\mathrm{g}} / \mathrm{L}\right. \\
\text { as } \mathrm{Mn})\end{array}$ & $\begin{array}{l}\text { Nickel, } \\
\text { dis- } \\
\text { solved } \\
\left(\mu_{\mathrm{g}} / \mathrm{L}\right. \\
\text { as } \mathrm{Ni})\end{array}$ & $\begin{array}{l}\text { Zinc, } \\
\text { dis- } \\
\text { solved } \\
\left(\mu_{g} / L\right. \\
\text { as } Z n)\end{array}$ & $\begin{array}{l}\text { Coli- } \\
\text { form, } \\
\text { fecal } \\
\text { (col./ } \\
100 \mathrm{~mL})\end{array}$ & $\begin{array}{c}\text { Strepto- } \\
\text { cocci, } \\
\text { fecal } \\
\text { (col./ } \\
100 \mathrm{~mL} \text { ) }\end{array}$ \\
\hline
\end{tabular}

WELL 10--Continued

JUNE 1985

\begin{tabular}{|c|c|c|c|c|c|c|c|c|}
\hline 14 & -- & 10 & -- & -- & -- & 110 & -- & -- \\
\hline 17 & -- & -- & -- & -- & -- & -- & $<1$ & 8 \\
\hline \multicolumn{9}{|l|}{ AUG } \\
\hline 30 & -- & -- & -- & -- & -- & -- & $<1$ & 20 \\
\hline 31 & 10 & $<50$ & $<10$ & $<20$ & 150 & 80 & -- & -- \\
\hline \multicolumn{9}{|l|}{ MAY 1986} \\
\hline 27 & -- & -- & -- & -- & -- & -- & -- & 350 \\
\hline 28 & $<20$ & $<50$ & $<40$ & $<20$ & $<130$ & 30 & -- & -- \\
\hline \multicolumn{9}{|l|}{ SEPT 1987} \\
\hline 15 & $<20$ & $<50$ & $<10$ & $<20$ & 140 & 20 & -- & -- \\
\hline 16 & -- & -- & -- & -- & -- & -- & -- & 84 \\
\hline \multicolumn{9}{|l|}{ MAR 1988} \\
\hline 15 & $<20$ & 50 & $<10$ & $<20$ & 90 & $<20$ & -- & -- \\
\hline 17 & -- & -- & -- & -- & -- & -- & $<2$ & 2 \\
\hline \multicolumn{9}{|l|}{ JULY } \\
\hline 13 & -- & -- & -- & -- & -- & -- & $<2$ & $<2$ \\
\hline 14 & $<20$ & 50 & $<10$ & $<20$ & 70 & 20 & -- & - \\
\hline \multicolumn{9}{|l|}{ SEPT } \\
\hline$\stackrel{23}{\text { MAR } 1989}$ & $<20$ & $<50$ & $<10$ & -- & 40 & $<20$ & $<2$ & 2 \\
\hline 15 & -- & -- & -- & -- & -- & -- & $<2$ & 50 \\
\hline 16 & $<20$ & 60 & $<10$ & $<20$ & 30 & 40 & -- & - \\
\hline \multicolumn{9}{|l|}{ JUNE } \\
\hline 02 & $<40$ & $<100$ & $<10$ & $<20$ & $<30$ & 40 & $<2$ & 7 \\
\hline \multicolumn{9}{|l|}{ JULY } \\
\hline 18 & $<20$ & $<50$ & $<10$ & $<20$ & $<20$ & $<20$ & $<2$ & $<2$ \\
\hline \multicolumn{9}{|l|}{ AUG } \\
\hline 29 & $<20$ & $<50$ & 12 & $<20$ & $<20$ & 1,500 & $<2$ & $<2$ \\
\hline \multicolumn{9}{|l|}{ JAN 1990} \\
\hline 25 & -- & -- & -- & -- & -- & -- & $<20$ & $<20$ \\
\hline 26 & $<2,000$ & $<5,000$ & $<10$ & $<2,000$ & $<2,000$ & 4 & -- & - \\
\hline \multicolumn{9}{|l|}{ MAY } \\
\hline 22 & $<20$ & $<50$ & $<10$ & $<20$ & 200 & $<20$ & $<20$ & $<20$ \\
\hline \multicolumn{9}{|l|}{ JULY } \\
\hline 31 & $<60$ & $<150$ & $<10$ & $<60$ & 100 & 20 & $<20$ & $<20$ \\
\hline \multicolumn{9}{|l|}{ SEPT } \\
\hline $\begin{array}{c}25 \\
\text { JAN } 1991\end{array}$ & $<200$ & $<500$ & $<10$ & $<200$ & $<200$ & 200 & $<20$ & $<20$ \\
\hline 24 & $<20$ & 250 & $<10$ & $<20$ & 60 & 20 & $<20$ & $<20$ \\
\hline
\end{tabular}


Table 5.--Chemical and bacteriological analyses of water from the observation wells--Continued

\begin{tabular}{|c|c|c|c|c|c|c|c|c|c|}
\hline $\begin{array}{c}\text { Sample } \\
\text { date }\end{array}$ & $\begin{array}{c}\text { Specific } \\
\text { conduct- } \\
\text { ance } \\
(\mu \mathrm{S} / \mathrm{cm})\end{array}$ & $\underset{\text { (units) }}{\mathrm{pH}}$ & $\begin{array}{l}\text { Residue } \\
\text { at } \\
105^{\circ} \mathrm{C}, \\
\text { dis- } \\
\text { solved } \\
(\mathrm{mg} / \mathrm{L})\end{array}$ & $\begin{array}{l}\text { Nitrogen, } \\
\text { ammonia, } \\
\text { dis- } \\
\text { solved } \\
\text { (mg/L } \\
\text { as } N \text { ) }\end{array}$ & $\begin{array}{l}\text { Nitrogen, } \\
\text { nitrite, } \\
\text { dis- } \\
\text { solved } \\
\text { (mg/L } \\
\text { as } \mathrm{N})\end{array}$ & $\begin{array}{l}\text { Nitrogen, } \\
\text { ammonia, } \\
\text { torganic, } \\
\text { dissolved } \\
\text { (mg/L } \\
\text { as } N \text { ) }\end{array}$ & $\begin{array}{c}\mathrm{Nitrogen}, \\
\mathrm{NO}_{2}+\mathrm{NO}_{3} \\
\text { dis- } \\
\text { solved } \\
\text { (mg/L } \\
\text { as } \mathrm{N} \text { ) }\end{array}$ & $\begin{array}{l}\text { Phos- } \\
\text { phorus, } \\
\text { ortho, } \\
\text { dissolved } \\
\text { (mg/L } \\
\text { as } \mathrm{P} \text { ) }\end{array}$ & $\begin{array}{l}\text { Hard- } \\
\text { ness, } \\
\text { total } \\
(\mathrm{mg} / \mathrm{L} \\
\text { as } \\
\left.\mathrm{CaCO}_{3}\right)\end{array}$ \\
\hline \multicolumn{10}{|c|}{ WELL 11} \\
\hline \multicolumn{10}{|l|}{ JUNE 1985} \\
\hline 14 & 1,740 & 8.5 & 1,240 & 0.080 & 4.10 & 35 & 11.3 & $<0.020$ & 720 \\
\hline 17 & - & - & -. & $\ldots$ & - & -. & - & -. & - \\
\hline \multicolumn{10}{|l|}{ AUG } \\
\hline 29 & -- & -- & -- & -- & -- & -- & - & -- & -- \\
\hline $\begin{array}{c}31 \\
\text { MAY } 1986\end{array}$ & 1,700 & 7.4 & 1,190 & .100 & .080 & 2.1 & 20.0 & .100 & 660 \\
\hline 27 & -- & -. & -. & -- & -. & -- & -. & -- & -- \\
\hline$\stackrel{28}{28}{ }_{\text {JULY }} 1987$ & 2,350 & 7.5 & 1,250 & $<.100$ & .010 & .90 & 19.0 & $<.020$ & 660 \\
\hline $\begin{array}{l}15 \\
\text { SEPT }\end{array}$ & 1,900 & 7.1 & 1,310 & 6.80 & .210 & 7.8 & 7.77 & .030 & 640 \\
\hline 15 & 2,300 & 7.3 & 1,280 & .100 & .040 & 1.3 & 18.4 & $<.020$ & 690 \\
\hline 16 & - & -- & - & - & -- & - & -- & -- & -- \\
\hline \multicolumn{10}{|l|}{ MAR 1988} \\
\hline 15 & 1,830 & 7.5 & 1,240 & $<.100$ & .020 & $<.30$ & 17.6 & $<.020$ & 670 \\
\hline 17 & -. & - & $\ldots$ & -- & -- & -- & - & -- & - \\
\hline \multicolumn{10}{|l|}{ JULY } \\
\hline 13 & $\ldots$ & -- & -. & -. & -- & - & -- & -. & - \\
\hline 14 & 1,880 & 7.1 & 1,280 & $<.100$ & $<.010$ & 1.1 & 15.0 & $<.020$ & 690 \\
\hline \multicolumn{10}{|l|}{ SEPT } \\
\hline 22 & 1,970 & 7.4 & 1,300 & $<.100$ & $<.020$ & .30 & 16.3 & .040 & 690 \\
\hline $\begin{array}{c}23 \\
\text { MAR } 1989\end{array}$ & - & - & - & -- & -- & -- & $\cdots$ & -- & - \\
\hline 15 & -- & -- & -- & -- & -- & -- & -- & -- & -- \\
\hline 16 & 2,030 & 7.3 & 1,320 & $<.100$ & $<.020$ & $<.30$ & 15.7 & $<.020$ & 720 \\
\hline \multicolumn{10}{|l|}{ JUNE } \\
\hline JULY & 1,900 & 7.5 & 1,340 & $<.200$ & $<.020$ & $<.30$ & 13.2 & .040 & 670 \\
\hline 18 & 1,960 & 7.5 & 1,360 & $<.100$ & $<.020$ & $<.30$ & 12.9 & $<.020$ & 690 \\
\hline \multicolumn{10}{|l|}{ AUG } \\
\hline $\begin{array}{c}29 \\
\text { JAN } 1990\end{array}$ & 2,030 & 7.5 & 1,350 & $<.100$ & $<.020$ & 1.0 & 18.0 & .040 & 720 \\
\hline MAY & 1,890 & -- & 1,140 & $<.100$ & $<.020$ & .80 & 15.7 & $<.020$ & 740 \\
\hline 22 & 2,100 & $7: 4$ & 1,380 & $<.100$ & $<.020$ & .90 & 13.6 & .040 & $<710$ \\
\hline 23 & -- & -- & - & -- & -- & -- & 17.0 & -- & 700 \\
\hline JULY & & & & & & & & & \\
\hline $\begin{array}{l}31 \\
\text { SEPT }\end{array}$ & 2,140 & 7.4 & 1,370 & $<.100$ & $<.020$ & 4.5 & 18.8 & $<.020$ & 720 \\
\hline$\stackrel{25}{\text { JAN } 1991}$ & 2,150 & 7.4 & 1,510 & $<.100$ & .020 & 1.1 & 16.5 & $<.020$ & 720 \\
\hline 24 & -- & -- & -- & -- & -- & -- & - & -- & -- \\
\hline 25 & 2,230 & 7.4 & 1,410 & $<.100$ & $<.020$ & .90 & 16.3 & .260 & 730 \\
\hline
\end{tabular}


Table 5.--Chemical and bacteriological analyses of water

from the observation wells--Continued

\begin{tabular}{|c|c|c|c|c|c|c|c|c|}
\hline $\begin{array}{c}\text { Sample } \\
\text { date }\end{array}$ & $\begin{array}{l}\text { Calcium } \\
\text { dis- } \\
\text { solved } \\
\text { (mg/L } \\
\text { as Ca) }\end{array}$ & $\begin{array}{l}\text { Magne- } \\
\text { sium, } \\
\text { dis- } \\
\text { solved } \\
\text { (mg/L } \\
\text { as } M g \text { ) }\end{array}$ & $\begin{array}{l}\text { Sodium, } \\
\text { dis - } \\
\text { solved } \\
\text { (mg/L } \\
\text { as } \mathrm{Na} \text { ) }\end{array}$ & $\begin{array}{l}\text { Potas- } \\
\text { sium, } \\
\text { dis- } \\
\text { solved } \\
\text { (mg/L } \\
\text { as } K \text { ) }\end{array}$ & $\begin{array}{c}\text { Chloride, } \\
\text { dis- } \\
\text { solved } \\
\text { (mg/L } \\
\text { as Cl) }\end{array}$ & $\begin{array}{l}\text { Sulfate, } \\
\text { dis- } \\
\text { solved } \\
\left(\mathrm{mg}^{\prime} / \mathrm{L}\right. \\
\left.\text { as } \mathrm{SO}_{4}\right)\end{array}$ & $\begin{array}{l}\text { Cadmium, } \\
\text { dis- } \\
\text { solved } \\
(\mu g / L \\
\text { as Cd) }\end{array}$ & $\begin{array}{c}\text { Chromium, } \\
\text { dis- } \\
\text { solved } \\
\left(\mu_{g} / L\right. \\
\text { as } C r)\end{array}$ \\
\hline
\end{tabular}

WELL 11--Continued

JUNE 1985

\begin{tabular}{|c|c|c|c|c|c|c|c|c|}
\hline 14 & 180 & 66 & 170 & 9.6 & 160 & 460 & -- & -- \\
\hline 17 & -- & -- & -- & -- & - & -- & -- & - \\
\hline \multicolumn{9}{|l|}{ AUG } \\
\hline 29 & $\cdots$ & - & - & -- & $\cdots$ & -- & -- & -- \\
\hline 31 & 170 & 55 & 140 & 5.4 & 150 & 380 & 0.4 & $<10$ \\
\hline \multicolumn{9}{|l|}{ MAY 1986} \\
\hline 27 & -- & -- & -- & -- & -- & -- & -- & -- \\
\hline 28 & 170 & 54 & 150 & 4.0 & 180 & 330 & .2 & $<20$ \\
\hline \multicolumn{9}{|l|}{ JULY 1987} \\
\hline \multicolumn{9}{|l|}{ SEPT } \\
\hline 15 & 180 & 58 & 140 & 5.4 & 200 & 370 & .6 & $<20$ \\
\hline 16 & $\cdots$ & - & -- & -- & $\cdots$ & -- & -- & -- \\
\hline \multicolumn{9}{|l|}{ MAR 1988} \\
\hline 15 & 170 & 57 & 140 & 4.8 & 220 & 330 & .3 & $<20$ \\
\hline 17 & -- & -- & -- & -- & -- & -- & -- & -- \\
\hline \multicolumn{9}{|l|}{ JULY } \\
\hline 13 & -- & -- & - & -- & -- & -- & -- & -- \\
\hline 14 & 180 & 58 & 150 & 5.6 & 230 & 340 & .3 & $<20$ \\
\hline \multicolumn{9}{|l|}{ SEPT } \\
\hline 22 & 180 & 58 & 140 & 4.8 & 270 & 350 & .4 & $<20$ \\
\hline 23 & - & -- & -- & -- & -- & -- & -- & -- \\
\hline \multicolumn{9}{|l|}{ MAR 1989} \\
\hline 15 & $\cdots$ & -- & -- & $\cdots$ & -- & -- & -- & -- \\
\hline 16 & 190 & 59 & 140 & 5.2 & 280 & 350 & .2 & $<20$ \\
\hline \multicolumn{9}{|l|}{ JUNE } \\
\hline 02 & 170 & 58 & 150 & 5.5 & 250 & 370 & $<.2$ & $<20$ \\
\hline \multicolumn{9}{|l|}{ JULY } \\
\hline \multicolumn{8}{|l|}{ AUG } & $<20$ \\
\hline 29 & 190 & 62 & 150 & 5.8 & 280 & 330 & $<.2$ & $<20$ \\
\hline \multicolumn{9}{|l|}{ JAN 1990} \\
\hline$\stackrel{25}{M A Y}$ & 190 & MAY & 170 & 6.0 & 260 & 360 & .3 & $<200$ \\
\hline 22 & 180 & $61^{\circ}$ & 150 & 5.4 & 270 & -- & .1 & $<20$ \\
\hline 23 & 180 & 62 & 160 & 5.9 & 250 & 330 & $<1.0$ & - \\
\hline \multicolumn{9}{|l|}{ JULY } \\
\hline 31 & 190 & 61 & 160 & 6.1 & 330 & 330 & .2 & $<20$ \\
\hline \multicolumn{9}{|l|}{ SEPT } \\
\hline $\begin{array}{c}25 \\
\text { JAN } 1991\end{array}$ & 180 & 63 & 170 & 6.2 & 290 & 360 & .9 & $<40$ \\
\hline 24 & - & - & -- & -- & -- & -- & -- & -- \\
\hline 25 & 190 & 63 & 160 & 5.4 & 330 & 210 & .3 & $<20$ \\
\hline
\end{tabular}


Table 5.--Chemical and bacteriological analyses of water from the observation wells--Continued

\begin{tabular}{|c|c|c|c|c|c|c|c|c|}
\hline $\begin{array}{c}\text { Sample } \\
\text { date }\end{array}$ & $\begin{array}{l}\text { Copper, } \\
\text { dis- } \\
\text { solved } \\
\left(\mu_{g} / L\right. \\
\text { as } \mathrm{Cu})\end{array}$ & $\begin{array}{l}\text { Iron, } \\
\text { dis- } \\
\text { solved } \\
\left(\mu_{\mathrm{g}} / \mathrm{L}\right. \\
\text { as Fe) }\end{array}$ & $\begin{array}{l}\text { Lead, } \\
\text { dis- } \\
\text { solved } \\
\left(\mu_{g} / L\right. \\
\text { as } \mathrm{Pb})\end{array}$ & $\begin{array}{c}\text { Manga- } \\
\text { nese, } \\
\text { dissolved } \\
(\mu g / L \\
\text { as Mn) }\end{array}$ & $\begin{array}{l}\text { Nickel, } \\
\text { dis- } \\
\text { solved } \\
(\mu \mathrm{g} / \mathrm{L} \\
\text { as } \mathrm{Ni})\end{array}$ & $\begin{array}{l}\text { Zinc, } \\
\text { dis- } \\
\text { solved } \\
\left(\mu_{g} / L\right. \\
\left.\text { as } Z_{n}\right)\end{array}$ & $\begin{array}{l}\text { Coli- } \\
\text { form, } \\
\text { fecal } \\
(\text { col. } / \\
100 \mathrm{~mL})\end{array}$ & $\begin{array}{l}\text { Strepto- } \\
\text { cocci, } \\
\text { fecal } \\
(\text { col./ } \\
100 \mathrm{~mL})\end{array}$ \\
\hline
\end{tabular}

\section{WELL 11--Continued}

JUNE 1985

\begin{tabular}{|c|c|c|c|c|c|c|c|c|}
\hline 14 & -- & 30 & -- & -- & -- & 60 & -- & -- \\
\hline 17 & -- & -- & -- & -- & -- & -- & $<1$ & 20 \\
\hline \multicolumn{9}{|l|}{ AUG } \\
\hline 29 & -- & -- & -- & -- & -- & -- & $<1$ & $<1$ \\
\hline 31 & $<10$ & $<50$ & $<10$ & $<10$ & 360 & 50 & -- & -- \\
\hline \multicolumn{9}{|l|}{ MAY 1986} \\
\hline 27 & -- & -- & - & -- & -- & -- & $<1$ & 7 \\
\hline 28 & $<20$ & $<50$ & $<80$ & $<20$ & $<20$ & 20 & -- & -- \\
\hline \multicolumn{9}{|l|}{ JULY 1987} \\
\hline 15 & $<20$ & -- & $<10$ & -- & 20 & 50 & $<2$ & $<2$ \\
\hline \multicolumn{9}{|l|}{ SEPT } \\
\hline 15 & $<20$ & $<50$ & $<10$ & $<20$ & $<20$ & $<20$ & -- & -- \\
\hline 16 & -- & -- & -- & $-\infty$ & -- & -- & -- & 8 \\
\hline \multicolumn{9}{|l|}{ MAR 1988} \\
\hline 15 & $<20$ & $<20$ & $<10$ & $<20$ & $<20$ & $<20$ & -- & -- \\
\hline 17 & -- & -- & -- & -- & - & -- & $<2$ & $<2$ \\
\hline \multicolumn{9}{|l|}{ JULY } \\
\hline 13 & -- & -- & -- & -- & -- & -- & $<2$ & $<2$ \\
\hline 14 & $<20$ & $<50$ & $<10$ & $<20$ & $<20$ & $<20$ & $<2$ & $<2$ \\
\hline \multicolumn{9}{|l|}{ SEPT } \\
\hline 22 & $<20$ & $<50$ & $<10$ & -- & $<20$ & $<20$ & -- & -- \\
\hline 23 & -- & -- & -- & -- & -- & -- & $<2$ & $<2$ \\
\hline \multicolumn{9}{|l|}{ MAR 1989} \\
\hline 15 & -- & -- & -- & -- & -- & -- & $<2$ & 13 \\
\hline 16 & $<20$ & 60 & $<10$ & $<20$ & $<20$ & 20 & -- & -- \\
\hline \multicolumn{9}{|l|}{ JUNE } \\
\hline 02 & $<20$ & $<50$ & $<10$ & $<20$ & $<20$ & $<20$ & $<2$ & $<2$ \\
\hline \multicolumn{9}{|l|}{ JULY } \\
\hline 18 & $<20$ & $<50$ & $<10$ & $<20$ & $<20$ & 20 & $<2$ & 4 \\
\hline \multicolumn{9}{|l|}{ AUG } \\
\hline 29 & $<20$ & $<50$ & $<10$ & $<20$ & $<20$ & 30 & $<2$ & $<2$ \\
\hline \multicolumn{9}{|l|}{ JAN 1990} \\
\hline 25 & $<200$ & $<500$ & $<10$ & $<200$ & $<200$ & -- & $<20$ & $<20$ \\
\hline \multicolumn{9}{|l|}{ MAY } \\
\hline 22 & $<20$ & $<50$ & $<10$ & $<20$ & $<20$ & $<20$ & $<20$ & 1 \\
\hline 23 & -- & $<3$ & $<1$ & 2 & -- & -- & -- & -- \\
\hline \multicolumn{9}{|l|}{ JULY } \\
\hline 31 & $<20$ & $<50$ & $<10$ & $<20$ & $<20$ & $<20$ & $<20$ & $<20$ \\
\hline \multicolumn{9}{|l|}{ SEPT } \\
\hline 25 & $<40$ & $<100$ & $<10$ & $<40$ & $<40$ & $<40$ & $<20$ & $<20$ \\
\hline \multicolumn{9}{|l|}{ JAN 1991} \\
\hline 24 & -- & -- & -- & - & -- & -- & $<20$ & 3 \\
\hline 25 & $<20$ & $<50$ & $<10$ & $<20$ & $<20$ & $<20$ & -- & -- \\
\hline
\end{tabular}


Table 5.--Chemical and bacteriological analyses of water from the observation wells--Continued

\begin{tabular}{|c|c|c|c|c|c|c|c|c|c|}
\hline $\begin{array}{c}\text { Sample } \\
\text { date }\end{array}$ & $\begin{array}{c}\text { Specific } \\
\text { conduct- } \\
\text { ance } \\
(\mu \mathrm{S} / \mathrm{cm})\end{array}$ & $\begin{array}{c}\mathrm{pH} \\
\text { (units) }\end{array}$ & $\begin{array}{c}\text { Residue } \\
\text { at } \\
105^{\circ} \mathrm{C}, \\
\text { dis- } \\
\text { solved } \\
(\mathrm{mg} / \mathrm{L})\end{array}$ & $\begin{array}{l}\text { Nitrogen, } \\
\text { ammonia, } \\
\text { dis- } \\
\text { solved } \\
\text { (mg/L } \\
\text { as } \mathrm{N} \text { ) }\end{array}$ & $\begin{array}{l}\text { Nitrogen, } \\
\text { nitrite, } \\
\text { dis- } \\
\text { solved } \\
\text { (mg/L } \\
\text { as } \mathrm{N} \text { ) }\end{array}$ & $\begin{array}{l}\text { Nitrogen, } \\
\text { ammonia, } \\
\text { torganic, } \\
\text { dissolved } \\
\text { (mg/L } \\
\text { as } \mathrm{N} \text { ) }\end{array}$ & $\begin{array}{c}\text { Nitrogen, } \\
\mathrm{NO}_{2}+\mathrm{NO}_{3} \\
\text { dis- } \\
\text { solved } \\
\text { (mg/L } \\
\text { as } \mathrm{N} \text { ) }\end{array}$ & $\begin{array}{l}\text { Phos- } \\
\text { phorus, } \\
\text { ortho, } \\
\text { dissolved } \\
\text { (mg/L } \\
\text { as P) }\end{array}$ & $\begin{array}{l}\text { Hard- } \\
\text { ness, } \\
\text { total } \\
\text { (mg/L } \\
\text { as } \\
\mathrm{CaCO}_{3} \text { ) }\end{array}$ \\
\hline \multicolumn{10}{|c|}{ WELL 12} \\
\hline \multicolumn{10}{|l|}{ JUNE 1985} \\
\hline 14 & 1,810 & 8.7 & 1,530 & 0.660 & 1.52 & 7.1 & 19.6 & $<0.020$ & 800 \\
\hline 17 & -- & -- & -- & -- & -- & -- & -- & -- & -- \\
\hline \multicolumn{10}{|l|}{ AUG } \\
\hline 30 & -- & -- & -- & -- & -- & -- & -- & -- & -- \\
\hline 31 & 1,900 & 7.7 & 1,520 & .200 & .100 & 1.9 & 28.0 & $<.020$ & 700 \\
\hline \multicolumn{10}{|l|}{ MAY 1986} \\
\hline 27 & $\cdots$ & -- & $=$ & $\cdots$ & -- & -- & -- & -- & -- \\
\hline 28 & 2,000 & 8.0 & 1,540 & $<.100$ & $<.010$ & .90 & 23.3 & $<.020$ & 750 \\
\hline \multicolumn{10}{|l|}{ AUG } \\
\hline $\begin{array}{c}28 \\
\text { APR } 1987\end{array}$ & 1,900 & 7.9 & 1,350 & $<.100$ & .040 & .90 & 41.4 & $<.020$ & 600 \\
\hline 28 & $-\infty$ & -- & -- & -. & -- & - & -. & -- & -- \\
\hline \multicolumn{6}{|c|}{. } & .40 & 31.0 & $<.020$ & 720 \\
\hline $\begin{array}{l}15 \\
\text { SEPT }\end{array}$ & 1,800 & 7.7 & 1,370 & $<.100$ & $<.010$ & 1.0 & 33.0 & $<.020$ & 640 \\
\hline $\begin{array}{l}16 \\
\text { MAR } 1988\end{array}$ & 2,190 & 7.6 & 1,430 & $<.100$ & .020 & .20 & 29.0 & .060 & 680 \\
\hline 15 & 2,100 & 7.5 & 1,570 & $<.100$ & $<.020$ & 1.0 & 22.0 & $<.020$ & 810 \\
\hline 17 & -- & -- & -- & -- & -- & -- & -- & -- & -- \\
\hline \multicolumn{10}{|l|}{ JULY } \\
\hline $\begin{array}{l}13 \\
14\end{array}$ & $1, \overline{440}$ & $7 . \overline{5}$ & $1, \overline{260}$ & $<\overline{100}$ & -- & $\cdots$ & -0 & $\overline{0}$ & $=-$ \\
\hline \multicolumn{8}{|l|}{ SEPT } & & 450 \\
\hline $\begin{array}{l}23 \\
\text { MAR } 1989\end{array}$ & 1,830 & 7.6 & 1,380 & $<.100$ & $<.020$ & $<.30$ & 46.0 & $<.020$ & 650 \\
\hline 15 & -- & -- & -- & -- & - & $\cdots$ & -- & -- & - \\
\hline $\mathrm{JUNE}^{16}$ & 2,180 & 7.5 & 2,190 & $<.100$ & $<.020$ & $<.30$ & 23.2 & $<.020$ & 840 \\
\hline 02 & 1,600 & 7.9 & 1,190 & $<.200$ & $<.020$ & $<.30$ & 48.2 & $<.020$ & 500 \\
\hline \multicolumn{10}{|l|}{ JULY } \\
\hline $\begin{array}{c}18 \\
\text { AUG }\end{array}$ & 1,560 & 7.8 & -- & -- & -- & -- & -- & -- & -- \\
\hline $\begin{array}{c}29 \\
\text { JAN } 1990\end{array}$ & 1,770 & 7.8 & 1,410 & $<.100$ & $<.020$ & .90 & 47.0 & $<.020$ & 570 \\
\hline 25 & -- & -- & -- & -- & -- & -- & -- & - & -- \\
\hline$\underset{\mathrm{MAY}}{26}$ & 2,190 & 7.4 & 1,920 & $<.100$ & $<.020$ & $<.30$ & 22.1 & $<.020$ & 930 \\
\hline 22 & 1,690 & 7.7 & 1,260 & .700 & $<.020$ & .90 & 51.5 & .100 & 510 \\
\hline \multicolumn{10}{|l|}{ JULY } \\
\hline $\begin{array}{c}31 \\
\text { JAN } 1991\end{array}$ & 1,880 & -- & -- & $<.100$ & $<.020$ & $<.30$ & 42.0 & .030 & -- \\
\hline 24 & 2,370 & 7.7 & 1,840 & $<.100$ & $<.020$ & .90 & 19.9 & .190 & 810 \\
\hline
\end{tabular}


Table 5.--Chemical and bacteriological analyses of water from the observation wells--Continued

\begin{tabular}{|c|c|c|c|c|c|c|c|c|}
\hline $\begin{array}{c}\text { Sample } \\
\text { date }\end{array}$ & $\begin{array}{l}\text { Calcium } \\
\text { dis- } \\
\text { solved } \\
\text { (mg/L } \\
\text { as Ca) }\end{array}$ & $\begin{array}{l}\text { Magne- } \\
\text { sium, } \\
\text { dis- } \\
\text { solved } \\
\text { (mg/L } \\
\text { as } M g \text { ) }\end{array}$ & $\begin{array}{l}\text { Sodium, } \\
\text { dis- } \\
\text { solved } \\
\text { (mg/L } \\
\text { as } \mathrm{Na} \text { ) }\end{array}$ & $\begin{array}{l}\text { Potas- } \\
\text { sium, } \\
\text { dis- } \\
\text { solved } \\
\text { (mg/L } \\
\text { as K) }\end{array}$ & $\begin{array}{c}\text { Chloride, } \\
\text { dis- } \\
\text { solved } \\
\text { (mg/L } \\
\text { as C1) }\end{array}$ & $\begin{array}{l}\text { Sulfate, } \\
\text { dis- } \\
\text { solved } \\
\left(\mathrm{mg}^{-} \mathrm{L}\right. \\
\left.\text { as } \mathrm{SO}_{4}\right)\end{array}$ & $\begin{array}{l}\text { Cadmium, } \\
\text { dis- } \\
\text { solved } \\
(\mu g / L \\
\text { as Cd) }\end{array}$ & $\begin{array}{l}\text { Chromium, } \\
\text { dis- } \\
\text { solved } \\
\text { ( } \mu \mathrm{g} / \mathrm{L} \\
\text { as } \mathrm{Cr} \text { ) }\end{array}$ \\
\hline
\end{tabular}

WELL 12--Continued

JUNE 1985

\begin{tabular}{|c|c|c|c|c|c|c|c|c|}
\hline \\
\hline 14 & 170 & 90 & 220 & 9.6 & 120 & 690 & -- & -- \\
\hline 17 & - & -- & - & -- & -. & -- & -- & -. \\
\hline \multicolumn{9}{|l|}{ AUG } \\
\hline 30 & -- & - & -- & -. & - & -- & -- & -- \\
\hline 31 & 140 & 84 & 180 & 5.2 & 84 & 570 & 0.4 & $<10$ \\
\hline \multicolumn{9}{|l|}{ MAY 1986} \\
\hline 27 & - & $\cdots$ & -. & -- & $\cdots$ & $\ldots$ & - & -. \\
\hline 28 & 160 & 88 & 200 & 4.0 & 110 & 640 & .3 & $<20$ \\
\hline \multicolumn{9}{|l|}{ AUG } \\
\hline 28 & 120 & 73 & 180 & 4.0 & 66 & 470 & 1.2 & $<20$ \\
\hline \multicolumn{9}{|l|}{ APR 1987} \\
\hline 28 & - & - & -- & -- & -. & - & -- & -- \\
\hline 29 & 150 & 85 & 180 & 4.5 & 83 & 550 & .3 & $<20$ \\
\hline \multicolumn{9}{|l|}{ JULY } \\
\hline 15 & 130 & 75 & 170 & 4.8 & 74 & 550 & .8 & $<20$ \\
\hline \multicolumn{9}{|l|}{ SEPT } \\
\hline \multirow{2}{*}{\multicolumn{9}{|c|}{ MAR 1988}} \\
\hline & & & & & & & & \\
\hline 15 & 160 & 97 & 200 & 4.8 & 110 & 680 & .6 & $<20$ \\
\hline 17 & $\ldots$ & - & -. & $=$ & - & $\ldots$ & - & - \\
\hline \multicolumn{9}{|l|}{ JULY } \\
\hline 13 & $\ldots$ & -. & - & $\ldots$ & -. & -. & -- & -- \\
\hline 14 & 88 & 56 & 140 & 3.9 & 36 & 340 & .2 & $<20$ \\
\hline \multicolumn{9}{|l|}{ SEPT } \\
\hline 23 & 130 & 76 & 160 & 4.3 & 73 & 510 & .2 & $<20$ \\
\hline \multicolumn{9}{|l|}{ MAR 1989} \\
\hline 15 & -- & - & - & -- & -- & - & -- & -- \\
\hline 16 & 170 & 99 & 190 & 4.9 & 110 & 770 & .5 & $<20$ \\
\hline \multicolumn{9}{|l|}{ JUNE } \\
\hline 02 & 100 & 60 & 170 & 4.4 & 48 & 350 & $<.2$ & $<20$ \\
\hline \multicolumn{9}{|l|}{ JULY } \\
\hline 18 & -- & - & $\ldots$ & - & -. & - & -- & - \\
\hline \multicolumn{9}{|l|}{ AUG } \\
\hline 29 & 120 & 66 & 160 & 4.7 & 100 & 290 & .5 & $<20$ \\
\hline 25 & -- & -. & $\ldots$ & - & -. & - & - & - \\
\hline 26 & 190 & 110 & 210 & 5.3 & 150 & 990 & .2 & $<200$ \\
\hline MAY & & & & & & & & \\
\hline 22 & 100 & 61 & 170 & 4.1 & 44 & - & $<.2$ & $<20$ \\
\hline JULY & & & & & & & & \\
\hline 31 & -- & - & $\ldots$ & -- & 70 & 510 & - & -- \\
\hline $\begin{array}{l}\text { JAN } 1991 \\
24\end{array}$ & 170 & 96 & 190 & 4.6 & 120 & 730 & .5 & $<20$ \\
\hline
\end{tabular}


Table 5.--Chemical and bacteriological analyses of water from the observation wells--Continued

\begin{tabular}{|c|c|c|c|c|c|c|c|c|}
\hline $\begin{array}{c}\text { Sample } \\
\text { date }\end{array}$ & $\begin{array}{l}\text { Copper, } \\
\text { dis- } \\
\text { solved } \\
\text { ( } \mu \mathrm{g} / \mathrm{L} \\
\text { as } \mathrm{Cu})\end{array}$ & $\begin{array}{l}\text { Iron, } \\
\text { dis-- } \\
\text { solved } \\
\text { ( } \mu \mathrm{g} / \mathrm{L} \\
\text { as } \mathrm{Fe})\end{array}$ & $\begin{array}{l}\text { Lead, } \\
\text { dis- } \\
\text { solved } \\
(\mu \mathrm{g} / \mathrm{L} \\
\text { as } \mathrm{Pb})\end{array}$ & $\begin{array}{c}\text { Manga- } \\
\text { nese, } \\
\text { dissolved } \\
(\mu \mathrm{g} / \mathrm{L} \\
\text { as Mn) }\end{array}$ & $\begin{array}{c}\text { Nickel, } \\
\text { dis- } \\
\text { solved } \\
(\mu \mathrm{g} / \mathrm{L} \\
\text { as } \mathrm{Ni})\end{array}$ & $\begin{array}{l}\text { Zinc, } \\
\text { dis- } \\
\text { solved } \\
(\mu g / L \\
\text { as } \mathrm{Zn})\end{array}$ & $\begin{array}{c}\text { Coli- } \\
\text { form, } \\
\text { fecal } \\
\text { (col.l } \\
100 \mathrm{~mL})\end{array}$ & $\begin{array}{c}\text { St repto } \\
\text { cocci, } \\
\text { fecal } \\
\text { (col. } \\
100 \mathrm{~mL})\end{array}$ \\
\hline \multicolumn{9}{|c|}{ WELL 12--Continued } \\
\hline \multicolumn{9}{|l|}{ JUNE 1985} \\
\hline 14 & -- & $<50$ & -- & -- & -- & 60 & -- & -- \\
\hline 17 & -- & -- & -- & -- & -- & -- & $<1$ & 1 \\
\hline \multicolumn{9}{|l|}{ AUG } \\
\hline 30 & -- & -- & -- & -- & -- & -- & $<1$ & 3 \\
\hline 31 & 10 & $<50$ & $<10$ & 130 & 240 & 20 & -- & -- \\
\hline \multicolumn{9}{|l|}{ MAY 1986} \\
\hline 27 & -- & -- & -- & -- & -- & -- & -- & 46 \\
\hline 28 & $<20$ & $<50$ & $<40$ & $<20$ & $<20$ & 20 & -- & - \\
\hline \multicolumn{9}{|l|}{ AUG } \\
\hline \multirow{2}{*}{\multicolumn{9}{|c|}{ APR 1987}} \\
\hline & & & & & & & & \\
\hline 28 & -- & -- & -- & -- & -- & -- & $<1$ & $<1$ \\
\hline \multirow{2}{*}{\multicolumn{9}{|c|}{ JULY }} \\
\hline & & & & & & & & \\
\hline \multirow{2}{*}{\multicolumn{9}{|c|}{ SEPT }} \\
\hline & & & & & & & & \\
\hline${ }_{\text {MAR }}^{16} 1988$ & $<20$ & $<50$ & $<10$ & $<20$ & 30 & 100 & -- & $<2$ \\
\hline 15 & $<20$ & $<50$ & $<10$ & $<20$ & $<20$ & $<20$ & -- & -- \\
\hline \multirow{2}{*}{\multicolumn{9}{|c|}{ JULY }} \\
\hline & & & & & & & & \\
\hline 13 & -- & -- & -- & -- & -- & -- & $<10$ & $<2$ \\
\hline 14 & $<20$ & $<50$ & $<10$ & $<20$ & $<20$ & $<20$ & -- & -- \\
\hline \multicolumn{9}{|l|}{ SEPT } \\
\hline \multicolumn{9}{|l|}{$\stackrel{23}{\text { MAR } 1989}$} \\
\hline 15 & -. & -- & -. & -- & -. & -. & $<2$ & 18 \\
\hline 16 & $<20$ & $<50$ & $<10$ & $<20$ & $<20$ & 30 & -- & -- \\
\hline \multicolumn{9}{|l|}{ JUNE } \\
\hline 02 & $<20$ & $<50$ & $<10$ & $<20$ & $<20$ & $<20$ & $<2$ & 4 \\
\hline \multicolumn{9}{|l|}{ JULY } \\
\hline 18 & -- & -- & -- & -- & -- & -- & $<20$ & 230 \\
\hline \multicolumn{9}{|l|}{ AUG } \\
\hline \multicolumn{6}{|l|}{$\stackrel{29}{29}$} & $<50$ & $<20$ & 230 \\
\hline 25 & -- & -- & -- & -- & -- & -- & $<20$ & $<20$ \\
\hline 26 & $<200$ & $<500$ & $<10$ & $<200$ & $<200$ & 400 & -- & -- \\
\hline \multicolumn{9}{|l|}{ MAY } \\
\hline 22 & $<20$ & $<50$ & $<10$ & $<20$ & $<20$ & $<20$ & $<20$ & 10 \\
\hline \multicolumn{9}{|l|}{ JULY } \\
\hline 31 & -- & -- & -- & -- & -- & -- & $<20$ & $<20$ \\
\hline 24 & $<20$ & $<50$ & $<10$ & $<20$ & $<20$ & $<20$ & $<20$ & $<20$ \\
\hline
\end{tabular}


Table 5.--Chemical and bacteriological analyses of water from the observation wells--Continued

\begin{tabular}{|c|c|c|c|c|c|c|c|c|c|c|}
\hline $\begin{array}{c}\text { Sample } \\
\text { date }\end{array}$ & $\begin{array}{l}\text { Spe- } \\
\text { cific } \\
\text { con- } \\
\text { duct- } \\
\text { ance } \\
(\mu S / \mathrm{cm})\end{array}$ & $\underset{\text { (units) }}{\mathrm{pH}}$ & $\begin{array}{l}\text { Residue } \\
\text { at } \\
105^{\circ} \mathrm{C}, \\
\text { dis- } \\
\text { solved } \\
(\mathrm{mg} / \mathrm{L})\end{array}$ & $\begin{array}{l}\text { Nitrogen, } \\
\text { ammonia, } \\
\text { dis- } \\
\text { solved } \\
\text { (mg/L } \\
\text { as } N \text { ) }\end{array}$ & $\begin{array}{l}\text { Nitrogen, } \\
\text { nitrite, } \\
\text { dis- } \\
\text { solved } \\
\text { (mg/L } \\
\text { as } N \text { ) }\end{array}$ & $\begin{array}{l}\text { Nitrogen, } \\
\text { ammonia, } \\
\text { +organic, } \\
\text { dissolved } \\
\text { (mg/L } \\
\text { as } \mathrm{N})\end{array}$ & $\begin{array}{c}\text { Nitrogen, } \\
\mathrm{NO}_{2}+\mathrm{NO}_{3} \\
\text { dis- } \\
\text { solved } \\
(\mathrm{mg} / \mathrm{L} \\
\text { as } \mathrm{N})\end{array}$ & $\begin{array}{l}\text { Phos- } \\
\text { phorus, } \\
\text { ortho, } \\
\text { dissolved } \\
\text { (mg/L } \\
\text { as P) }\end{array}$ & $\begin{array}{l}\text { Hard- } \\
\text { ness, } \\
\text { total } \\
(\mathrm{mg} / \mathrm{L} \\
\text { as } \\
\left.\mathrm{CaCO}_{3}\right)\end{array}$ & $\begin{array}{l}\text { Cal- } \\
\text { cium, } \\
\text { dis- } \\
\text { solved } \\
\text { (mg/L } \\
\text { as Ca) }\end{array}$ \\
\hline \multicolumn{11}{|c|}{ WELL 13} \\
\hline \multicolumn{11}{|l|}{ JUNE 1985} \\
\hline 14 & 1,210 & 8.7 & 862 & 0.730 & 0.440 & 6.1 & 19.8 & $<0.020$ & 360 & 65 \\
\hline 17 & -- & -- & -- & -- & -- & -- & -- & -- & -- & -- \\
\hline \multicolumn{11}{|l|}{ AUG } \\
\hline 30 & - & -- & $-\infty$ & -- & -- & -- & -- & -- & -- & -- \\
\hline 31 & 1,220 & 7.6 & 802 & .300 & .330 & .80 & 19.4 & $<.020$ & 280 & 56 \\
\hline \multicolumn{11}{|l|}{ MAY 1986} \\
\hline 27 & -- & $-\infty$ & -- & -- & -- & -- & -- & -- & -- & -- \\
\hline${ }_{\text {AUG }}^{28}$ & \multicolumn{4}{|c|}{ AUG } & $<.010$ & .30 & 16.5 & $<.020$ & 330 & 68 \\
\hline $\begin{array}{c}28 \\
\text { APR } 1987\end{array}$ & 1,400 & 7.5 & 857 & $<.100$ & $<.010$ & .40 & 17.0 & $<.020$ & 300 & 61 \\
\hline 28 & -- & -- & -- & -- & - & -- & -- & -- & -- & -- \\
\hline $\begin{array}{r}29 \\
\text { JuLY }\end{array}$ & 1,280 & 7.9 & 854 & $<.100$ & $<.010$ & .50 & 16.5 & $<.020$ & 340 & 68 \\
\hline \multicolumn{11}{|l|}{ JULY } \\
\hline $\begin{array}{l}15 \\
\text { SEPT }\end{array}$ & 1,280 & 7.6 & 486 & $<.100$ & $<.010$ & .50 & 18.6 & $<.020$ & 310 & 62 \\
\hline$\stackrel{16}{\text { MAR } 1988}$ & 1,500 & 7.5 & 856 & $<.100$ & $<.020$ & $<.30$ & 19.3 & .020 & $330^{\circ}$ & 65 \\
\hline 15 & 1,260 & 8.0 & 818 & $<.100$ & $<.020$ & 1.0 & 20.2 & .070 & 320 & 62 \\
\hline 17 & -- & -- & -- & -- & -- & -- & -- & -- & -- & -- \\
\hline JULY & & & & & & & & & $=$ & \\
\hline 13 & -- & -- & -- & -- & -- & -- & -- & -- & -- & -- \\
\hline 14 & 1,230 & 7.6 & 877 & $<.100$ & $<.010$ & 1.0 & 23.0 & $<.020$ & 310 & 60 \\
\hline \multicolumn{11}{|l|}{ SEPT } \\
\hline 02 & -- & -- & -- & -- & -- & -- & -- & -- & -- & -- \\
\hline 23 & 1,250 & 7.7 & 840 & $<.100$ & .020 & .40 & 20.4 & $<.020$ & 340 & 65 \\
\hline \multicolumn{11}{|l|}{ MAR 1989} \\
\hline 15 & -- & - & - & $-\infty$ & -- & -- & -- & -- & -- & -- \\
\hline 16 & 1,200 & 7.5 & 728 & $<.100$ & $<.020$ & .40 & 24.8 & $<.020$ & 270 & 54 \\
\hline \multicolumn{11}{|l|}{ JUNE } \\
\hline $\begin{array}{l}02 \\
\text { JULY }\end{array}$ & 1,100 & 7.8 & 766 & $<.200$ & $<.020$ & .80 & 23.8 & $<.020$ & 270 & 52 \\
\hline $\begin{array}{l}18 \\
\text { AUG }\end{array}$ & 1,150 & 7.8 & 753 & $<.100$ & $<.020$ & .30 & 21.1 & $<.020$ & 280 & 56 \\
\hline$\stackrel{29}{\text { JAN } 1990}$ & 1,170 & 7.8 & $765^{\circ}$ & $<.100$ & $<.020$ & .40 & 22.6 & $<.020$ & 280 & 56 \\
\hline 25 & -- & -- & -- & -- & -- & -- & -- & -- & -- & -. \\
\hline 26 & 1,120 & 7.5 & 767 & $<.100$ & .050 & $<.30$ & 20.1 & $<.020$ & 290 & 58 \\
\hline MAY & & & & & & & & & & \\
\hline JULY & 1,160 & 7.8 & 757 & .400 & $<.020$ & 1.2 & 18.4 & .080 & 270 & 52 \\
\hline $\begin{array}{l}31 \\
\text { SEPT }\end{array}$ & 1,180 & 7.7 & 759 & $<.100$ & $<.020$ & 1.3 & 20.0 & $<.020$ & 280 & 54 \\
\hline$\stackrel{25}{\text { JAN }} 1991^{25}$ & 1,190 & 7.5 & 753 & .300 & $<.020$ & $<.30$ & 19.4 & $<.020$ & 290 & 58 \\
\hline 24 & 1,190 & 7.7 & 757 & $<.100$ & $<.020$ & .60 & 18.2 & .120 & 270 & 52 \\
\hline
\end{tabular}


Table 5.--Chemical and bacteriological analyses of water from the observation wells--Continued

\begin{tabular}{|c|c|c|c|c|c|c|c|c|c|c|c|}
\hline $\begin{array}{c}\text { Sample } \\
\text { date }\end{array}$ & $\begin{array}{l}\text { Magne- } \\
\text { sium, } \\
\text { dis- } \\
\text { solved } \\
\text { (mg/L } \\
\text { as } \mathrm{Mg} \text { ) }\end{array}$ & $\begin{array}{l}\text { Sodium, } \\
\text { dis- } \\
\text { solved } \\
(\mathrm{mg} / \mathrm{L} \\
\text { as } \mathrm{Na})\end{array}$ & $\begin{array}{l}\text { Potas- } \\
\text { sium, } \\
\text { dis- } \\
\text { solved } \\
\text { (mg/L } \\
\text { as K) }\end{array}$ & $\begin{array}{l}\text { Chlo- } \\
\text { ride, } \\
\text { dis- } \\
\text { solved } \\
\text { (mg/L } \\
\text { as } \mathrm{Cl} \text { ) }\end{array}$ & $\begin{array}{c}\text { Sulfate, } \\
\text { dis- } \\
\text { solved } \\
\left(\mathrm{mg}^{-} \mathrm{L}\right. \\
\left.\text { as } \mathrm{SO}_{4}\right)\end{array}$ & $\begin{array}{c}\text { Cadmi um, } \\
\text { dis- } \\
\text { solved } \\
\left(\mu_{g} / L\right. \\
\text { as Cd) }\end{array}$ & $\begin{array}{l}\text { Chro- } \\
\text { mium, } \\
\text { dis- } \\
\text { solved } \\
(\mu g / L \\
\text { as } C r)\end{array}$ & $\begin{array}{l}\text { Copper, } \\
\text { dis- } \\
\text { solved } \\
\left(\mu_{g} / L\right. \\
\text { as } C u)\end{array}$ & $\begin{array}{l}\text { Iron, } \\
\text { dis- } \\
\text { solved } \\
\left(\mu_{g} / \mathrm{L}\right. \\
\text { as } \mathrm{Fe})\end{array}$ & $\begin{array}{l}\text { Lead, } \\
\text { dis- } \\
\text { solved } \\
\left(\mu_{\mathbf{g}} / \mathrm{L}\right. \\
\text { as } \mathrm{Pb})\end{array}$ & $\begin{array}{l}\text { Manga- } \\
\text { nese, } \\
\text { dis- } \\
\text { solved } \\
(\mu g / L \\
\text { as Mn) }\end{array}$ \\
\hline
\end{tabular}

WELL 13--Continued

JUNE 1985

\begin{tabular}{|c|c|c|c|c|c|c|c|c|c|c|c|}
\hline 14 & 48 & 210 & 6.4 & 53 & 330 & -- & $\cdots$ & -- & 10 & -. & - \\
\hline 17 & $\ldots$ & $\ldots$ & -- & - & -- & -- & - & - & - & -- & - \\
\hline \multicolumn{12}{|l|}{ AUG } \\
\hline 30 & -- & -- & -- & -- & -- & -- & -- & -- & - & -- & -. \\
\hline 31 & 34 & 160 & 3.5 & 56 & 270 & 0.2 & $<10$ & $<10$ & $<50$ & $<10$ & $<10$ \\
\hline \multicolumn{12}{|l|}{ MAY 1986} \\
\hline 27 & -- & - & -- & - & -- & - & -- & -- & -- & -- & - \\
\hline 28 & 39 & 180 & 3.0 & 68 & 260 & $<.1$ & $<20$ & $<20$ & $<50$ & $<80$ & $<20$ \\
\hline \multicolumn{12}{|l|}{ AUG } \\
\hline 28 & 36 & 170 & 4.0 & 66 & 260 & .8 & $<20$ & $<20$ & $<50$ & $<50$ & $<20$ \\
\hline \multicolumn{12}{|l|}{ APR 1987} \\
\hline 28 & -- & -- & -- & -- & -- & -- & - & -- & -- & -. & - \\
\hline 29 & 42 & 170 & 3.8 & 65 & 270 & .6 & $<20$ & $<20$ & $<50$ & $<50$ & $<20$ \\
\hline \multicolumn{12}{|l|}{ JULY } \\
\hline 15 & 38 & 160 & 3.6 & 61 & 270 & .4 & $<20$ & $<20$ & 210 & $<10$ & 50 \\
\hline \multicolumn{12}{|l|}{ SEPT } \\
\hline 16 & 40 & 170 & 3.7 & 62 & 260 & .3 & $<20$ & $<20$ & $<50$ & $<10$ & $<20$ \\
\hline 15 & 39 & 160 & 3.5 & 60 & 220 & .3 & $<20$ & $<20$ & $<50$ & $<10$ & $<20$ \\
\hline 17 & - & -- & -- & - & -- & - & -- & -- & -- & -- & - \\
\hline \multicolumn{12}{|l|}{ JULY } \\
\hline 13 & -- & -- & $\cdots$ & -- & -- & -- & $\cdots$ & -- & -- & -- & $\cdots$ \\
\hline 14 & 38 & 160 & 3.9 & 57 & 220 & .3 & $<20$ & $<20$ & $<50$ & $<10$ & $<20$ \\
\hline \multicolumn{12}{|l|}{ SEPT } \\
\hline 02 & -- & -- & -- & -- & -- & -- & -- & -- & -- & -- & -- \\
\hline 23 & 44 & 180 & 3.9 & 64 & 250 & .2 & $<20$ & $<20$ & $<50$ & $<10$ & - \\
\hline \multicolumn{12}{|l|}{ MAR 1989} \\
\hline 15 & -- & -- & -- & -- & -- & -- & -- & - & -- & -- & - \\
\hline 16 & 34 & 150 & 3.6 & 59 & 200 & .1 & $<20$ & $<20$ & $<50$ & $<10$ & $<20$ \\
\hline \multicolumn{12}{|l|}{ JUNE } \\
\hline 02 & 33 & 140 & 3.3 & 69 & 170 & .2 & $<20$ & $<20$ & $<50$ & $<10$ & $<20$ \\
\hline \multicolumn{12}{|l|}{ JULY } \\
\hline 18 & 34 & 160 & 3.7 & 60 & 170 & .8 & $<20$ & $<20$ & $<50$ & $<10$ & $<20$ \\
\hline \multicolumn{12}{|l|}{ AUG } \\
\hline 29 & 35 & 140 & 3.3 & 60 & 140 & $<.2$ & $<20$ & $<20$ & $<50$ & $<10$ & $<20$ \\
\hline \multicolumn{12}{|l|}{ JAN 1990} \\
\hline 25 & $-\bar{c}$ & -- & -- & -- & -- & $\cdots$ & $\cdots$ & -- & -- & -- & -- \\
\hline${ }_{\mathrm{MAY}}^{26}$ & 36 & 150 & 3.7 & 70 & 190 & .3 & $<20$ & $<20$ & 130 & $<10$ & $<20$ \\
\hline \multicolumn{12}{|l|}{ MAY } \\
\hline \multirow{2}{*}{\multicolumn{12}{|c|}{ JULY }} \\
\hline & 35 & & & & & & & & & & \\
\hline \multicolumn{12}{|l|}{ SEPT } \\
\hline 25 & 36 & 160 & 3.4 & 70 & 220 & .5 & $<40$ & $<40$ & $<100$ & $<10$ & $<40$ \\
\hline \multicolumn{12}{|l|}{ JAN 1991} \\
\hline 24 & 34 & 140 & 3.0 & 75 & 100 & .4 & $<20$ & $<20$ & 60 & $<10$ & $<20$ \\
\hline
\end{tabular}


Table 5.--Chemical and bacteriological analyses of water from the observation wells--Continued

\begin{tabular}{|c|c|c|c|c|c|c|c|c|c|c|}
\hline $\begin{array}{c}\text { Sample } \\
\text { date }\end{array}$ & $\begin{array}{l}\text { Nickel, } \\
\text { dis- } \\
\text { solved } \\
(\mu g / L \\
\text { as Ni) }\end{array}$ & $\begin{array}{l}\text { Zinc, } \\
\text { dis- } \\
\text { solved } \\
(\mu \mathrm{g} / \mathrm{L} \\
\text { as } \mathrm{Zn})\end{array}$ & $\begin{array}{l}\text { Coli- } \\
\text { form, } \\
\text { fecal } \\
(\text { col./ } \\
100 \mathrm{~mL})\end{array}$ & $\begin{array}{c}\text { Strepto- } \\
\text { cocci, } \\
\text { fecal } \\
\text { (col./ } \\
100 \mathrm{~mL})\end{array}$ & $\begin{array}{c}\text { Dichloro- } \\
\text { bromo- } \\
\text { methane, } \\
\text { total } \\
\left(\mu_{g} / L\right)\end{array}$ & $\begin{array}{c}\text { Carbon } \\
\text { tetra- } \\
\text { chloride, } \\
\text { total } \\
(\mu g / L)\end{array}$ & $\begin{array}{l}1,2 \text {-di- } \\
\text { chloro- } \\
\text { ethane, } \\
\text { total } \\
\left(\mu_{g} / L\right)\end{array}$ & $\begin{array}{c}\text { Bromo- } \\
\text { form, } \\
\text { total } \\
(\mu \mathrm{g} / \mathrm{L})\end{array}$ & $\begin{array}{l}\text { Chloro- } \\
\text { dibromo- } \\
\text { methane, } \\
\text { total } \\
\left(\mu_{\mathrm{g}} / \mathrm{L}\right)\end{array}$ & $\begin{array}{l}\text { Chloro- } \\
\text { form, } \\
\text { total } \\
(\mu \mathrm{g} / \mathrm{L})\end{array}$ \\
\hline
\end{tabular}

WELL 13--Continued

JUNE 1985

\begin{tabular}{|c|c|c|c|c|c|c|c|c|c|c|}
\hline 14 & -- & 60 & -- & -- & -- & -- & -- & -- & -- & -- \\
\hline 17 & -- & - & $<1$ & 8 & -- & $\cdots$ & -- & -- & -- & -- \\
\hline \multicolumn{11}{|l|}{ AUG } \\
\hline 30 & -- & -- & $<1$ & $<1$ & -- & -- & -- & - & -- & $\cdots$ \\
\hline 31 & 180 & $<10$ & -- & -- & -- & -- & -- & -- & -- & -- \\
\hline \multicolumn{11}{|l|}{ MAY 1986} \\
\hline 27 & -- & - & -- & 16 & -- & -- & -- & -- & -- & -- \\
\hline$\stackrel{28}{A \cup G}$ & $<20$ & $<20$ & -- & - & -- & -- & -- & -- & -- & -- \\
\hline $\begin{array}{l}28 \\
\text { APR } 1987\end{array}$ & $<20$ & $<20$ & $<1$ & 8 & -- & -- & - & -- & -- & -- \\
\hline 28 & - & -- & $<1$ & $<1$ & -- & - & - & - & - & -- \\
\hline 29 & $<20$ & $<20$ & -- & -- & -- & -- & -- & -- & -- & -- \\
\hline \multicolumn{11}{|l|}{ JULY } \\
\hline $\begin{array}{l}15 \\
\text { SEPT }\end{array}$ & $<20$ & 50 & $<2$ & $<2$ & -- & -- & -- & - & -- & -- \\
\hline $\operatorname{MAR}^{16} 1988$ & 20 & 20 & $<2$ & $<2$ & -- & -- & -- & -- & -- & -- \\
\hline 15 & $<20$ & $<20$ & -- & -- & -- & -- & -- & -- & -- & -- \\
\hline \multirow{2}{*}{\multicolumn{11}{|c|}{ JULY }} \\
\hline & & & & & & & & & & \\
\hline 13 & -- & -- & $<2$ & $<2$ & -- & -- & -- & -- & -- & -- \\
\hline 14 & $<20$ & $<20$ & -- & -- & -- & -- & -- & -- & -- & -- \\
\hline \multicolumn{11}{|l|}{ SEPT } \\
\hline 02 & -- & -- & -- & -- & $<3.0$ & $<3.0$ & $<3.0$ & $<3.0$ & $<3.0$ & $<3.0$ \\
\hline 23 & $<20$ & 20 & $<2$ & $<2$ & -- & -- & -- & -- & -- & -- \\
\hline \multicolumn{11}{|l|}{ MAR 1989} \\
\hline 15 & -- & -- & $<2$ & 24 & -- & -- & -- & -- & -- & -- \\
\hline 16 & $<20$ & $<20$ & -- & -- & -- & -- & -- & -- & -- & -- \\
\hline \multicolumn{11}{|l|}{ JUNE } \\
\hline $\begin{array}{c}02 \\
\text { JULY }\end{array}$ & $<20$ & $<20$ & $<2$ & 5 & -- & -- & -- & \multicolumn{2}{|c|}{ JULY } & -- \\
\hline 18 & $<20$ & $<20$ & $<2$ & $<2$ & -- & -- & -- & -- & -- & -- \\
\hline \multicolumn{11}{|l|}{ AUG } \\
\hline 29 & $<20$ & $<30$ & $<2$. & $<2$ & -- & -- & -- & -- & -- & - \\
\hline \multicolumn{11}{|l|}{ JAN 1990} \\
\hline 25 & - & -- & $<20$ & $<20$ & -- & -- & -- & -- & -- & -- \\
\hline 26 & $<20$ & 20 & -- & -- & -- & -- & -- & -- & -- & -- \\
\hline \multicolumn{11}{|l|}{ MAY } \\
\hline 22 & 30 & $<20$ & $<20$ & $<20$ & -- & -- & -- & -- & -- & -- \\
\hline \multicolumn{11}{|l|}{ JULY } \\
\hline $\begin{array}{l}31 \\
\text { SEPT }\end{array}$ & $<20$ & $<20$ & $<20$ & $<20$ & -- & -- & -- & -- & -- & -- \\
\hline $\begin{array}{c}25 \\
\text { JAN } 1991\end{array}$ & $<40$ & $<40$ & $<20$ & $<20$ & -- & -- & -- & -- & -- & -- \\
\hline 24 & $<20$ & $<20$ & $<20$ & $<20$ & -- & -- & -- & -- & -- & - \\
\hline
\end{tabular}


Table 5.--Chemical and bacteriological analyses of water

from the observation wells--Continued

\begin{tabular}{|c|c|c|c|c|c|c|c|c|c|c|}
\hline $\begin{array}{c}\text { Sample } \\
\text { date }\end{array}$ & $\begin{array}{l}\text { Toluene, } \\
\text { total } \\
\left(\mu_{\mathrm{g}} / \mathrm{L}\right)\end{array}$ & $\begin{array}{l}\text { Benzene, } \\
\text { total } \\
(\mu \mathrm{g} / L)\end{array}$ & $\begin{array}{l}\text { Chloro- } \\
\text { benzene, } \\
\text { total } \\
(\mu \mathrm{g} / \mathrm{L})\end{array}$ & $\begin{array}{l}\text { Chloro- } \\
\text { ethane, } \\
\text { total } \\
\left(\mu_{g} / L\right)\end{array}$ & $\begin{array}{c}\text { Ethyl- } \\
\text { benzene, } \\
\text { total } \\
\left(\mu_{\mathrm{g}} / \mathrm{L}\right)\end{array}$ & $\begin{array}{l}\text { Methyl- } \\
\text { bromide, } \\
\text { total } \\
\left(\mu_{g} / \mathrm{L}\right)\end{array}$ & $\begin{array}{l}\text { Methyl- } \\
\text { chloride, } \\
\text { total } \\
\left(\mu_{g} / L\right)\end{array}$ & $\begin{array}{c}\text { Methyl- } \\
\text { ene } \\
\text { chlo- } \\
\text { ride, } \\
\text { total } \\
\left(\mu_{g} / L\right)\end{array}$ & $\begin{array}{l}\text { Tetra- } \\
\text { chloro- } \\
\text { ethyl- } \\
\text { ene, } \\
\text { total } \\
\left(\mu_{g} / L\right)\end{array}$ & $\begin{array}{l}\text { Tri- } \\
\text { chloro- } \\
\text { fluoro- } \\
\text { methane, } \\
\text { total } \\
\left(\mu_{g} / L\right)\end{array}$ \\
\hline
\end{tabular}

JUNE 1985

\begin{tabular}{|c|c|c|c|c|c|c|c|c|c|c|}
\hline 14 & -- & -- & -- & -- & -- & -- & -- & -- & -- & -- \\
\hline 17 & -- & -- & -- & -- & -- & -- & -- & -- & -- & - \\
\hline \multicolumn{11}{|l|}{ AUG } \\
\hline 30 & -- & -- & -- & -- & -- & -- & -- & -- & - & -- \\
\hline 31 & -- & -- & -- & -- & -- & -- & -- & -- & -- & -- \\
\hline \multicolumn{11}{|l|}{ MAY 1986} \\
\hline 27 & -- & -- & -- & -- & -- & -- & -- & -- & -- & -- \\
\hline 28 & $-\infty$ & -- & -- & -- & -- & -- & -- & - & -- & -- \\
\hline \multicolumn{11}{|l|}{ AUG } \\
\hline 28 & -- & -- & -- & -- & -- & -- & -- & -- & -- & -- \\
\hline \multicolumn{11}{|l|}{ APR 1987} \\
\hline 28 & -- & -- & -- & -- & -- & -- & -- & -- & -- & -- \\
\hline 29 & -- & -- & -- & -- & -- & -- & -- & -- & -- & - \\
\hline \multicolumn{11}{|l|}{ JuLY } \\
\hline 15 & -- & - & -- & -- & -- & - & -- & -- & -- & -- \\
\hline \multicolumn{11}{|l|}{ SEPT } \\
\hline 16 & -- & -- & -- & -- & -- & -- & -- & -- & -- & -- \\
\hline 15 & -- & - & -- & -- & -- & -- & -- & -- & - & -- \\
\hline 17 & - & -- & -- & -- & -- & -- & -- & -- & -- & -- \\
\hline \multicolumn{11}{|l|}{ JULY } \\
\hline 13 & - & -- & -- & -- & -- & -- & -- & -- & -- & -- \\
\hline 14 & - & -- & -- & - & -- & - & -- & -- & -- & -- \\
\hline \multicolumn{11}{|l|}{ SEPT } \\
\hline 02 & $<3.0$ & $<3.0$ & $<3.0$ & $<3.0$ & $<3.0$ & $<3.0$ & $<3.0$ & $<3.0$ & $<3.0$ & $<3.0$ \\
\hline 23 & -- & - & -- & -- & -- & - & -- & -- & -- & -- \\
\hline
\end{tabular}


Table 5.--Chemical and bacteriological analyses of water from the observation wells--Continued

\begin{tabular}{|c|c|c|c|c|c|c|c|c|c|c|}
\hline $\begin{array}{c}\text { Sample } \\
\text { date }\end{array}$ & $\begin{array}{l}1,1-\mathrm{di}- \\
\text { chloro- } \\
\text { ethane, } \\
\text { total } \\
(\mu \mathrm{g} / \mathrm{L})\end{array}$ & $\begin{array}{l}1,1-d i- \\
\text { chloro- } \\
\text { ethyl- } \\
\text { ene, } \\
\text { total } \\
\left(\mu_{g} / L\right)\end{array}$ & $\begin{array}{c}1,1,1- \\
\text { tri- } \\
\text { chloro- } \\
\text { ethane, } \\
\text { total } \\
(\mu g / L)\end{array}$ & $\begin{array}{c}1,1,2- \\
\text { tri- } \\
\text { chloro- } \\
\text { ethane, } \\
\text { total } \\
\left(\mu_{g} / L\right)\end{array}$ & $\begin{array}{l}1,1,2,2 \\
\text { tetra- } \\
\text { chloro- } \\
\text { ethane, } \\
\text { total } \\
\left(\mu_{8} / L\right)\end{array}$ & $\begin{array}{l}1,2-d i- \\
\text { chloro- } \\
\text { benzene, } \\
\text { total } \\
(\mu \mathrm{g} / \mathrm{L})\end{array}$ & $\begin{array}{l}1,2-d i- \\
\text { chloro- } \\
\text { propane, } \\
\text { total } \\
\left(\mu_{\mathrm{g}} / \mathrm{L}\right)\end{array}$ & $\begin{array}{c}\text { Trans- } \\
1,2-d i- \\
\text { chloro- } \\
\text { ethane, } \\
\text { total } \\
\left(\mu_{\mathrm{g}} / \mathrm{L}\right)\end{array}$ & $\begin{array}{l}1,3-d i- \\
\text { chloro- } \\
\text { propene, } \\
\text { total } \\
(\mu g / L)\end{array}$ & $\begin{array}{c}1,3-d i- \\
\text { chloro- } \\
\text { benzene, } \\
\text { total } \\
\left(\mu_{g} / L\right)\end{array}$ \\
\hline
\end{tabular}

WELL 13--Continued

\begin{tabular}{|c|c|c|c|c|c|c|c|c|c|c|}
\hline \multicolumn{11}{|l|}{ JUNE 1985} \\
\hline 14 & -- & -- & -- & -- & -- & -- & -- & -- & -- & -- \\
\hline 17 & -- & -- & -- & -- & -- & - & -- & -- & -- & -- \\
\hline \multicolumn{11}{|l|}{ AUG } \\
\hline 30 & -- & - & -- & -- & -- & -- & - & -- & -- & -- \\
\hline \multirow{2}{*}{\multicolumn{11}{|c|}{ MAY 1986}} \\
\hline & & & & & & & & & & \\
\hline 27 & - & -- & -- & -- & - & - & -- & -- & -- & -- \\
\hline 28 & -- & -- & -- & -- & -- & - & -- & -- & -- & -- \\
\hline \multicolumn{11}{|l|}{ AUG } \\
\hline $\begin{array}{c}28 \\
\text { APR } 1987\end{array}$ & -- & -- & -- & -- & -- & -- & -- & -- & -- & -- \\
\hline 28 & -. & -. & -- & -- & -- & -- & -- & -- & -- & -- \\
\hline 29 & -- & -- & - & -- & - & -- & - & -- & -- & - \\
\hline \multicolumn{11}{|l|}{ JULY } \\
\hline 15 & -- & -- & -- & -- & -- & -- & -- & -- & -- & -- \\
\hline \multicolumn{11}{|l|}{ SEPT } \\
\hline \multirow{2}{*}{\multicolumn{11}{|c|}{$\operatorname{MAR}^{16} 1988$}} \\
\hline $\begin{array}{l}\text { MAR } 1988 \\
15\end{array}$ & & -- & -- & - & -- & -- & -- & -- & -- & -- \\
\hline 17 & -- & -- & -- & -- & -- & -- & -- & -- & -- & -- \\
\hline \multicolumn{11}{|l|}{ JULY } \\
\hline 13 & -- & -- & - & -- & - & -- & -- & -- & -- & - \\
\hline 14 & -- & -- & -- & -- & - & -- & -- & -- & -- & \\
\hline \multicolumn{11}{|l|}{ SEPT } \\
\hline 02 & $<3.0$ & $<3.0$ & $<3.0$ & $<3.0$ & $<3.0$ & $<3.0$ & $<3.0$ & $<3.0$ & $<3.0$ & $<3.0$ \\
\hline 23 & -- & -- & -- & -- & -- & -- & -- & -- & -- & 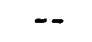 \\
\hline
\end{tabular}


Table 5.--Chemical and bacteriological analyses of water from the observation wells--Continued

\begin{tabular}{|c|c|c|c|c|c|c|c|c|c|}
\hline $\begin{array}{c}\text { Sample } \\
\text { date }\end{array}$ & $\begin{array}{l}1,4,- \text { di- } \\
\text { chloro- } \\
\text { benzene, } \\
\text { total } \\
\left(\mu_{\mathrm{g}} / \mathrm{L}\right)\end{array}$ & $\begin{array}{l}\text { 2-chloro- } \\
\text { ethyl- } \\
\text { vinyl- } \\
\text { ether, } \\
\text { total } \\
\left(\mu_{\mathrm{g}} / \mathrm{L}\right)\end{array}$ & $\begin{array}{c}\text { Dichloro- } \\
\text { difluoro- } \\
\text { methane, } \\
\text { total } \\
(\mu \mathrm{g} / \mathrm{L})\end{array}$ & $\begin{array}{l}\text { Trans- } \\
1,3-d i- \\
\text { chloro- } \\
\text { propene, } \\
\text { total } \\
(\mu \mathrm{g} / \mathrm{L})\end{array}$ & $\begin{array}{l}\text { Cis- } \\
\text { 1,3-di- } \\
\text { chloro- } \\
\text { propene, } \\
\text { total } \\
(\mu \mathrm{g} / \mathrm{L})\end{array}$ & $\begin{array}{c}\text { Vinyl } \\
\text { chloride, } \\
\text { total } \\
(\mu \mathrm{g} / \mathrm{L})\end{array}$ & $\begin{array}{c}\text { Tri- } \\
\text { chloro- } \\
\text { ethylene, } \\
\text { total } \\
(\mu g / L)\end{array}$ & $\begin{array}{c}\text { Styrene, } \\
\text { total } \\
(\mu \mathrm{g} / \mathrm{L})\end{array}$ & $\begin{array}{c}\text { Xylene, } \\
\text { total } \\
\text { tot rec } \\
\left(\mu_{\mathrm{g}} / \mathrm{L}\right)\end{array}$ \\
\hline
\end{tabular}

\section{WELL 13--Continued}

\begin{tabular}{|c|c|c|c|c|c|c|c|c|c|}
\hline \multicolumn{10}{|l|}{ JUNE 1985} \\
\hline 14 & -- & -- & -- & -- & -- & -- & -- & -- & -- \\
\hline 17 & -- & -- & -- & -- & -- & -- & -- & -- & -- \\
\hline \multicolumn{10}{|l|}{ AUG } \\
\hline 30 & -- & -- & -- & -- & -- & -- & -- & -- & -- \\
\hline 31 & -- & -- & -- & -- & -- & -- & -- & -- & -- \\
\hline \multicolumn{10}{|l|}{ MAY 1986} \\
\hline 27 & -- & -- & -- & -- & -- & -- & -- & -- & -- \\
\hline 28 & -- & -- & -- & -- & -- & -- & -- & -- & -- \\
\hline \multicolumn{10}{|l|}{ AUG } \\
\hline 28 & -- & -- & -- & -- & -- & -- & -- & -- & -- \\
\hline \multicolumn{10}{|l|}{ APR 1987} \\
\hline 28 & -- & -- & -- & -- & -- & -- & -- & -- & -- \\
\hline 29 & -- & -- & -- & -- & -- & -- & -- & -- & -- \\
\hline \multicolumn{10}{|l|}{ JULY } \\
\hline 15 & -- & -- & -- & $-\infty$ & -- & -- & -- & -- & -- \\
\hline \multicolumn{10}{|l|}{ SEPT } \\
\hline$\stackrel{16}{\text { MAR } 1988}$ & -- & -- & -- & -- & -- & -- & -- & -- & -- \\
\hline 15 & -- & -- & -- & -- & -- & -- & -- & -- & -- \\
\hline 17 & -- & -- & -- & -- & -- & -- & -- & -- & -- \\
\hline \multicolumn{10}{|l|}{ JULY } \\
\hline 13 & -- & -- & -- & -- & -- & -- & -- & -- & -- \\
\hline 14 & -- & -- & -- & -- & -- & -- & -- & -- & -- \\
\hline \multicolumn{10}{|l|}{ SEPT } \\
\hline 02 & $<3.0$ & $<3.0$ & $<3.0$ & $<3.0$ & $<3.0$ & $<3.0$ & $<3.0$ & $<3.0$ & $<3.0$ \\
\hline 23 & -- & - & -- & - & -- & - & -- & -- & -- \\
\hline
\end{tabular}


Table 5.--Chemical and bacteriological analyses of water

from the observation wells--Continued

\begin{tabular}{|c|c|c|c|c|c|c|c|c|c|}
\hline $\begin{array}{c}\text { Sample } \\
\text { date }\end{array}$ & $\begin{array}{c}\text { Specific } \\
\text { conduct- } \\
\text { ance } \\
(\mu \mathrm{S} / \mathrm{cm})\end{array}$ & $\underset{\text { (units) }}{\mathrm{pH}}$ & $\begin{array}{l}\text { Residue } \\
\text { at } \\
105^{\circ} \mathrm{C}, \\
\text { dis- } \\
\text { solved } \\
\text { (mg/L) }\end{array}$ & $\begin{array}{l}\text { Nitrogen, } \\
\text { ammonia, } \\
\text { dis- } \\
\text { solved } \\
\text { (mg/L } \\
\text { as } \mathrm{N})\end{array}$ & $\begin{array}{l}\text { Nitrogen, } \\
\text { nitrite, } \\
\text { dis- } \\
\text { solved } \\
(\mathrm{mg} / \mathrm{L} \\
\text { as } \mathrm{N})\end{array}$ & $\begin{array}{l}\text { Nitrogen, } \\
\text { ammonia, } \\
\text { torganic, } \\
\text { dissolved } \\
\text { (mg/L } \\
\text { as } N \text { ) }\end{array}$ & $\begin{array}{c}\text { Nit rogen, } \\
\mathrm{NO}_{2}+\mathrm{NO}_{3} \\
\text { dis- } \\
\text { solved } \\
\text { (mg/L } \\
\text { as } \mathrm{N} \text { ) }\end{array}$ & $\begin{array}{l}\text { Phos- } \\
\text { phorus, } \\
\text { ortho, } \\
\text { dissolved } \\
\text { (mg/L } \\
\text { as P) }\end{array}$ & $\begin{array}{l}\text { Hard- } \\
\text { ness, } \\
\text { total } \\
\text { (mg/L } \\
\text { as } \\
\left.\mathrm{CaCO}_{3}\right)\end{array}$ \\
\hline \multicolumn{10}{|c|}{ WELL 14} \\
\hline JUNE 1985 & & & & & & & & & \\
\hline 14 & 1,000 & 8.9 & 703 & 0.030 & 0.030 & 0.81 & 6.90 & $<0.020$ & 410 \\
\hline $\begin{array}{c}17 \\
\text { AUG }\end{array}$ & -- & -- & -- & -- & -- & -- & -- & -- & -- \\
\hline 30 & - & -- & - & - & $\ldots$ & -- & - & -- & -- \\
\hline 31 & 1,090 & 7.8 & 701 & .200 & .070 & .50 & 7.30 & $<.020$ & 410 \\
\hline MAY 1986 & & & & & & & & & \\
\hline 27 & -- & - & -- & -- & -- & -- & -- & -- & -- \\
\hline$\stackrel{28}{\text { AUG }}$ & 1,120 & 8.2 & 714 & $<.100$ & $<.010$ & .50 & 6.38 & $<.020$ & 420 \\
\hline $\begin{array}{c}28 \\
\text { APR } 1987\end{array}$ & 1,280 & 7.6 & 718 & $<.100$ & $<.010$ & $<.30$ & 6.19 & $<.020$ & 410 \\
\hline$\stackrel{29}{\text { MAY }}$ & 1,190 & 8.0 & 730 & $<.100$ & $<.010$ & .50 & 5.00 & $<.020$ & 450 \\
\hline $\begin{array}{l}28 \\
\text { JULY }\end{array}$ & -- & -- & -- & - & - & -- & -- & -- & -- \\
\hline $\begin{array}{l}14 \\
\text { SEPT }\end{array}$ & 1,200 & 7.8 & 748 & $<.100$ & $<.010$ & .40 & 7.65 & .030 & 420 \\
\hline $\begin{array}{c}16 \\
\text { MAR } 1988\end{array}$ & 1,300 & 7.8 & 752 & $<.100$ & $<.020$ & $<.30$ & 8.10 & .020 & 420 \\
\hline 15 & 1,120 & 8.0 & 728 & $<.100$ & $<.020$ & .30 & 8.30 & .020 & 410 \\
\hline 17 & - & -- & -- & -- & -- & -- & $\cdots$ & -- & -- \\
\hline JULY & & & & & & & & & \\
\hline 13 & -- & -- & -- & -- & -- & -- & -- & -- & -- \\
\hline 14 & 1,110 & 7.5 & 840 & $<.100$ & $<.010$ & $<.30$ & 9.00 & $<.020$ & 420 \\
\hline SEPT & & & & & & & & & \\
\hline$\stackrel{23}{\text { MAR } 1989}$ & 1,170 & 7.8 & 750 & $<.100$ & $<.020$ & $<.30$ & 7.90 & .030 & 460 \\
\hline 15 & -- & -- & -- & -- & -- & -- & -- & -- & -- \\
\hline 16 & 1,140 & 7.7 & 734 & $<.100$ & $<.020$ & $<.30$ & 8.43 & $<.020$ & 430 \\
\hline JUNE & & & & & & & & & \\
\hline 02 & 1,100 & 7.9 & 741 & $<.200$ & $<.020$ & $<.30$ & 9.60 & $<.020$ & 390 \\
\hline $\begin{array}{r}\text { JULY } \\
18\end{array}$ & 1,150 & 8.0 & 716 & $<.100$ & $<.020$ & 30 & 8.70 & $<.020$ & 420 \\
\hline AUG & & & & & & .00 & 0.10 & $0.0<0$ & 420 \\
\hline $\begin{array}{c}29 \\
\text { JAN } 1990\end{array}$ & 1,140 & 7.9 & $\cdot 744$ & $<.100$ & $<.020$ & .50 & 11.0 & .030 & 430 \\
\hline 25 & -- & -- & -- & -- & -- & -- & -- & -- & - \\
\hline 26 & 1,040 & 7.7 & 788 & $<.100$ & $<.020$ & $<.30$ & 8.50 & $<.020$ & 420 \\
\hline MAY & & & & & & & & & \\
\hline 22 & 1,160 & 7.8 & 728 & $<.100$ & $<.020$ & 1.1 & 9.90 & .090 & 390 \\
\hline $\begin{array}{l}\text { JULY } \\
31\end{array}$ & & & & & & & & & \\
\hline $\begin{array}{c}31 \\
\text { AUG }\end{array}$ & 1,180 & 7.8 & 763 & $<.100$ & $<.020$ & 1.0 & 11.0 & $<.020$ & 430 \\
\hline 03 & -- & - & -- & -- & -- & -- & -- & -- & -- \\
\hline SEPT & & & & & & & & & \\
\hline$\stackrel{25}{\text { JAN } 1991}$ & 1,190 & 8.0 & 782 & $<.100$ & $<.020$ & .90 & 9.90 & $<.020$ & 450 \\
\hline 24 & 1,190 & 7.8 & 755 & $<.100$ & $<.020$ & .60 & 12.1 & .190 & 440 \\
\hline
\end{tabular}


Table 5.--Chemical and bacteriological analyses of water from the observation wells--Continued

\begin{tabular}{|c|c|c|c|c|c|c|c|c|}
\hline $\begin{array}{c}\text { Sample } \\
\text { date }\end{array}$ & $\begin{array}{l}\text { Calcium } \\
\text { dis- } \\
\text { solved } \\
\text { (mg/L } \\
\text { as } \mathrm{Ca} \text { ) }\end{array}$ & $\begin{array}{l}\text { Magne- } \\
\text { sium, } \\
\text { dis- } \\
\text { solved } \\
\text { (mg/L } \\
\text { as Mg) }\end{array}$ & $\begin{array}{l}\text { Sodium, } \\
\text { dis- } \\
\text { solved } \\
\text { (mg/L } \\
\text { as } \mathrm{Na} \text { ) }\end{array}$ & $\begin{array}{l}\text { Potas- } \\
\text { sium, } \\
\text { dis- } \\
\text { solved } \\
\text { (mg/L } \\
\text { as K) }\end{array}$ & $\begin{array}{c}\text { Chloride, } \\
\text { dis- } \\
\text { solved } \\
\text { (mg/L } \\
\text { as } \mathrm{Cl} \text { ) }\end{array}$ & $\begin{array}{c}\text { Sulfate, } \\
\text { dis- } \\
\text { solved } \\
\left(\mathrm{mg}^{-} \mathrm{L}\right. \\
\left.\text { as } \mathrm{SO}_{4}\right)\end{array}$ & $\begin{array}{c}\text { Cadmium, } \\
\text { dis- } \\
\text { solved } \\
(\mu g / L \\
\text { as } C d)\end{array}$ & $\begin{array}{c}\text { Chromium, } \\
\text { dis- } \\
\text { solved } \\
\left(\mu_{g} / L\right. \\
\text { as } \mathrm{Cr})\end{array}$ \\
\hline
\end{tabular}

WELL 14--Continued

JUNE 1985

\begin{tabular}{|c|c|c|c|c|c|c|c|c|}
\hline 14 & 68 & 59 & 100 & 4.6 & 75 & 240 & -- & -- \\
\hline 17 & $\ldots$ & - & $\ldots$ & $\ldots$ & $-\infty$ & $\ldots$ & -- & - \\
\hline \multicolumn{9}{|l|}{ AUG } \\
\hline 30 & -- & -- & $-\infty$ & -- & -- & -- & -- & -- \\
\hline 31 & 67 & 60 & 89 & 3.2 & 70 & 240 & 0.3 & $<10$ \\
\hline \multicolumn{9}{|l|}{ MAY 1986} \\
\hline 27 & - & -- & $\infty$ & -- & -- & -- & -- & -- \\
\hline 28 & 70 & 60 & 94 & 2.0 & 76 & 220 & .2 & $<20$ \\
\hline \multicolumn{9}{|l|}{ AUG } \\
\hline \multicolumn{9}{|l|}{ APR 1987} \\
\hline $\begin{array}{l}29 \\
\text { MAY }\end{array}$ & MAY & 66 & 88 & 2.9 & 83 & 250 & .8 & $<20$ \\
\hline 28 & $\cdots$ & - & - & - & $\ldots$ & - & -. & - \\
\hline \multicolumn{9}{|l|}{ JULY } \\
\hline 14 & 66 & 61 & 82 & 3.0 & 76 & 240 & .5 & $<20$ \\
\hline \multicolumn{9}{|l|}{ SEPT } \\
\hline \multicolumn{9}{|l|}{ MAR 1988} \\
\hline 15 & 66 & 60 & 90 & 2.8 & 73 & 220 & .3 & $<20$ \\
\hline 17 & -- & -- & -- & - & -- & -- & -- & - \\
\hline \multicolumn{9}{|l|}{ JULY } \\
\hline 13 & -- & $-\infty$ & - & - & - & - & -- & -- \\
\hline 14 & 66 & 62 & 84 & 3.1 & 75 & 250 & .2 & $<20$ \\
\hline \multicolumn{9}{|l|}{ SEPT } \\
\hline 23 & 74 & 67 & 100 & 3.4 & 80 & 240 & -- & $<20$ \\
\hline \multicolumn{9}{|l|}{ MAR 1989} \\
\hline 15 & $-\infty$ & -- & -- & $-\infty$ & - & -- & - & -- \\
\hline 16 & 67 & 63 & 83 & 2.9 & 75 & 230 & $<.1$ & $<20$ \\
\hline \multicolumn{9}{|l|}{ JUNE } \\
\hline 02 & 61 & 58 & 84 & 2.8 & 85 & 210 & $<.2$ & $<20$ \\
\hline \multicolumn{9}{|l|}{ JULY } \\
\hline 18 & 67 & 61 & 89 & 2.9 & 75 & 230 & .7 & $<20$ \\
\hline \multicolumn{9}{|l|}{ AUG } \\
\hline 29 & 68 & 63 & 85 & 3.1 & 70 & 180 & $<.2$ & $<20$ \\
\hline \multicolumn{9}{|l|}{ JAN 1990} \\
\hline 25 & -- & -- & -- & - & -- & -- & -- & -- \\
\hline 26 & 68 & 61 & 88 & 4.1 & 80 & 230 & .2 & $<20$ \\
\hline \multicolumn{9}{|l|}{ MAY } \\
\hline 22 & 62 & 57 & 82 & 2.6 & 76 & -- & .1 & $<20$ \\
\hline \multicolumn{9}{|l|}{ JULY } \\
\hline 31 & 68 & 64 & 92 & 3.1 & 80 & 190 & .2 & $<20$ \\
\hline \multicolumn{9}{|l|}{ AUG } \\
\hline 03 & - & -- & - & -- & -- & -- & -- & -- \\
\hline \multicolumn{9}{|l|}{ SEPT } \\
\hline $\begin{array}{c}25 \\
\text { JAN } 1991\end{array}$ & 72 & 66 & 94 & 3.6 & 80 & 240 & .6 & $<40$ \\
\hline 24 & 70 & 64 & 92 & 2.2 & 76 & 180 & .4 & $<20$ \\
\hline
\end{tabular}


Table 5.--Chemical and bacteriological analyses of water from the observation wells--Continued

\begin{tabular}{|c|c|c|c|c|c|c|c|c|}
\hline $\begin{array}{l}\text { Sample } \\
\text { date }\end{array}$ & $\begin{array}{l}\text { Copper, } \\
\text { dis- } \\
\text { solved } \\
(\mu \mathrm{g} / \mathrm{L} \\
\text { as } \mathrm{Cu})\end{array}$ & $\begin{array}{l}\text { Iron, } \\
\text { dis- } \\
\text { solved } \\
(\mu \mathrm{g} / \mathrm{L} \\
\text { as } \mathrm{Fe})\end{array}$ & $\begin{array}{l}\text { Lead, } \\
\text { dis- } \\
\text { solved } \\
(\mu g / L \\
\text { as } \mathrm{Pb})\end{array}$ & $\begin{array}{c}\text { Manga- } \\
\text { nese, } \\
\text { dissolved } \\
(\mu g / L \\
\text { as Mn) }\end{array}$ & $\begin{array}{l}\text { Nickel, } \\
\text { dis- } \\
\text { solved } \\
\text { ( } \mu \mathrm{g} / \mathrm{L} \\
\text { as } \mathrm{Ni})\end{array}$ & $\begin{array}{l}\text { Zinc, } \\
\text { dis- } \\
\text { solved } \\
(\mu g / L \\
\text { as } Z n)\end{array}$ & $\begin{array}{l}\text { Coli- } \\
\text { form, } \\
\text { fecal } \\
\text { (col./ } \\
100 \mathrm{~mL} \text { ) }\end{array}$ & $\begin{array}{l}\text { St repto- } \\
\text { cocci, } \\
\text { fecal } \\
(\text { col./ } \\
100 \mathrm{~mL})\end{array}$ \\
\hline
\end{tabular}

WELL 14---Continued

JUNE 1985

\begin{tabular}{|c|c|c|c|c|c|c|c|c|}
\hline & & & & & & & & \\
\hline $\begin{array}{l}14 \\
17\end{array}$ & $\cdots$ & $<50$ & -- & -- & -- & $<20$ & -- & -- \\
\hline \multicolumn{9}{|l|}{ AUG } \\
\hline 30 & -- & -- & - & -- & -. & -- & $<1$ & $<1$ \\
\hline 31 & 10 & $<50$ & 10 & $<20$ & 310 & 10 & -- & -- \\
\hline \multicolumn{9}{|l|}{ MAY 1986} \\
\hline 27 & -- & -- & -- & -- & -- & -- & $<1$ & $<1$ \\
\hline 28 & $<20$ & $<50$ & $<20$ & $<20$ & $<20$ & $<20$ & -- & - \\
\hline \multicolumn{9}{|l|}{ AUG } \\
\hline 28 & 20 & $<50$ & $<50$ & $<20$ & $<20$ & $<20$ & $<1$ & 13 \\
\hline \multicolumn{9}{|l|}{ APR 1987} \\
\hline $\begin{array}{c}29 \\
\mathrm{MAY}\end{array}$ & $<20$ & $<50$ & $<50$ & $<20$ & $<20$ & $<20$ & -- & - \\
\hline \multicolumn{9}{|l|}{ MAY } \\
\hline \multicolumn{9}{|l|}{ JULY } \\
\hline 14 & $<20$ & 130 & $<10$ & $<20$ & 20 & 280 & $<2$ & $<2$ \\
\hline \multicolumn{9}{|l|}{ SEPT } \\
\hline $\begin{array}{c}16 \\
\text { MAR } 1988\end{array}$ & $<20$ & $<50$ & $<10$ & $<20$ & $<20$ & $<20$ & -- & $<2$ \\
\hline 15 & $<20$ & $<50$ & $<10$ & $<20$ & $<20$ & $<20$ & -- & -- \\
\hline 17 & -- & -- & -- & -- & - & -- & $<2$ & $<2$ \\
\hline \multicolumn{9}{|l|}{ JULY } \\
\hline 13 & -- & -- & -- & - & -- & -- & $<2$ & $<2$ \\
\hline 14 & $<20$ & $<50$ & $<10$ & $<20$ & $<20$ & $<20$ & -- & -- \\
\hline \multicolumn{9}{|l|}{ SEPT } \\
\hline \multicolumn{9}{|l|}{ MAR 1989} \\
\hline 15 & -- & -- & -- & -- & -- & -- & $<2$ & 33 \\
\hline 16 & $<20$ & $<50$ & $<10$ & $<20$ & $<20$ & $<20$ & -- & - \\
\hline \multicolumn{9}{|l|}{ JUNE } \\
\hline \multirow{2}{*}{\multicolumn{9}{|c|}{ JULY }} \\
\hline & & & & & & & & \\
\hline \multicolumn{9}{|l|}{ AUG } \\
\hline 29 & $<20$ & $<50$ & $<10$ & $<20$ & $<20$ & $<30$ & $<2$ & $<2$ \\
\hline \multicolumn{9}{|l|}{ JAN 1990} \\
\hline 25 & -- & - & -- & -- & - & -- & $<20$ & $<20$ \\
\hline \multirow{2}{*}{\multicolumn{9}{|c|}{ MAY }} \\
\hline & & & & & & & & \\
\hline \multicolumn{5}{|l|}{ JULY } & 40 & $<20$ & $<20$ & $<20$ \\
\hline 31 & $<20$ & $<50$ & $<10$ & $<20$ & $<20$ & 80 & $<20$ & $<20$ \\
\hline \multicolumn{9}{|l|}{ AUG } \\
\hline $\begin{aligned} 03 \\
0\end{aligned}$ & -- & -- & -- & -- & -- & -- & -- & - \\
\hline \multicolumn{9}{|l|}{ SEPT } \\
\hline $\begin{array}{c}25 \\
\text { JAN } 1991\end{array}$ & $<40$ & $<100$ & $<10$ & $<40$ & $<40$ & $<40$ & $<20$ & $<20$ \\
\hline 24 & $<20$ & $<50$ & $<10$ & $<20$ & $<20$ & $<20$ & $<20$ & $<20$ \\
\hline
\end{tabular}


Table 5.--Chemical and bacteriological analyses of water

from the observation wells--Continued

\begin{tabular}{|c|c|c|c|c|c|c|c|c|c|c|}
\hline $\begin{array}{c}\text { Sample } \\
\text { date }\end{array}$ & $\begin{array}{l}\text { Spe- } \\
\text { cific } \\
\text { con- } \\
\text { duct- } \\
\text { ance } \\
(\mu \mathrm{S} / \mathrm{cm})\end{array}$ & $\begin{array}{c}\mathrm{pH} \\
\text { (units) }\end{array}$ & $\begin{array}{l}\text { Residue } \\
\text { at } \\
105^{\circ} \mathrm{C}, \\
\text { dis- } \\
\text { solved } \\
\text { (mg/L) }\end{array}$ & $\begin{array}{c}\text { Nitrogen, } \\
\text { ammonia, } \\
\text { dis- } \\
\text { solved } \\
(\mathrm{mg} / \mathrm{L} \\
\text { as } \mathrm{N})\end{array}$ & $\begin{array}{l}\text { Nitrogen, } \\
\text { nitrite, } \\
\text { dis- } \\
\text { solved } \\
\text { (mg/L } \\
\text { as N) }\end{array}$ & $\begin{array}{l}\text { Nitrogen, } \\
\text { ammonia, } \\
\text { torganic, } \\
\text { dissolved } \\
\text { (mg/L } \\
\text { as N) }\end{array}$ & $\begin{array}{c}\text { Nitrogen, } \\
\mathrm{NO}_{2}+\mathrm{NO}_{3} \\
\text { dis- } \\
\text { solved } \\
\text { (mg/L } \\
\text { as } \mathrm{N} \text { ) }\end{array}$ & $\begin{array}{l}\text { Phos- } \\
\text { phorus, } \\
\text { ortho, } \\
\text { dissolved } \\
\text { (mg/L } \\
\text { as P) }\end{array}$ & $\begin{array}{l}\text { Hard- } \\
\text { ness, } \\
\text { total } \\
(\mathrm{mg} / \mathrm{L} \\
\text { as } \\
\left.\mathrm{CaCO}_{3}\right)\end{array}$ & $\begin{array}{l}\text { Cal- } \\
\text { cium, } \\
\text { dis- } \\
\text { solved } \\
\text { (mg/L } \\
\text { as Ca) }\end{array}$ \\
\hline
\end{tabular}

WELL 15

JUNE 1985

\begin{tabular}{|c|c|c|c|c|c|c|c|c|c|c|}
\hline 14 & -- & -- & 3,110 & 0.040 & 0.090 & 1.1 & 6.20 & $<0.020$ & 1,700 & 130 \\
\hline 17 & -- & -- & -- & -- & -- & -- & -- & -- & -- & -- \\
\hline \multicolumn{11}{|l|}{ AUG } \\
\hline 30 & -- & -- & -- & -- & -- & -- & -- & -- & -- & -- \\
\hline$\stackrel{31}{\text { MAY } 1986}$ & 3,500 & 7.6 & 3,090 & .100 & .030 & .90 & 7.70 & $<.020$ & 1,700 & 160 \\
\hline 27 & -- & -- & -- & -- & -- & -- & -- & -- & -- & - \\
\hline 28 & 4,000 & 8.0 & 2,700 & $<.100$ & $<.010$ & .80 & 8.10 & $<.020$ & 1,400 & 130 \\
\hline \multicolumn{11}{|l|}{ AUG } \\
\hline $\begin{array}{c}28 \\
\text { APR } 1987\end{array}$ & 3,400 & 7.5 & 2,870 & $<.100$ & $<.010$ & .90 & 8.13 & $<.020$ & 1,400 & 120 \\
\hline 28 & -- & -- & -- & -- & -- & -- & - & - & - & -- \\
\hline 29 & 3,400 & 7.8 & 3,110 & $<.100$ & $<.010$ & .90 & 6.00 & $<.020$ & 1,800 & 160 \\
\hline & \multicolumn{10}{|c|}{ JUY } \\
\hline \multicolumn{11}{|l|}{ SEPT } \\
\hline$\stackrel{16}{\text { MAR } 1988}$ & 4,000 & 7.5 & 3,100 & $<.100$ & $<.020$ & $<.30$ & 8.30 & $<.020$ & 1,700 & 170 \\
\hline 15 & 3,150 & 7.7 & 3,040 & .200 & .030 & .60 & 7.80 & .040 & 1,500 & 140 \\
\hline 17 & -- & -- & -- & -- & -- & -- & -- & -- & - & -- \\
\hline \multicolumn{11}{|l|}{ JULY } \\
\hline 13 & -- & -- & -- & -- & -- & -- & -- & -- & -- & -- \\
\hline 14 & 3,250 & 7.4 & 2,830 & $<.100$ & .150 & .30 & 3.60 & $<.020$ & 1,400 & 130 \\
\hline \multicolumn{11}{|l|}{ SEPT } \\
\hline 02 & -- & -- & -- & -- & -- & -- & -- & -- & -- & -- \\
\hline 23 & 2,930 & 7.7 & 2,560 & $<.100$ & .020 & $<.30$ & 1.54 & .020 & 1,400 & 120 \\
\hline \multicolumn{11}{|l|}{ MAR 1989} \\
\hline 15 & -- & -- & -- & -- & -- & -- & -- & -- & -- & -- \\
\hline 16 & 2,760 & 7.7 & 2,260 & $<.100$ & $<.020$ & .40 & 4.88 & $<.020$ & 1,200 & 120 \\
\hline \multicolumn{11}{|l|}{ JUNE } \\
\hline 02 & 2,750 & 7.7 & 2,430 & $<.200$ & $<.020$ & .60 & 8.20 & $<.020$ & 1,300 & 120 \\
\hline \multicolumn{11}{|l|}{ JULY } \\
\hline \multicolumn{10}{|l|}{ AUG } & 170 \\
\hline 29 & 2,770 & 7.7 & 2,250 & $<.100$ & .040 & 1.3 & 10.0 & $<.020$ & 1,100 & 120 \\
\hline \multicolumn{11}{|l|}{ JAN 1990} \\
\hline $\begin{array}{l}25 \\
26\end{array}$ & $\overline{-}$ & $-\overline{0}$ & $\overline{-10}$ & $\overline{-}$ & $\overline{--}$ & -- & -- & -- & $-\overline{-}$ & $r$ \\
\hline \multicolumn{11}{|l|}{ MAY } \\
\hline 22 & -- & -- & 1,680 & .300 & $<.020$ & 1.2 & 8.10 & .070 & 780 & 72 \\
\hline \multicolumn{11}{|l|}{ JULY } \\
\hline 31 & 2,160 & 7.6 & 1,600 & .300 & $<.020$ & $<.30$ & 10.5 & .020 & 820 & 74 \\
\hline \multicolumn{11}{|l|}{ SEPT } \\
\hline$\stackrel{25}{\text { JAN } 1991}$ & 2,160 & 7.6 & 1,680 & $<.100$ & $<.020$ & 1.4 & 9.60 & .050 & 850 & 0 \\
\hline 24 & 2,240 & 7.9 & 1,690 & $<.100$ & $<.020$ & .70 & 12.0 & .090 & 790 & 59 \\
\hline
\end{tabular}


Table 5.--Chemical and bacteriological analyses of water

from the observation wells--Continued

\begin{tabular}{|c|c|c|c|c|c|c|c|c|c|c|c|}
\hline $\begin{array}{c}\text { Sample } \\
\text { date }\end{array}$ & $\begin{array}{c}\text { Magne- } \\
\text { sium, } \\
\text { dis- } \\
\text { solved } \\
\text { (mg/L } \\
\text { as } \mathrm{Mg} \text { ) }\end{array}$ & $\begin{array}{l}\text { Sodium, } \\
\text { dis- } \\
\text { solved } \\
\text { (mg/L } \\
\text { as } \mathrm{Na} \text { ) }\end{array}$ & $\begin{array}{l}\text { Potas- } \\
\text { sium, } \\
\text { dis- } \\
\text { solved } \\
(\mathrm{mg} / \mathrm{L} \\
\text { as } \mathrm{K})\end{array}$ & $\begin{array}{l}\text { Chlo- } \\
\text { ride, } \\
\text { dis- } \\
\text { solved } \\
\text { (mg/L } \\
\text { as }(1)\end{array}$ & $\begin{array}{c}\text { Sulfate, } \\
\text { dis- } \\
\text { solved } \\
(\mathrm{mg} / \mathrm{L} \\
\left.\text { as } \mathrm{SO}_{4}\right)\end{array}$ & $\begin{array}{c}\text { Cadmi um, } \\
\text { dis- } \\
\text { solved } \\
(\mu g / L \\
\text { as Cd) }\end{array}$ & $\begin{array}{l}\text { Chro- } \\
\text { mium, } \\
\text { dis- } \\
\text { solved } \\
(\mu g / L \\
\text { as Cr) }\end{array}$ & $\begin{array}{c}\text { Copper, } \\
\text { dis- } \\
\text { solved } \\
\left(\mu_{g} / L\right. \\
\text { as } \mathrm{Cu})\end{array}$ & $\begin{array}{l}\text { Iron, } \\
\text { dis- } \\
\text { solved } \\
\left(\mu_{g} / L\right. \\
\text { as Fe) }\end{array}$ & $\begin{array}{l}\text { Lead, } \\
\text { dis- } \\
\text { solved } \\
(\mu \mathrm{g} / \mathrm{L} \\
\text { as } \mathrm{Pb})\end{array}$ & $\begin{array}{l}\text { Manga- } \\
\text { nese, } \\
\text { dis- } \\
\text { solved } \\
(\mu g / L \\
\text { as } M n)\end{array}$ \\
\hline
\end{tabular}

WELL 15--Continued

JUNE 1985

\begin{tabular}{|c|c|c|c|c|c|c|c|c|c|c|c|}
\hline 14 & 330 & 360 & 15 & 57 & 2,000 & -- & -- & -- & $<50$ & -- & -- \\
\hline 17 & -- & -- & - & -- & -- & -- & -- & - & - & - & - \\
\hline \multicolumn{12}{|l|}{ AUG } \\
\hline 30 & -- & -- & -- & -- & -- & -- & - & -- & -- & -- & - \\
\hline 31 & 310 & 320 & 7.9 & 45 & 1,900 & 0.6 & $<20$ & 10 & 30 & 10 & 20 \\
\hline \multicolumn{12}{|l|}{ MAY 1986} \\
\hline 27 & -- & -- & -- & -- & -- & -- & -- & -- & -- & -- & -- \\
\hline 28 & 270 & 310 & 6.0 & 40 & 1,500 & $<.1$ & $<20$ & $<20$ & $<50$ & $<40$ & $<20$ \\
\hline \multicolumn{12}{|l|}{ AUG } \\
\hline 28 & 270 & 290 & 8.0 & 54 & 1,700 & .7 & 80 & $<40$ & 420 & $<80$ & $<40$ \\
\hline \multicolumn{12}{|l|}{ APR 1987} \\
\hline 28 & -- & -- & -- & -- & -- & -- & $\cdots$ & -- & -- & - & -- \\
\hline 29 & 350 & 300 & 6.4 & 53 & 1,800 & $<.2$ & $<20$ & $<20$ & $<50$ & $<50$ & $<20$ \\
\hline \multicolumn{12}{|l|}{ JULY } \\
\hline 14 & 310 & 300 & 7.0 & 47 & 1,800 & .5 & $<40$ & $<40$ & 220 & $<10$ & $<20$ \\
\hline \multicolumn{12}{|l|}{ SEPT } \\
\hline${ }_{\text {MAR }}^{16} 1988$ & 310 & 350 & 7.5 & 50 & 2,000 & $<.2$ & $<20$ & $<20$ & $<50$ & $<10$ & $<20$ \\
\hline 15 & 280 & 360 & 6.1 & 43 & 1,700 & 2.4 & $<20$ & $<20$ & $<50$ & $<10$ & $<20$ \\
\hline 17 & -- & -- & -- & -- & -- & -- & -- & -- & -- & -- & -- \\
\hline \multicolumn{12}{|l|}{ JULY } \\
\hline 13 & -- & -- & -- & -- & -- & -- & -- & -- & -- & -- & -- \\
\hline 14 & 270 & 310 & 6.8 & 42 & 1,500 & .4 & $<20$ & $<20$ & 70 & $<10$ & 20 \\
\hline \multicolumn{12}{|l|}{ SEPT } \\
\hline 02 & -- & -- & -- & -- & -- & -- & -- & -- & -- & -- & -- \\
\hline 23 & 250 & 300 & 7.6 & 38 & 1,500 & .2 & $<20$ & $<20$ & $<50$ & $<10$ & -- \\
\hline \multicolumn{12}{|l|}{ MAR 1989} \\
\hline 15 & -- & -- & -- & -- & -- & -- & -- & -- & -- & -- & -- \\
\hline 16 & 220 & 230 & 5.2 & 31 & 1,400 & 1.9 & $<20$ & $<20$ & 80 & $<10$ & $<20$ \\
\hline \multicolumn{12}{|l|}{ JUNE } \\
\hline 02 & 240 & 290 & 5.8 & 43 & 1,300 & $<.2$ & $<20$ & $<40$ & $<100$ & $<10$ & $<40$ \\
\hline \multicolumn{12}{|l|}{ JULY } \\
\hline AUG $^{18}$ & 180 & 280 & 3.4 & 38 & 1,200 & 2.4 & $<20$ & $<20$ & $<50$ & $<10$ & $<20$ \\
\hline 29 & 210 & 270 & 6.6 & 35 & 1,200 & $<.2$ & $<20$ & $<20$ & $<50$ & $<10$ & $<20$ \\
\hline \multicolumn{12}{|l|}{ JAN 1990} \\
\hline 25 & -- & -- & -- & -- & -- & -- & -- & -- & -- & -- & -- \\
\hline 26 & 180 & 230 & 5.5 & 50 & 1,000 & .1 & $<200$ & $<200$ & $<500$ & $<10$ & $<200$ \\
\hline \multicolumn{12}{|l|}{ MAY } \\
\hline 22 & 150 & 210 & 5.3 & 46 & 850 & .1 & $<20$ & $<20$ & $<50$ & $<10$ & $<20$ \\
\hline \multicolumn{12}{|l|}{ JULY } \\
\hline $\begin{array}{l}31 \\
\text { SEPT }\end{array}$ & 150 & 210 & 6.0 & 49 & 710 & .2 & $<40$ & $<40$ & $<100$ & $<10$ & $<40$ \\
\hline $\begin{array}{c}25 \\
\text { JAN } 1991\end{array}$ & 160 & 140 & 6.8 & 72 & 640 & .1 & $<40$ & $<40$ & $<100$ & $<10$ & $<40$ \\
\hline 24 & 150 & 200 & 4.7 & 89 & 700 & 1.0 & $<20$ & $<20$ & $<50$ & $<10$ & $<20$ \\
\hline
\end{tabular}


Table 5.--Chemical and bacteriological analyses of water from the observation wells--Continued

\begin{tabular}{|c|c|c|c|c|c|c|c|c|c|c|}
\hline $\begin{array}{c}\text { Sample } \\
\text { date }\end{array}$ & $\begin{array}{l}\text { Nickel, } \\
\text { dis- } \\
\text { solved } \\
(\mu \mathrm{g} / \mathrm{L} \\
\text { as } \mathrm{Ni})\end{array}$ & $\begin{array}{l}\text { Zinc, } \\
\text { dis- } \\
\text { solved } \\
(\mu g / L \\
\text { as } Z n)\end{array}$ & $\begin{array}{l}\text { Coli- } \\
\text { form, } \\
\text { fecal } \\
\text { (col./ } \\
100 \mathrm{~mL})\end{array}$ & $\begin{array}{l}\text { Strepto- } \\
\text { cocci, } \\
\text { fecal } \\
(\text { col. } \\
100 \mathrm{~mL})\end{array}$ & $\begin{array}{c}\text { Dichloro- } \\
\text { bromo- } \\
\text { methane, } \\
\text { total } \\
(\mu g / L)\end{array}$ & $\begin{array}{c}\text { Carbon } \\
\text { tetra- } \\
\text { chloride, } \\
\text { total } \\
(\mu g / L)\end{array}$ & $\begin{array}{l}1,2-d i- \\
\text { chloro- } \\
\text { ethane, } \\
\text { total } \\
(\mu g / L)\end{array}$ & $\begin{array}{l}\text { Bromo- } \\
\text { form, } \\
\text { total } \\
(\mu g / L)\end{array}$ & $\begin{array}{l}\text { Chloro- } \\
\text { dibromo- } \\
\text { methane, } \\
\text { total } \\
(\mu \mathrm{g} / \mathrm{L})\end{array}$ & $\begin{array}{c}\text { Chloro- } \\
\text { form, } \\
\text { total } \\
\left(\mu_{g} / L\right)\end{array}$ \\
\hline
\end{tabular}

WELL 15--Continued

JUNE 1985

\begin{tabular}{|c|c|c|c|c|c|c|c|c|c|c|}
\hline 14 & -- & 10 & - & -- & -- & -- & -- & - & - & - \\
\hline 17 & - & - & $<1$ & 1 & - & - & - & -- & - & -- \\
\hline \multicolumn{11}{|l|}{ AUG } \\
\hline 30 & -- & -- & $<1$ & $<1$ & -- & -- & - & -- & -- & -- \\
\hline 31 & 160 & 30 & - & -- & $\cdots$ & -- & -- & -- & -- & - \\
\hline \multicolumn{11}{|l|}{ MAY 1986} \\
\hline 27 & -- & -- & - & 1 & -- & -- & - & -- & -- & $\ldots$ \\
\hline 28 & $<60$ & $<20$ & -- & -- & -- & -- & -- & -- & -- & -- \\
\hline \multicolumn{11}{|l|}{ AUG } \\
\hline $\begin{array}{c}28 \\
\text { APR } 1987\end{array}$ & 120 & 60 & \multicolumn{8}{|c|}{ APR 1987} \\
\hline 28 & -- & $\cdots$ & $<1$ & $<1$ & $\cdots$ & -- & - & - & - & -. \\
\hline 29 & $<20$ & $<20$ & -- & -- & -- & -- & -- & -- & -- & -- \\
\hline \multicolumn{11}{|l|}{ JULY } \\
\hline \multirow{2}{*}{\multicolumn{11}{|c|}{ SEPT }} \\
\hline & & & & & & & & & & \\
\hline$\stackrel{16}{\text { MAR }} 1988^{16}$ & \multicolumn{9}{|c|}{ MAR 1988} & -- \\
\hline 15 & 30 & $<20$ & -- & -- & -- & -- & -- & -- & -- & -- \\
\hline 17 & -- & -- & $<2$ & $<2$ & -- & -- & -- & -- & -- & - \\
\hline \multicolumn{11}{|l|}{ JULY } \\
\hline 13 & -- & - & $<2$ & $<2$ & -- & -- & -- & -- & -- & - \\
\hline 14 & 40 & $<20$ & -- & -- & -- & -- & -- & -- & -- & -- \\
\hline \multicolumn{11}{|l|}{ SEPT } \\
\hline 02 & -- & -- & -- & -- & $<3.0$ & $<3.0$ & $<3.0$ & $<3.0$ & $<3.0$ & $<3.0$ \\
\hline 23 & 20 & $<20$ & $<2$ & 2 & -- & -- & -- & -- & -- & -- \\
\hline \multicolumn{11}{|l|}{ MAR 1989} \\
\hline 15 & -- & -- & $<2$ & 40 & -- & - & -- & -- & -- & -- \\
\hline 16 & $<20$ & $<20$ & -- & -- & -- & -- & -- & -- & -- & - \\
\hline \multicolumn{11}{|l|}{ JUNE } \\
\hline 02 & $<20$ & $<20$ & $<2$ & 27 & -- & - & -- & -- & -- & - \\
\hline \multicolumn{11}{|l|}{ JULY } \\
\hline 18 & $<20$ & $<20$ & $<2$ & 33 & - & -- & -- & - & - & -- \\
\hline \multicolumn{11}{|l|}{ AUG } \\
\hline 29 & $<20$ & $<20$ & $<2$ & $<2$ & -- & - & -- & -- & -- & - \\
\hline \multicolumn{11}{|l|}{ JAN 1990} \\
\hline 25 & -- & -- & $<20$ & $<20$ & -- & -- & -- & -- & -- & -- \\
\hline 26 & $<200$ & -- & - & -- & -- & -- & -- & -- & -- & -- \\
\hline \multicolumn{11}{|l|}{ MAY } \\
\hline 22 & 30 & $<20$ & $<20$ & $<20$ & - & -- & -- & -- & -- & -- \\
\hline \multicolumn{11}{|l|}{ JULY } \\
\hline 31 & 20 & 20 & $<20$ & 110 & -- & -- & -- & -- & -- & -- \\
\hline \multicolumn{11}{|l|}{ SEPT } \\
\hline 25 & $<40$ & $<40$ & $<20$ & $<20$ & -- & -- & - & -- & -- & $\cdots$ \\
\hline $\begin{array}{l}\text { JAN } 1991 \\
24\end{array}$ & 20 & $<20$ & $<20$ & $<20$ & - & -- & -- & - & -- & -- \\
\hline
\end{tabular}


Table 5.--Chemical and bacteriological analyses of water from the observation wells--Continued

\begin{tabular}{|c|c|c|c|c|c|c|c|c|c|c|}
\hline $\begin{array}{c}\text { Sample } \\
\text { date }\end{array}$ & $\begin{array}{c}\text { Toluene, } \\
\text { total } \\
(\mu g / L)\end{array}$ & $\begin{array}{l}\text { Benzene, } \\
\text { total } \\
(\mu \mathrm{g} / \mathrm{L})\end{array}$ & $\begin{array}{l}\text { Chloro- } \\
\text { benzene, } \\
\text { total } \\
(\mu \mathrm{g} / \mathrm{L})\end{array}$ & $\begin{array}{l}\text { Chloro- } \\
\text { ethane, } \\
\text { total } \\
(\mu \mathrm{g} / \mathrm{L})\end{array}$ & $\begin{array}{c}\text { Ethyl- } \\
\text { benzene, } \\
\text { total } \\
(\mu \mathrm{g} / \mathrm{L})\end{array}$ & $\begin{array}{l}\text { Methyl- } \\
\text { bromide, } \\
\text { total } \\
\left(\mu_{\mathrm{g}} / \mathrm{L}\right)\end{array}$ & $\begin{array}{c}\text { Methyl- } \\
\text { chloride, } \\
\text { total } \\
\left(\mu_{\mathrm{g}} / \mathrm{L}\right)\end{array}$ & $\begin{array}{l}\text { Methyl- } \\
\text { ene } \\
\text { chlo- } \\
\text { ride, } \\
\text { total } \\
(\mu \mathrm{g} / \mathrm{L})\end{array}$ & $\begin{array}{l}\text { Tetra- } \\
\text { chloro- } \\
\text { ethyl- } \\
\text { ene, } \\
\text { total } \\
(\mu \mathrm{g} / \mathrm{L})\end{array}$ & $\begin{array}{l}\text { Tri- } \\
\text { chloro- } \\
\text { fluoro- } \\
\text { methane, } \\
\text { total } \\
(\mu g / L)\end{array}$ \\
\hline
\end{tabular}

WELL 15--Continued

\begin{tabular}{|c|c|c|c|c|c|c|c|c|c|c|}
\hline \multicolumn{11}{|l|}{ JUNE 1985} \\
\hline 14 & -- & -- & -- & -- & -- & -- & -- & -- & -- & -- \\
\hline 17 & -- & -- & -- & -- & -- & -- & -- & -- & -- & -- \\
\hline \multicolumn{11}{|l|}{ AUG } \\
\hline 30 & -- & -- & -- & -- & -- & -- & -- & -- & -- & -- \\
\hline 31 & -- & -- & -- & -- & -- & -- & -- & - & -- & -- \\
\hline \multicolumn{11}{|l|}{ MAY 1986} \\
\hline 27 & -- & -- & -- & -- & -- & -- & -- & -- & -- & -- \\
\hline 28 & -- & -- & -- & -- & -- & -- & -- & -- & -- & -- \\
\hline \multicolumn{11}{|l|}{ AUG } \\
\hline 28 & -- & -- & -- & -- & -- & -- & -- & -- & -- & -- \\
\hline \multicolumn{11}{|l|}{ APR 1987} \\
\hline 28 & -- & -- & -- & -- & -- & -- & -- & $-\infty$ & -- & -- \\
\hline 29 & -- & -- & -- & -- & -- & -- & -- & -- & -- & -- \\
\hline \multicolumn{11}{|l|}{ JULY } \\
\hline 14 & -- & -- & -- & -- & -- & -- & -- & -- & -- & -- \\
\hline \multicolumn{11}{|l|}{ SEPT } \\
\hline $\begin{array}{c}16 \\
\text { MAR } 1988\end{array}$ & - & -- & -- & -- & -- & -- & -- & -- & -- & -- \\
\hline 15 & -- & -- & -- & -- & -- & -- & -- & -- & -- & -- \\
\hline 17 & -- & -- & -- & -- & -- & -- & -- & -- & -- & -- \\
\hline \multicolumn{11}{|l|}{ JULY } \\
\hline 13 & -- & -- & -- & -- & -- & -- & -- & -- & -- & -- \\
\hline 14 & -- & -- & -- & -- & -- & -- & -- & -- & -- & -- \\
\hline \multicolumn{11}{|l|}{ SEPT } \\
\hline 02 & $<3.0$ & $<3.0$ & $<3.0$ & $<3.0$ & $<3.0$ & $<3.0$ & $<3.0$ & $<3.0$ & $<3.0$ & $<3.0$ \\
\hline 23 & -- & -- & -- & -- & -- & -- & -- & -- & -- & -- \\
\hline
\end{tabular}


Table 5.--Chemical and bacteriological analyses of water from the observation wells--Continued

\begin{tabular}{|c|c|c|c|c|c|c|c|c|c|c|}
\hline $\begin{array}{c}\text { Sample } \\
\text { date }\end{array}$ & $\begin{array}{c}1,1 \text {-di- } \\
\text { chloro- } \\
\text { ethane, } \\
\text { total } \\
(\mu g / L)\end{array}$ & $\begin{array}{l}\text { 1,1-di- } \\
\text { chloro- } \\
\text { ethyl- } \\
\text { ene, } \\
\text { total } \\
(\mu g / L)\end{array}$ & $\begin{array}{c}1,1,1- \\
\text { tri- } \\
\text { chloro- } \\
\text { ethane, } \\
\text { total } \\
(\mu \mathrm{g} / \mathrm{L})\end{array}$ & $\begin{array}{c}1,1,2- \\
\text { tri- } \\
\text { chloro- } \\
\text { ethane, } \\
\text { total } \\
(\mu g / L)\end{array}$ & $\begin{array}{l}1,1,2,2 \\
\text { tetra- } \\
\text { chloro- } \\
\text { ethane, } \\
\text { total } \\
(\mu \mathrm{g} / L)\end{array}$ & $\begin{array}{c}1,2-\mathrm{di}- \\
\text { chloro- } \\
\text { benzene, } \\
\text { total } \\
(\mu \mathrm{g} / \mathrm{L})\end{array}$ & $\begin{array}{l}1,2-d i- \\
\text { chloro- } \\
\text { propane, } \\
\text { total } \\
(\mu g / L)\end{array}$ & $\begin{array}{c}\text { Trans- } \\
\text { 1,2-di- } \\
\text { chloro- } \\
\text { ethane, } \\
\text { total } \\
(\mu \mathrm{g} / \mathrm{L})\end{array}$ & $\begin{array}{c}1,3-d i- \\
\text { chloro- } \\
\text { propene, } \\
\text { total } \\
\left(\mu_{\mathrm{g}} / \mathrm{L}\right)\end{array}$ & $\begin{array}{c}1,3-\mathrm{di}- \\
\text { chloro- } \\
\text { benzene, } \\
\text { total } \\
\left(\mu_{\mathrm{g}} / \mathrm{L}\right)\end{array}$ \\
\hline
\end{tabular}

WELL 15--Continued

JUNE 1985

\begin{tabular}{|c|c|c|c|c|c|c|c|c|c|c|}
\hline 14 & - & - & - & - & - & - & - & -- & -. & - \\
\hline 17 & -- & -- & -- & -- & -- & -- & -- & -- & -- & -- \\
\hline \multicolumn{11}{|l|}{ AUG } \\
\hline 30 & -- & -- & -- & -- & -- & -- & -- & -- & -- & -- \\
\hline 31 & -- & -- & - & - & -- & $\cdots$ & -- & -- & -- & -- \\
\hline \multicolumn{11}{|l|}{ MAY 1986} \\
\hline 27 & -- & -- & -- & - & - & - & -- & -- & -- & -- \\
\hline 28 & -- & -- & -- & $m$ & - & - & -- & - & - & -- \\
\hline \multicolumn{11}{|l|}{ AUG } \\
\hline 28 & - & - & - & - & -- & - & -- & -- & -- & -- \\
\hline \multicolumn{11}{|l|}{ APR 1987} \\
\hline 28 & -- & -- & -- & - & - & -- & -- & -- & -- & -- \\
\hline 29 & -- & - & -- & -- & -- & -- & -- & -- & -- & -- \\
\hline \multicolumn{11}{|l|}{ JULY } \\
\hline \multicolumn{11}{|l|}{ SEPT } \\
\hline $\begin{array}{l}16 \\
\text { MAR } 1988\end{array}$ & - & -- & -- & - & $\cdots$ & -. & - & $\ldots$ & - & - \\
\hline 15 & -- & -- & -- & -- & - & -- & -- & - & -- & -- \\
\hline 17 & -- & -- & -- & -- & -- & - & $\cdots$ & -- & -- & -- \\
\hline \multicolumn{11}{|l|}{ JULY } \\
\hline 13 & -- & - & - & - & -- & -- & -- & -- & -- & -- \\
\hline 14 & - & $-\cdots$ & - & -- & $\cdots$ & - & $\cdots$ & -- & -- & -- \\
\hline \multicolumn{11}{|l|}{ SEPT } \\
\hline 02 & $<3.0$ & $<3.0$ & $<3.0$ & $<3.0$ & $<3.0$ & $<3.0$ & $<3.0$ & $<3.0$ & $<3.0$ & $<3.0$ \\
\hline 23 & -- & -- & -- & - & -- & -- & -- & -- & -- & 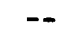 \\
\hline
\end{tabular}


Table 5.--Chemical and bacteriological analyses of water from the observation wells--Continued

\begin{tabular}{|c|c|c|c|c|c|c|c|c|c|}
\hline $\begin{array}{c}\text { Sample } \\
\text { date }\end{array}$ & $\begin{array}{l}1,4,-\mathrm{di}- \\
\text { chloro- } \\
\text { benzene, } \\
\text { total } \\
\left(\mu_{\mathrm{g}} / \mathrm{L}\right)\end{array}$ & $\begin{array}{l}\text { 2-chloro- } \\
\text { ethyl- } \\
\text { vinyl- } \\
\text { ether, } \\
\text { total } \\
\left(\mu_{\mathrm{g}} / \mathrm{L}\right)\end{array}$ & $\begin{array}{c}\text { Dichloro- } \\
\text { difluoro- } \\
\text { methane, } \\
\text { total } \\
\left(\mu_{g} / L\right)\end{array}$ & $\begin{array}{l}\text { Trans- } \\
1,3-d i- \\
\text { chloro- } \\
\text { propene, } \\
\text { total } \\
(\mu \mathrm{g} / \mathrm{L})\end{array}$ & $\begin{array}{l}\text { Cis- } \\
1,3-\text { di- } \\
\text { chloro- } \\
\text { propene, } \\
\text { total } \\
(\mu \mathrm{g} / \mathrm{L})\end{array}$ & $\begin{array}{c}\text { Vinyl } \\
\text { chloride, } \\
\text { total } \\
\left(\mu_{8} / L\right)\end{array}$ & $\begin{array}{c}\text { Tri- } \\
\text { chloro- } \\
\text { ethylene, } \\
\text { total } \\
\left(\mu_{8} / L\right)\end{array}$ & $\begin{array}{c}\text { Styrene, } \\
\text { total } \\
\left(\mu_{g} / L\right)\end{array}$ & $\begin{array}{l}\text { Xylene, } \\
\text { total } \\
\text { tot rec } \\
\left(\mu_{g} / \mathrm{L}\right)\end{array}$ \\
\hline
\end{tabular}

WELL 15--Continued

\begin{tabular}{|c|c|c|c|c|c|c|c|c|c|}
\hline \multirow{2}{*}{\multicolumn{10}{|c|}{ JUNE 1985}} \\
\hline & & & & & & & & & \\
\hline 14 & -- & -- & $\rightarrow$ & $\rightarrow$ & -- & -- & -- & -- & -- \\
\hline 17 & -- & -- & -- & -- & -- & -- & -- & -- & -- \\
\hline \multicolumn{10}{|l|}{ AUG } \\
\hline 30 & -- & -- & -- & -- & -- & -- & -- & -- & -- \\
\hline 31 & $\rightarrow$ & -- & -- & -- & -- & -- & -- & -- & -- \\
\hline \multicolumn{10}{|l|}{ MAY 1986} \\
\hline 27 & -- & -- & -- & -- & -- & -- & -- & -- & -- \\
\hline 28 & -- & -- & -- & -- & -- & -- & -- & -- & -- \\
\hline \multicolumn{10}{|l|}{ AUG } \\
\hline \multirow{2}{*}{\multicolumn{10}{|c|}{ APR 1987}} \\
\hline & & & & & & & & & \\
\hline 28 & -- & -- & -- & -- & -- & - & -- & -- & -- \\
\hline 29 & -- & -- & -- & -- & - & -- & -- & -- & -- \\
\hline \multicolumn{10}{|l|}{ JULY } \\
\hline 14 & -- & -- & -- & -- & -- & - & -- & -- & -- \\
\hline \multicolumn{10}{|l|}{ SEPT } \\
\hline $\begin{array}{c}16 \\
\text { MAR } 1988\end{array}$ & \multicolumn{8}{|c|}{ MAR 1988} & -- \\
\hline 15 & -- & -- & -- & -- & -- & -- & -- & -- & -- \\
\hline 17 & -- & -- & -- & -- & - & -- & -- & -- & -- \\
\hline \multicolumn{10}{|l|}{ JULY } \\
\hline 13 & -- & -- & -- & -- & -- & -- & -- & -- & -- \\
\hline 14 & -- & -- & -- & -- & -- & -- & -- & -- & -- \\
\hline \multicolumn{10}{|l|}{ SEPT } \\
\hline 02 & $<3.0$ & $<3.0$ & $<3.0$ & $<3.0$ & $<3.0$ & $<3.0$ & $<3.0$ & $<3.0$ & $<3.0$ \\
\hline 23 & $\cdots$ & -- & - & -- & $=$ & -- & -- & -- & -- \\
\hline
\end{tabular}


Table 5.--Chemical and bacteriological analyses of water from the observation wells--Continued

\begin{tabular}{|c|c|c|c|c|c|c|c|c|c|}
\hline $\begin{array}{c}\text { Sample } \\
\text { date }\end{array}$ & $\begin{array}{c}\text { Specific } \\
\text { conduct- } \\
\text { ance } \\
(\mu \mathrm{S} / \mathrm{cm})\end{array}$ & $\begin{array}{c}\mathrm{pH} \\
\text { (units) }\end{array}$ & $\begin{array}{l}\text { Residue } \\
\text { at } \\
105^{\circ} \mathrm{C}, \\
\text { dis- } \\
\text { solved } \\
\text { (mg/L) }\end{array}$ & $\begin{array}{l}\text { Nitrogen, } \\
\text { ammonia, } \\
\text { dis- } \\
\text { solved } \\
\text { (mg/L } \\
\text { as N) }\end{array}$ & $\begin{array}{c}\text { Nitrogen, } \\
\text { nitrite, } \\
\text { dis- } \\
\text { solved } \\
(\mathrm{mg} / \mathrm{L} \\
\text { as } N)\end{array}$ & $\begin{array}{l}\text { Nitrogen, } \\
\text { ammonia, } \\
\text { torganic, } \\
\text { dissolved } \\
\text { (mg/L } \\
\text { as } N \text { ) }\end{array}$ & $\begin{array}{c}\mathrm{Nitrogen}, \\
\mathrm{NO}_{2}+\mathrm{NO}_{3} \\
\text { dis- } \\
\text { solved } \\
(\mathrm{mg} / \mathrm{L} \\
\text { as } \mathrm{N})\end{array}$ & $\begin{array}{l}\text { Phos- } \\
\text { phorus, } \\
\text { ortho, } \\
\text { dissolved } \\
\text { (mg/L } \\
\text { as } P \text { ) }\end{array}$ & $\begin{array}{l}\text { Hard- } \\
\text { ness, } \\
\text { total } \\
\text { (mg/L } \\
\text { as } \\
\mathrm{CaCO}_{3} \text { ) }\end{array}$ \\
\hline
\end{tabular}

WELL 16

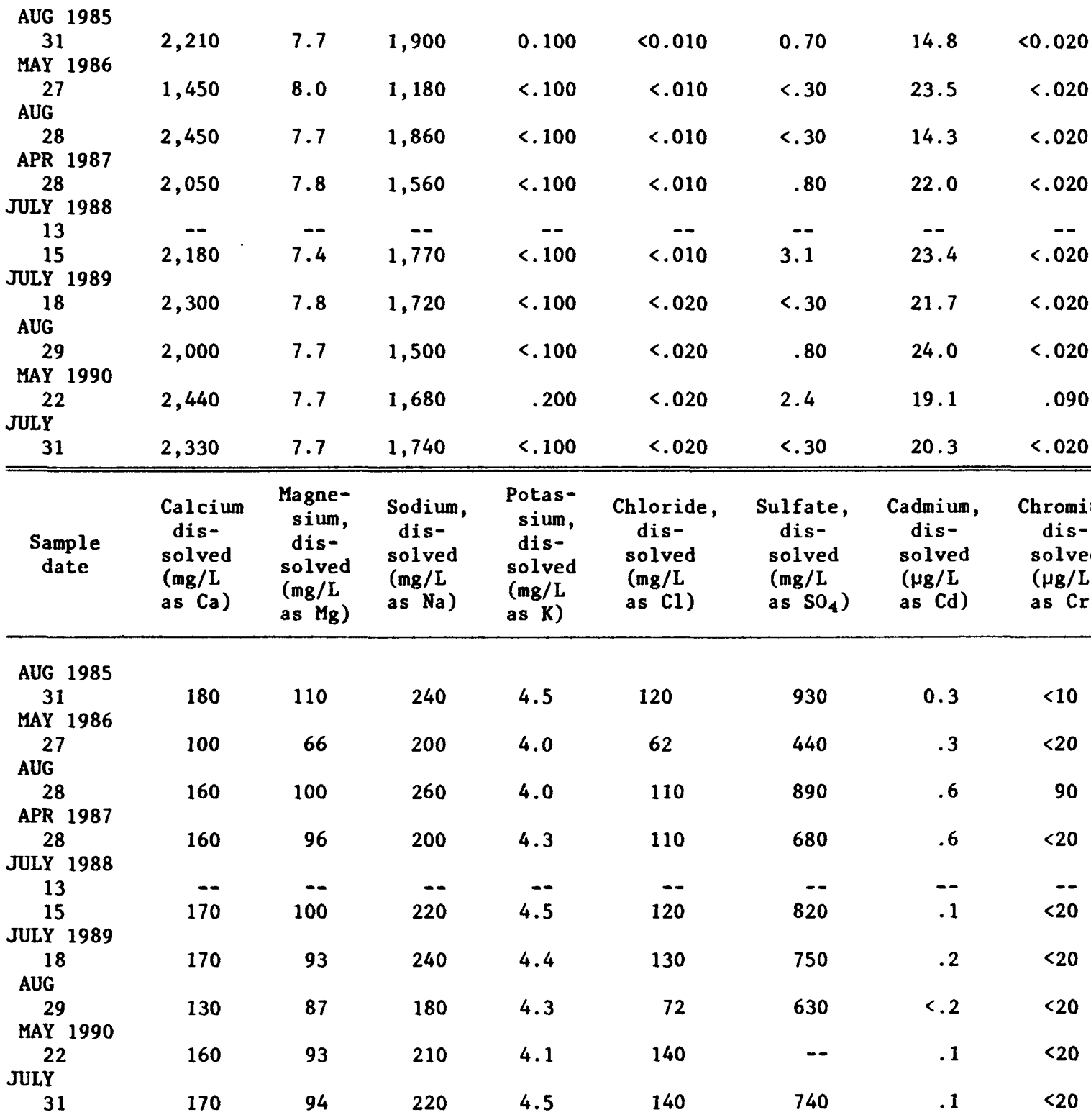


Table 5.--Chemical and bacteriological analyses of water from the observation wells--Continued

\begin{tabular}{|c|c|c|c|c|c|c|c|c|c|}
\hline $\begin{array}{c}\text { Sample } \\
\text { date }\end{array}$ & $\begin{array}{l}\text { Copper, } \\
\text { dis- } \\
\text { solved } \\
\left(\mu_{8} / L\right. \\
\text { as } C u)\end{array}$ & $\begin{array}{l}\text { Iron, } \\
\text { dis- } \\
\text { solved } \\
(\mu g / L \\
\text { as } \mathrm{Fe})\end{array}$ & $\begin{array}{l}\text { Lead, } \\
\text { dis- } \\
\text { solved } \\
\left(\mu_{8} / \mathrm{L}\right. \\
\text { as } \mathrm{Pb})\end{array}$ & $\begin{array}{c}\text { Manga- } \\
\text { nese, } \\
\text { dissolved } \\
\left(\mu_{g} / L\right. \\
\text { as } M n)\end{array}$ & $\begin{array}{l}\text { Nickel, } \\
\text { dis- } \\
\text { solved } \\
\left(\mu_{8} / L\right. \\
\text { as } N i)\end{array}$ & $\begin{array}{l}\text { Zinc, } \\
\text { dis- } \\
\text { solved } \\
(\mu g / L \\
\text { as } Z n)\end{array}$ & $\begin{array}{l}\text { Coli- } \\
\text { form, } \\
\text { fecal } \\
\text { (col./ } \\
100 \mathrm{~mL})\end{array}$ & $\begin{array}{c}\text { Strepto- } \\
\text { cocci, } \\
\text { fecal } \\
(\text { col.l } \\
100 \mathrm{~mL})\end{array}$ & \\
\hline \multicolumn{10}{|c|}{ WELt 16--Cont inued } \\
\hline AUG 1985 & & & & & & & & & \\
\hline $\begin{array}{l}31 \\
\text { MAY } 1986\end{array}$ & $<10$ & $<50$ & $<10$ & $<10$ & 270 & 80 & $<1$ & 400 & \\
\hline $\begin{array}{l}27 \\
\text { AUG }\end{array}$ & $<20$ & $<50$ & $<10$ & $<20$ & $<20$ & $<20$ & -- & -- & \\
\hline AUG & & & & & & & & & \\
\hline $\begin{array}{c}28 \\
\text { APR } 1987\end{array}$ & $<40$ & 520 & $<100$ & 30 & 140 & 60 & $<1$ & $<1$ & \\
\hline$\stackrel{28}{\text { JULY } 1988}$ & $<20$ & $<50$ & 50 & $<20$ & 30 & 20 & $<1$ & $<1$ & \\
\hline 13 & -- & -- & -- & -- & -- & -- & $<2$ & $<2$ & \\
\hline 15 & $<20$ & $<50$ & $<10$ & $<20$ & $<20$ & $<20$ & -- & -- & \\
\hline JULY 1989 & & & & & & & & & \\
\hline $\begin{array}{c}18 \\
\text { AUG }\end{array}$ & $<20$ & $<50$ & $<10$ & $<20$ & $<20$ & $<20$ & $<2$ & $<2$ & \\
\hline $\begin{array}{l}29 \\
\text { MAY } 1990\end{array}$ & $<20$ & $<50$ & $<10$ & $<20$ & $<20$ & $<20$ & $<2$ & 7 & \\
\hline 22 & $<20$ & 150 & $<10$ & $<20$ & $<20$ & $<20$ & 1 & $<20$ & \\
\hline JULY & & & & & & & & & \\
\hline 31 & 20 & $<50$ & $<10$ & $<20$ & 20 & $<20$ & $<20$ & $<20$ & \\
\hline $\begin{array}{l}\text { Sample } \\
\text { date }\end{array}$ & $\begin{array}{c}\text { Specific } \\
\text { conduct- } \\
\text { ance } \\
(\mu \mathrm{S} / \mathrm{cm})\end{array}$ & $\underset{\text { (units) }}{\mathrm{pH}}$ & $\begin{array}{c}\text { Residue } \\
\text { at } \\
105^{\circ} \mathrm{C}, \\
\text { dis- } \\
\text { solved } \\
(\mathrm{mg} / \mathrm{L})\end{array}$ & $\begin{array}{l}\text { Nitrogen, } \\
\text { ammonia, } \\
\text { dis- } \\
\text { solved } \\
\text { (mg/L } \\
\text { as } N \text { ) }\end{array}$ & $\begin{array}{c}\text { Nitrogen, } \\
\text { nitrite, } \\
\text { dis- } \\
\text { solved } \\
\text { (mg/L } \\
\text { as } N)\end{array}$ & $\begin{array}{l}\text { Nitrogen, } \\
\text { ammonia, } \\
\text { torganic, } \\
\text { dissolved } \\
\text { (mg/L } \\
\text { as } \mathrm{N})\end{array}$ & $\begin{array}{c}\mathrm{Nitrogen}, \\
\mathrm{NO}_{2}+\mathrm{NO}_{3} \\
\text { dis- } \\
\text { solved } \\
\text { (mg/L } \\
\text { as } \mathrm{N})\end{array}$ & $\begin{array}{l}\text { Phos- } \\
\text { phorus, } \\
\text { ortho, } \\
\text { dissolved } \\
\text { (mg/L } \\
\text { as P) }\end{array}$ & $\begin{array}{l}\text { Hard- } \\
\text { ness, } \\
\text { total } \\
(\mathrm{mg} / \mathrm{L} \\
\text { as } \\
\left.\mathrm{CaCO}_{3}\right)\end{array}$ \\
\hline
\end{tabular}

AUG 1985




Table 5.--Chemical and bacteriological analyses of water

from the observation wells--Continued

\begin{tabular}{|c|c|c|c|c|c|c|c|c|c|}
\hline $\begin{array}{c}\text { Sample } \\
\text { date }\end{array}$ & 1 & $\begin{array}{l}\text { Calcium } \\
\text { dis- } \\
\text { solved } \\
\text { (mg/L } \\
\text { as Ca) }\end{array}$ & $\begin{array}{l}\text { Magne- } \\
\text { sium, } \\
\text { dis- } \\
\text { solved } \\
\text { (mg/L } \\
\text { as } \mathrm{Mg} \text { ) }\end{array}$ & $\begin{array}{l}\text { Sodium, } \\
\text { dis- } \\
\text { solved } \\
\text { (mg/L } \\
\text { as } \mathrm{Na} \text { ) }\end{array}$ & $\begin{array}{l}\text { Potas- } \\
\text { sium, } \\
\text { dis- } \\
\text { solved } \\
\text { (mg/L } \\
\text { as K) }\end{array}$ & $\begin{array}{c}\text { Chloride, } \\
\text { dis- } \\
\text { solved } \\
\text { (mg/L } \\
\text { as } \mathrm{Cl} \text { ) }\end{array}$ & $\begin{array}{l}\text { Sulfate, } \\
\text { dis- } \\
\text { solved } \\
\left(\mathrm{mg}^{\prime} / \mathrm{L}\right. \\
\left.\text { as } \mathrm{SO}_{4}\right)\end{array}$ & $\begin{array}{l}\text { Cadmium, } \\
\text { dis- } \\
\text { solved } \\
\left(\mu_{g} / L\right. \\
\text { as Cd) }\end{array}$ & $\begin{array}{c}\text { Chromium, } \\
\text { dis- } \\
\text { solved } \\
\left(\mu_{g} / L\right. \\
\text { as } C r)\end{array}$ \\
\hline
\end{tabular}

WELL 17--Continued

AUG 1985

$4.0<1.0 \quad 220 \quad 1.1$

MAY 1986

27

AUG

$4.0<1.0 \quad 220$

1.1

6.0

0.1

$<10$

28

29

APR 1987

28

$4.0<1.0 \quad 250$

2.0

5.0

$<.1$

$<20$

4.0

1.0

$<3.0$

$-\overline{5}$

$--$

4.0

.90

220

1.4

10

1.1

$<20$

JULY 14

SEPT

4.0

.80

220

1.4

20

$<.2<20$

16

$4.0<1.0<220$

1.3

14

$<.2$

$<20$

JULY 1988

13

SEPT

-- $\quad--\quad-$

$--$

77

14

3.0

$\begin{array}{ll}-- & <20\end{array}$

$4.0<1.0 \quad 220$

$1.5 \quad 70$

$<3.0$

22

23

JUNE 1989

01
JULY

$\begin{array}{lll}4.0 & -. & 220\end{array}$

1.3

$<3.0$

$<.2<20$

$3.0<1.0<220$

1.3

$--$

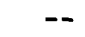

84

$<10$

$<.2$

$<20$

18
AUG

29
JAN 1990

26

3.0

$<1.0$

240

1.5

73

11

.3

$<20$

4.0

$<1.0$

210

1.4

75

$<10$

$<.2$

$<20$

4.0

$<1.0$

210

1.4

80

31

$<.2$

$<20$

22

JULY

4.0

$<1.0$

210

1.3

75



.2

$<20$

$4.0<1.0 \quad 230$

1.5

76

22

$<.2$

$<20$

4.0

1.0

210

1.4

75

20

.3

$<40$ 
Table 5.--Chemical and bacteriological analyses of water from the observation wells--Continued

\begin{tabular}{|c|c|c|c|c|c|c|c|c|}
\hline $\begin{array}{c}\text { Sample } \\
\text { date }\end{array}$ & $\begin{array}{l}\text { Copper, } \\
\text { dis- } \\
\text { solved } \\
\left(\mu_{\mathrm{g}} / \mathrm{L}\right. \\
\text { as } \mathrm{Cu})\end{array}$ & $\begin{array}{l}\text { Iron, } \\
\text { dis- } \\
\text { solved } \\
\left(\mu_{8} / L\right. \\
\text { as Fe) }\end{array}$ & $\begin{array}{l}\text { Lead, } \\
\text { dis- } \\
\text { solved } \\
\left(\mu_{8} / L\right. \\
\text { as } \mathrm{Pb})\end{array}$ & $\begin{array}{c}\text { Manga- } \\
\text { nese, } \\
\text { dissolved } \\
\left(\mu_{g} / L\right. \\
\text { as } M n)\end{array}$ & $\begin{array}{l}\text { Nickel, } \\
\text { dis- } \\
\text { solved } \\
\left(\mu_{\mathrm{g}} / \mathrm{L}\right. \\
\text { as } \mathrm{Ni})\end{array}$ & $\begin{array}{l}\text { Zinc, } \\
\text { dis- } \\
\text { solved } \\
\left(\mu_{\mathbf{g}} / L\right. \\
\text { as } \mathrm{Zn})\end{array}$ & $\begin{array}{l}\text { Coli- } \\
\text { form, } \\
\text { fecal } \\
\text { (col./ } \\
100 \mathrm{~mL})\end{array}$ & $\begin{array}{c}\text { Strepto } \\
\text { cocci, } \\
\text { fecal } \\
(\text { col./ } \\
100 \mathrm{~mL})\end{array}$ \\
\hline \multicolumn{9}{|c|}{ WELL $17-$-Continued } \\
\hline AUG 1985 & & & & & & & & \\
\hline $\begin{array}{l}31 \\
\text { MAY } 1986\end{array}$ & $<10$ & $<50$ & $<10$ & $<10$ & 80 & $<10$ & $<1$ & $<1$ \\
\hline $\begin{array}{l}27 \\
\text { AUG }\end{array}$ & $<20$ & $<50$ & $<10$ & $<20$ & $<20$ & $<20$ & 63 & $<1$ \\
\hline 28 & $-\infty$ & - & -- & -- & -- & -- & $<1$ & $<1$ \\
\hline$\stackrel{29}{\text { APR } 1987}$ & $<20$ & $<50$ & $<50$ & $<20$ & $<20$ & $<20$ & -- & -- \\
\hline$\stackrel{28}{\text { JULY }}$ & $<20$ & $<50$ & $<50$ & $<20$ & $<20$ & $<20$ & $<1$ & $<1$ \\
\hline $\begin{array}{l}14 \\
\text { SEPT }\end{array}$ & $<20$ & 110 & $<10$ & $<20$ & $<20$ & 20 & $<2$ & $<2$ \\
\hline $\begin{array}{l}16 \\
\text { JULY } 1988\end{array}$ & $<20$ & $<50$ & $<10$ & $<20$ & 20 & $<20$ & $<2$ & $<2$ \\
\hline 13 & -- & -- & -- & -- & -- & -- & $<2$ & $<2$ \\
\hline 15 & $<20$ & $<50$ & $<10$ & $<20$ & $<20$ & $<20$ & -- & -- \\
\hline SEPT & & & & & & & & \\
\hline 22 & $<20$ & $<50$ & $<10$ & -- & $<20$ & $<20$ & -- & -- \\
\hline$\stackrel{23}{\text { JUNE } 1989}$ & -- & -- & -- & -- & -- & -- & $<2$ & $<2$ \\
\hline $\begin{array}{l}01 \\
\text { JULY }\end{array}$ & $<20$ & $<50$ & $<10$ & $<20$ & $<20$ & 20 & $<2$ & $<2$ \\
\hline $\begin{array}{l}18 \\
\text { AUG }\end{array}$ & $<20$ & $<50$ & $<10$ & $<20$ & $<20$ & $<20$ & $<2$ & $<2$ \\
\hline $\begin{array}{c}29 \\
\text { JAN } 1990\end{array}$ & $<20$ & $<50$ & $<10$ & $<20$ & $<20$ & $<20$ & $<2$ & $<2$ \\
\hline MAY & $<20$ & $<50$ & $<10$ & $<20$ & $<20$ & $<20$ & -- & -- \\
\hline JULY & $<20$ & $<50$ & $<10$ & $<20$ & $<20$ & $<20$ & $<20$ & $<20$ \\
\hline $\begin{array}{l}31 \\
\text { SEPT }\end{array}$ & $<20$ & $<50$ & $<10$ & $<20$ & $<20$ & $<20$ & $<20$ & $<20$ \\
\hline 25 & $<40$ & $<100$ & $<10$ & $<40$ & $<40$ & $<40$ & $<20$ & $<20$ \\
\hline
\end{tabular}


Table 5.--Chemical and bacteriological analyses of water from the observation wells--Continued

\begin{tabular}{|c|c|c|c|c|c|c|c|c|c|}
\hline $\begin{array}{c}\text { Sample } \\
\text { date }\end{array}$ & $\begin{array}{c}\text { Specific } \\
\text { conduct- } \\
\text { ance } \\
(\mu \mathrm{S} / \mathrm{cm})\end{array}$ & $\underset{\text { (units) }}{\mathrm{pH}}$ & $\begin{array}{l}\text { Residue } \\
\text { at } \\
105^{\circ} \mathrm{C}, \\
\text { dis- } \\
\text { solved } \\
\text { (mg/L) }\end{array}$ & $\begin{array}{l}\text { Nitrogen, } \\
\text { ammonia, } \\
\text { dis- } \\
\text { solved } \\
\text { (mg/L } \\
\text { as } N)\end{array}$ & $\begin{array}{c}\text { Nitrogen, } \\
\text { nitrite, } \\
\text { dis- } \\
\text { solved } \\
(\mathrm{mg} / \mathrm{L} \\
\text { as } \mathrm{N})\end{array}$ & $\begin{array}{l}\text { Nitrogen, } \\
\text { ammonia, } \\
\text { torganic, } \\
\text { dissolved } \\
\text { (mg/L } \\
\text { as } N \text { ) }\end{array}$ & $\begin{array}{c}\mathrm{Nitrogen}, \\
\mathrm{NO}_{2}+\mathrm{NO}_{3} \\
\text { dis- } \\
\text { solved } \\
(\mathrm{mg} / \mathrm{L} \\
\text { as } \mathrm{N})\end{array}$ & $\begin{array}{l}\text { Phos- } \\
\text { phorus, } \\
\text { ortho, } \\
\text { dissolved } \\
\text { (mg/L } \\
\text { as P) }\end{array}$ & $\begin{array}{l}\text { Hard- } \\
\text { ness, } \\
\text { total } \\
(\mathrm{mg} / \mathrm{L} \\
\text { as } \\
\left.\mathrm{CaCO}_{3}\right)\end{array}$ \\
\hline
\end{tabular}

WELL 18

SEPT 1985

MAY 1986

27

AUG

28

29

APR 1987

28

JULY

14

SEPT

16

MAR 1988

18

JULY

13

SEPT

22

MAR 1989

15
16
JUNE

JUNE

JULY

AUG

1,500

8.2782

0.500

$<0.010$

1.4

0.040

0.040

42

.400

.010

.50

.090

$<.020 \quad 54$

820

$\begin{array}{ll}-- & - \\ 8.0 & 818\end{array}$

.--

$<.010$

$--$

030

$<.020 \quad 40$

.500

$<.010$

.80

$<.010$

$<.020 \quad 45$

.500

$<.020$

1.1

.040

$<.020 \quad 40$

.500

$<.020$

$<.30$

$<.020$

$<.020$

46

$.500<.020$

.40

.020

$.080 \quad 51$

$-$

.600

$<.010$

$--$

$--$

$<.020 \quad 40$

.300

$<.020$

$<.30$

$<.020$

$<.020 \quad 40$

1,330

8.2806

$<.-\overline{100}$

$<.020$

$<.30$

.050

$<\overline{--} \quad 44$

$1, \overline{280}$

$8.2 \quad 746$

.400

$<.020$

.70

.060

$.090 \quad 32$

1,300

$8.3 \quad 797$

$<.100$

$<.020$

.40

.020

$<.020$

42

29

1,280

8.2779

.600

$<.020$

.70

.120

$<.020 \quad 40$

22

JULY

1,470

$8.3 \quad 819$

$<.100$

$<.020$

1.0

$<.010$

$<.020 \quad 42$

1,330

$8.3 \quad 785$

$<.100$

$<.020$

.40

.200

$<.020 \quad 46$

1,310

$8.4 \quad 807$

$<.100$

$<.020$

.50

$<.020$

$<.020 \quad 37$ 
Table 5.--Chemical and bacteriological analyses of water from the observation wells--Continued

\begin{tabular}{|c|c|c|c|c|c|c|c|c|}
\hline $\begin{array}{c}\text { Sample } \\
\text { date }\end{array}$ & $\begin{array}{l}\text { Calcium } \\
\text { dis- } \\
\text { solved } \\
\text { (mg/L } \\
\text { as Ca) }\end{array}$ & $\begin{array}{c}\text { Magne- } \\
\text { sium, } \\
\text { dis- } \\
\text { solved } \\
\text { (mg/L } \\
\text { as } \mathrm{Mg} \text { ) }\end{array}$ & $\begin{array}{l}\text { Sodium, } \\
\text { dis- } \\
\text { solved } \\
\text { (mg/L } \\
\text { as Na) }\end{array}$ & $\begin{array}{l}\text { Potas- } \\
\text { sium, } \\
\text { dis- } \\
\text { solved } \\
\text { (mg/L } \\
\text { as K) }\end{array}$ & $\begin{array}{c}\text { Chloride, } \\
\text { dis- } \\
\text { solved } \\
\text { (mg/L } \\
\text { as } \mathrm{Cl} \text { ) }\end{array}$ & $\begin{array}{c}\text { Sulfate, } \\
\text { dis- } \\
\text { solved } \\
\left(\mathrm{mg}^{2} / \mathrm{L}\right. \\
\left.\text { as } \mathrm{SO}_{4}\right)\end{array}$ & $\begin{array}{c}\text { Cadmium, } \\
\text { dis- } \\
\text { solved } \\
\text { ( } \mu g / L \\
\text { as } C d)\end{array}$ & $\begin{array}{c}\text { Chromiu } \\
\text { dis- } \\
\text { solved } \\
(\mu \mathrm{g} / \mathrm{L} \\
\text { as } \mathrm{Cr})\end{array}$ \\
\hline \multicolumn{9}{|c|}{ WELL 18--Continued } \\
\hline $\begin{array}{c}\text { SEPT } 1985 \\
06 \\
\text { MAY } 1986\end{array}$ & 12 & 3.0 & 310 & 2.1 & 77 & 240 & 0.2 & $<10$ \\
\hline $\begin{array}{c}27 \\
\text { AUG }\end{array}$ & 15 & 4.0 & 310 & 2.0 & 80 & 240 & .5 & $<20$ \\
\hline $\begin{array}{l}28 \\
29\end{array}$ & $\overline{11}$ & 3.0 & $2 \overline{--}$ & $2 . \overline{0}$ & $\overline{76}$ & 230 & -- & $-\overline{0}$ \\
\hline APR 1987 & & & & & & & & \\
\hline $\begin{array}{l}28 \\
J U L Y\end{array}$ & 12 & 3.7 & 280 & 1.8 & 73 & 180 & $<.2$ & $<20$ \\
\hline $\begin{array}{l}14 \\
\text { SEPT }\end{array}$ & 11 & 3.1 & 270 & 1.6 & 66 & 200 & $<.2$ & $<20$ \\
\hline${ }_{\text {MAR }}^{16} 1988$ & 12 & 4.0 & 270 & 1.8 & 76 & 220 & $<.2$ & $<20$ \\
\hline${ }_{\text {JULY }}^{18}$ & 14 & 4.0 & 280 & 1.8 & 73 & 220 & .2 & $<20$ \\
\hline 13 & -- & -- & -- & -- & -. & -- & -. & -- \\
\hline $\begin{array}{l}15 \\
\text { SEPT }\end{array}$ & 11 & 3.0 & 280 & 1.9 & 77 & 240 & $<.1$ & $<20$ \\
\hline $\begin{array}{l}22 \\
\operatorname{MAR} 1989\end{array}$ & 11 & 3.0 & 260 & 1.7 & 78 & 220 & $<.2$ & $<20$ \\
\hline $\begin{array}{l}15 \\
16\end{array}$ & $\overline{11}$ & $4 . \overline{0}$ & $\overline{270}$ & $\overline{1}$ & $\overline{72}$ & $\overline{190}$ & -- & $<20$ \\
\hline JUNE & & & & & & & & \\
\hline $\begin{array}{l}01 \\
\text { JULY }\end{array}$ & 8.0 & 3.0 & 280 & 1.6 & 78 & 150 & $<.2$ & $<20$ \\
\hline${ }_{\text {AUG }}^{18}$ & 12 & 3.0 & 290 & 2.0 & 75 & 210 & .7 & $<20$ \\
\hline$\stackrel{29}{\text { MAY }}$ & 11 & 3.0 & 270 & 1.8 & 120 & 130 & $<.2$ & $<20$ \\
\hline$\stackrel{22}{\text { JULY }}$ & 12 & 3.0 & 270 & 1.8 & 76 & - & $<.2$ & 20 \\
\hline $\begin{array}{r}31 \\
\text { SEPT }\end{array}$ & 12 & 4.0 & 270 & 2.0 & 76 & 220 & .1 & $<20$ \\
\hline 25 & 10 & 3.0 & 270 & 2.0 & 76 & 230 & .3 & $<40$ \\
\hline
\end{tabular}


Table 5.--Chemical and bacteriological analyses of water from the observation wells--Continued

\begin{tabular}{|c|c|c|c|c|c|c|c|c|}
\hline $\begin{array}{c}\text { Sample } \\
\text { date }\end{array}$ & $\begin{array}{l}\text { Copper, } \\
\text { dis- } \\
\text { solved } \\
\text { ( } \mu \mathrm{g} / \mathrm{L} \\
\text { as } \mathrm{Cu})\end{array}$ & $\begin{array}{l}\text { Iron, } \\
\text { dis- } \\
\text { solved } \\
(\mu \mathrm{g} / \mathrm{L} \\
\text { as } \mathrm{Fe})\end{array}$ & $\begin{array}{l}\text { Lead, } \\
\text { dis- } \\
\text { solved } \\
\text { ( } \mu \mathrm{g} / \mathrm{L} \\
\text { as } \mathrm{Pb} \text { ) }\end{array}$ & $\begin{array}{c}\text { Manga- } \\
\text { nese, } \\
\text { dissolved } \\
\text { ( } \mu g / L \\
\text { as Mn) }\end{array}$ & $\begin{array}{l}\text { Nickel, } \\
\text { dis- } \\
\text { solved } \\
\text { ( } \mu \mathrm{g} / \mathrm{L} \\
\text { as } \mathrm{Ni} \text { ) }\end{array}$ & $\begin{array}{l}\text { Zinc, } \\
\text { dis- } \\
\text { solved } \\
(\mu \mathrm{g} / \mathrm{L} \\
\text { as } \mathrm{Zn})\end{array}$ & $\begin{array}{l}\text { Coli- } \\
\text { form, } \\
\text { fecal } \\
\text { (col./ } \\
100 \mathrm{~mL} \text { ) }\end{array}$ & $\begin{array}{r}\text { Strept } \\
\text { cocci } \\
\text { fecal } \\
(\text { col. } \\
100 \mathrm{~mL}\end{array}$ \\
\hline \multicolumn{9}{|c|}{ WELL 18--Continued } \\
\hline \multicolumn{9}{|l|}{ SEPT 1985} \\
\hline$\stackrel{06}{\text { MAY } 1986}$ & $<10$ & 40 & 20 & 30 & 100 & 120 & $<1$ & $<1$ \\
\hline 27 & $<50$ & $<50$ & $<10$ & $<40$ & $<20$ & 170 & $<1$ & $<1$ \\
\hline \multicolumn{9}{|l|}{ AUG } \\
\hline 28 & -- & -- & -- & -- & -- & -- & $<1$ & $<1$ \\
\hline 29 & $<20$ & $<50$ & $<50$ & 30 & $<20$ & 90 & -- & -- \\
\hline \multicolumn{9}{|l|}{ APR 1987} \\
\hline \multirow{2}{*}{\multicolumn{9}{|c|}{ JULY }} \\
\hline & & & & & & & & \\
\hline 14 & $<20$ & $<50$ & $<10$ & $<20$ & $<20$ & 60 & $<2$ & $<2$ \\
\hline \multicolumn{9}{|l|}{ SEPT } \\
\hline 16 & $<20$ & $<50$ & $<10$ & 30 & 20 & 60 & $<2$ & 3 \\
\hline \multicolumn{9}{|l|}{ MAR 1988} \\
\hline 18 & $<20$ & $<50$ & $<10$ & 30 & $<20$ & 80 & $<2$ & $<2$ \\
\hline \multicolumn{9}{|l|}{ JULY } \\
\hline 13 & -- & -- & -- & -- & -- & -- & $<2$ & $<2$ \\
\hline 15 & $<20$ & $<50$ & $<10$ & 30 & $<20$ & 40 & -- & -- \\
\hline \multicolumn{9}{|l|}{ SEPT } \\
\hline 22 & $<20$ & $<50$ & $<10$ & -- & $<20$ & $<20$ & -- & -- \\
\hline \multicolumn{9}{|l|}{ MAR 1989} \\
\hline 15 & -- & -- & -- & -- & -- & -- & $<2$ & $<2$ \\
\hline 16 & $<20$ & 60 & $<10$ & 20 & 20 & 20 & -- & -- \\
\hline \multicolumn{9}{|l|}{ JUNE } \\
\hline 01 & $<20$ & $<50$ & $<10$ & 20 & $<20$ & 30 & $<2$ & 4 \\
\hline \multicolumn{9}{|l|}{ JULY } \\
\hline 18 & $<20$ & $<50$ & $<10$ & 30 & $<20$ & 40 & $<2$ & $<2$ \\
\hline \multicolumn{9}{|l|}{ AUG } \\
\hline 29 & $<20$ & $<50$ & $<10$ & $<20$ & $<20$ & 40 & $<2$ & $<2$ \\
\hline \multicolumn{9}{|l|}{ MAY 1990} \\
\hline \multirow{2}{*}{\multicolumn{9}{|c|}{ JULY }} \\
\hline & & & & & & & & \\
\hline 31 & $<20$ & $<50$ & $<10$ & 30 & $<20$ & 60 & $<20$ & $<20$ \\
\hline \multicolumn{9}{|l|}{ SEPT } \\
\hline 25 & $<40$ & $<100$ & $<10$ & $<40$ & $<40$ & $<40$ & $<20$ & 3 \\
\hline
\end{tabular}


Table 5.--Chemical and bacteriological analyses of water from the observation wells--Continued

\begin{tabular}{|c|c|c|c|c|c|c|c|c|c|}
\hline $\begin{array}{c}\text { Sample } \\
\text { date }\end{array}$ & $\begin{array}{c}\text { Specific } \\
\text { conduct- } \\
\text { ance } \\
(\mu \mathrm{S} / \mathrm{cm})\end{array}$ & $\begin{array}{c}\mathrm{pH} \\
\text { (units) }\end{array}$ & $\begin{array}{l}\text { Residue } \\
\text { at } \\
105^{\circ} \mathrm{C}, \\
\text { dis- } \\
\text { solved } \\
\text { (mg/L) }\end{array}$ & $\begin{array}{c}\text { Nitrogen, } \\
\text { ammonia, } \\
\text { dis- } \\
\text { solved } \\
(\text { mg/L } \\
\text { as N) }\end{array}$ & $\begin{array}{c}\text { Nitrogen, } \\
\text { nitrite, } \\
\text { dis- } \\
\text { solved } \\
(\mathrm{mg} / \mathrm{L} \\
\text { as } \mathrm{N})\end{array}$ & $\begin{array}{l}\text { Nitrogen, } \\
\text { ammonia, } \\
\text { torganic, } \\
\text { dissolved } \\
\text { (mg/L } \\
\text { as } N)\end{array}$ & $\begin{array}{c}\mathrm{Nitrogen}, \\
\mathrm{NO}_{2}+\mathrm{NO}_{3} \\
\text { dis- } \\
\text { solved } \\
\text { (mg/L } \\
\text { as } \mathrm{N})\end{array}$ & $\begin{array}{l}\text { Phos- } \\
\text { phorus, } \\
\text { ortho, } \\
\text { dissolved } \\
\text { (mg/L } \\
\text { as P) }\end{array}$ & $\begin{array}{l}\text { Hard- } \\
\text { ness, } \\
\text { total } \\
(\mathrm{mg} / \mathrm{L} \\
\text { as } \\
\left.\mathrm{CaCO}_{3}\right)\end{array}$ \\
\hline
\end{tabular}

WELL 19

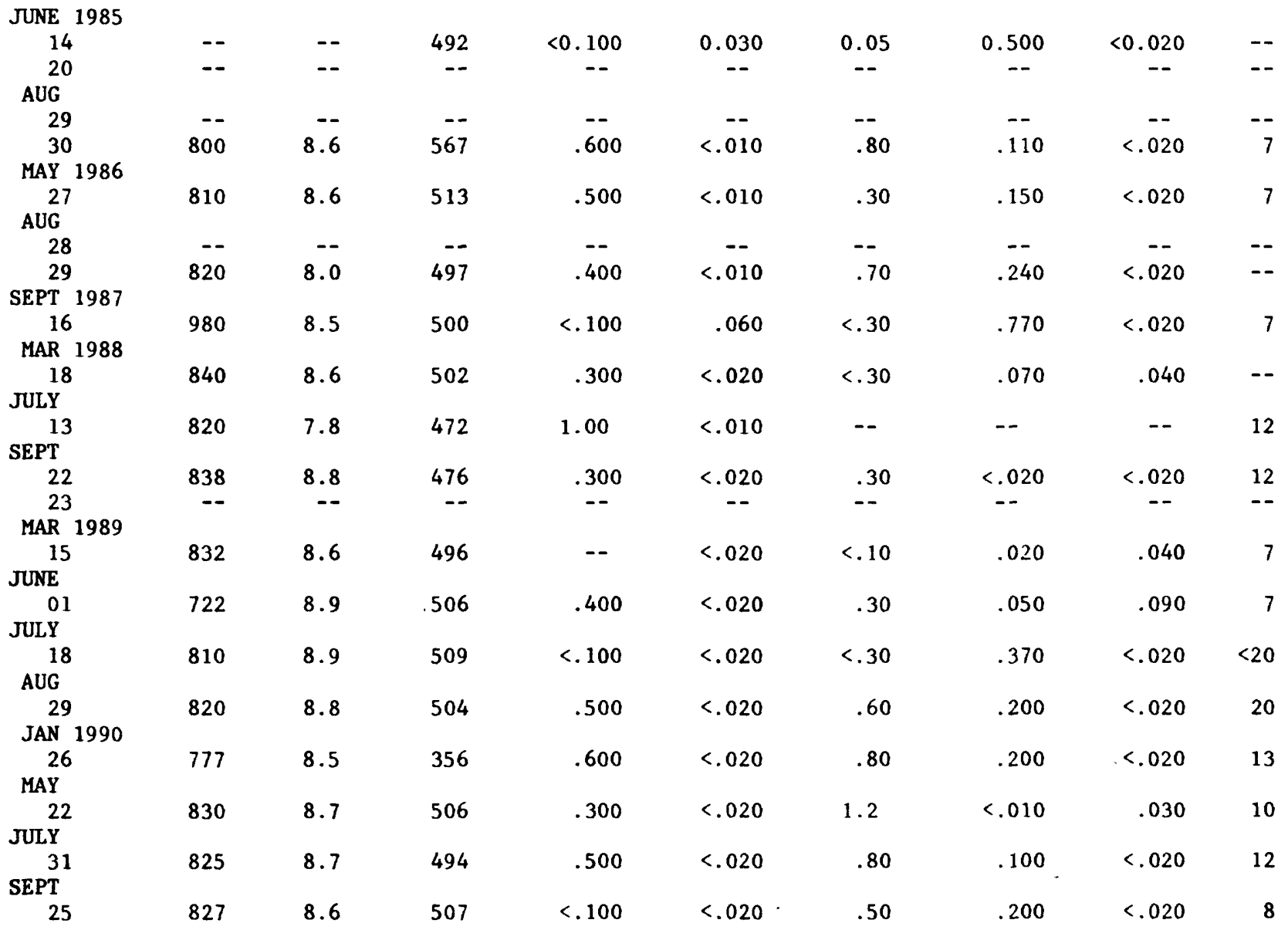


Table 5.--Chemical and bacteriological analyses of water from the observation wells--Continued

\begin{tabular}{|c|c|c|c|c|c|c|c|c|}
\hline $\begin{array}{c}\text { Sample } \\
\text { date }\end{array}$ & $\begin{array}{l}\text { Calcium } \\
\text { dis- } \\
\text { solved } \\
\text { (mg/L } \\
\text { as } \mathrm{Ca} \text { ) }\end{array}$ & $\begin{array}{c}\text { Magne- } \\
\text { sium, } \\
\text { dis- } \\
\text { solved } \\
\text { (mg/L } \\
\text { as } M g \text { ) }\end{array}$ & $\begin{array}{l}\text { Sodium, } \\
\text { dis- } \\
\text { solved } \\
(\mathrm{mg} / \mathrm{L} \\
\text { as } \mathrm{Na})\end{array}$ & $\begin{array}{l}\text { Potas- } \\
\text { sium, } \\
\text { dis- } \\
\text { solved } \\
\text { (mg/L } \\
\text { as K) }\end{array}$ & $\begin{array}{l}\text { Chloride, } \\
\text { dis- } \\
\text { solved } \\
\text { (mg/L } \\
\text { as } \mathrm{Cl} \text { ) }\end{array}$ & $\begin{array}{c}\text { Sulfate, } \\
\text { dis- } \\
\text { solved } \\
\left(\mathrm{mg}^{-} / \mathrm{L}^{-}\right. \\
\left.\text {as } \mathrm{SO}_{4}\right)\end{array}$ & $\begin{array}{c}\text { Cadmium, } \\
\text { dis- } \\
\text { solved } \\
(\mu g / L \\
\text { as Cd) }\end{array}$ & $\begin{array}{c}\text { Chromium, } \\
\text { dis- } \\
\text { solved } \\
(\mu g / L \\
\text { as } C r)\end{array}$ \\
\hline
\end{tabular}

WELL 19--Continued

JUNE 1985

\begin{tabular}{|c|c|c|c|c|c|c|c|c|}
\hline 14 & $<5.0$ & $<5.0$ & 200 & 1.3 & 16 & 190 & -- & $-\infty$ \\
\hline 20 & -- & -- & -- & -- & -- & -- & -- & -- \\
\hline \multicolumn{9}{|l|}{ AUG } \\
\hline 29 & -- & -- & -- & -- & -- & -- & -- & -- \\
\hline 30 & 3.0 & $<1.0$ & 200 & 1.3 & 22 & 230 & 0.2 & $<10$ \\
\hline \multicolumn{9}{|l|}{ MAY 1986} \\
\hline 27 & 3.0 & $<1.0$ & 200 & 1.0 & 18 & 170 & .3 & $<20$ \\
\hline \multicolumn{9}{|l|}{ AUG } \\
\hline 28 & -- & -- & -- & -- & -- & -- & -- & - \\
\hline 29 & 3.0 & $<1.0$ & 190 & 1.0 & 19 & 160 & .7 & $<20$ \\
\hline \multicolumn{9}{|l|}{ SEPT 1987} \\
\hline$\stackrel{16}{\text { MAR } 1988}$ & 3.0 & $<1.0$ & 170 & 1.1 & 17 & 170 & $<.2$ & $<20$ \\
\hline 18 & 4.0 & $<1.0$ & 180 & .90 & 18 & 160 & .2 & $<20$ \\
\hline \multicolumn{9}{|l|}{ JULY } \\
\hline 13 & 4.0 & $<1.0$ & 180 & 1.3 & 19 & 150 & -- & $<20$ \\
\hline \multicolumn{9}{|l|}{ SEPT } \\
\hline 22 & 3.0 & $<1.0$ & 170 & 1.0 & 19 & 170 & .2 & $<20$ \\
\hline 23 & -- & -- & -- & -- & - & -- & -- & -- \\
\hline \multicolumn{9}{|l|}{ MAR 1989} \\
\hline 15 & 3.0 & $<1.0$ & 170 & 1.0 & 21 & 180 & -- & $<20$ \\
\hline \multicolumn{9}{|l|}{ JUNE } \\
\hline 01 & 3.0 & $<1.0$ & 170 & 1.1 & 20 & 170 & $<.2$ & $<20$ \\
\hline \multicolumn{9}{|l|}{ JULY } \\
\hline 18 & 3.0 & $<1.0$ & 170 & 1.8 & 18 & 160 & $<.3$ & $<20$ \\
\hline \multicolumn{9}{|l|}{ AUG } \\
\hline 29 & 4.0 & $<1.0$ & 180 & 1.2 & 19 & 140 & $<.2$ & $<20$ \\
\hline \multicolumn{9}{|l|}{ JAN 1990} \\
\hline 26 & 4.0 & $<1.0$ & 170 & 1.1 & 25 & 160 & .1 & $<20$ \\
\hline \multicolumn{9}{|l|}{ MAY } \\
\hline 22 & 3.0 & $<1.0$ & 160 & 1.0 & 19 & -- & $<.2$ & $<20$ \\
\hline \multicolumn{9}{|l|}{ JULY } \\
\hline $\begin{array}{l}31 \\
\text { SEPT }\end{array}$ & 3.0 & $<1.0$ & 170 & 1.2 & 18 & 170 & $<.2$ & $<20$ \\
\hline 25 & 2.0 & $<2.0$ & 170 & 1.2 & 21 & 190 & $<.2$ & $<40$ \\
\hline
\end{tabular}


Table 5.--Chemical and bacteriological analyses of water from the observation wells--Continued

\begin{tabular}{|c|c|c|c|c|c|c|c|c|}
\hline $\begin{array}{c}\text { Sample } \\
\text { date }\end{array}$ & $\begin{array}{l}\text { Copper, } \\
\text { dis- } \\
\text { solved } \\
\left(\mu_{g} / \mathrm{L}\right. \\
\text { as } \mathrm{Cu})\end{array}$ & $\begin{array}{l}\text { Iron, } \\
\text { dis- } \\
\text { solved } \\
\left(\mu_{g} / L\right. \\
\text { as Fe) }\end{array}$ & $\begin{array}{l}\text { Lead, } \\
\text { dis- } \\
\text { solved } \\
\left(\mu_{g} / \mathrm{L}\right. \\
\text { as } \mathrm{Pb})\end{array}$ & $\begin{array}{c}\text { Manga- } \\
\text { nese, } \\
\text { dissolved } \\
\left(\mu_{g} / L\right. \\
\text { as } M n)\end{array}$ & $\begin{array}{l}\text { Nickel, } \\
\text { dis- } \\
\text { solved } \\
\left(\mu_{g} / L\right. \\
\text { as } \mathrm{Ni})\end{array}$ & $\begin{array}{l}\text { Zinc, } \\
\text { dis - } \\
\text { solved } \\
\left(\mu_{\mathrm{g}} / \mathrm{L}\right. \\
\text { as } \mathrm{Zn})\end{array}$ & $\begin{array}{l}\text { Coli- } \\
\text { form, } \\
\text { fecal } \\
\text { (col./ } \\
100 \mathrm{~mL} \text { ) }\end{array}$ & $\begin{array}{c}\text { Strepto- } \\
\text { cocci, } \\
\text { fecal } \\
(\text { col. } \\
100 \mathrm{~mL})\end{array}$ \\
\hline
\end{tabular}

WELL 19--Continued

\begin{tabular}{|c|c|c|c|c|c|c|c|c|}
\hline \multicolumn{9}{|l|}{ JUNE 1985} \\
\hline 14 & -- & 20 & -- & -- & -- & 60 & -- & -- \\
\hline 20 & -- & -- & -- & -- & -- & -- & $<1$ & 160 \\
\hline \multicolumn{9}{|l|}{ AUG } \\
\hline 29 & -- & -- & -- & -- & -- & -- & 8 & 460 \\
\hline 30 & $<10$ & 100 & $<50$ & 10 & 80 & 30 & -- & - \\
\hline \multicolumn{9}{|l|}{ MAY 1986} \\
\hline 27 & $<20$ & $<50$ & $<20$ & -- & $<20$ & 50 & $<1$ & $<1$ \\
\hline \multicolumn{9}{|l|}{ AUG } \\
\hline 28 & -- & -- & -- & -- & -- & -- & $<1$ & $<1$ \\
\hline 29 & $<20$ & 130 & $<50$ & $<20$ & $<20$ & 390 & -- & -- \\
\hline \multicolumn{9}{|l|}{ SEPT 1987} \\
\hline$\stackrel{16}{\text { MAR } 1988}$ & $<20$ & $<50$ & $<10$ & $<20$ & $<20$ & 90 & $<2$ & $<2$ \\
\hline 18 & $<20$ & $<50$ & $<10$ & $<20$ & $<20$ & 30 & 23 & 3 \\
\hline \multicolumn{9}{|l|}{ JULY } \\
\hline 13 & $<20$ & $<50$ & $<10$ & $<20$ & $<20$ & $<20$ & 6 & 4 \\
\hline \multicolumn{9}{|l|}{ SEPT } \\
\hline 22 & $<20$ & $<50$ & $<10$ & -- & $<20$ & 20 & -- & -- \\
\hline 23 & -- & -- & -- & -- & - & -- & $<2$ & $<2$ \\
\hline \multicolumn{9}{|l|}{ MAR 1989} \\
\hline 15 & $<20$ & $<50$ & $<10$ & $<20$ & $<20$ & 30 & $<2$ & $<2$ \\
\hline \multicolumn{9}{|l|}{ JUNE } \\
\hline 01 & $<20$ & $<50$ & $<10$ & $<20$ & $<20$ & $<20$ & $<2$ & 7 \\
\hline \multicolumn{9}{|l|}{ JULY } \\
\hline 18 & $<20$ & 70 & $<10$ & $<20$ & $<20$ & 40 & $<2$ & 1,500 \\
\hline \multicolumn{9}{|l|}{ AUG } \\
\hline 29 & $<20$ & $<50$ & $<10$ & $<20$ & $<20$ & 330 & $<2$ & $<2$ \\
\hline \multicolumn{9}{|l|}{ JAN 1990} \\
\hline 26 & $<20$ & 50 & $<10$ & $<20$ & $<20$ & 100 & -- & - \\
\hline \multicolumn{9}{|l|}{ MAY } \\
\hline 22 & $<20$ & $<50$ & $<10$ & $<20$ & $<20$ & 60 & $<20$ & 1 \\
\hline \multicolumn{9}{|l|}{ JULY } \\
\hline 31 & $<20$ & $<50$ & $<10$ & $<20$ & $<20$ & 50 & $<20$ & $<20$ \\
\hline \multicolumn{9}{|l|}{ SEPT } \\
\hline 25 & $<40$ & 100 & $<10$ & $<40$ & $<40$ & 80 & $<20$ & 3 \\
\hline
\end{tabular}


Table 6.--Chemical analyses of water from the multilevel ground-water sampling devices

[MLGWSD, multilevel ground-water sampling device; ft, feet; ${ }^{\circ} \mathrm{C}$, degrees Celsius; $\mu \mathrm{S} / \mathrm{cm}, \mathrm{micsosiemens}$ per centimeter; tot rec, total recoverable; mg/L, milligrams per liter; $\mu g / \mathrm{L}$, micrograms per 1 iter; $\mathrm{NO}_{2}+\mathrm{NO}_{3}$, nitrite plus nitrate; --, no data; <, less than the detection limit for analytical method and sample dilution used]

\begin{tabular}{|c|c|c|c|c|c|c|c|c|c|c|c|}
\hline $\begin{array}{c}\text { Sample } \\
\text { date }\end{array}$ & $\begin{array}{l}\text { Depth to } \\
\text { top of } \\
\text { sample } \\
\text { inter- } \\
\text { val } \\
\text { (ft) }\end{array}$ & $\begin{array}{l}\text { Depth to } \\
\text { bottom } \\
\text { of } \\
\text { sample } \\
\text { interval } \\
\text { (ft) }\end{array}$ & $\begin{array}{c}\text { Temper- } \\
\text { ature, } \\
\text { water } \\
\left({ }^{\circ} \mathrm{C}\right)\end{array}$ & $\begin{array}{l}\text { Spe- } \\
\text { cific } \\
\text { con- } \\
\text { duct- } \\
\text { ance } \\
(\mu S / \mathrm{cm})\end{array}$ & $\begin{array}{c}\mathrm{pH} \\
\text { (units) }\end{array}$ & $\begin{array}{c}\text { Nitrogen } \\
\text { ammonia, } \\
\text { dis- } \\
\text { solved } \\
\text { (mg/L } \\
\text { as } N \text { ) }\end{array}$ & $\begin{array}{c}\text { Nitrogen } \\
\text { nitrite, } \\
\text { dis- } \\
\text { solved } \\
\text { (mg/L } \\
\text { as } N \text { ) }\end{array}$ & $\begin{array}{c}\text { Nitrogen } \\
\text { ammonia, } \\
\text { torganic, } \\
\text { dissolved } \\
\text { (mg/L } \\
\text { as } N \text { ) }\end{array}$ & $\begin{array}{c}\mathrm{Nitrogen} \\
\mathrm{NO}_{2}+\mathrm{NO}_{3}, \\
\text { dis - } \\
\text { solved } \\
(\mathrm{mg} / \mathrm{L} \\
\text { as } \mathrm{N} \text { ) }\end{array}$ & $\begin{array}{l}\text { Hard- } \\
\text { ness, } \\
\text { total } \\
(\mathrm{mg} / \mathrm{L} \\
\text { as } \\
\left.\mathrm{CaCO}_{3}\right)\end{array}$ & $\begin{array}{l}\text { Cal- } \\
\text { cium, } \\
\text { dis- } \\
\text { solved } \\
\text { (mg/L } \\
\text { as Ca) }\end{array}$ \\
\hline
\end{tabular}

\section{MLGWSD-1}

SEPT 1987

\begin{tabular}{|c|c|c|c|c|c|c|c|c|c|c|c|c|}
\hline 09 & 19 & 20 & 14.0 & 2,650 & 7.5 & -- & & -- & -- & 14.0 & 980 & 210 \\
\hline 09 & 24 & 25 & 13.5 & 3,400 & 7.5 & -- & & -- & -- & 24.0 & 670 & 140 \\
\hline 09 & 29 & 30 & 13.5 & 3,900 & 7.5 & -- & & -- & -- & 9.60 & 1,200 & 230 \\
\hline 22 & 19 & 20 & 14.0 & 2,550 & 7.5 & -- & & -- & 1.2 & -- & $=-$ & $=-$ \\
\hline 22 & 24 & 25 & 14.0 & 3,300 & 7.4 & -- & & -- & .70 & -- & -- & -- \\
\hline 22 & 29 & 30 & 15.0 & 3,900 & 7.5 & -- & & -- & .50 & -- & -- & -- \\
\hline \multicolumn{13}{|l|}{ MAR 1988} \\
\hline 22 & 19 & 20 & 13.0 & 2,580 & 7.4 & 0.020 & & - & .50 & 22.0 & -- & -- \\
\hline 22 & 24 & 25 & 13.0 & 4,050 & 7.4 & .050 & & -- & .50 & 13.0 & -- & $=-$ \\
\hline 22 & 29 & 30 & 13.0 & 4,300 & 7.5 & .070 & & -- & .70 & 11.0 & -- & - \\
\hline \multicolumn{13}{|l|}{ AUG } \\
\hline 17 & 24 & 25 & -- & 4,400 & 7.4 & -- & & -- & -- & -- & -- & -- \\
\hline 17 & 29 & 30 & -- & 3,940 & 7.7 & -- & & -- & -- & -- & -- & -- \\
\hline \multicolumn{13}{|l|}{ SEPT } \\
\hline 01 & 24 & 25 & -- & -- & -- & -- & & - & -- & -- & -- & - \\
\hline 01 & 29 & 30 & -- & -- & -- & -- & & -- & -- & -- & -- & -- \\
\hline 20 & 24 & 25 & 18.5 & 4,390 & 7.6 & .030 & $<0$ & 010 & 1.0 & 15.0 & 1,200 & 240 \\
\hline 20 & 29 & 30 & 17.5 & 4,790 & 7.7 & .090 & & 021 & .30 & 15.0 & 1,300 & 240 \\
\hline $\begin{array}{c}\text { Sample } \\
\text { date }\end{array}$ & $\begin{array}{l}\text { Magne- } \\
\text { sium, } \\
\text { dis- } \\
\text { solved } \\
\text { (mg/L } \\
\text { as } \mathrm{Mg}_{\mathrm{g}} \text { ) }\end{array}$ & $\begin{array}{l}\text { Sodium, } \\
\text { dis- } \\
\text { solved } \\
\text { (mg/L } \\
\text { as } \mathrm{Na} \text { ) }\end{array}$ & $\begin{array}{l}\text { Potas- } \\
\text { sium, } \\
\text { dis- } \\
\text { solved } \\
\text { (mg/L } \\
\text { as K) }\end{array}$ & $\begin{array}{l}\text { Chlo- } \\
\text { ride, } \\
\text { dis- } \\
\text { solved } \\
\text { (mg/L } \\
\text { as Cl) }\end{array}$ & $\begin{array}{l}\text { Sul- } \\
\text { fate, } \\
\text { dis- } \\
\text { solved } \\
\left(\mathrm{mg}^{2} / \mathrm{L}\right. \\
\left.\text { as } \mathrm{SO}_{4}\right)\end{array}$ & $\begin{array}{l}\text { Cad- } \\
\text { mium- } \\
\text { dis- } \\
\text { solved } \\
(\mu \mathrm{g} / \mathrm{L} \\
\text { as Cd) }\end{array}$ & $\begin{array}{l}\text { Iron, } \\
\text { dis- } \\
\text { solved } \\
(\mu g / L \\
\text { as Fe) }\end{array}$ & $\begin{array}{l}\text { Lead, } \\
\text { dis- } \\
\text { solved } \\
\left(\mu_{8} / L\right. \\
\text { as } \mathrm{Pb})\end{array}$ & $\begin{array}{l}\text { Manga- } \\
\text { nese, } \\
\text { dis- } \\
\text { solved } \\
(\mu g / L \\
\text { as Mn) }\end{array}$ & $\begin{array}{c}\text { Di- } \\
\text { chloro- } \\
\text { bromo- } \\
\text { methane, } \\
\text { total } \\
\left(\mu_{g} / L\right)\end{array}$ & $\begin{array}{l}\text { Carbon } \\
\text { tetra- } \\
\text { chlo- } \\
\text { ride, } \\
\text { total } \\
(\mu g / L)\end{array}$ & \\
\hline
\end{tabular}

SEPT 1987

\begin{tabular}{|c|c|c|c|c|c|c|c|c|c|c|c|}
\hline 09 & 110 & 510 & 7.0 & 200 & 1,500 & -- & 30 & -- & 30 & -- & -- \\
\hline 09 & 77 & 380 & 6.4 & 130 & 970 & -- & 20 & -- & 30 & -- & -- \\
\hline 09 & 140 & 620 & 10 & 250 & 1,900 & -- & 40 & -- & 90 & -- & -- \\
\hline 22 & $-\infty$ & -- & -- & 130 & -- & -- & -- & -- & -- & -- & -- \\
\hline 22 & -- & -- & -- & 200 & -- & -- & -- & -- & -- & -- & -- \\
\hline 22 & -- & -- & -- & 240 & -- & -- & -- & -- & -- & -- & -- \\
\hline \multicolumn{12}{|c|}{ MAR 1988} \\
\hline 22 & $\therefore$ & -- & -- & 140 & -- & -- & -- & -- & -- & $=$ & -- \\
\hline 22 & -- & -- & -- & 210 & -- & -- & -- & -- & -- & -- & $=-$ \\
\hline 22 & -- & -- & -- & 240 & -- & -- & -- & -- & -- & -- & -- \\
\hline \multicolumn{12}{|l|}{ AUG } \\
\hline 17 & -- & -- & -- & 260 & -- & -- & -- & -- & -- & -- & -- \\
\hline 17 & -- & -- & -- & -- & -- & $=-$ & -- & -- & -- & -- & -- \\
\hline \multicolumn{12}{|l|}{ SEPT } \\
\hline 01 & -- & -- & -- & -- & -- & -- & -- & -- & -- & $<3.0$ & $<3.0$ \\
\hline 01 & -- & -- & -- & -- & -- & -- & -- & -- & $=$ & $<3.0$ & -- \\
\hline 20 & 150 & 630 & 8.1 & 260 & 2,000 & $<1$ & 20 & $<5$ & 20 & $\cdots$ & -- \\
\hline 20 & 160 & 640 & 9.7 & 290 & 2,100 & $<1$ & 10 & $<5$ & $<10$ & -- & $=-$ \\
\hline
\end{tabular}


Table 6.--Chemical analyses of water from the multilevel ground-water sampling devices--Continued

\begin{tabular}{|c|c|c|c|c|c|c|c|c|c|c|c|}
\hline $\begin{array}{c}\text { Sample } \\
\text { date }\end{array}$ & $\begin{array}{l}1,2-d i- \\
\text { chloro } \\
\text { ethane, } \\
\text { total } \\
\left(\mu_{g} / \mathrm{L}\right)\end{array}$ & $\begin{array}{l}\text { Bromo- } \\
\text { form, } \\
\text { total } \\
\left(\mu_{g} / L\right)\end{array}$ & $\begin{array}{l}\text { Chloro- } \\
\text { dibromo- } \\
\text { methane, } \\
\text { total } \\
\left(\mu_{g} / L\right)\end{array}$ & $\begin{array}{l}\text { Chloro- } \\
\text { form, } \\
\text { total } \\
(\mu \mathrm{g} / \mathrm{L})\end{array}$ & $\begin{array}{l}\text { Tol- } \\
\text { uene, } \\
\text { total } \\
\left(\mu_{g} / L\right)\end{array}$ & $\begin{array}{l}\text { Ben- } \\
\text { zene, } \\
\text { total } \\
(\mu g / L)\end{array}$ & $\begin{array}{c}\text { Chloro- } \\
\text { benzene, } \\
\text { total } \\
(\mu g / L)\end{array}$ & $\begin{array}{c}\text { Chloro- } \\
\text { ethane, } \\
\text { tota } 1 \\
\left(\mu_{\mathrm{g} / L}\right)\end{array}$ & $\begin{array}{c}\text { Ethyl- } \\
\text { benzene, } \\
\text { total } \\
\left(\mu_{\mathrm{g}} / \mathrm{L}\right)\end{array}$ & $\begin{array}{c}\text { Methyl- } \\
\text { bromide, } \\
\text { total } \\
\left(\mu_{\mathrm{g}} / \mathrm{L}\right)\end{array}$ & $\begin{array}{c}\text { Methyl- } \\
\text { chlo- } \\
\text { ride, } \\
\text { total } \\
\left(\mu_{g} / \mathrm{L}\right)\end{array}$ \\
\hline
\end{tabular}

MLGWSD-1--Continued

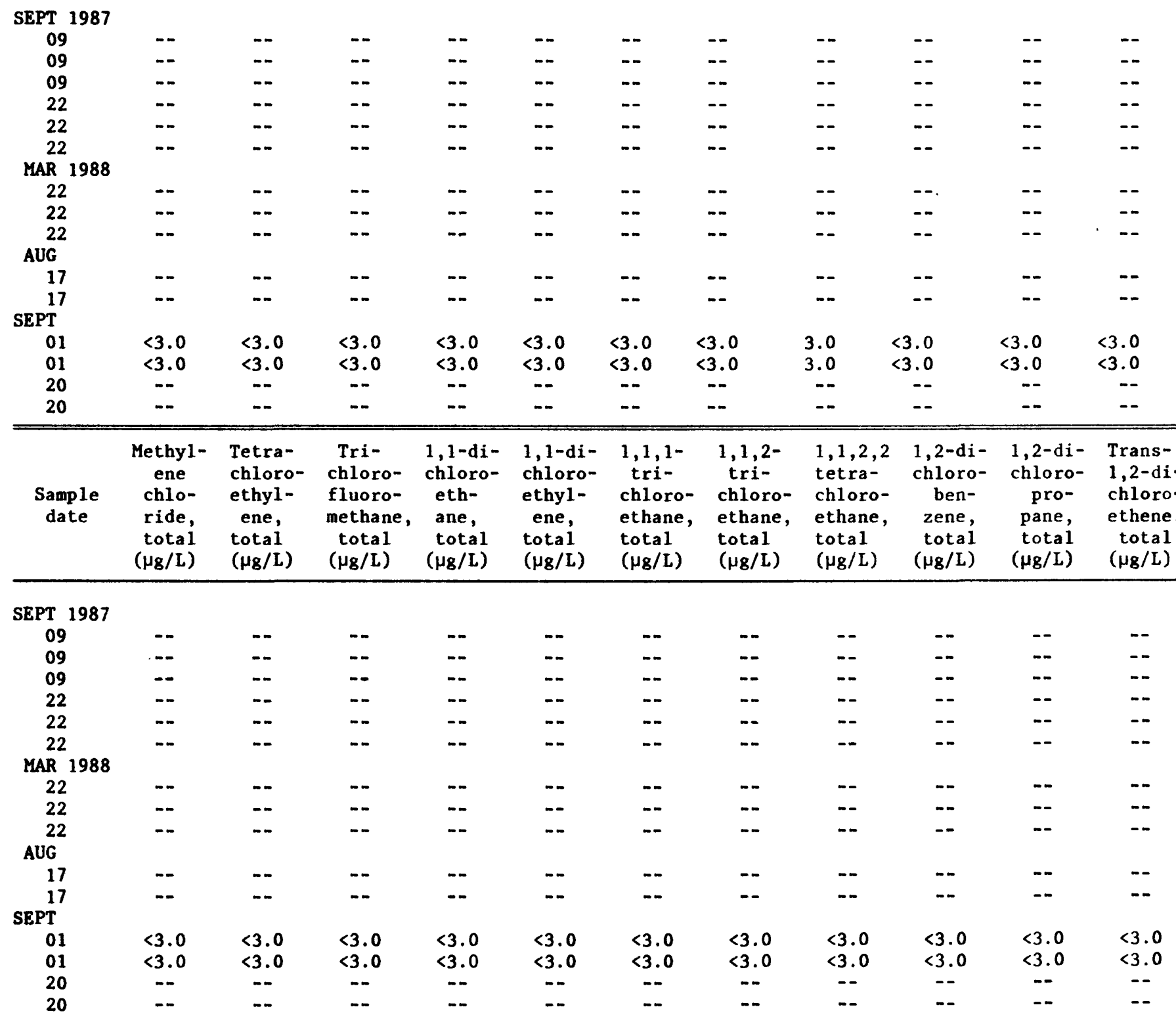


Table 6.--Chemical analyses of water from the multilevel ground-water sampling devices--Continued

\begin{tabular}{|c|c|c|c|c|c|c|c|c|c|c|c|}
\hline $\begin{array}{c}\text { Sample } \\
\text { date }\end{array}$ & $\begin{array}{l}\text { 1,3-di- } \\
\text { chloro- } \\
\text { propene, } \\
\text { total } \\
\left(\mu_{g} / L\right)\end{array}$ & $\begin{array}{l}1,3-d i- \\
\text { chloro- } \\
\text { benzene, } \\
\text { total } \\
\left(\mu_{\mathrm{g}} / \mathrm{L}\right)\end{array}$ & $\begin{array}{l}1,4-d i- \\
\text { chloro- } \\
\text { benzene, } \\
\text { total } \\
\left(\mu_{8} / L\right)\end{array}$ & $\begin{array}{l}\text { 2-chloro- } \\
\text { ethyl- } \\
\text { vinyl- } \\
\text { ether, } \\
\text { total } \\
(\mu \mathrm{g} / \mathrm{L})\end{array}$ & $\begin{array}{l}\text { Di- } \\
\text { chloro- } \\
\text { difluoro- } \\
\text { methane, } \\
\text { total } \\
\left(\mu_{\mathrm{g}} / \mathrm{L}\right)\end{array}$ & $\begin{array}{l}\text { Trans- } \\
1,3-d i- \\
\text { chloro- } \\
\text { propene, } \\
\text { total } \\
\left(\mu_{g} / L\right)\end{array}$ & $\begin{array}{l}\text { Cis- } \\
1,3-\text { di- } \\
\text { chloro- } \\
\text { propene, } \\
\text { total } \\
\left(\mu_{g} / L\right)\end{array}$ & $\begin{array}{l}\text { Vinyl } \\
\text { chlo- } \\
\text { ride, } \\
\text { total } \\
\left(\mu_{g} / L_{.}\right)\end{array}$ & $\begin{array}{l}\text { Tri- } \\
\text { chloro- } \\
\text { ethy- } \\
\text { ene, } \\
\text { total } \\
\left(\mu_{g} / L\right)\end{array}$ & $\begin{array}{l}\text { Sty- } \\
\text { rene, } \\
\text { total } \\
\left(\mu_{g} / L\right)\end{array}$ & $\begin{array}{c}\text { Xy- } \\
\text { lene, } \\
\text { tot } \\
\text { rec } \\
\left(\mu_{8} / L\right)\end{array}$ \\
\hline
\end{tabular}

\section{MLGWSD-1--Continued}

\begin{tabular}{|c|c|c|c|c|c|c|c|c|c|c|c|c|}
\hline \multicolumn{13}{|l|}{ SEPT 1987} \\
\hline 09 & - & -- & -- & -- & & -- & -- & -- & -- & -- & - & -- \\
\hline 09 & -- & -- & -- & -- & & -- & -- & - & -- & -- & -- & -- \\
\hline 09 & -- & -- & -- & - & & -- & -- & $\cdots$ & -- & - & - & -- \\
\hline 22 & -- & -- & -- & - & & -- & -- & - & - & -- & -- & -- \\
\hline 22 & -- & -- & -- & -- & & -- & -- & -- & -- & -- & -- & -- \\
\hline 22 & -- & -- & -- & - & & -- & -- & -- & -- & - & $\cdots$ & - \\
\hline MAR 1988 & & & & & & & & & & & & \\
\hline 22 & -- & -- & -- & -- & & -- & -- & -- & $\ldots$ & -- & -- & -- \\
\hline 22 & -- & - & -- & -- & & -- & -- & -- & -- & - & -- & -- \\
\hline 22 & - & -- & -- & -- & & -- & -- & -- & - & - & -- & -- \\
\hline AUG & & & & & & & & & & & & \\
\hline 17 & -- & -- & -- & -- & & -- & -- & - & $-\infty$ & -- & -- & -- \\
\hline 17 & -- & - & $-\therefore$ & - & & -- & - & - & -- & -- & -- & -- \\
\hline SEPT & & & & & & & & & & & & \\
\hline 01 & $<3.0$ & $<3.0$ & $<3.0$ & $<3.0$ & & $<3.0$ & $<3.0$ & $<3.0$ & $<3.0$ & $<3.0$ & $<3.0$ & $<3.0$ \\
\hline 01 & $<3.0$ & $<3.0$ & $<3.0$ & $<3.0$ & & $<3.0$ & $<3.0$ & $<3.0$ & $<3.0$ & $<3.0$ & $<3.0$ & $<3.0$ \\
\hline 20 & -- & -- & - & -- & & -- & -- & -- & -- & $\therefore$ & -- & -- \\
\hline 20 & -- & -- & -- & -- & & -- & -- & -- & -- & -- & -- & -- \\
\hline $\begin{array}{c}\text { Sample } \\
\text { date }\end{array}$ & $\begin{array}{l}\text { Depth to } \\
\text { top of } \\
\text { sample } \\
\text { inter- } \\
\text { val } \\
\text { (ft) }\end{array}$ & $\begin{array}{l}\text { Depth to } \\
\text { bottom } \\
\text { of } \\
\text { sample } \\
\text { interval } \\
\text { (ft) }\end{array}$ & $\begin{array}{l}\text { Temper- } \\
\text { ature, } \\
\text { water } \\
\left({ }^{\circ} \mathrm{C}\right)\end{array}$ & $\begin{array}{l}\text { Spe- } \\
\text { cific } \\
\text { con- } \\
\text { duct- } \\
\text { ance } \\
(\mu S / \mathrm{cm})\end{array}$ & $\begin{array}{c}\mathrm{pH} \\
\text { (units) }\end{array}$ & $\begin{array}{c}\text { Nitrogen } \\
\text { ammonia, } \\
\text { dis- } \\
\text { solved } \\
(\mathrm{mg} / \mathrm{L} \\
\text { as } \mathrm{N})\end{array}$ & $\begin{array}{c}\text { Nitrogen } \\
\text { nitrite, } \\
\text { dis- } \\
\text { solved } \\
(\mathrm{mg} / \mathrm{L} \\
\text { as } \mathrm{N})\end{array}$ & $\begin{array}{l}\text { Nitrogen } \\
\text { ammonia, } \\
\text { torganic, } \\
\text { dissolved } \\
\text { (mg/L } \\
\text { as } \mathrm{N})\end{array}$ & $\begin{array}{l}\mathrm{Ni} \\
\mathrm{NO} \\
\mathrm{d} \\
\mathrm{d}\end{array}$ & $\begin{array}{l}\text { ogen } \\
\mathrm{NO}_{3}, \\
\text { s- } \\
\text { ved } \\
\mathrm{g} / \mathrm{L} \\
\mathrm{N})\end{array}$ & $\begin{array}{l}\text { Hard- } \\
\text { ness, } \\
\text { total } \\
(\mathrm{mg} / \mathrm{L} \\
\text { as } \\
\left.\mathrm{CaCO}_{3}\right)\end{array}$ & $\begin{array}{l}\text { Cal- } \\
\text { cium, } \\
\text { dis- } \\
\text { solved } \\
\text { (mg/L } \\
\text { as } \text { Ca) }\end{array}$ \\
\hline
\end{tabular}

\section{MLGWSD-2}

SEPT 1987




Table 6.--Chemical analyses of water from the multilevel ground-water sampling devices--Continued

\begin{tabular}{|c|c|c|c|c|c|c|c|c|c|c|c|}
\hline $\begin{array}{c}\text { Sample } \\
\text { date }\end{array}$ & $\begin{array}{l}\text { Magne- } \\
\text { sium, } \\
\text { dis- } \\
\text { solved } \\
\text { (mg/L } \\
\text { as } \mathrm{Mg} \text { ) }\end{array}$ & $\begin{array}{l}\text { Sodium, } \\
\text { dis- } \\
\text { solved } \\
\text { (mg/L } \\
\text { as } \mathrm{Na} \text { ) }\end{array}$ & $\begin{array}{l}\text { Potas- } \\
\text { sium, } \\
\text { dis- } \\
\text { solved } \\
\text { (mg/L } \\
\text { as } \mathrm{K})\end{array}$ & $\begin{array}{l}\text { Chlo- } \\
\text { ride, } \\
\text { dis- } \\
\text { solved } \\
\text { (mg/L } \\
\text { as }(1)\end{array}$ & $\begin{array}{l}\text { Sul- } \\
\text { fate, } \\
\text { dis- } \\
\text { solved } \\
\left(\mathrm{mg}^{\prime} / \mathrm{L}\right. \\
\text { as } \mathrm{SO}_{4} \text { ) }\end{array}$ & $\begin{array}{l}\text { Cad- } \\
\text { mium- } \\
\text { dis- } \\
\text { solved } \\
(\mu g / L \\
\text { as } C d)\end{array}$ & $\begin{array}{l}\text { Iron, } \\
\text { dis- } \\
\text { solved } \\
(\mu g / L \\
\text { as Fe) }\end{array}$ & $\begin{array}{l}\text { Lead, } \\
\text { dis- } \\
\text { solved } \\
(\mu g / L \\
\text { as } \mathrm{Pb})\end{array}$ & $\begin{array}{l}\text { Manga- } \\
\text { nese, } \\
\text { dis- } \\
\text { solved } \\
\left(\mu_{g} / L\right. \\
\text { as } M n)\end{array}$ & $\begin{array}{c}\text { Di- } \\
\text { chloro- } \\
\text { bromo- } \\
\text { methane, } \\
\text { total } \\
(\mu g / L)\end{array}$ & $\begin{array}{l}\text { Carbon } \\
\text { tetra- } \\
\text { chlo- } \\
\text { ride, } \\
\text { total } \\
(\mu \mathrm{g} / \mathrm{L})\end{array}$ \\
\hline
\end{tabular}

MLGWSD-2--Continued

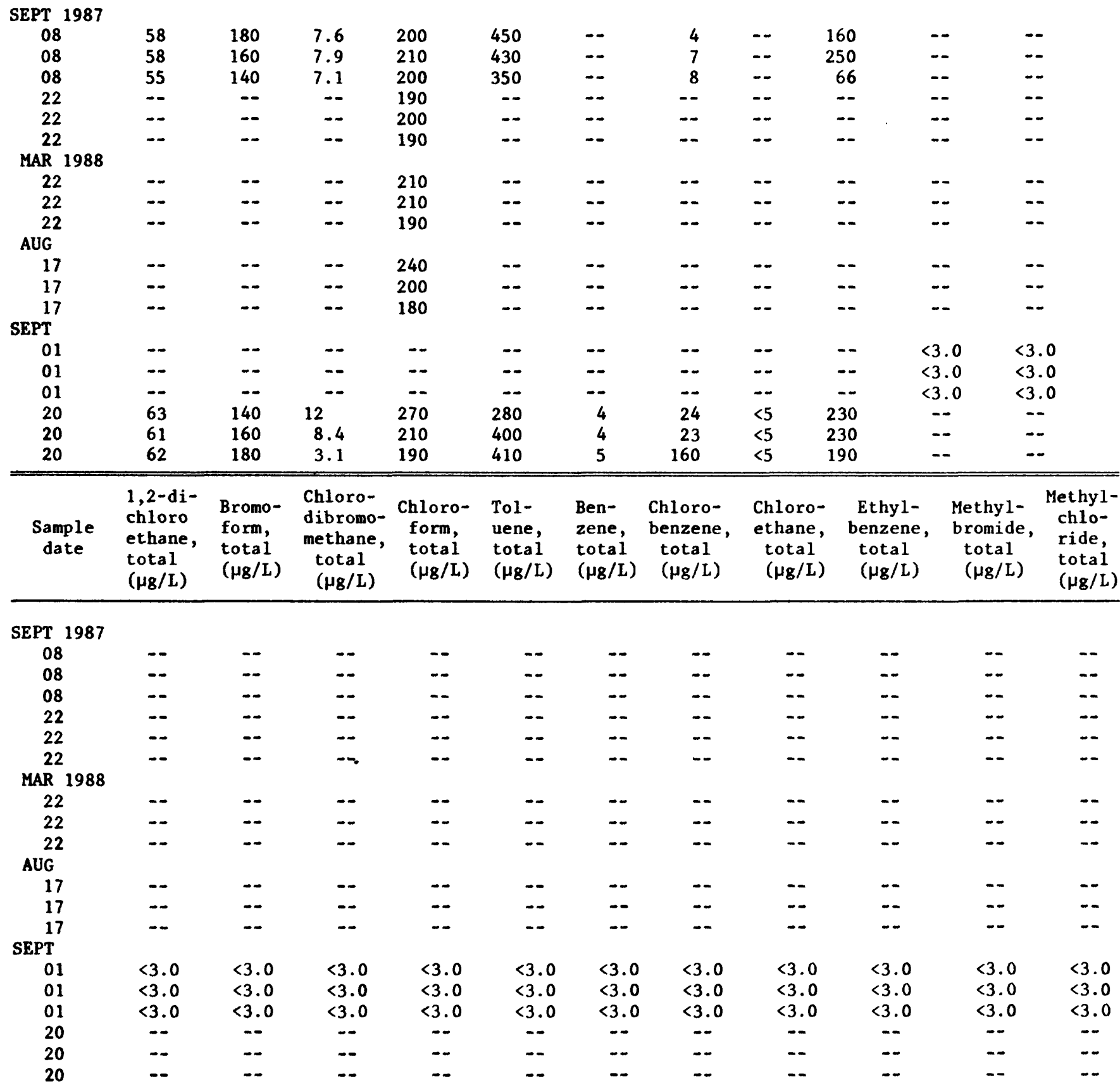


Table 6.--Chemical analyses of water from the multilevel ground-water sampling devices--Continued

\begin{tabular}{|c|c|c|c|c|c|c|c|c|c|c|c|}
\hline $\begin{array}{c}\text { Sample } \\
\text { date }\end{array}$ & $\begin{array}{c}\text { Methyl- } \\
\text { ene } \\
\text { chlo- } \\
\text { ride, } \\
\text { total } \\
\left(\mu_{8} / L\right)\end{array}$ & $\begin{array}{l}\text { Tetra- } \\
\text { chloro- } \\
\text { ethyl- } \\
\text { ene, } \\
\text { total } \\
\left(\mu_{8} / L\right)\end{array}$ & $\begin{array}{l}\text { Tri- } \\
\text { chloro- } \\
\text { fluoro- } \\
\text { methane, } \\
\text { total } \\
\left(\mu_{8} / L\right)\end{array}$ & $\begin{array}{l}\text { 1,1-di- } \\
\text { chloro- } \\
\text { eth- } \\
\text { ane, } \\
\text { total } \\
\left(\mu_{8} / L\right)\end{array}$ & $\begin{array}{l}\text { 1,1-di- } \\
\text { chloro- } \\
\text { ethyl- } \\
\text { ene; } \\
\text { total } \\
\left(\mu_{8} / L\right)\end{array}$ & $\begin{array}{c}1,1,1- \\
\text { tri- } \\
\text { chloro- } \\
\text { ethane, } \\
\text { total } \\
\left(\mu_{g} / L\right)\end{array}$ & $\begin{array}{l}1,1,2- \\
\text { tri- } \\
\text { chloro- } \\
\text { ethane, } \\
\text { total } \\
\left(\mu_{8} / L\right)\end{array}$ & $\begin{array}{l}1,1,2,2 \\
\text { tetra- } \\
\text { chloro- } \\
\text { ethane, } \\
\text { total } \\
(\mu g / L)\end{array}$ & $\begin{array}{c}1,2-\mathrm{di}- \\
\text { chloro- } \\
\cdot \text { ben- } \\
\text { zene, } \\
\text { total } \\
\left(\mu_{8} / \mathrm{L}\right)\end{array}$ & $\begin{array}{c}\text { 1,2-di- } \\
\text { chloro- } \\
\text { pro- } \\
\text { pane, } \\
\text { total } \\
\left(\mu_{g} / L\right)\end{array}$ & $\begin{array}{l}\text { Trans- } \\
1,2-\text { di- } \\
\text { chloro- } \\
\text { ethene, } \\
\text { total } \\
\left(\mu_{8} / L\right)\end{array}$ \\
\hline
\end{tabular}

MLGWSD-2--Continued

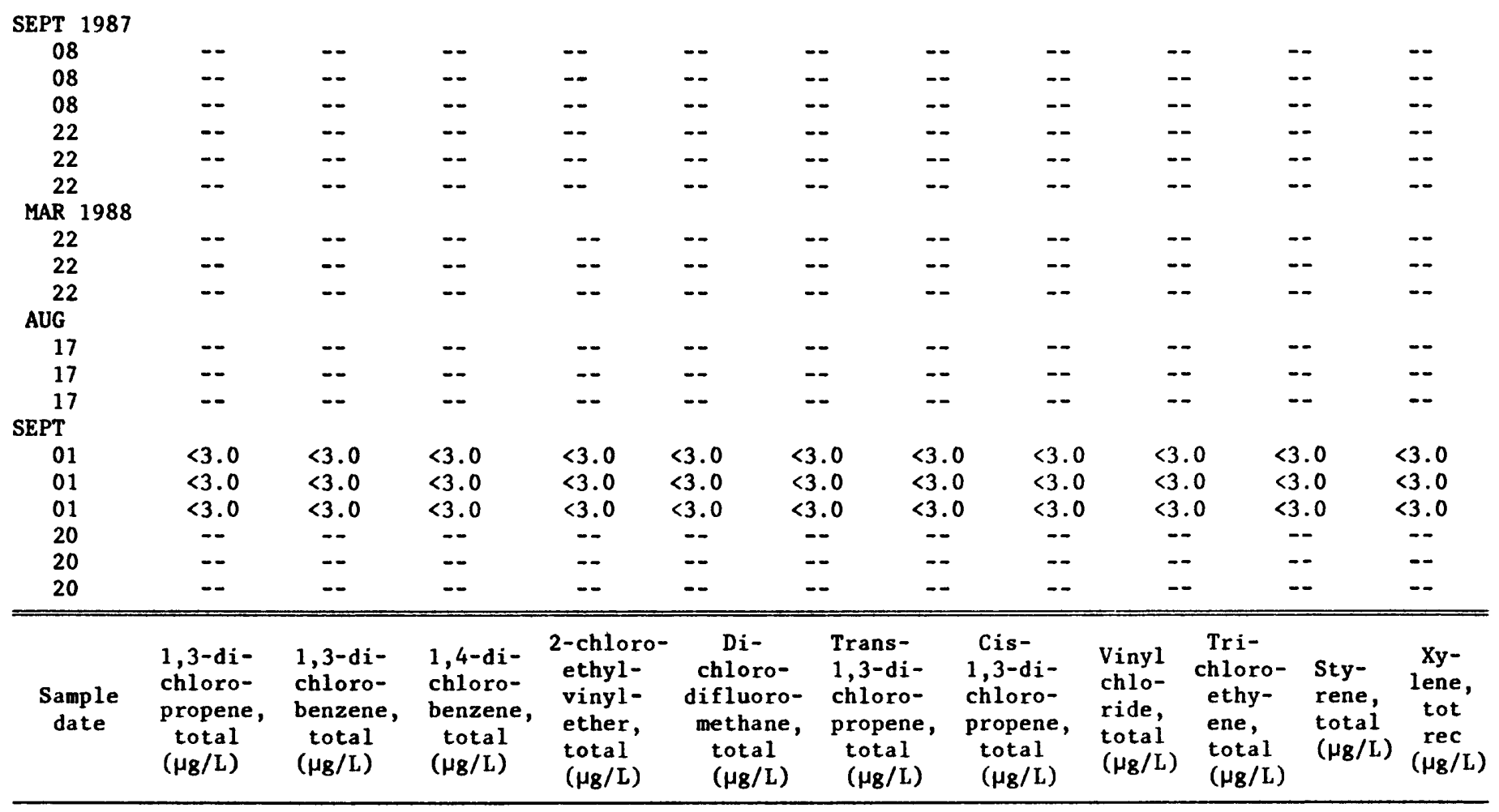

SEPT 1987

\begin{tabular}{|c|c|c|c|c|c|c|c|c|c|c|c|}
\hline 08 & -- & -- & -- & - & -- & -- & -- & -- & -- & -- & -- \\
\hline 08 & -- & -- & -- & -- & - & -- & -- & -- & -- & -- & -- \\
\hline 08 & -- & -- & -- & -- & -- & -- & -- & -- & -- & -- & -- \\
\hline 22 & -- & -- & -- & -- & -- & - & -- & -- & -- & -- & -- \\
\hline 22 & -- & -- &.-- & -- & -- & -- & -- & -- & -- & -- & -- \\
\hline 22 & -- & -- & -- & -- & -- & -- & -- & -- & -- & -- & -- \\
\hline \multicolumn{12}{|l|}{ MAR 1988} \\
\hline 22 & -- & -- & -- & -- & -- & -- & -- & -- & -- & -- & -- \\
\hline 22 & -- & -- & -- & -- & -- & -- & -- & -- & -- & -- & -- \\
\hline 22 & -- & -- & -- & -- & -- & -- & -- & -- & -- & -- & -- \\
\hline \multicolumn{12}{|l|}{ AUG } \\
\hline 17 & -- & -- & - & -- & -- & -- & -- & -- & -- & -- & -- \\
\hline 17 & -- & -- & -- & -- & -- & -- & -- & -- & -- & -- & -- \\
\hline 17 & -- & -- & -- & -- & -- & -- & -- & -- & -- & -- & -- \\
\hline \multicolumn{12}{|l|}{ SEPT } \\
\hline 01 & $<3.0$ & $<3.0$ & $<3.0$ & $<3.0$ & $<3.0$ & $<3.0$ & $<3.0$ & $<3.0$ & $<3.0$ & $<3.0$ & $<3.0$ \\
\hline 01 & $<3.0$ & $<3.0$ & $<3.0$ & $<3.0$ & $<3.0$ & $<3.0$ & $<3.0$ & $<3.0$ & $<3.0$ & $<3.0$ & $<3.0$ \\
\hline 01 & $<3.0$ & $<3.0$ & $<3.0$ & $<3.0$ & $<3.0$ & $<3.0$ & $<3.0$ & $<3.0$ & $<3.0$ & $<3.0$ & $<3.0$ \\
\hline 20 & -- & -- & -- & -- & -- & -- & -- & -- & -- & -- & -- \\
\hline 20 & -- & -- & -- & -- & -- & -- & -- & -- & -- & -- & -- \\
\hline 20 & -- & -- & -- & -- & -- & -- & -- & -- & -- & -- & -- \\
\hline
\end{tabular}


Table 6.--Chemical analyses of water from the multilevel ground-water sampling devices--Continued

\begin{tabular}{|c|c|c|c|c|c|c|c|c|c|c|c|}
\hline $\begin{array}{c}\text { Sample } \\
\text { date }\end{array}$ & $\begin{array}{l}\text { Depth to } \\
\text { top of } \\
\text { sample } \\
\text { inter- } \\
\text { val } \\
\text { (ft) }\end{array}$ & $\begin{array}{l}\text { Depth to } \\
\text { bottom } \\
\text { of } \\
\text { sample } \\
\text { interval } \\
\text { (ft) }\end{array}$ & $\begin{array}{c}\text { Temper- } \\
\text { ature, } \\
\text { water } \\
\left({ }^{\circ} \mathrm{C}\right)\end{array}$ & $\begin{array}{l}\text { Spe- } \\
\text { cific } \\
\text { con- } \\
\text { duct- } \\
\text { ance } \\
(\mu S / \mathrm{cm})\end{array}$ & $\underset{\text { (units) }}{\mathrm{pH}}$ & $\begin{array}{c}\text { Nitrogen } \\
\text { ammonia, } \\
\text { dis- } \\
\text { solved } \\
(\mathrm{mg} / \mathrm{L} \\
\text { as } \mathrm{N})\end{array}$ & $\begin{array}{c}\text { Nitrogen } \\
\text { nitrite, } \\
\text { dis- } \\
\text { solved } \\
(\mathrm{mg} / \mathrm{L} \\
\text { as } \mathrm{N})\end{array}$ & $\begin{array}{l}\text { Nitrogen } \\
\text { ammonia, } \\
\text { torganic, } \\
\text { dissolved } \\
\text { (mg/L } \\
\text { as N) }\end{array}$ & $\begin{array}{c}\text { Nitrogen } \\
\mathrm{NO}_{2}+\mathrm{NO}_{3}, \\
\text { dis- } \\
\text { solved } \\
(\mathrm{mg} / \mathrm{L} \\
\text { as } \mathrm{N})\end{array}$ & $\begin{array}{l}\text { Hard- } \\
\text { ness, } \\
\text { total } \\
(\mathrm{mg} / \mathrm{L} \\
\text { as } \\
\left.\mathrm{CaCO}_{3}\right)\end{array}$ & $\begin{array}{l}\text { Cal- } \\
\text { cium, } \\
\text { dis- } \\
\text { solved } \\
\text { (mg/L } \\
\text { as Ca) }\end{array}$ \\
\hline
\end{tabular}

MLGWSD-3

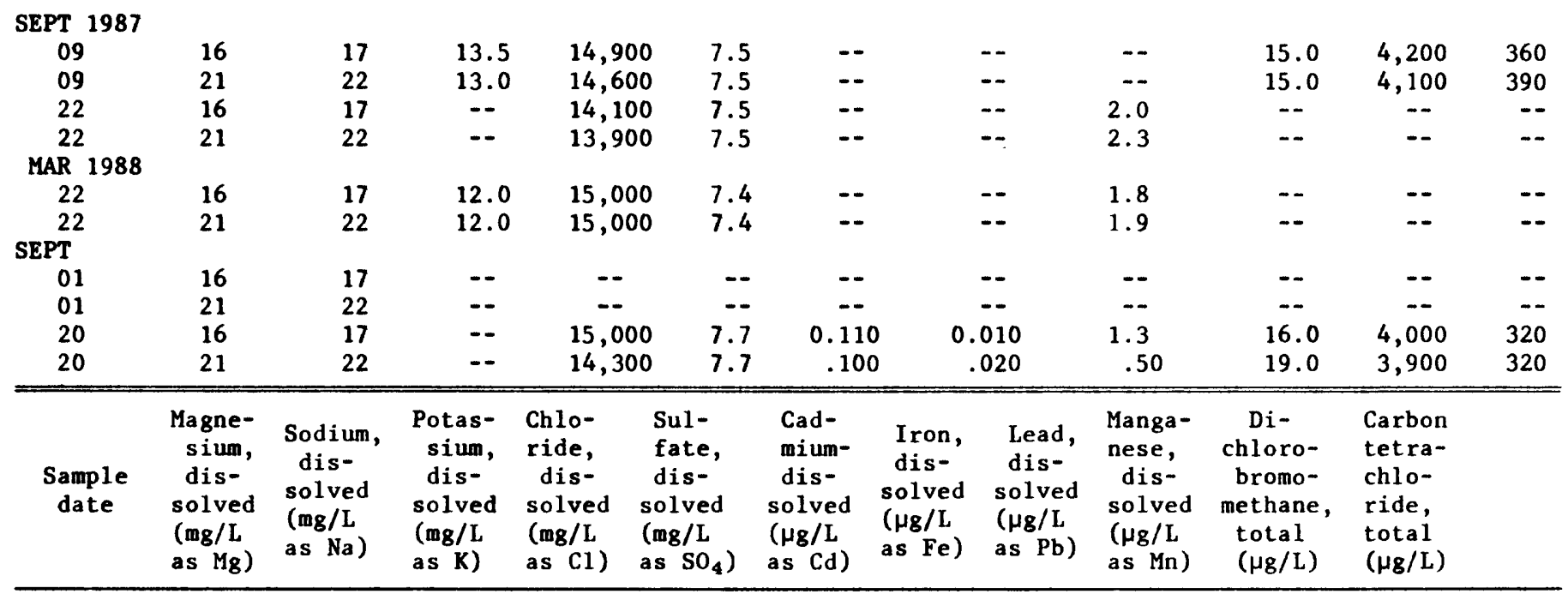

\begin{tabular}{|c|c|c|c|c|c|c|c|c|c|c|c|}
\hline SEPT 1987 & & & & & & & & & & & \\
\hline 09 & 790 & 2,100 & 15 & 1,100 & 7,700 & -- & 60 & -- & 40 & -- & -- \\
\hline 09 & 770 & 2,100 & 14 & 1,200 & 7,600 & -- & 60 & -- & 30 & -- & -- \\
\hline 22 & -- & -- & -- & 1,000 & -. & -- & -- & -- & -- & - & -- \\
\hline$\stackrel{22}{\operatorname{MAR}^{2} 1988}$ & -- & -- & -- & 1,100 & -- & -- & -- & -- & -- & - & -- \\
\hline 22 & -- & -- & -- & 890 & -- & -- & -- & -- & -- & -- & -- \\
\hline 22 & -- & -- & -- & 1,100 & -- & -- & -- & -- & -- & -- & -- \\
\hline SEPT & & & & & & & & & & & \\
\hline 01 & - & -- & -- & -- & - & -- & - & -- & -- & $<3.0$ & $<3.0$ \\
\hline 01 & - & -- & - & - & -- & -- & -- & -- & -- & $<3.0$ & $<3.0$ \\
\hline 20 & 770 & 2,200 & 16 & 820 & 7,500 & $<1$ & 50 & $<5$ & 30 & -- & -- \\
\hline 20 & 750 & 2,100 & 15 & 1,100 & 7,000 & $<1$ & 50 & $<5$ & 20 & - & -- \\
\hline
\end{tabular}

\begin{tabular}{|c|c|c|c|c|c|c|c|c|c|c|c|}
\hline $\begin{array}{c}\text { Sample } \\
\text { date }\end{array}$ & $\begin{array}{l}1,2-d i- \\
\text { chloro } \\
\text { ethane, } \\
\text { total } \\
\left(\mu_{g} / L\right)\end{array}$ & $\begin{array}{l}\text { Bromo- } \\
\text { form, } \\
\text { total } \\
\left(\mu_{8} / L\right)\end{array}$ & $\begin{array}{l}\text { Chloror } \\
\text { dibromo- } \\
\text { methane, } \\
\text { total } \\
\left(\mu_{8} / L\right)\end{array}$ & $\begin{array}{c}\text { Chloro- } \\
\text { form, } \\
\text { total } \\
\left(\mu_{g} / L\right)\end{array}$ & $\begin{array}{l}\text { Tol- } \\
\text { uene, } \\
\text { total } \\
\left(\mu_{g} / L\right)\end{array}$ & $\begin{array}{l}\text { Ben- } \\
\text { zene, } \\
\text { tota } 1 \\
\left(\mu_{g} / L\right)\end{array}$ & $\begin{array}{c}\text { Chloro- } \\
\text { benzene, } \\
\text { total } \\
\left(\mu_{g} / L\right)\end{array}$ & $\begin{array}{c}\text { Chloro- } \\
\text { ethane, } \\
\text { tota } 1 \\
\left(\mu_{g} / L\right)\end{array}$ & $\begin{array}{c}\text { Ethyl- } \\
\text { benzene, } \\
\text { total } \\
(\mu \mathrm{g} / \mathrm{L})\end{array}$ & $\begin{array}{l}\text { Methy } 1- \\
\text { bromide, } \\
\text { total } \\
(\mu \mathrm{g} / \mathrm{L})\end{array}$ & $\begin{array}{c}\text { Methyl- } \\
\text { chlo- } \\
\text { ride, } \\
\text { total } \\
\left(\mu_{8} / \mathrm{L}\right)\end{array}$ \\
\hline
\end{tabular}

SEPT 1987




Table 6.--Chemical analyses of water from the multilevel ground-water sampling devices--Continued

\begin{tabular}{|c|c|c|c|c|c|c|c|c|c|c|c|}
\hline $\begin{array}{c}\text { Sample } \\
\text { date }\end{array}$ & $\begin{array}{c}\text { Methyl- } \\
\text { ene } \\
\text { chlo- } \\
\text { ride, } \\
\text { total } \\
\left(\mu_{\mathrm{g}} / \mathrm{L}\right)\end{array}$ & $\begin{array}{l}\text { Tetra- } \\
\text { chloro- } \\
\text { ethyl- } \\
\text { ene, } \\
\text { total } \\
\left(\mu_{\mathrm{g}} / \mathrm{L}\right)\end{array}$ & $\begin{array}{l}\text { Tri- } \\
\text { chloro- } \\
\text { fluoro- } \\
\text { methane, } \\
\text { total } \\
(\mu \mathrm{g} / \mathrm{L})\end{array}$ & $\begin{array}{l}\text { 1,1-di- } \\
\text { chloro- } \\
\text { eth- } \\
\text { ane, } \\
\text { total } \\
\left(\mu_{g} / L\right)\end{array}$ & $\begin{array}{l}\text { 1,1-di- } \\
\text { chloro- } \\
\text { ethyl- } \\
\text { ene, } \\
\text { total } \\
(\mu g / L)\end{array}$ & $\begin{array}{l}1,1,1- \\
\text { tri- } \\
\text { chloro- } \\
\text { ethane, } \\
\text { total } \\
\left(\mu_{\mathrm{g}} / \mathrm{L}\right)\end{array}$ & $\begin{array}{l}1,1,2- \\
\text { tri- } \\
\text { chloro- } \\
\text { ethane, } \\
\text { total } \\
(\mu \mathrm{g} / \mathrm{L})\end{array}$ & $\begin{array}{l}1,1,2,2 \\
\text { tetra- } \\
\text { chloro- } \\
\text { ethane, } \\
\text { total } \\
(\mu \mathrm{g} / \mathrm{L})\end{array}$ & $\begin{array}{c}\text { 1,2-di- } \\
\text { chloro- } \\
\text { ben- } \\
\text { zene, } \\
\text { total } \\
\left(\mu_{\mathrm{g}} / \mathrm{L}\right)\end{array}$ & $\begin{array}{c}\text { 1,2-di- } \\
\text { chloro- } \\
\text { pro- } \\
\text { pane, } \\
\text { total } \\
\left(\mu_{g} / L\right)\end{array}$ & $\begin{array}{l}\text { Trans- } \\
1,2-\text { di- } \\
\text { chloro- } \\
\text { ethene, } \\
\text { total } \\
\left(\mu_{\mathrm{g}} / \mathrm{L}\right)\end{array}$ \\
\hline
\end{tabular}

MLGWSD-3--Continued

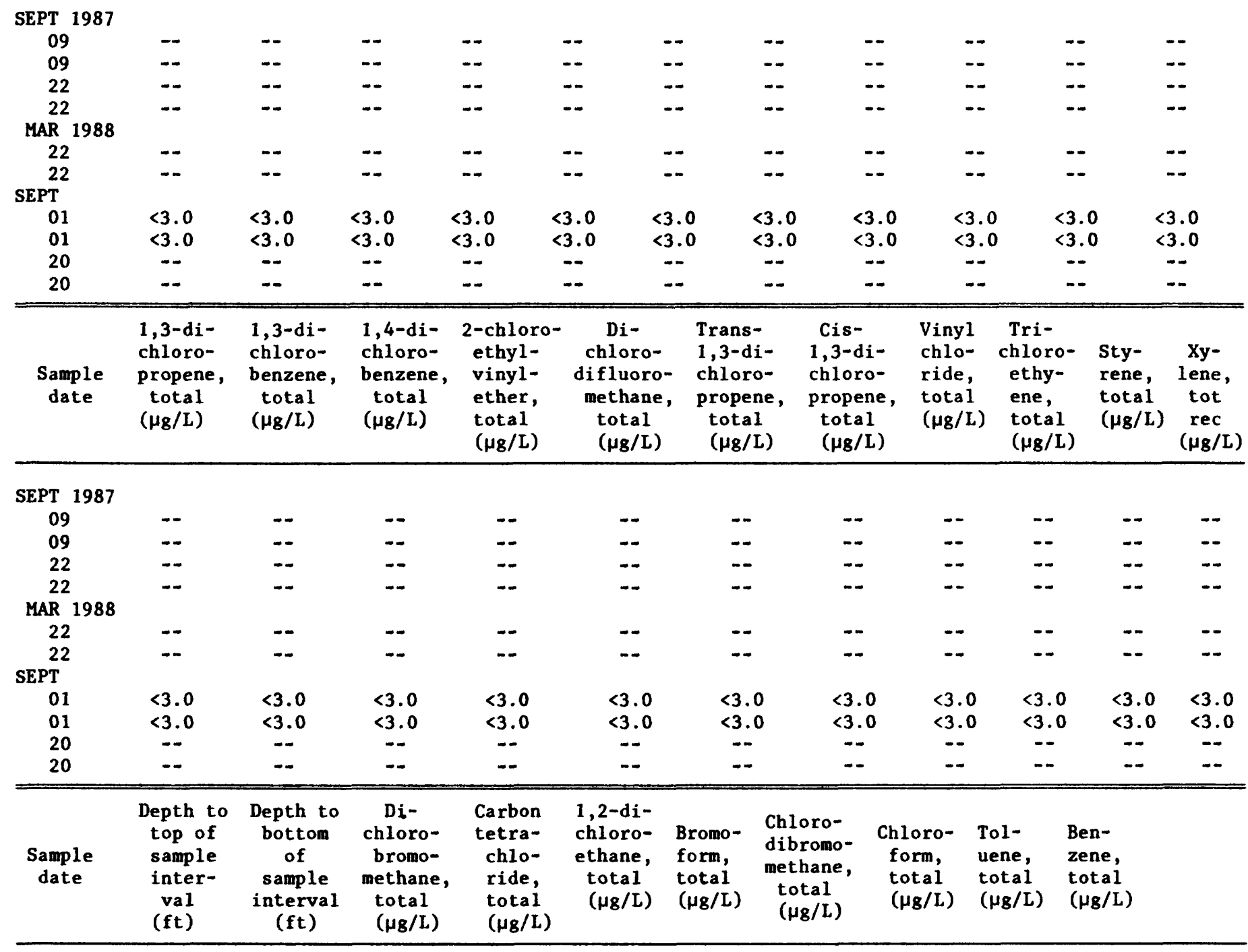

MLGWSD-4

SEPT 1988

01

27

28

$<3.0$

$<3.0$

$<3.0$

$<3.0$

$<3.0$

$<3.0$

$<3.0$

$<3.0$

\begin{tabular}{|c|c|c|c|c|c|c|c|c|c|}
\hline $\begin{array}{c}\text { Sample } \\
\text { date }\end{array}$ & $\begin{array}{l}\text { Chloro- } \\
\text { benzene, } \\
\text { total } \\
\left(\mu_{g} / L\right)\end{array}$ & $\begin{array}{c}\text { Chloro- } \\
\text { ethane, } \\
\text { tota } 1 \\
(\mu \mathrm{g} / \mathrm{L})\end{array}$ & $\begin{array}{c}\text { Ethyl- } \\
\text { benzene, } \\
\text { total } \\
\left(\mu_{\mathrm{g}} / \mathrm{L}\right)\end{array}$ & $\begin{array}{c}\text { Methyl- } \\
\text { bromide, } \\
\text { total } \\
\left(\mu_{g} / L_{1}\right)\end{array}$ & $\begin{array}{c}\text { Methyl- } \\
\text { chlo- } \\
\text { ride, } \\
\text { total } \\
\left(\mu_{8} / L\right)\end{array}$ & $\begin{array}{c}\text { Methyl- } \\
\text { ene } \\
\text { chlo- } \\
\text { ride, } \\
\text { total } \\
\left(\mu_{8} / \mathrm{L}\right)\end{array}$ & $\begin{array}{c}\text { Tetra- } \\
\text { chloro- } \\
\text { ethyl- } \\
\text { ene, } \\
\text { total } \\
(\mu g / L)\end{array}$ & $\begin{array}{l}\text { Tri- } \\
\text { chloro- } \\
\text { fluoro- } \\
\text { methane, } \\
\text { total } \\
\left(\mu_{g} / L\right)\end{array}$ & $\begin{array}{l}1,1-\mathrm{di}- \\
\text { chloro- } \\
\text { ethane, } \\
\text { total } \\
\left(\mu_{\mathrm{g}} / \mathrm{L}\right)\end{array}$ \\
\hline
\end{tabular}

SEPT 1988

$<3.0$

$<3.0$

$<3.0$

$<3.0$

$<3.0$

$<3.0$

$<3.0$ 
Table 6.--Chemical analyses of water from the multilevel ground-water sampling devices--Continued

\begin{tabular}{|c|c|c|c|c|c|c|c|c|c|}
\hline $\begin{array}{c}\text { Sample } \\
\text { date }\end{array}$ & $\begin{array}{l}\text { 1,1-Di- } \\
\text { chloro- } \\
\text { ethyl- } \\
\text { ene, } \\
\text { total } \\
\left(\mu_{\mathrm{g}} / \mathrm{L}\right)\end{array}$ & $\begin{array}{c}1,1,1- \\
\text { tri- } \\
\text { chloro- } \\
\text { ethane, } \\
\text { total } \\
\left(\mu_{g} / L\right)\end{array}$ & $\begin{array}{c}1,1,2- \\
\text { tri- } \\
\text { chloro- } \\
\text { ethane, } \\
\text { total } \\
\left(\mu_{g} / L\right)\end{array}$ & $\begin{array}{l}1,1,2,2 \\
\text { tetra- } \\
\text { chloro- } \\
\text { ethane, } \\
\text { total } \\
\left(\mu_{8} / L\right)\end{array}$ & $\begin{array}{l}1,2-d i- \\
\text { chloro- } \\
\text { benzene, } \\
\text { total } \\
\left(\mu_{g} / L\right)\end{array}$ & $\begin{array}{l}\text { 1,2-di- } \\
\text { chloro- } \\
\text { propane, } \\
\text { total } \\
\left(\mu_{g} / L\right)\end{array}$ & $\begin{array}{l}\text { Trans- } \\
1,2-\text { di- } \\
\text { chloro- } \\
\text { ethene, } \\
\text { total } \\
\left(\mu_{g} / L\right)\end{array}$ & $\begin{array}{l}1,3 \text {-di- } \\
\text { chloro- } \\
\text { propene, } \\
\text { total } \\
(\mu \mathrm{g} / \mathrm{L})\end{array}$ & $\begin{array}{c}1,3 \text {-di- } \\
\text { chloro- } \\
\text { benzene, } \\
\text { total } \\
(\mu \mathrm{g} / \mathrm{L})\end{array}$ \\
\hline
\end{tabular}

\section{MLGWSD-4--Continued}

\begin{tabular}{|c|c|c|c|c|c|c|c|c|c|c|c|c|c|c|}
\hline $\begin{array}{c}\text { SEPT } \\
01\end{array}$ & $<3.0$ & $<3.0$ & $<3.0$ & & $<3.0$ & & 3.0 & $<3.0$ & $<3.0$ & & & $<3$ & & \\
\hline $\begin{array}{c}\text { Sample } \\
\text { date }\end{array}$ & $\begin{array}{l}\text { 1,4-di- } \\
\text { chloro- } \\
\text { benzene, } \\
\text { total } \\
\left(\mu_{g} / L\right)\end{array}$ & $\begin{array}{l}\text { 2-chloro- } \\
\text { ethyl- } \\
\text { vinyl- } \\
\text { ether, } \\
\text { total } \\
\left(\mu_{g} / L\right)\end{array}$ & $\begin{array}{c}\text { Dichlor } \\
\text { difluor } \\
\text { methane } \\
\text { total } \\
(\mu g / L)\end{array}$ & $\begin{array}{l}\text { ro- } \\
\text { ro- } \\
\text { e, } \\
\text { ) }\end{array}$ & $\begin{array}{l}\text { Tr } \\
1,3 \\
\text { chl } \\
\text { pro } \\
\text { to } \\
\left(\mu_{8}\right.\end{array}$ & $\begin{array}{l}\text { ans- } \\
\text {-di- } \\
\text { oro- } \\
\text { pene, } \\
\text { tal } \\
\text { /L) }\end{array}$ & $\begin{array}{l}\text { Cis- } \\
1,3-\text { di- } \\
\text { chloro- } \\
\text { propene, } \\
\text { total } \\
\left(\mu_{g} / L\right)\end{array}$ & $\begin{array}{l}\text { Vinyl } \\
\text { chlo- } \\
\text { ride, } \\
\text { total } \\
\left(\mu_{8} / L\right)\end{array}$ & $\begin{array}{l}\text { Tri- } \\
\text { chloro- } \\
\text { ethyl- } \\
\text { ene, } \\
\text { total } \\
(\mu g / L)\end{array}$ & & $\begin{array}{l}\text { ene, } \\
\text { al } \\
(L)\end{array}$ & $\begin{array}{l}\text { Xyl } \\
\text { tot } \\
(\mu g\end{array}$ & $\begin{array}{l}\text { ne, } \\
\text { rec } \\
\text { L) }\end{array}$ & \\
\hline $\begin{array}{l}\text { SEPT } 1988 \\
01\end{array}$ & $<3.0$ & $<3.0$ & $<3.0$ & & & .0 & $<3.0$ & $<3.0$ & $<3.0$ & & 3.0 & $<3$ & & \\
\hline $\begin{array}{c}\text { Sample } \\
\text { date }\end{array}$ & $\begin{array}{l}\text { Depth to } \\
\text { top of } \\
\text { sample } \\
\text { inter- } \\
\text { val } \\
\text { (ft) }\end{array}$ & $\begin{array}{l}\text { Depth to } \\
\text { bottom } \\
\text { of } \\
\text { sample } \\
\text { interval } \\
\text { (ft) }\end{array}$ & $\begin{array}{l}\text { Temper- } \\
\text { ature, } \\
\text { water } \\
\left({ }^{\circ} \mathrm{C}\right)\end{array}$ & $\begin{array}{r}\mathrm{Sp} \\
\text { cif } \\
\mathrm{co} \\
\text { duc } \\
\text { anc } \\
(\mu \mathrm{S} /\end{array}$ & $\begin{array}{l}e- \\
\text { ic } \\
\text { n- } \\
\text { t- } \\
e \\
\mathrm{~cm})\end{array}$ & $\underset{\text { (units) }}{\mathrm{pH}}$ & $\begin{array}{c}\text { Nitrogen } \\
\text { ammonia, } \\
\text { dis- } \\
\text { solved } \\
\text { (mg/L } \\
\text { as } N \text { ) }\end{array}$ & $\begin{array}{r}\text { Nitro } \\
\text { nitri } \\
\text { dis } \\
\text { solv } \\
\text { (mg } \\
\text { as }\end{array}$ & $\begin{array}{lr}\text { en } & \text { Nitro } \\
\text { e, } & \text { ammon } \\
& \text { torga } \\
\text { d } & \text { disso } \\
\text { L } & \text { (mg } \\
\text { ) } & \text { as }\end{array}$ & $\begin{array}{l}\text { en } \\
\text { a, } \\
\text { ic, } \\
\text { ved } \\
\text { L } \\
\text { ) }\end{array}$ & $\begin{array}{r}\mathrm{Nitro} \\
\mathrm{NO}_{2}+\mathrm{N} \\
\text { dis } \\
\text { solv } \\
\text { (mg } \\
\text { as }\end{array}$ & $\begin{array}{l}\text { gen } \\
b_{3}, \\
\text { ed } \\
\text { L } \\
\text { N) }\end{array}$ & $\begin{array}{l}\text { Hard- } \\
\text { ness, } \\
\text { total } \\
\text { (mg/L } \\
\text { as } \\
\left.\mathrm{CaCO}_{3}\right)\end{array}$ & $\begin{array}{l}\text { Cal- } \\
\text { cium, } \\
\text { dis- } \\
\text { solved } \\
\text { (mg/L } \\
\text { as Ca) }\end{array}$ \\
\hline
\end{tabular}

SEPT 1987

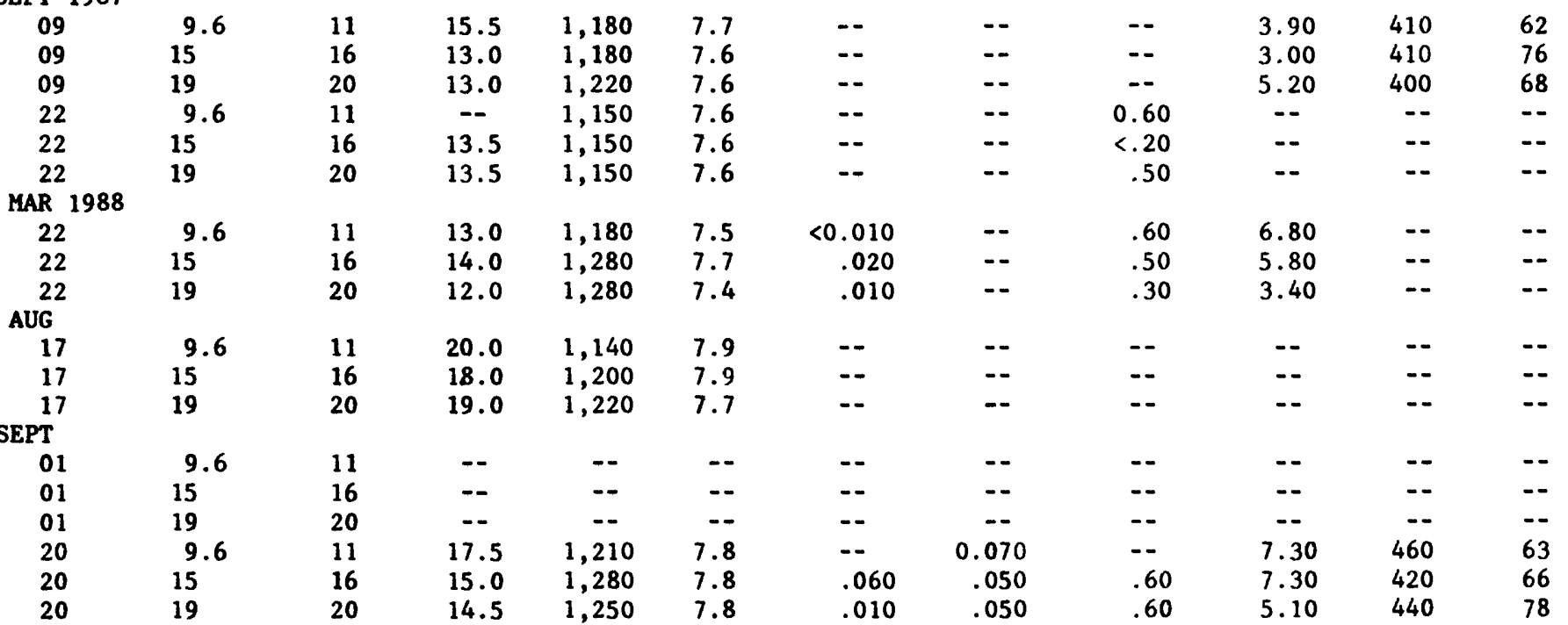


Table 6.--Chemical analyses of water from the multilevel ground-water sampling devices--Continued

\begin{tabular}{|c|c|c|c|c|c|c|c|c|c|c|c|}
\hline $\begin{array}{c}\text { Sample } \\
\text { date }\end{array}$ & $\begin{array}{l}\text { Magne- } \\
\text { sium, } \\
\text { dis- } \\
\text { solved } \\
\text { (mg/L } \\
\text { as } \mathrm{Mg} \text { ) }\end{array}$ & $\begin{array}{l}\text { Sodium, } \\
\text { dis- } \\
\text { solved } \\
\text { (mg/L } \\
\text { as } \mathrm{Na} \text { ) }\end{array}$ & $\begin{array}{l}\text { Potas- } \\
\text { sium, } \\
\text { dis- } \\
\text { solved } \\
\text { (mg/L } \\
\text { as } K \text { ) }\end{array}$ & $\begin{array}{l}\text { Chlo- } \\
\text { ride, } \\
\text { dis- } \\
\text { solved } \\
\text { (mg/L } \\
\text { as } C 1 \text { ) }\end{array}$ & $\begin{array}{l}\text { Sul- } \\
\text { fate, } \\
\text { dis- } \\
\text { solved } \\
\left(\mathrm{mg}^{\circ} / \mathrm{L}\right. \\
\left.\text { as } \mathrm{SO}_{4}\right)\end{array}$ & $\begin{array}{l}\text { Cad- } \\
\text { mium- } \\
\text { dis- } \\
\text { solved } \\
\text { ( } \mu g / L \\
\text { as Cd) }\end{array}$ & $\begin{array}{l}\text { Iron, } \\
\text { dis- } \\
\text { solved } \\
\left(\mu_{g} / L\right. \\
\text { as Fe) }\end{array}$ & $\begin{array}{l}\text { Lead, } \\
\text { dis- } \\
\text { solved } \\
(\mu g / L \\
\text { as } \mathrm{Pb})\end{array}$ & $\begin{array}{l}\text { Manga- } \\
\text { nese, } \\
\text { dis- } \\
\text { solved } \\
(\mu g / L \\
\text { as } M n)\end{array}$ & $\begin{array}{c}\text { Di- } \\
\text { chloro- } \\
\text { bromo- } \\
\text { methane, } \\
\text { total } \\
\left(\mu_{\mathrm{g}} / \mathrm{L}\right)\end{array}$ & $\begin{array}{l}\text { Carbon } \\
\text { tetra- } \\
\text { chlo- } \\
\text { ride, } \\
\text { total } \\
(\mu g / L)\end{array}$ \\
\hline
\end{tabular}

MLGWSD-5--Continued

SEPT 1987



SEPT 1987

09
09
09
22
22
22

MAR 1988

22
22

22

AUG

17
17

17

SEPT

$\begin{array}{lccccccccccc}01 & <3.0 & <3.0 & <3.0 & <3.0 & <3.0 & <3.0 & <3.0 & <3.0 & <3.0 & <3.0 & <3.0 \\ 01 & <3.0 & <3.0 & <3.0 & <3.0 & <3.0 & <3.0 & <3.0 & <3.0 & <3.0 & <3.0 & <3.0 \\ 01 & <3.0 & <3.0 & <3.0 & <3.0 & <3.0 & <3.0 & <3.0 & <3.0 & <3.0 & <3.0 & <3.0 \\ 20 & -- & -- & -- & -- & -- & -- & -- & -- & -- & -- & -- \\ 20 & -- & -- & -- & -- & -- & -- & -- & -- & -- & -- & -- \\ 20 & -- & -- & -- & -- & -- & -- & -- & -- & -- & -- & --\end{array}$


Table 6.--Chemical analyses of water from the multilevel ground-water sampling devices--Continued

\begin{tabular}{|c|c|c|c|c|c|c|c|c|c|c|c|}
\hline $\begin{array}{c}\text { Sample } \\
\text { date }\end{array}$ & $\begin{array}{c}\text { Methyl- } \\
\text { ene } \\
\text { chlo- } \\
\text { ride, } \\
\text { total } \\
\left(\mu_{8} / L\right)\end{array}$ & $\begin{array}{l}\text { Tetra- } \\
\text { chloro- } \\
\text { ethyl- } \\
\text { ene, } \\
\text { total } \\
\left(\mu_{8} / \mathrm{L}\right)\end{array}$ & $\begin{array}{l}\text { Tri- } \\
\text { chloro- } \\
\text { fluoro- } \\
\text { methane, } \\
\text { total } \\
\left(\mu_{8} / \mathrm{L}\right)\end{array}$ & $\begin{array}{l}1,1-d i- \\
\text { chloro- } \\
\text { eth- } \\
\text { ane, } \\
\text { total } \\
\left(\mu_{8} / L\right)\end{array}$ & $\begin{array}{l}\text { 1,1-di- } \\
\text { chloro- } \\
\text { ethyl- } \\
\text { ene, } \\
\text { total } \\
\left(\mu_{8} / L\right)\end{array}$ & $\begin{array}{l}1,1,1- \\
\text { tri- } \\
\text { chloro- } \\
\text { ethane, } \\
\text { total } \\
\left(\mu_{8} / L\right)\end{array}$ & $\begin{array}{l}1,1,2- \\
\text { tri- } \\
\text { chloro- } \\
\text { ethane, } \\
\text { total } \\
\left(\mu_{8} / L\right)\end{array}$ & $\begin{array}{l}1,1,2,2 \\
\text { tetra- } \\
\text { chloro- } \\
\text { ethane, } \\
\text { total } \\
\left(\mu_{g} / \mathrm{L}\right)\end{array}$ & $\begin{array}{c}\text { 1,2-di- } \\
\text { chloro- } \\
\text { ben- } \\
\text { zene, } \\
\text { total } \\
\left(\mu_{8} / L\right)\end{array}$ & $\begin{array}{c}1,2-d i- \\
\text { chloro- } \\
\text { pro- } \\
\text { pane, } \\
\text { total } \\
\left(\mu_{g} / L\right)\end{array}$ & $\begin{array}{l}\text { Trans- } \\
1,2-\text { di- } \\
\text { chloro- } \\
\text { ethene, } \\
\text { total } \\
\left(\mu_{g} / L\right)\end{array}$ \\
\hline
\end{tabular}

MLGWSD-5--Continued

SEPT 1987

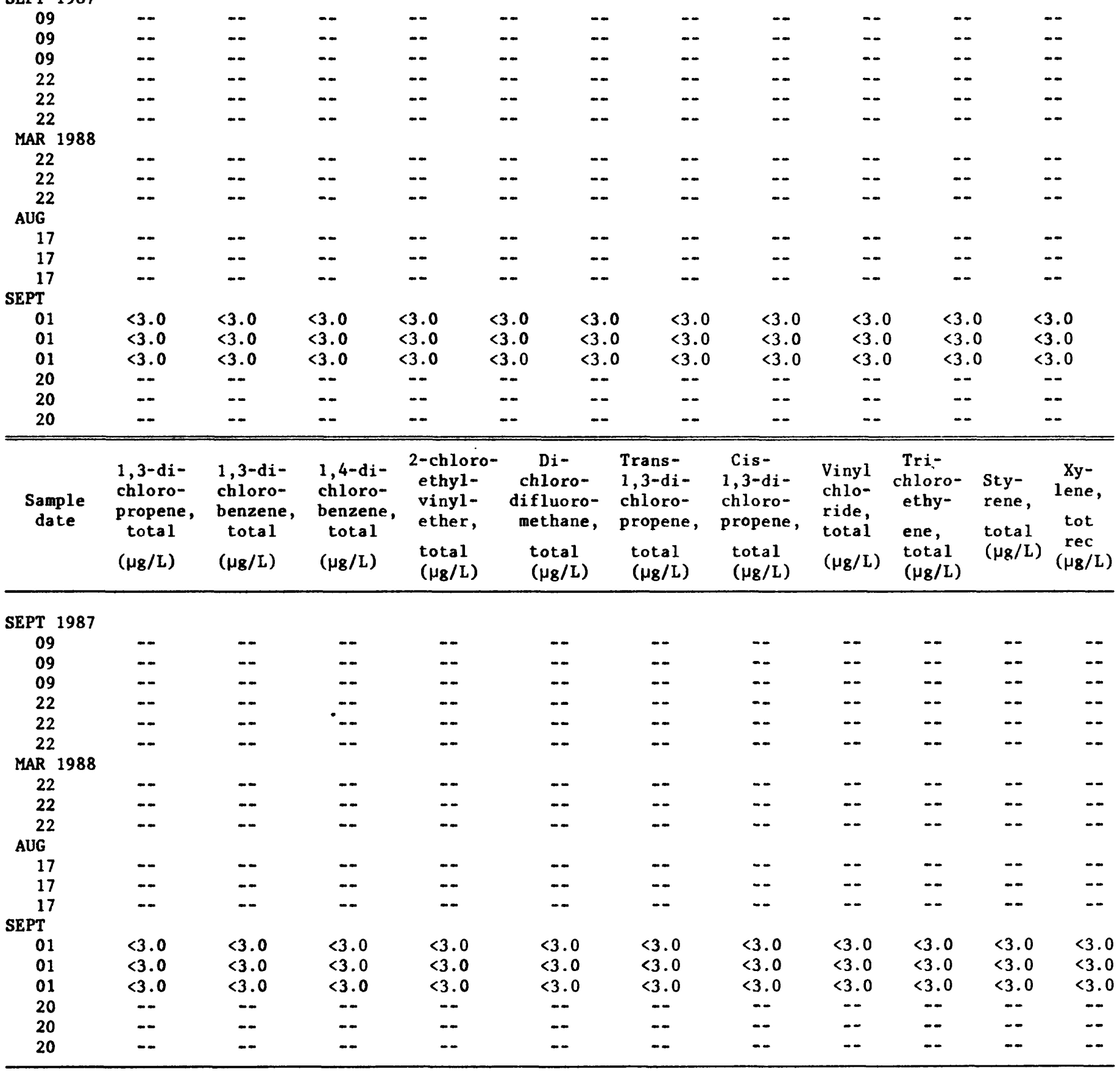


Table 7.--Chemical analyses of soil at selected depths in the unsaturated zone

[ft, feet; mg/kg, milligrams per kilogram; $\mu g / g$, micrograms per gram; $\mathrm{NH}_{4}$, ammonia; $\mathrm{NO}_{2}+\mathrm{NO}_{3}$, nitrite plus nitrate; <, less than the detection limit for analytical method and sample dilution used; sites are shown in figure 3]

\begin{tabular}{|c|c|c|c|c|c|c|c|c|c|}
\hline $\begin{array}{c}\text { Site } \\
\text { number }\end{array}$ & $\begin{array}{c}\text { Date } \\
\text { of } \\
\text { sample }\end{array}$ & $\begin{array}{l}\text { Depth } \\
\text { of } \\
\text { sample } \\
(f t)\end{array}$ & $\begin{array}{c}\text { Nitrogen, } \\
\mathrm{NH}_{4} \\
\text { total } \\
\text { (mg/kg } \\
\text { as } N)\end{array}$ & $\begin{array}{l}\text { Nitrogen, } \\
\mathrm{NH}_{4} \text { plus } \\
\text { organic } \\
\text { total } \\
(\mathrm{mg} / \mathrm{kg} \\
\text { as } \mathrm{N})\end{array}$ & $\begin{array}{c}\mathrm{Nitrogen}, \\
\mathrm{NO}_{2}+\mathrm{NO}_{3} \\
\text { total } \\
(\mathrm{mg} / \mathrm{kg} \\
\text { as } \mathrm{N})\end{array}$ & $\begin{array}{l}\text { Phos- } \\
\text { phorus, } \\
\text { total } \\
\text { (mg/kg } \\
\text { as P) }\end{array}$ & $\begin{array}{c}\text { Arsenic, } \\
\text { total } \\
(\mu g / g \\
\text { as As) }\end{array}$ & $\begin{array}{c}\text { Cadmium, } \\
\text { total } \\
\text { recov- } \\
\text { able } \\
(\mu g / 8 \\
\text { as cd) }\end{array}$ & $\begin{array}{l}\text { Chro- } \\
\text { mium, } \\
\text { total } \\
\text { recov- } \\
\text { able } \\
\left(\mu_{g} / g\right)\end{array}$ \\
\hline $\mathrm{UZ}-1$ & $\begin{array}{l}04-25-85 \\
04-25-85 \\
04-25-85 \\
11-16-88 \\
11-16-88 \\
11-16-88 \\
11-16-88\end{array}$ & $\begin{array}{r}1.5 \\
3.5 \\
5.5 \\
.0 \\
1.5 \\
3.5 \\
5.5\end{array}$ & $\begin{array}{l}3.5 \\
2.1 \\
2.8 \\
5.4 \\
3.5 \\
9.9 \\
8.3\end{array}$ & $\begin{array}{r}340 \\
130 \\
<20 \\
370 \\
420 \\
90 \\
80\end{array}$ & $\begin{array}{l}12 \\
4.0 \\
4.0 \\
8.0 \\
5.0 \\
4.0 \\
26\end{array}$ & $\begin{array}{r}400 \\
110 \\
62 \\
120 \\
130 \\
<40 \\
57\end{array}$ & $\begin{array}{l}1 \\
1 \\
2 \\
3 \\
3 \\
2 \\
1\end{array}$ & $\begin{array}{r}<1 \\
<1 \\
1 \\
<10 \\
<10 \\
<10 \\
<10\end{array}$ & $\begin{array}{r}170 \\
140 \\
150 \\
2 \\
3 \\
3 \\
2\end{array}$ \\
\hline$U Z-2$ & $\begin{array}{l}11-16-88 \\
11-16-88 \\
11-16-88 \\
11-16-88\end{array}$ & $\begin{array}{r}.0 \\
1.5 \\
3.5 \\
5.5\end{array}$ & $\begin{array}{l}9.3 \\
7.2 \\
3.9 \\
4.3\end{array}$ & $\begin{array}{r}170 \\
80 \\
190 \\
210\end{array}$ & $\begin{array}{l}40 \\
4.0 \\
5.0 \\
7.0\end{array}$ & $\begin{array}{r}130 \\
140 \\
50 \\
63\end{array}$ & $\begin{array}{l}2 \\
2 \\
1 \\
1\end{array}$ & $\begin{array}{l}<10 \\
<10 \\
<10 \\
<10\end{array}$ & $\begin{array}{r}8 \\
<1 \\
2 \\
2\end{array}$ \\
\hline UZ-3 & $\begin{array}{l}11-16-88 \\
11-16-88 \\
11-16-88 \\
11-16-88\end{array}$ & $\begin{array}{r}.0 \\
1.5 \\
3.5 \\
5.5\end{array}$ & $\begin{array}{r}9.5 \\
2.8 \\
1.2 \\
.8\end{array}$ & $\begin{array}{r}80 \\
170 \\
210 \\
80\end{array}$ & $\begin{array}{r}5.0 \\
4.0 \\
3.0 \\
<2.0\end{array}$ & $\begin{array}{l}<40 \\
220 \\
<40 \\
<40\end{array}$ & $\begin{array}{l}2 \\
2 \\
1 \\
1\end{array}$ & $\begin{array}{l}<10 \\
<10 \\
<10 \\
<10\end{array}$ & $\begin{array}{l}2 \\
1 \\
3 \\
2\end{array}$ \\
\hline$U Z-4$ & $\begin{array}{l}11-16-88 \\
11-16-88 \\
11-16-88\end{array}$ & $\begin{array}{l}.0 \\
1.5 \\
3.5\end{array}$ & $\begin{array}{l}8.8 \\
3.5 \\
8.7\end{array}$ & $\begin{array}{r}370 \\
40 \\
40\end{array}$ & $\begin{array}{r}5.0 \\
3.0 \\
<2.0\end{array}$ & $\begin{array}{r}170 \\
100 \\
75\end{array}$ & $\begin{array}{l}3 \\
3 \\
3\end{array}$ & $\begin{array}{r}<1 \\
<1 \\
<10\end{array}$ & $\begin{array}{r}20 \\
8 \\
10\end{array}$ \\
\hline UZ-5 & $\begin{array}{l}11-16-88 \\
11-16-88 \\
11-16-88 \\
11-16-88\end{array}$ & $\begin{array}{r}.0 \\
1.5 \\
3.5 \\
5.5\end{array}$ & $\begin{array}{l}6.4 \\
2.4 \\
1.9 \\
4.0\end{array}$ & $\begin{array}{l}330 \\
170 \\
130 \\
120\end{array}$ & $\begin{array}{c}34 \\
8.0 \\
31 \\
21\end{array}$ & $\begin{array}{r}91 \\
46 \\
<40 \\
130\end{array}$ & $\begin{array}{l}1 \\
2 \\
2 \\
2\end{array}$ & $\begin{array}{l}<10 \\
<10 \\
<10 \\
<10\end{array}$ & $\begin{array}{r}5 \\
3 \\
5 \\
10\end{array}$ \\
\hline $\begin{array}{c}\text { Site } \\
\text { number }\end{array}$ & $\begin{array}{c}\text { Date } \\
\text { of } \\
\text { sample }\end{array}$ & $\begin{array}{l}\text { Cobalt, } \\
\text { total } \\
\text { recov- } \\
\text { erable } \\
(\mu g / g \\
\text { as Co })\end{array}$ & $\begin{array}{l}\text { Copper, } \\
\text { total } \\
\text { recov- } \\
\text { erable } \\
\left(\mu_{g} / g\right. \\
\text { as } \mathrm{Cu})\end{array}$ & $\begin{array}{l}\text { Iron, } \\
\text { total } \\
\text { recov- } \\
\text { erable } \\
(\mu \mathrm{g} / \mathrm{g} \\
\text { as } \mathrm{Fe})\end{array}$ & $\begin{array}{l}\text { Lead, } \\
\text { total } \\
\text { recov- } \\
\text { erable } \\
(\mu g / 8 \\
\text { as } \mathrm{Pb})\end{array}$ & $\begin{array}{l}\text { Man } \\
\text { nes } \\
\text { tot } \\
\text { rec } \\
\text { era } \\
(\mu 8\end{array}$ & \multicolumn{2}{|c|}{$\begin{array}{l}\text { Mercury, } \\
\text { total } \\
\text { recov- } \\
\text { erable } \\
(\mu 8 / 8 \\
\left.\text { as } \mathrm{Hg}_{8}\right)\end{array}$} & $\begin{array}{l}\text { Zinc, } \\
\text { total } \\
\text { recov- } \\
\text { erable } \\
\left(\mu_{8} / 8\right. \\
\text { as } Z n)\end{array}$ \\
\hline UZ-1 & $\begin{array}{l}04-25-85 \\
04-25-85 \\
04-25-85 \\
11-16-88 \\
11-16-88 \\
11-16-88 \\
11-16-88\end{array}$ & $\begin{array}{l}<10 \\
<10 \\
<10 \\
<50 \\
<50 \\
<50 \\
<50\end{array}$ & $\begin{array}{r}<1 \\
<1 \\
<1 \\
10 \\
5 \\
4 \\
4\end{array}$ & $\begin{array}{l}4,700 \\
4,000 \\
3,300 \\
3,400 \\
4,300 \\
4,300 \\
3,300\end{array}$ & $\begin{array}{l}<10 \\
<10 \\
<10 \\
<100 \\
<100 \\
<100 \\
<100\end{array}$ & & \multicolumn{2}{|c|}{$\begin{array}{l}0.01 \\
<.01 \\
<.01 \\
.03 \\
<.01 \\
<.01 \\
<.01\end{array}$} & $\begin{array}{l}20 \\
10 \\
10 \\
30 \\
20 \\
10 \\
10\end{array}$ \\
\hline $\mathrm{UZ}-2$ & $\begin{array}{l}11-16-88 \\
11-16-88 \\
11-16-88 \\
11-16-88\end{array}$ & $\begin{array}{l}<10 \\
<50 \\
<50 \\
<50\end{array}$ & $\begin{array}{r}6 \\
<1 \\
3 \\
4\end{array}$ & $\begin{array}{l}6,700 \\
1,600 \\
2,400 \\
3,600\end{array}$ & $\begin{array}{l}<100 \\
<100 \\
<100 \\
<100\end{array}$ & & \multicolumn{2}{|c|}{$\begin{array}{l}.02 \\
<.01 \\
<.01 \\
<.01\end{array}$} & $\begin{array}{r}20 \\
<10 \\
<10 \\
10\end{array}$ \\
\hline UZ-3 & $\begin{array}{l}11-16-88 \\
11-16-88 \\
11-16-88 \\
11-16-88\end{array}$ & $\begin{array}{r}<50 \\
50 \\
<50 \\
<50\end{array}$ & $\begin{array}{l}4 \\
4 \\
3 \\
4\end{array}$ & $\begin{array}{l}2,800 \\
3,000 \\
4,000 \\
3,200\end{array}$ & $\begin{array}{l}<100 \\
<100 \\
<100 \\
<100\end{array}$ & & \multicolumn{2}{|c|}{$\begin{array}{l}<.01 \\
<.01 \\
<.01 \\
<.01\end{array}$} & $\begin{array}{l}20 \\
10 \\
10 \\
10\end{array}$ \\
\hline$v z-4$ & $\begin{array}{l}11-16-88 \\
11-16-88 \\
11-16-88\end{array}$ & $\begin{array}{l}10 \\
10 \\
10\end{array}$ & $\begin{array}{r}10 \\
6 \\
10\end{array}$ & $\begin{array}{l}9,700 \\
6,700 \\
9,000\end{array}$ & $\begin{array}{r}10 \\
<100 \\
<100\end{array}$ & & \multicolumn{2}{|c|}{$\begin{array}{r}.01 \\
<.01 \\
<.01\end{array}$} & $\begin{array}{l}40 \\
20 \\
30\end{array}$ \\
\hline UZ-5 & $\begin{array}{l}11-16-88 \\
11-16-88 \\
11-16-88 \\
11-16-88\end{array}$ & $\begin{array}{r}10 \\
<50 \\
<50 \\
10\end{array}$ & $\begin{array}{r}10 \\
6 \\
5 \\
6\end{array}$ & $\begin{array}{l}3,100 \\
4,500 \\
6,100 \\
6,300\end{array}$ & $\begin{array}{l}<100 \\
<100 \\
<100 \\
<100\end{array}$ & & \multicolumn{2}{|c|}{$\begin{array}{l}.04 \\
<.01 \\
<.01 \\
<.01\end{array}$} & $\begin{array}{l}30 \\
20 \\
20 \\
20\end{array}$ \\
\hline
\end{tabular}









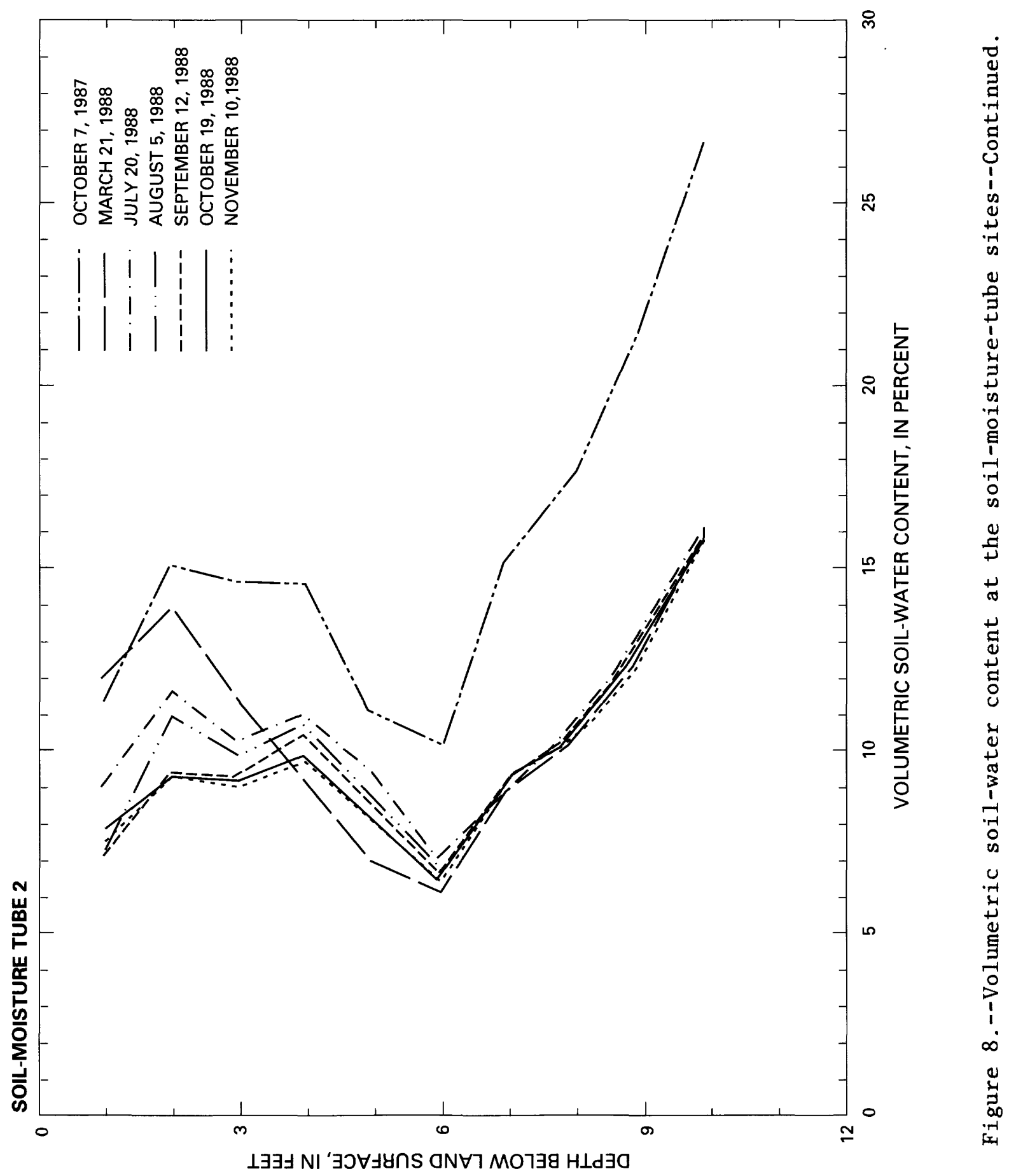




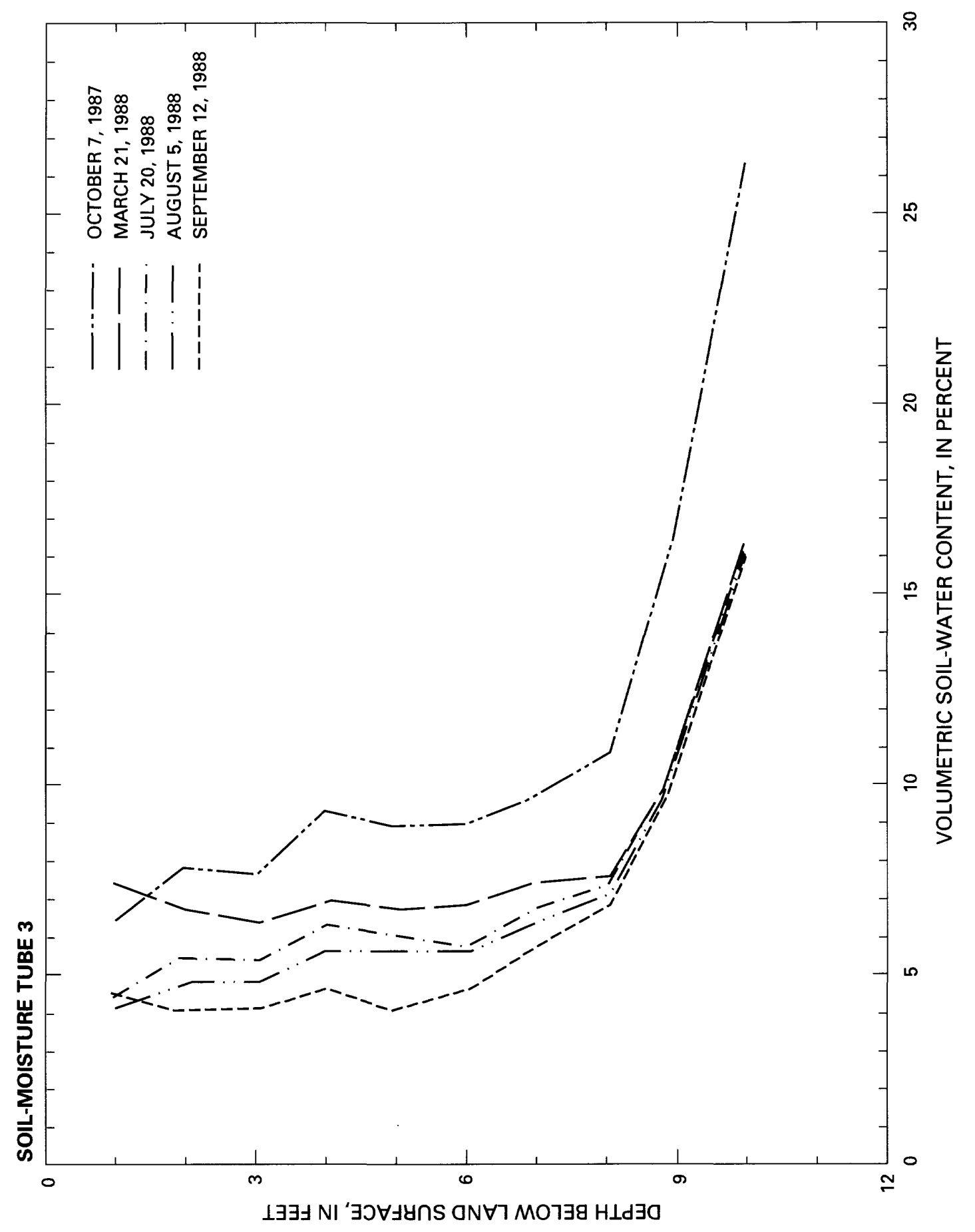

D 


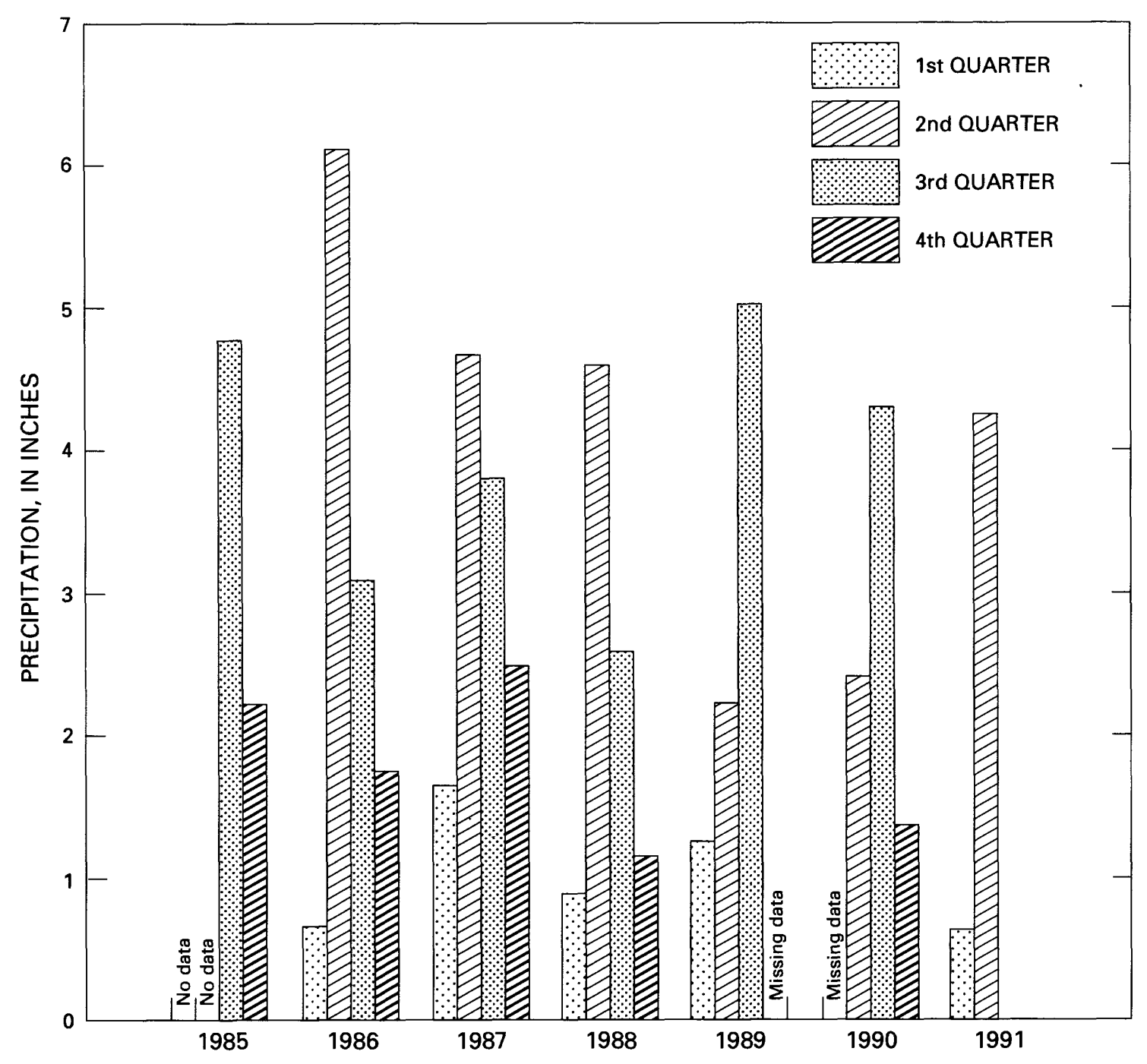

Figure 9.--Quarterly accumulative precipitation recorded at precipitation station in the study area, 1985-91. 